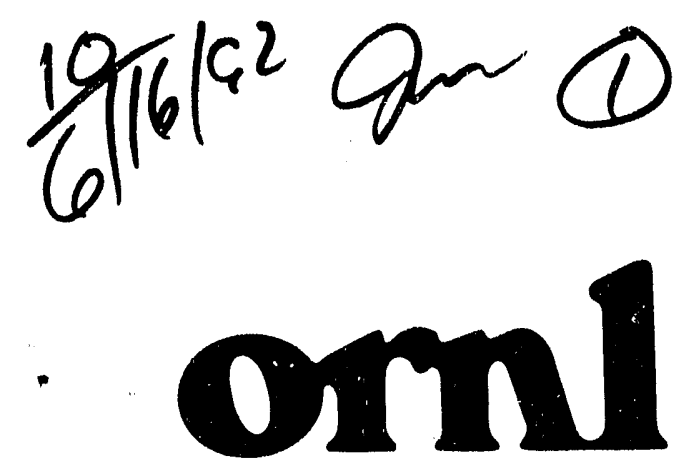

\section{OAK RIDGE \\ NATIONAL LABORATORY}

MARTIN MARIETRA
ORNL/TM-11946

\section{STUDIES OF NEAR-SURFACE PHENOMENA AND EROSION MECHANISMS IN METALLIC ALLOYS USING SINGLE-AND MULTI-PARTICLE IMPACTS}

M. Rao and J. R. Keiser

\author{
Fossil \\ Enengy \\ Progham
}


This report has been reproduced directly from the best available copy.

Available 10 DOE and DOE contractors from the Office of Scientific and Technical Information, P.O. Box 62, Oak Ridge, TN 37831; prices available from (615) 576-8401, FTS 626-8401.

Available to the public from the National Technical Information Service, U.S. Department of Commerce, 5285 Port Royal Rd., Springfield, VA 22161.

This report was prepared as an account of work sponsornd by an agency of the United States Government. Neither the United States Government nor any agency thereof, nor any of their employees, makes any warranty, expressed or implied, of assumes any legal liability or responsibility for the accuracy, completeness, or usefulness of any information, apparatus, product, or process disclosed, or represents that its use would not infringe privately owned rights. Reference herein to any specific commercial product, process, or service by trade name, trademark, manufacturer, or otherwise, does not necessarily constitute or imply its endorsement, recommendation, or favoring by the United Slates Government or any ageacy thereot. The views and opinions of authors expressad herein do not necessarily state or reflect those of the United States Government or any agency theroot. 
Metals and Ceramics Division

\title{
STUDIES OF NEAR-SURFACE PHENOMENA AND EROSION MECHANISMS IN METALLIC ALLOYS USING SINGLE- AND MULTI-PARTICLE IMPACTS
}

M. Rao and J. R. Keiser

Date Published - March 1992

NOTICE: This document contains information of a preliminary nature. It is subject to revision or correction and therefore does not represent a final report.

\author{
Prepared for the \\ U.S. Department of Energy \\ Office of Fossil Energy
}

Advanced Research and Technology Development Mute: ials Program AA 1510100

Prepared by the

C.AK RIDGE NATIONAL LABOR.ATORY

Oak Ridge, Tennessee 37831-6285 managed by

MARTIN MARIETTA ENERGY SYSTEMS, INC. for the U.S. DEPARTMENT OF ENERGY linder contract DE-AC05-84OR2140) 


\section{CONTENTS}

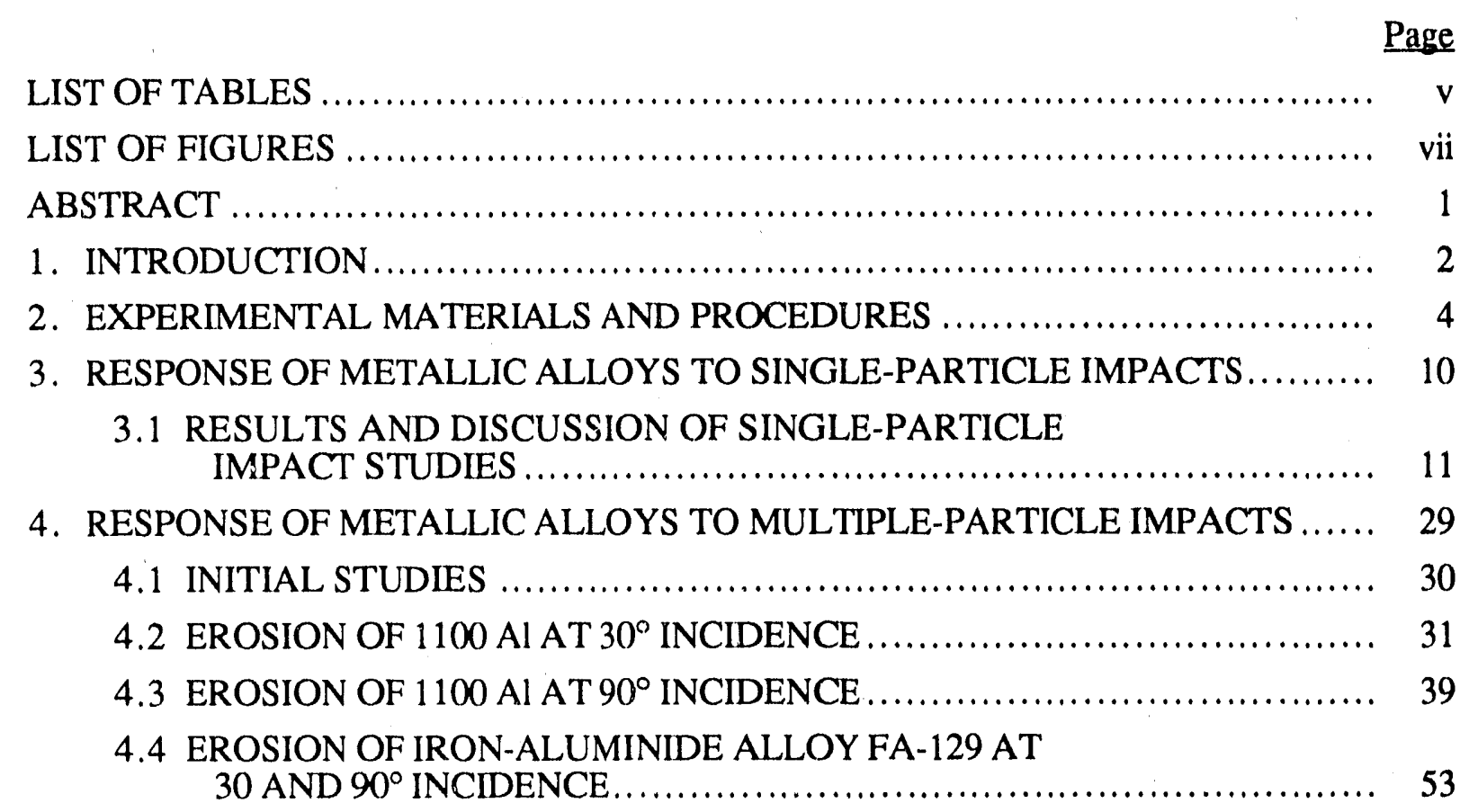

5. SURFACE AND NEAR-SURFACE EFFECTS DUE TO PARTICLE

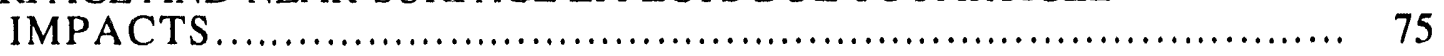

5.1 DEVELOPMENT OF SURFACE TOPOGRAPHY ........................ $\quad 75$

5.2 EFFECT OF INCIDENCE ANGLE ON NEAR-SURFACE HARDENING ...................................................... 79

5.3 EFFECT OF MECHANICAL PROPERTIES ON MATERIAL DEFORMATION AND REMOVAL .......................... 86

5.4 IMPACT-INDUCED PHASE TRANSFORMATIONS _.................... 94

5.5 EFFECTS OF RESIDUAL STRESSES ................................. 96

5.6 THERMAL EFFECTS ................................................. 98

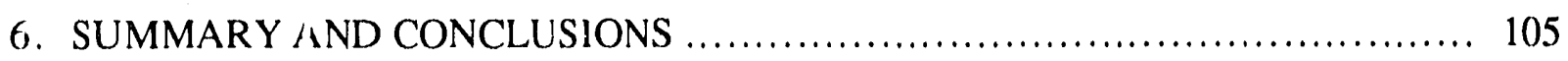

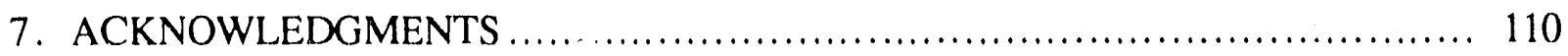

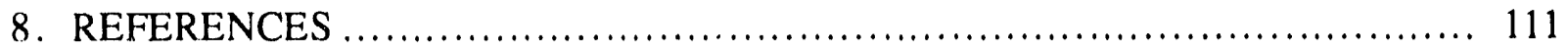




\section{LIST OF TABLES}

Table

Page

1 Vickers hardness (500-g load) of alloys used in study ....................... 6

2 Summary of MPM data from single-pi rticle impact studies......................... 80

3 Summary of MPM data from multiple-particle erosion studies $\ldots \ldots \ldots \ldots \ldots \ldots \ldots . \quad 81$

4 Crater dimensions for sirigle-particle impacts at $90^{\circ}$ incidence.................. 88

5 Crater size ratios for single-particle impacts at 30 and $90^{\circ}$ incidence and various velocities ......................................... 101 


\section{LIST OF FIGURES}

Figure

Page

1 (a) High-velocity gas gun and (b) closeup of fast valve and chambering mechanism in "load" position.

2 Relative hardness versus depth below cral ers due to single impacts at $30^{\circ}$ incidence and $28.5 \mathrm{~m} / \mathrm{s}$ for: (a) !100 Al, (b) 6061-T6 Al, (c) 7075-T6 Al, and $(d) 50 \%$ cold-worked 1100 f.l.

3 Craters due to single-particle impacts at $30^{\circ}$ incidence on: $(a)$ annealed $1100 \mathrm{Al}$ at $18 \mathrm{~m} / \mathrm{s},(b)$ annealed $1100 \mathrm{Al}$ at $50 \mathrm{~m} / \mathrm{s},(c)$ ordered iron-aluminide alloy at $16 \mathrm{~m} / \mathrm{s}$, and $(d)$ ordered iron-aluminide alloy at $55 \mathrm{~m} / \mathrm{s}$

4 Craters due to single-particle impacts at $30^{\circ}$ incidence on: (a) $50 \%$ cold-worked $1100 \mathrm{Al}$ at $61 \mathrm{~m} / \mathrm{s}$ and $(b) 5 \%$ cold-worked ordered iron-aluminide alloy at $58 \mathrm{~m} / \mathrm{s}$.

5 Craters due to single-particle impacts at $90^{\circ}$ incidence on: $(a)$ annealed $1100 \mathrm{Al}$ at $58 \mathrm{~m} / \mathrm{s},(b) 50 \%$ cold-worked $1100 \mathrm{Al}$ at $59 \mathrm{~m} / \mathrm{s},(c)$ ordered iron-aluminide alloy at $59 \mathrm{~m} / \mathrm{s}$, and (d) $5 \%$ cold-worked ordered iron-aluminide alloy at $58 \mathrm{~m} / \mathrm{s}$.

6 MPM relative hardness profiles beneath craters formed due to single impacts at $90^{\circ}$ incidence on: (a) annealed $1100 \mathrm{Al}$ at $58 \mathrm{~m} / \mathrm{s},(b) 50 \%$ cold-worked $1100 \mathrm{Al}$ at $59 \mathrm{~m} / \mathrm{s},(c)$ ordered iron-aluminide alloy at $59 \mathrm{~m} / \mathrm{s}$, and $(d) 5 \%$ cold-worked ordered iron-aluminide alloy at $58 \mathrm{~m} / \mathrm{s}$.

7 Cross-sectioned, high-velocity impact craters with superimposed MPM relative hardness profiles for: $(a)$ annealed $1100 \mathrm{Al}$ at $794 \mathrm{~m} / \mathrm{s}$ and $(b)$ ordered iron-aluminide alloy at $894 \mathrm{~m} / \mathrm{s}$

8 Relative hardness profiles beneath craters formed due to single impacts at $90^{\circ}$ incidence and velocities around $50 \mathrm{~m} / \mathrm{s}$ on eroded-corroded 2.25Cr1Mo steels

9 Craters due to single-particle impacts at $30^{\circ}$ incidence on annealed $1100 \mathrm{Al}$ : (a) at $280 \mathrm{~m} / \mathrm{s},(b) 420 \mathrm{~m} / \mathrm{s},(c) 625 \mathrm{~m} / \mathrm{s}$, and (d) $740 \mathrm{~m} / \mathrm{s}$

10 Craters due to single-particle impacts at $30^{\circ}$ incidence on ordered iron-aluminide alloy: (a) at 340 and $280 \mathrm{~m} / \mathrm{s},(b) 450 \mathrm{~m} / \mathrm{s}$, and (c) $429 \mathrm{~m} / \mathrm{s}$

11 Craters due to single-particle impacts at $30^{\circ}$ incidence on: (a) $50 \%$ cold-worked $1100 \mathrm{Al}$ at $661 \mathrm{~m} / \mathrm{s}$ and $(b) 5 \%$ cold-worked ordered iron-aluminide alloy at $464 \mathrm{~m} / \mathrm{s}$

12 (a) Cross-sectioned crater on annealed $1100 \mathrm{Al}$ due to single impact at $30^{\circ}$ incidence and $740 \mathrm{~m} / \mathrm{s}$. (b) and (c) MPM relative hardness profiles along traces 1-1 and 2-2 marked in $(a)$.

13 MPM relative hardness profiles beneath: $(a) 7075-\mathrm{T} 6 \mathrm{Al}$ and $(b)$ annealed $1100 \mathrm{Al}$ eroded at $30^{\circ}$ incidence 
14 Typical taper-sectioned specimen (eroded $1100 \mathrm{Al}$ ) used for making MPM measurements.

15 Typical mass loss curve for annealed $1100 \mathrm{Al}$ eroded in Lawrence Berkeley Laboratories' erosion tester

16 Tracings of surface contours from tapered sections of eroded $1100 \mathrm{Al}$ samples

17 Relative hardness versus depth below eroded surface for $1100 \mathrm{Al}$ eroded with $5 \mathrm{~g}$ of $600-$ to $700-\mu \mathrm{m}$-diam steel shot at $45 \mathrm{~m} / \mathrm{s}, 30^{\circ}$ incidence...

18 Relative hardness versus depth below eroded surface for $1100 \mathrm{Al}$ eroded with $20 \mathrm{~g}$ of $60(0)$ to $7\left(00-\mu \mathrm{m}\right.$-diam steel shot at $45 \mathrm{~m} / \mathrm{s}, 30^{\circ}$ incidence. .............

19 Relative hardness versus depth below eroded surface for $1100 \mathrm{Al}$ eroded with $40 \mathrm{~g}$ of 600 - to $700-\mu \mathrm{m}$-diam steel shot at $45 \mathrm{~m} / \mathrm{s}, 30^{\circ}$ incidence

20 Relative hardness versus depth below eroded surface data for $1100 \mathrm{Al}$ eroded with $129 \mathrm{~g}$ of 600 - to $700-\mu \mathrm{m}$-diam steel shot at $45 \mathrm{~m} / \mathrm{s}, 30^{\circ}$ incidence.

21 Relative hardness versus depth below eroded surface data for $1100 \mathrm{Al}$ eroded with $500 \mathrm{~g}$ (steady state) of 600 - to $700-\mu \mathrm{m}$-diam steel shot at $45 \mathrm{~m} / \mathrm{s}$, $30^{\circ}$ incidence

22 Graph summarizing information from the hardness profiles in Figs. 16 through 21 as a function of erodent dose

23 Relative hardness contours drawn on a tapered-section micrograph from an area of the specimen exposed to $120 \mathrm{~g}$ of erodent.

24 Hardness indentations across a lip of fracturing material on the leeward side of a crest on a taper-sectioned specimen....

25 Mass loss or gain of annealed $1100 \mathrm{Al}$ eroded at 30 and $90^{\circ}$ incidence in a University of Notre Dame rotating-arm erosion tester

26 Micrographs of $1100 \mathrm{Al}$ surfaces eroded at $90^{\circ}$ incidence by: (a) $11 \mathrm{~g}$, (b) $100 \mathrm{~g},(c)$ and $(d) 480 \mathrm{~g}$ of $297-$ to $420-\mu \mathrm{m}$-diam steel shot at $45 \mathrm{~m} / \mathrm{s} \ldots \ldots \ldots$.

27 3:1 tapered section and corresponding Fe X-ray map of $1100 \mathrm{Al}$ specimen eroded with $11 \mathrm{~g}$ of 297 - to $420-\mu \mathrm{m}$-diam steel shot at $45 \mathrm{~m} / \mathrm{s}$, $90^{\circ}$ incidence

$283: 1$ tapered section and corresponding Fe X-ray map of $1100 \mathrm{Al}$ specimen eroded with $100 \mathrm{~g}$ of $297-$ to $420-\mu \mathrm{m}$-diam steel shot at $45 \mathrm{~m} / \mathrm{s}$, $90^{\circ}$ incidence

$293: 1$ tapered section of $1100 \mathrm{Al}$ specimen eroded with $480 \mathrm{~g}$ of $297-$ to 42()$-\mu \mathrm{m}$-diam steel shot at $45 \mathrm{~m} / \mathrm{s}, 9)^{\circ}$ incidence 
30 Perpendicular cross section of sample subjected to an erodent dose of $480 \mathrm{~g}$, 297 - to $420-\mu \mathrm{m}$-diam steel shot, $45 \mathrm{~m} / \mathrm{s}, 90^{\circ}$ incidence.

31 (a) and (b) Perpendicular cross-sections of eroded specimens showing deformation contours traced from distorted lines of precipitates such as those seen in Fig. 30

32 MPM relative hardness profile on tapered section of sample subjected to an erodent dose of $11 \mathrm{~g}$

33 MPM relative hardness profiles beneath: $(a)$ hill and $(b)$ valley locations on tapered section of sample subjected to an erodent dose of $100 \mathrm{~g}$.

34 (a) and (b) MPM hardness profile on perpendicular cross section seen in Fig. 30, along the vertical dotted lines marked " $\mathrm{A}$ " and "B," respectively

35 Sketches showing that hardness indentations close to the eroded surface edge on a tapered-section specimen: $(a)$ are supported by adjacent material to a greater extent than indentations on a perpendicularly cross-sectioned specimen $(b)$.

36 Micrographs of the 297- to $420-\mu \mathrm{m}$-diam steel shot used in the erosion experiments: $(a)$ whole and broken particles and $(b)$ cross-sectional view clearly showing the scale covering some particles

37 Mass loss or gain of iron-aluminide alloy FA-129 due to erosion as a function of the erodent dose at three angles of incidence

38 Appearance of eroded surfaces of iron-aluminide alloy FA-129 at $30^{\circ}$ incidence

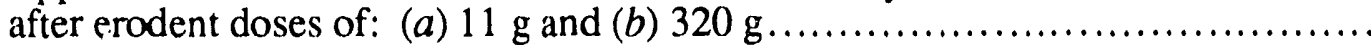

39 Appearance of eroded surfaces of iron-aluminide alloy FA-129 at $90^{\circ}$ incidence

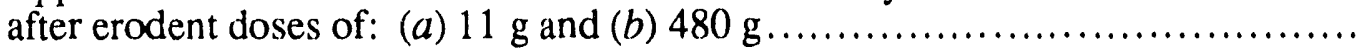

40 Individual impact craters seen on iron-aluminide alloy FA-129 sample eroded by $11 \mathrm{~g}$ of erodent at $30^{\circ}$ incidence

41 Details of surfaces of iron-aluminide alloy FA-129 eroded by $320 \mathrm{~g}$ of steel shot at $30^{\circ}$ incidence showing extruded platelets formed by the impact of rounded particles and ploughing and gouging due to impact of angular particles

42 Details of surfaces of iron-aluminide alloy FA-129 eroded by $11 \mathrm{~g}$ of steel shot at $90^{\circ}$ incidence: $(a)$ single-impact crater showing little plastic deformation within or around the crater and $(b)$ area near center of specimen where individual impacts cannot be identified

43 Details of surfaces of iron-aluminide alloy FA-129 eroded by $480 \mathrm{~g}$ of steel shot at $90^{\circ}$ incidence showing few extruded platelets and damage mainly by the impact of angular particles 
44 Micrographs of 3:1 tapered sections of samples of: (a) iron-aluminide alloy FA-129 and (b) $1100 \mathrm{Al}$ eroded by $320 \mathrm{~g}$ of steel shot at $30^{\circ}$ incidence.

45 Relative hardness versus depth below eroded surface for iron-aluminide alloy FA-129 eroded with: (a) $11 \mathrm{~g},(b) 100 \mathrm{~g}$, and (c) $320 \mathrm{~g}$ of 297- to $420-\mu \mathrm{m}$-diam steel shot at $45 \mathrm{~m} / \mathrm{s}, 30^{\circ}$ incidence.

46 Relative hardness versus depth below eroded surface for iron-aluminide alloy FA-129 eroded with: (a) $11 \mathrm{~g}$, (b) $100 \mathrm{~g}$, and (c) $480 \mathrm{~g}$ of 297- to $420-\mu \mathrm{m}$-diam steel shot at $45 \mathrm{~m} / \mathrm{s}, 90^{\circ}$ incidence.

47 Relative hardness versus depth below eroded surface for iron-aluminide alloy FA-129 eroded with 297 - to $420-\mu \mathrm{m}$-diam steel shot at $45 \mathrm{~m} / \mathrm{s}$, showing greater near-surface softening than observed in Figs. 45 and 46:

(a) $30^{\circ}$ incidence, 320-g dose, and (b) $90^{\circ}$ incidence, 480-g dose

48 Crater size versus alloy hardness for single-particle impacts at various velocities

49 Depth of hardening under single-particle impacts versus alloy hardness at various impact velocities 


\title{
STUDIES OF NEAR-SUREACE PHENOMENA AND EROSION MECHANISMS IN METALLIC ALLOYS USING SINGLE- AND MUL'CL-PARTUCLE IMPACTS*
}

\author{
M. Rao' and J. R. Keiser
}

\begin{abstract}
An experimental study of the effects of material properties on erosion mechanisms was conducted by subjecting targets to single as well as multiple impacts of spherical particles at various velocities. A mechanical properties microprobe (MPM) was used to monitor the hardening due to the impacts.

Initial studies on several engineering alloys showed that work hardening was associated with single impacts, and the results suggested that the capacity to distribute the impact energy over large volumes improved a material's erosion resistance. Detailed, single-impact studies over a wide range of velocities were conducted on $1100 \mathrm{Al}$ and Fe3Al-based, ordered iron-aluminide alloy FA-129, in both heat-treated and cold-worked conditions. The impact responses could not be explained by strength and hardness changes alone. A dropoff in near-surface hardness was observed in the cold-worked iron-aluminide alloy at relatively low velocities and was observed in both alloys at velocities of several hundred meters per second. For high-velocity impacts at $30^{\circ}$ incidence, significant material fracture was seen in alloy FA-129 but not in $1100 \mathrm{Al}$.

Studies also showed that the alloys work hardened significantly under multiple-particle impacts. However, unlike $1100 \mathrm{Al}$, the hardness of alloy FA129 dropped off in near-surface regions, and the thickness of this layer increased with erodent dose. Characteristic ripple and hill-and-valley structures developed on aluminum alloys but not on alloy FA-129. The development of the structures was examined in detail for $1100 \mathrm{Al}$, emphasizing material deformation and flow, hardening behavior, and effects on erosion. In the case of alloy FA-129, erosion occurred even though most of the impacting particles were softer than the target material. Two distinct erosion mechanisms were observed: extrusion and fracture of platelets by the impact of spherical particles and a cutting or "gouging out" of material by the impact of angular particle fragments. The alloy lost its ordered structure due to the impacts, but the effects of the transformation on the erosion process were unclear.

Single-particle impact studies were found to correlate well with results from low-velocity, multiple-particle erosion experiments. Material loss in the ironaluminide alloy was related to its lower ductility as well as its propensity to localize deformation due to its ordered structure. The high dynamic recovery of $1100 \mathrm{Al}$ allowed impact energy to be spread more uniformly, explaining the lack of brittle failure observations in cold-worked $1100 \mathrm{Al}$, even though ductility was greatly reduced. However, the observed hardening behavior under the various impact conditions could not be completely explained based on mechanical properties
\end{abstract}

${ }^{*}$ Research sponsored by the U.S. Department of Energy, Office of Fossil Energy, Advanced Research and Technology Development Materials Program, under contract DE-AC(05-84OR21400) with Martin Marietta Energy Systems, Inc.

†Consultant, Corrosion Science and Technology Group, Metals and Ceramics Division, Martin Marietta Energy Systems, Inc., Oak Ridge National Laboratory. 
effects alone. Residual stress effects explained the dropoff in near-surface hardness in the iron-aluminide alloy but could not satisfactorily explain the hardening behavior observed for single-particle impacts at various velocities. Thermal effects were evidently important and could more completely explain the results. A combination of mechanical properties and thermal effects could explain the general observation that the erosion resistance of engineering alloys is insensitive to strengthening treatments.

\section{INTRODUCTION}

Materials used in fossil energy systems are expected to withstand damage both from hot corrosive gases, as well as fine particulates, in the gas stream. The erosion and erosioncorrosion behavior of the alloys, therefore, becomes of prime importance. The major source of erosive particles is non-combustible mineral matter, and considerable research has been conducted to identify appropriate erosion-resistant materials, as well as to determine erosion mechanisms.

Previous studies on erosion have tried to relate a material's erosion resistance to one or more of the material's mechanical or physical properties, and several mechanistic theories have been proposed. Finnie et al. ${ }^{1}$ demonstrated a relationship between erosion resistance and indentation hardness for annealed pure metals. However, the relationship did not hold when alloys or work-hardened pure metals were considered. 2,3 Other researchers have demonstrated relationships between erosion behavior and metal-metal bond energy, ${ }^{4}$ melting point, ${ }^{5}$ and elastic modulus. ${ }^{6}$ Although erosion behavior can be related to some physical or mechanical property for a carefully defined set of materials, none of these relationships hold for materials in all conditions of heat treatment or mechanical working.

A relationship between erosion behavior and thermal properties has also been demonstrated. Ascarelli ${ }^{7}$ related erosion behavior to a property he calls thermal pressure, $\alpha \mathrm{k} \Delta \mathrm{T}$, where $\alpha$ is the coetficient of linear thermal expansion, $\mathrm{k}$ is the bulk modulus, and $\Delta \mathrm{T}$ is the difference between the ambient temperature and the melting point of the target material. Hutchings ${ }^{8}$ proposed using the product $\rho c_{p} \Delta \mathrm{T}$ where $\rho$ is the density, $c_{p}$ is the specific heat at constant pressure, and $\Delta \mathrm{T}$ is as previously definea. Malkin ${ }^{9}$ related erosion resistance to the specific melting energy $\rho \Delta \mathrm{H} / \mathrm{a}$, where $\Delta \mathrm{H}$ is the enthalpy change asscciated with transforming solid target material at ambient temperature to liquid at the melting temperature, and a is the atomic mass. A dimensional analysis was developed by Jennings et al. ${ }^{10}$ in which several material properties that might influence erosion resistance were incorporated. Under certain test conditions, a correlation between each of these parameters and erosion resistance can be 
shown. However, as in the case of the relationships developed using physical properties, none provides a satisfactory correlation for all metals and alloys under all test conditions.

The association of erosion behavior and thermal properties is, in part, related to the observation that significant heating of the surface can occur as a result of a particle impact. Calculations have shown that if a major portion of the energy of the incident particle is transferred to the target and if adiabatic behavior is assumed, the temperature can be raised appreciably and may even exceed the melting point of the target. 11,12 Melting of a target material has been reported by several researchers, ${ }^{13-15}$ and there are many reports of annealing or softening of the surface of a target as a result of the heat introduced by particle impacts. $16-18$ Conclusions that softening had occurred were made from hardness measurements and microstructural studies on samples previously exposed to a stream of erosive particles.

Transmission electron microscopy (TEM) has provided evidence of work hardening below eroded surfaces of 310 stainless steel, ${ }^{19}$ Stellite $6 \mathrm{~B},{ }^{20}$ and nickel. ${ }^{21}$ Microstructural changes in AISI 1096 steel have been reported at or just below the bottom of an erosion crater formed by a stream of particles. ${ }^{17}$ These changes were presumed to be related to a short-duration temperature increase in the thin layer at the surface of the erosion crater. In nearly all cases, microstructural changes were noted after tests involving multiple impacts. Many results have shown that heat treatments and alloying additions have little effect on erosion resistance. 17,22-24 Some of these results have been attributed to thermal effects, but there is a lack of direct evidence. 17,24

Material removal mechanisms have also been studied in detail. Angular particles remove material efficiently by a mechanism similar to the cutting action of an abrasive particle. 25 Particles tending to bi . uore spherical in shape lack a cutting edge and remove material more slowly by the formation of lips around an impact site and subsequent removal by repeated impacts or by overlapping of craters. $26-28$

For ductile metals, material loss rates fall dramatically toward normal incidence, ${ }^{1}$ and even angular particles do not remcve material very efficiently. Finnie, Levy, and McFadden 29 described debris generation under normal impacts of angular particles as being a result of a continuous battering of the surface, which led to flakes of material being extruded and finally removed by ductile fracture. Sequential erosion and observation of eroded surfaces under perpendicular impingement have show'n that impinging particles created platelets of material upon impact, with material removal occurring by detachment of these platelets under succeeding impacts. ${ }^{30}$ Some authors have suggested flake and platelet formation as the main mechanism of material removal irrespective of impact angles or particle shape. ${ }^{16,31}$ 
The concept of a critical strain has been used in mudeling erosion processes where material removal occurs by the formation and fracture of features described as lips, ridges, and platelets. ${ }^{32,33}$ In such cases, an important role is played by the ductility of the material under erosion conditions, which may be different than the ductility measured in a normal tensile test. 32,33

This report describes the results of a research program exploring fundamental aspects of erosion-corrosion in fossil energy systems, with an emphasis on understanding erosion mechanisms in metallic alloys. A two-pronged approach has been used in order to achieve this goal-examining material response to single-particle impacts and studying erosion mechanisms under conditions of multiple-particle erosion. Multiple-particle erosion studies enable evaluation of materials under conditions approaching those in the field to the extent that material loss occurs as a result of thousands of impacts over a specific area. Single-impact studies provide a means to experimentally model impact conditions realized in multiple-particle erosion.

Since material removal occurs from near-surface layers, changes in these layers will have a profound effect on subsequent material removal, as described in the introduction. The experiments have, therefore, been directed toward examining such regions by assessing changes in mechanical properties of the impacted surfaces using a mechanical-properties microprobe (MPM). This would, for example, provide experimental evidence for the thermal effects described earlier. The effect of the mechanical properties of the impacted alloys on their response has also been a major issue addressed throughout the program.

\section{EXPERIMENTAL MATERIALS AND PROCEDURES}

In order to facilitate analysis of a fundamental nature, the impact studies were conducted using spherical particles on relatively simple alloy systems. Under field conditions, impacting particles are almost invariably irregular in shape, and irregular particles also remove materials more efficiently. However, the impact of a spherical particle on a flat surface is easier to analyze since the orientation of the particle relative to the surface is always well characterized. Additionally, under multiple-impact conditions, angular particles tend to embed themselves on the surfaces of ductile alloys, thus complicating analysis of the results. The use of simple alloy systems as target materials enabled controlled variation of properties without interference from complicating factors due to the presence of a second phase with widely differing properties. 
The alloys studied included several aluminum alloys (1100, 6061-T6, and 7075-T6) and an ordered Fe3Al-based iron-aluminide alloy designated FA-129. The aluminum alloys provided a relatively simple alloy system in which mechanical properties could be varied by thermo-mechanical treatment. The iron aluminides have potential practical applications in fossil-energy systems requiring erosion or erosion-corrosion resistance. In addition, their mechanical properties and unique elevated-temperature strength ${ }^{34}$ provide a clear contrast with the properties of the aluminum alloys.

The $1100 \mathrm{Al}$ was annealed in vacuum at $300^{\circ} \mathrm{C}$ for $15 \mathrm{~min}$. Annealed samples were also reduced $50 \%$ in thickness by cold rolling to produce a cold-worked condition of the alloy. The cold-worked alloy was used only for single-particle impact tests.

The composition of the vacuum-induction melted (VIM) aluminide alloy FA-129 was (in weight percent) Fe-15.9Al-5.2Cr-1.0Nb-0.033B-0.011C with trace amounts of Mo, N, Ni, O, $\mathrm{P}, \mathrm{S}, \mathrm{Si}$, and $\mathrm{Zr}$. The $\mathrm{B}$ concentration was about three times higher and the $\mathrm{C}$ concentration about four times lower than previously studied compositions. ${ }^{34}$ The additional B crf:ated a finer distribution of precipitates within the grains than previous compositions but nad similar ambient and elevated-temperature mechanical properties. ${ }^{34}$ Following homogenization at $1150^{\circ} \mathrm{C}$ for $20 \mathrm{~h}$, the alloy was hot forged at $1000^{\circ} \mathrm{C}$ and then hot rolled at $80{ }^{\circ} \mathrm{C}$ to a final plate thickness of $2.5 \mathrm{~mm}$. Samples $25-\mathrm{mm}$ square were cut from this plate and rough polished on 600 -grit $\mathrm{SiC}$ paper. These samples ware, then annealed in air at $700^{\circ} \mathrm{C}$ for $1 \mathrm{~h}$ and quenched in mineral oil. The surfaces were repolished on 600 -grit $\mathrm{SiC}$ prior to multi-particle erosion testing. For single-impact studies, samples were further polished to a $0.5-\mu \mathrm{m}$ diamond finish. Samples of heat-treated FA-129 were also subjected to single-particle impacts in the cold-worked condition. However, the low room-temperature ductility of the alloy limited the amount of cold work to $5 \%$ reduction in thickness by cold rolling.

Table 1 shows the Vickers hardness of the various alloys measured under a 50()$-\mathrm{g}$ load. Cold working increased the hardness of the $1100 \mathrm{Al}$, but the small amount of cold work in the iron-aluminide alloy barely increased its hardness.

Two systems were constructed to study the impact effects of single spherical particles of the size found in coal-conversion systems. The first system, built in the early stages of the program, consists of an erosive-particle gas gun attached to the side of a scanning electron microscope (SEM,. There are also provisions for a hot stage to heat the samples to temperatures of $10(x)^{\circ} \mathrm{C}$, as well as a hot-gas delivery system that can introduce small quantities of corrosive gases locally on sample surfaces. The details of the system have been published earlier, 35 and the system will, hereafter, be referred to as the "SEM gas gun." The gun shoots 343- $\mu \mathrm{m}$-diam balls at velocities between 10 to $90 \mathrm{~m} / \mathrm{s}$. Targets may be oriented at angles 
Table 1. Vickers hardness (500)-g load) of alloys used in study

\begin{tabular}{lc}
\hline \multicolumn{1}{c}{ Alloy } & Hardness (HV) \\
\hline Annealed 1100 aluminum & $28.9 \pm 0.9$ \\
50\% cold-worked 1100 aluminum & $46.7 \pm 1.8$ \\
6061-T6 aluminum & $100 \pm 2$ \\
7075-T6 aluminum & $174 \pm 5$ \\
Ordered iron aluminide, FA-129 & $276 \pm 9$ \\
5\% cold-worked iron aluminide, FA-129 & $305 \pm 2.5$ \\
\hline
\end{tabular}

between 10 to $90^{\circ}$ to the impacting sphere. All studies to date have been conducted using cobalt-bonded WC spheres as the impacting particles. The high density of this material provides a large amount of kinetic energy at a given velocity, and the high hardness of the material prevents any significant deformation in the balls on impact (this was verified by examining impacted balls). Most of the impact experiments have been conducted at room temperature. A few experiments were conducted at elevated temperatures using the hot stage, but the results were inconclusive and are not discussed in this report. In situ corrosion studies using the hot stage have not been conducted, although some preliminary data were geneiated early in the program. 35

Recently, a second higher velocity gun was cc nstructed in order to conduct studies of the effect of increasing kinetic energy on impact characteristics and providing the means to establish transitions in material response (for example, to establish conditions under which thermal effects are dominant). The gun uses technology used to inject frozen hydrogen pellets into fusion plasmas and was developed and built by M. J. Gouge and C. R. Foust of Oak Ridge National Laboratory (ORNL) Fusion Energy Division. The key component is a magnetically driven fast valve, which opens on a time scale of approximately $1 \mathrm{~ms}$ (ref. 36), providing a sharp pulse of gas at pressures up to 70 bar $(7 \mathrm{MPa}$ or $1000 \mathrm{psi})$, which accelerates a projectile down a launch tube. The gun, hereafter referred to as the "high-velocity gas gun," is designed to achieve particle velocities up to $2000 \mathrm{~m} / \mathrm{s}$ using helium or argon as the accelerating gas. A photograph of the system is shown in Fig. 1(a). The launch tube is contained within the uppermost tube seen in the picture. The fast valve is enclosed in the Lexan enclosure at the right-hand end of the tube and is seen in closeup in Fig. 1(b). Three 


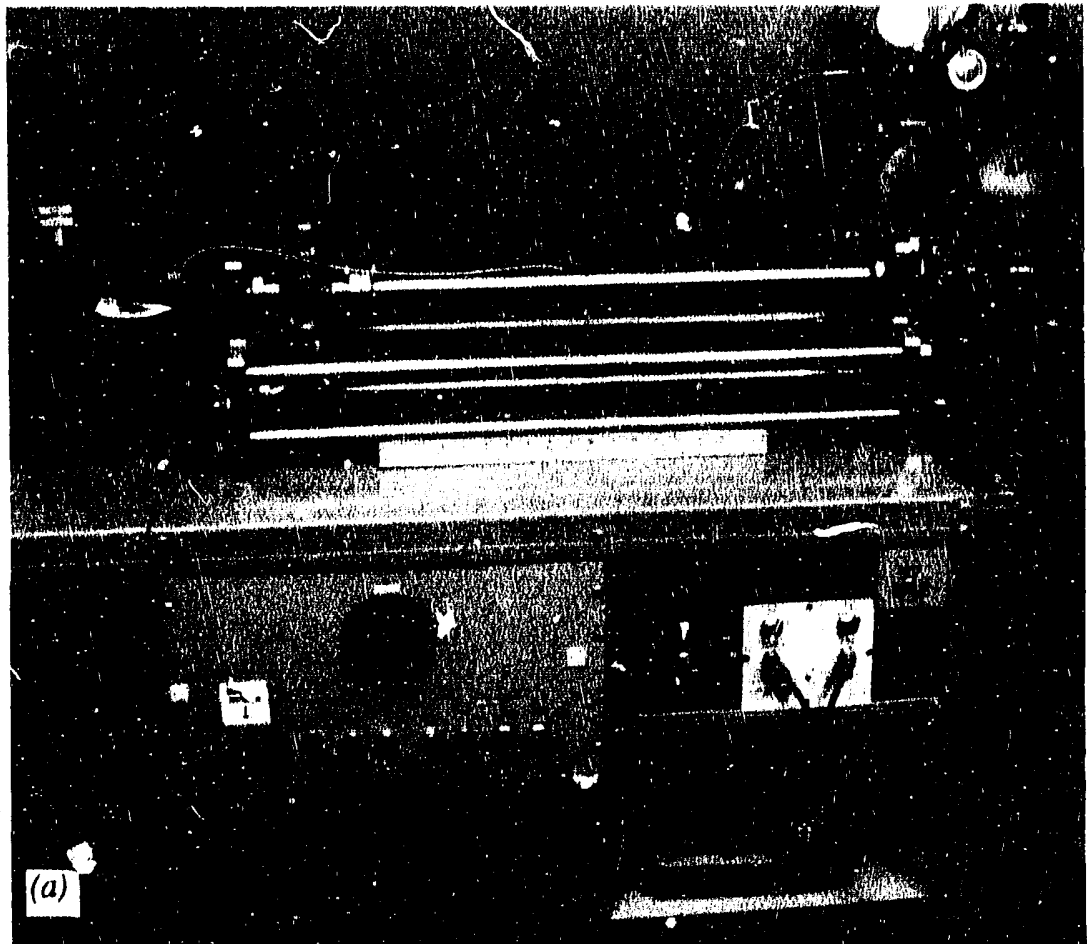

YP11962

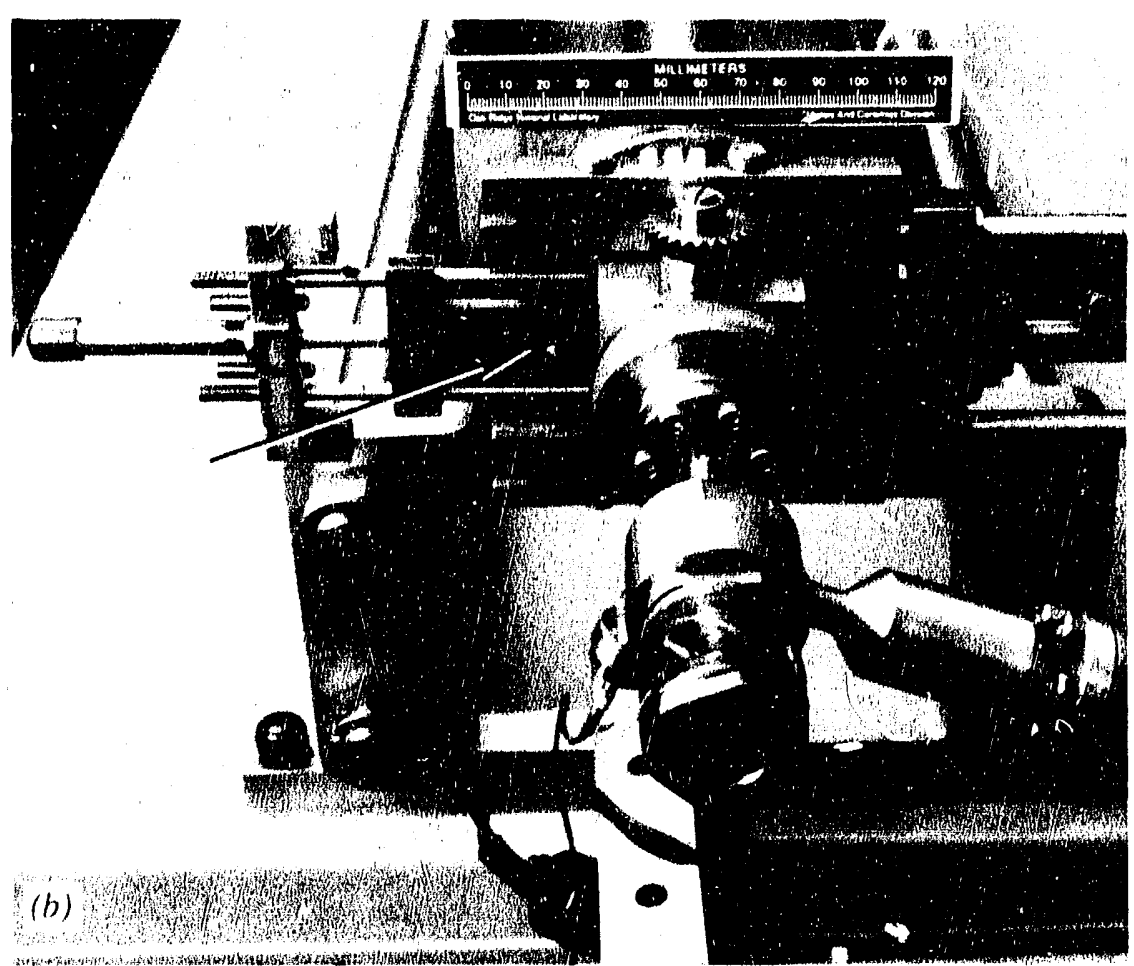

Fig. 1. (a) High-velocity gas gun and (b) closeup of fast valve and chambering mechanism in "load" position 
projectiles, in the form of 3-mm-diam cylindrical Delrin sabots, can be seen lying beneath the scale near the top of the photograph. Each of the sabots contains a $343-\mu \mathrm{m}$-diam WC ball press-fitted into one end. (Particles up to $1 \mathrm{~mm}$ in size, with no constraint on particle shape,

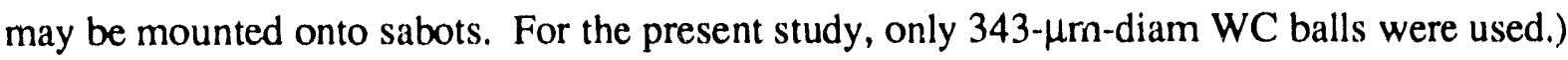

The sabot, with its open end containing the press-fit particle facing down the launch tube, is brought into alignment with the fast valve and launch tube by means of a sliding chambering mechanism. The chambering mechanism can be seen in Fig. 1 $(b)$ in the load position, ready to receive a fresh projectile (which is inserted into the cylindrical hole visible in the slide, left of center of the photograph). When the gun is fired, the sabot is accelerated down the launch tube and hits a sabot scraper at the end of the tubs: [at the port holes seen in Fig. 1(a)]. The scraper is conically shaped with its narrow end facing the oncoming sabot. The sabot shatters as it hits the scraper (aided by pre-cut slots down the open end of the sabot cylinder), and the embedded particle continues toward the target through a cylindrical annulus in the scraper. The target is mounted on a sample holder, seen on the left side of Fig. 1(a), and may be oriented at any desired angle to the impacting particle. A Textronix DC 5009 counter/timer picks up pulses from two piezoelectric shock transducers, one attached to the sabot scraper and the other clamped to the side of the specimen. The first pulse is triggered as the sabot hits the scraper, and the second pulse is generated when the particle hits the sample. The velocity of the particle is determined from the time delay between these two pulses and the distance between the tip of the sabot scraper and the impact site.

Impacts were made at velocities between 200 to $1000 \mathrm{~m} / \mathrm{s}$. Higher velocities were not attempted, and a lower velocity could not be achieved since a ruinimum back-pressure of around 25 bar ( $2.5 \mathrm{MPa}$ or $360 \mathrm{psi}$ ) is needed in order to set the fast valve.

Impact craters made using both the SEM gas gun and the high-velocity gas gun were examined in a similar manner. Craters were microscopically examined, both optically and in a SEM equipped with energy dispersive x-ray analysis (EDXA). A Tencor Alphastep II profilometer was used to measure crater dimensions and shapes, except when impact craters were so large as to be out of the profilometer's measurement range. An MPM was used to monitor the deformation associated with an impact, either by measuring the hardness directly in the crater ("top-down" measurements) or by cross-sectioning the craters and making hardness indentations beneath the crater. In the second technique, samples were typically etched prior to the hardness measurements in order to remove the mechanical damage associated with the sectioning and polishing processes.

The MPM is a depth-sensing indentation tester that allows the measurement of elastic and plastic properties of a material on a submicron scale. 37,38 The instrument has a load resolution 
of $0.3 \mu \mathrm{N}$ and an indenter-penetration depth resolution of $0.16 \mathrm{~nm}$. Indentations can be placed within $0.5 \mathrm{um}$ of a target area. Continuous load and penetration depth sensing allows the measurement of mechanical properties during any instant of the loading and unloading cycle. Since the MPM makes measurements based on indenter penetration (as opposed to dimensions of the relaxed impression), accuracy of MPM hardness numbers at low-penetration depths depends on precisely defining indenter tip geometries. In addition, the indenter is a three-faced triangular pyramid, and numerical MPM hardness values have not yet been correlated with traditional microindentation hardness numbers. For these reasons, hardness values have been normalized with respect to the hardness of unaffected bulk material (the hardness measured on the specimens at distances far from the impacted surface, where no plastic deformation effects associated with the impact process are expected). In most cases, the relative hardness of the bulk material (previously cold-worked or heat-treated material) has been fixed at 1 on this scale. In some cases, specifically for data obtained early in the program, the relative hardnesses were not similarly scaled; however, these exceptions are pointed out in the text.

For the multiple-particle impact tests, the lack of an erosion testing rig at ORNL meant that samples had to be eroded elsewhere. Two test systems were used for this purpose, a gas-jet tester at Lawrence Berkeley Laboratory 37 and a rotating-arm (slinger) rig at the University of Notre Dame. ${ }^{21}$ The gas-jet tester is the most common form of erosion-testing apparatus, wherein erodent particles are accelerated toward the target by being entrained in a flow of compressed air, the velocity of the particles depending on the air pressure. Usually, a separate velocity-measuring unit is required to measure particle velocity, ${ }^{39}$ and testing of samples proceeds sequentially. The rotating-arm apparatus launches erodent particles tangentially from the tips of a tubular arm rotating at high speeds around a vertical axis. The velocity of the particles is determined by the speed of rotation (about $25(0) \mathrm{rpm}$ for the present experiments). The rotating-arm specimen assembly is contained in an evacuated chamber, and samples are located circumferentially around the rotating arm, oriented at the desired angle to the impinging particle stream so that a number of samples can be eroded at the same time. Testing in vacuum without accelerating gases makes for a simpler experimental setup. However, the particle loading rate on the sample is typically very low /around $0.1 \mathrm{~g} / \mathrm{min}^{-1}\left(\mathrm{~cm}^{-2}\right)$ compared to about $1.2 \mathrm{~g} / \mathrm{min}^{-1}\left(\mathrm{~cm}^{-2}\right)$ in the gas-jet tests]. In addition, since the rotating arm sprays abrasive continuously, most of the erodent particles are wasted, and large charges are required to achieve significant erosion (approximately $15 \mathrm{~kg}$ of erodent has to be fed to achieve a dose of $100 \mathrm{~g}$ on one sample).

All multiple-particle erosion tests were conducted at room temperature at an erodentparticle velocity of $45 \mathrm{~m} / \mathrm{s}$. As discussed earlier, spherical particles were used as the erodent to 
more easily model the impact characteristics. The erodent used in the gas-jet tester was spherical-steel shot sieved to within a diameter range of $6(0)$ to $7(0) \mu \mathrm{m}$, and the erodent in the rotating-arm tester was spherical-steel shot sieved to within a diameter range of 297 to $420 \mu \mathrm{m}$. The selected size range allowed for possible correlation with previous and ongoing singleimpact studies with $343-\mu \mathrm{m}$ spherical WC particles.

Multiple-particle-impacted samples were examined in a manner similar to single-particleimpacted samples, mainly using an SEM/EDXA and an MPM. Detailed observations on the appearance of the impacted surface in the SEM provided information on material deformation and removal mechanisms. The MPM was used to measure hardnesses below the impacted surfaces by making indentations on cross-sectioned eroded samples. In order to be able to make indents as close to the surface as possible, some samples were taper sectioned. Samples were initially sectioned perpendicular to the eroded surface with the cut parallel to the trace of the erodent impact direction on the sample surface. One piece was then mounted in a 3:1 taper section with the taper edge lying along the length of the specimen (i.e., along the erodent direction trace). Taper-sectioned samples were usually polished through $0.5-\mu \mathrm{m}$ diamond and lightly etched to remove deformation associated with the polishing operations. MPM indentations made $5 \mu \mathrm{m}$ from the eroded surface on the tapered section therefore gave hardness measurements effectively, less than $2 \mu \mathrm{m}$ below the erode's surface.

\section{RESPONSE OF METALLIC ALLOYS TO SINGLE- PARTICLE IMPACTS}

Over the years, there have been several studies that have experimentally modeled solidparticle erosion by subjecting metallic targets to impacts from single spherical projectiles. ${ }^{27,28,40-44}$ These studies established material removal mechanisms such as by the formation and subsequent removal of extruded lips of material by successive impacts or by the overlap of impact craters. They also provided evidence of high-strain-rate deformation in the form of shear bands or surface melting. However, one of the major drawbacks of these studies is that particles were relatively large compared to those expected in fossil-energy systems-the particle size in the above studies ranged from 1.6 to $9.5 \mathrm{~mm}$ in diameter. The energy transferred to a surface by an impacting particle is limited to the kinetic energy contained in that particle; the greater the kinetic energy, the more the potential damage to the surface. Since the kinetic energy is proportional to the cube of the particle size, it is not clear whether all of the observations, especially those pertaining to thermal effects, would have occurred with smaller, more realistically sized particles as have been used in the present sludy. 


\subsection{RESULTS AND DISCUSSION OF SINGLE-PARTICLE IMPACT STUDIES}

All initial studies were conducted using the SEM gas gun. Results of these experiments have been published extensively $35,45-47$ and are reviewed here briefly to provide a perspective on the more recent work.

The earliest work 35,45 was on strong engineering alloys (Hastelloy C-276, Berylco 25, and 4340 steel) with a range of mechanical properties that were further modified by thermal or mechanical treatments. Targets were impacted with $343-\mu \mathrm{m}$-diam WC balls at velocities of $30 \mathrm{~m} / \mathrm{s}$ at impact angles of 30 and $90^{\circ}$. It was found that craters were consistently larger on annealed specimens compared to strengthened specimens. Among all the alloys taken as a group, there was a general trend in which crater depth increased with increasing ductility and decreased with increasing strength. However, multiple-particle impact tests conducted elsewhere on the same alloys showed that the strengthening treatments had little effect on the

erosion rates. ${ }^{31}$ Crater volumes after single-particle impact were, therefore, a poor predictor of erosion rates, at least at velocities on the order of tens of meters per second. Top-down MPM indentations were made in the single-impact craters formed on polished specimens of Hastelloy C-276. It was found that crater bottoms were harder than adjacent unimpacted surfaces, indicating that the material work hardened due to the impacts. No measurements were made on cross-sectioned craters, so it was not known how the hardness varied with distance beneath the impact craters.

The results from impacts on Hastelloy C-276 suggested that thermal effects previously associated with erosion may be more easily observable in lower melting alloys. As a result, a series of aluminum alloys with a wide range of mechanical properties were chosen for the next series of experiments. ${ }^{46,47}$ These were subjected to single impacts at $30^{\circ}$ incidence by $343-\mu \mathrm{m}$ diam WC balls at a velocity of $28.5 \mathrm{~m} / \mathrm{s}$. As in the earlier study, the crater sizes decreased with increasing alloy strength. MPM indentations were made both in the craters, as well as beneath cross-sectioned craters. The resulting hardness versus distance profiles are shown in Fig. 2. All alloys were work hardened by the impacts, with no evidence for thermal softening effects. A calculation on expected temperature rises, assuming adiabatic conditions and that all the energy in the impacting particle was transferred to the target, predicted a temperature rise of $284 \mathrm{~K}$ in 7075-T6 Al compared to 50 $\mathrm{K}$ in annealed 110) $\mathrm{Al}$ (ref. 47). However, the actual temperature rise should be lower since a significant fraction of the incident energy is returned in 

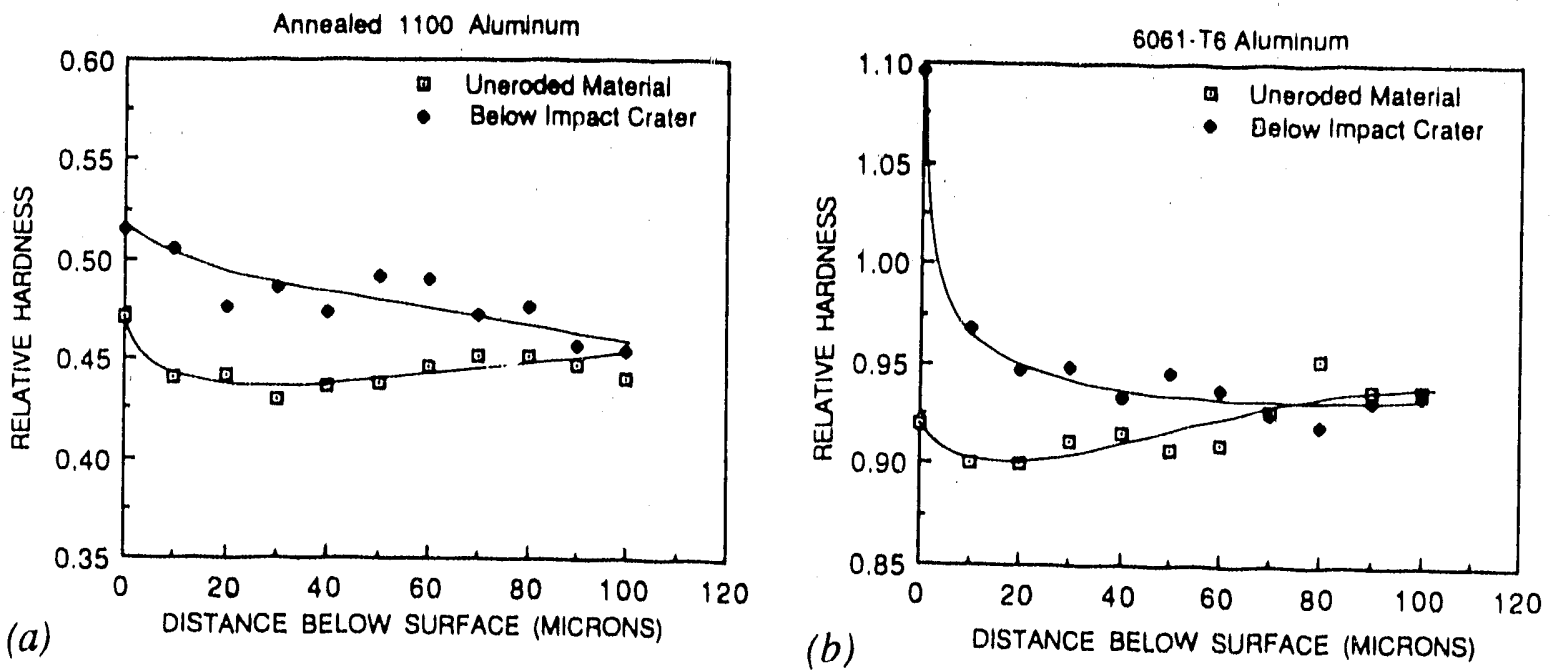

ORNL DWG $92-5049$

ORNL DWG 92-5050
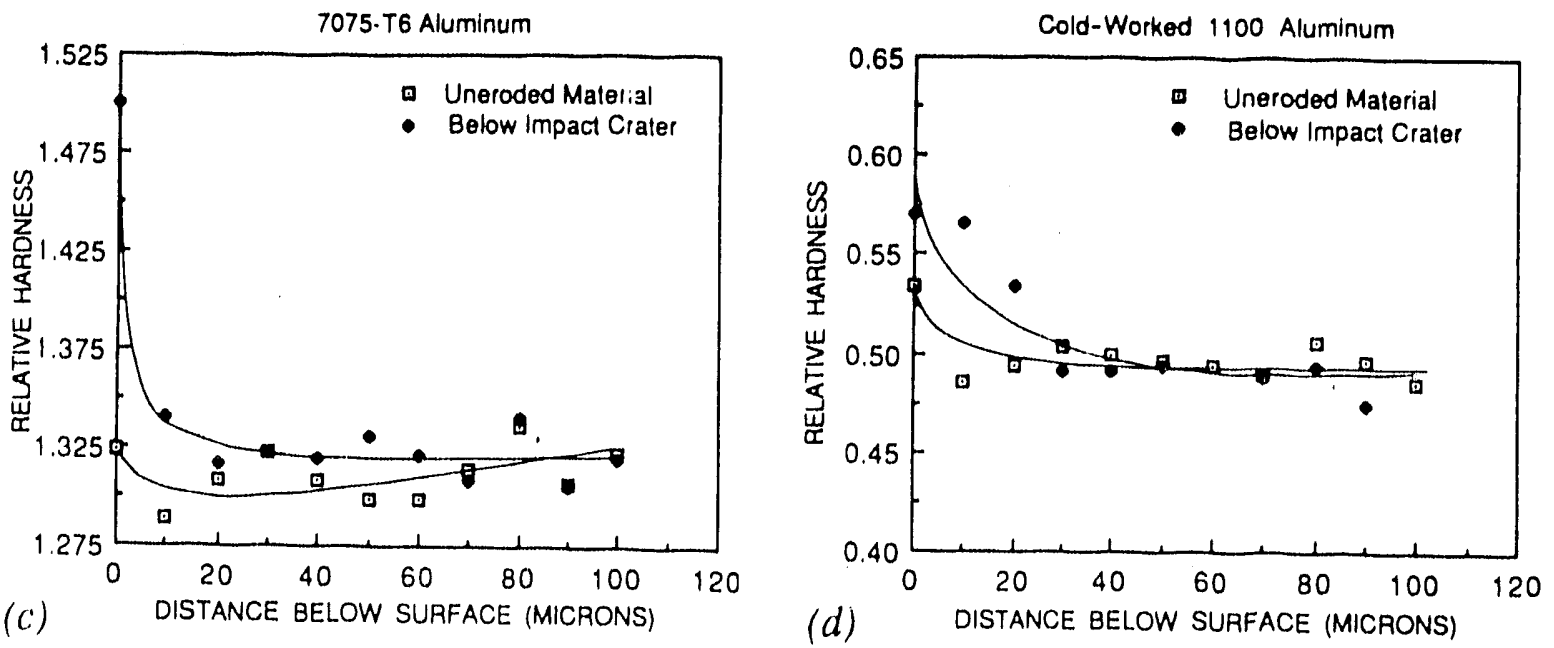

Fig. 2. Relative hardness versus depth below craters due to single impacts at $30^{\circ}$ incidence and $28.5 \mathrm{~m} / \mathrm{s}$ for: $(a) 1100 \mathrm{Al},(b) 6061-\mathrm{T} 6 \mathrm{Al},(c) 7075-\mathrm{T} 6 \mathrm{Al}$, and (d) $50 \%$ cold-worked $1100 \mathrm{Al}$. 
the rebounding ball, and this fraction would be larger in stronger alloys (i.e., in 7075-T6 Al compared to annealed $1100 \mathrm{Al}$ ). The calculated temperatures were thus not high enough to cause thermal softening.

In Fig. 2, the depth over which hardening occurs is significantly greater in the softer annealed $1100 \mathrm{Al}$ compared to cold-worked $1100 \mathrm{Al}$ or the precipitation-hardened alloys. Studies by other authors 28,31 had shown that precipitation-hardened $7075 \mathrm{Al}$ alloy eroded faster than the annealed $1100 \mathrm{Al}$. The hardness results in Fig. 2, therefore, suggest that when dealing with the same basic alloy system, the ability to accommodate the impact energy vi? plastic deformation over a large volume improves a material's resistance to erosion.

Further detailed examination of the deformation due to single-particle impacts was done using $1100 \mathrm{Al}$ and iron-aluminide alloy FA-129 as the target materials. The two alloys provided a large variation in mechanical properties, $1100 \mathrm{Al}$ being a low-strength, highductility alloy, whereas the aluminide is a relatively high-strength alloy with limited roomtemperature ductility. From a fundamental viewpoint, the iron-aluminide alloy's unique elevated-temperature strength characteristics may be expected to influence impact-induced thermal effects described above.

Relatively low-velocity impacts using the SEM gas gun showed only small differences in the general appearance of the craters on the two alloys, as shown in Fig. 3, for impacts at $30^{\circ}$ incidence at velocities between 15 to $20 \mathrm{~m} / \mathrm{s}$ and 50 to $55 \mathrm{~m} / \mathrm{s}$. As would be intuitively obvious, larger craters formed at the higher velocities, and as may be expected based on the hardness values in Table 1, the craters were also significantly larger in the softer $1100 \mathrm{Al}$ compared to FA-129. In both alloys, material is pushed forward in the direction of the impact forming a small pileup of material at the end of the elongated crater, although this is barely observable in FA-129 impacted at $16 \mathrm{~m} / \mathrm{s}$. The deformation surrounding the affected material, as well as the amount of piled-up material, is greater in the softer $1100 \mathrm{Al}$. Figure 4 shows craters formed in $50 \%$ cold-worked $1100 \mathrm{Al}$ and in 5\% cold-worked FA-129 by impacts at similar velocities. Comparison with Fig. 3 (and allowing for the small differences in velocity) shows that the crater is somewhat smaller in cold-worked $1100 \mathrm{Al}$ compared to annealed $1100 \mathrm{Al}$ due to the higher hardness of the cold-worked alloy. There is no discernible difference in crater size in the case of the heat-treated and cold-worked iron-aluminide samples, a fact that may be related to the small difference in hardness between the two conditions. In both alloys, the deformation pattern and the appearance of the lip is similar in both the heattreated and cold-worked conditions. MPM hardness profiles beneath the impact craters showed moderate work hardening due to the impacts, similar to the profiles shown in Fig. 2 for obliquely impacted aluminum alloys. 

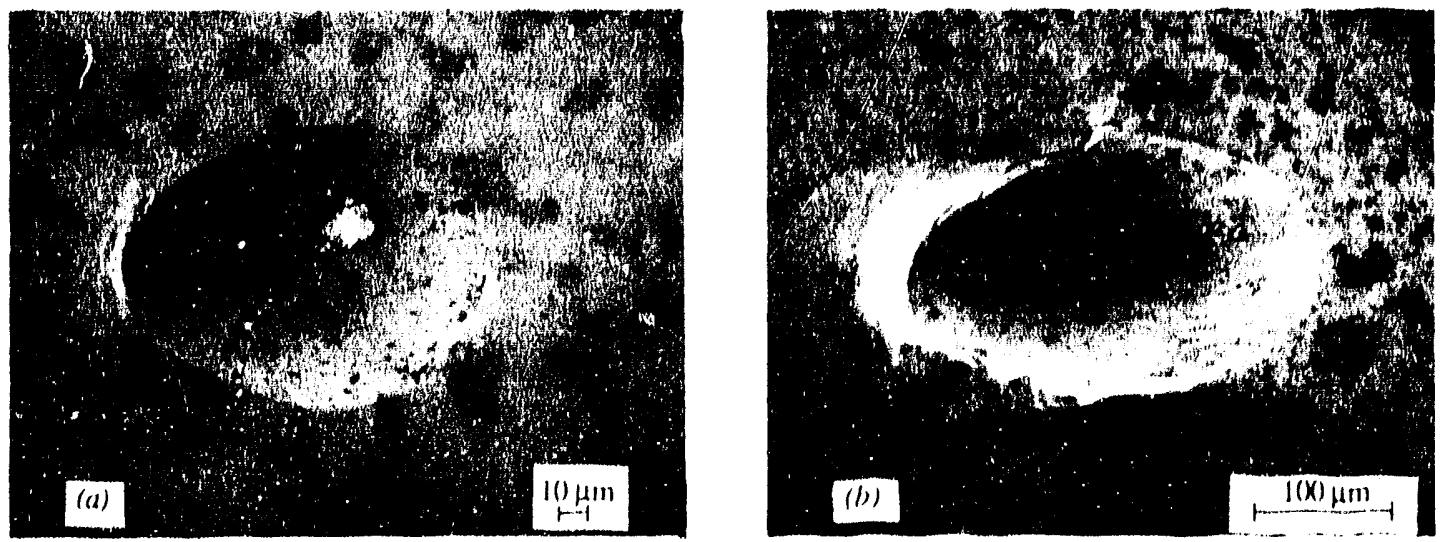

M31283

M31281
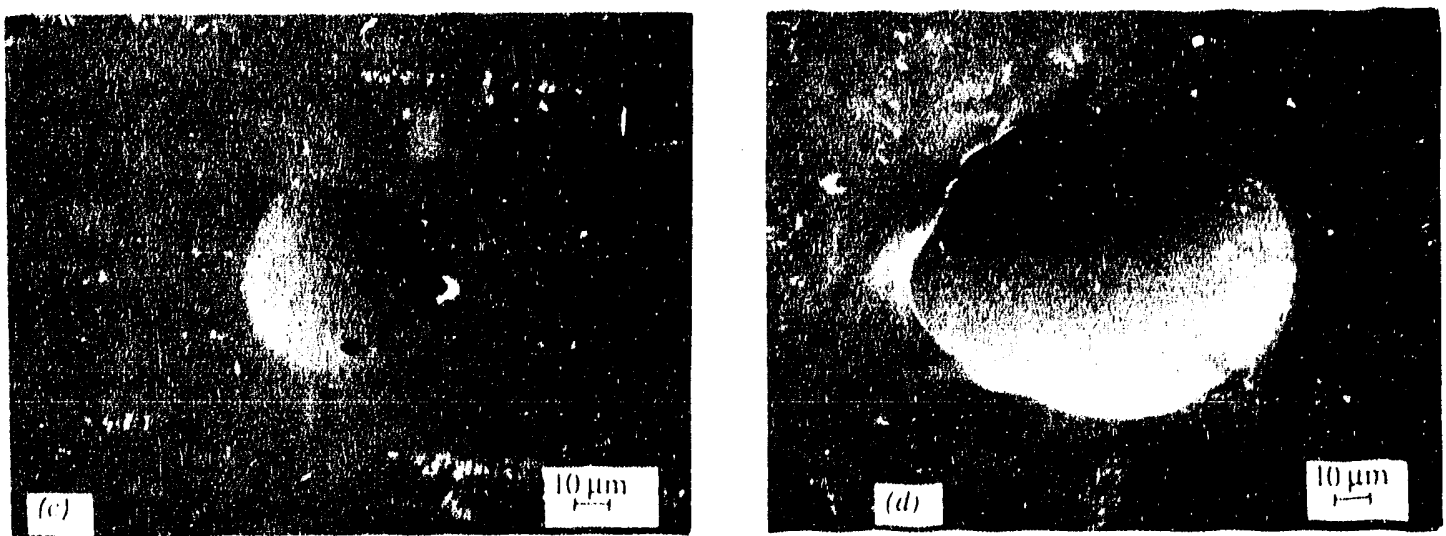

Fig. 3. Craters due to single-particle impacts at $30^{\circ}$ incidence on: $(a)$ annealed $1100 \mathrm{Al}$ at $18 \mathrm{~m} / \mathrm{s},(b)$ annealed $1100 \mathrm{Al}$ at $50 \mathrm{~m} / \mathrm{s},(c)$ ordered iron-aluminide alloy at $16 \mathrm{~m} / \mathrm{s}$, and $(d)$ ordered iron-aluminide alloy at $55 \mathrm{~m} / \mathrm{s}$. 
M31491

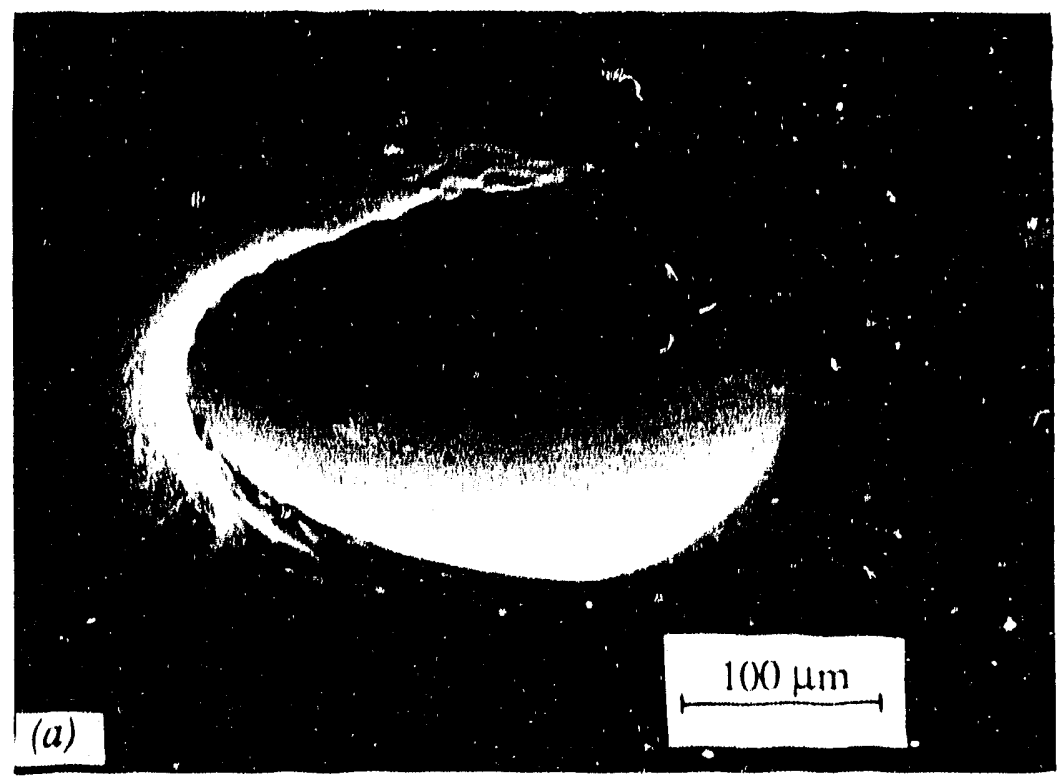

M31495

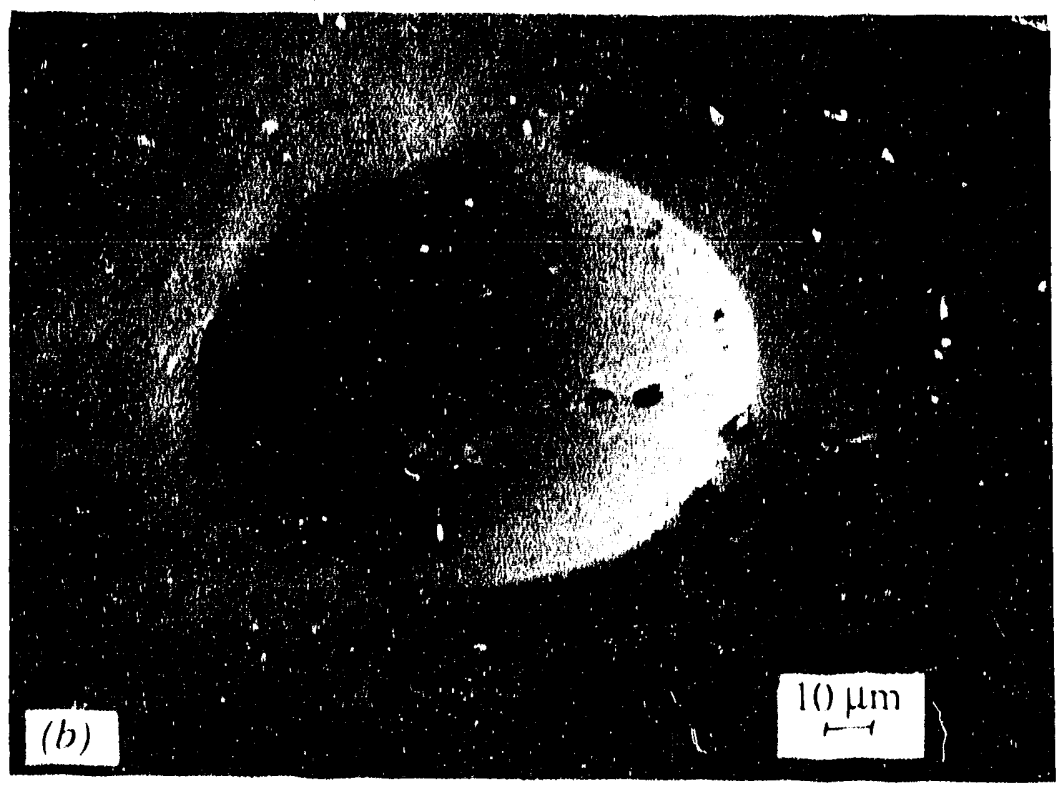

Fig. 4. Craters due to single-particle impacts at $30^{\circ}$ incidence on: (a) $50 \%$ cold-worked $1100 \mathrm{Al}$ at $61 \mathrm{~m} / \mathrm{s}$ and (b) $5 \%$ cold-worked ordered iron-aluminide alloy at $58 \mathrm{~m} / \mathrm{s}$. 
For relatively low-velocity $90^{\circ}$ impacts, craters were roughly circular with little evidence of deformation around the crater edges, as shown in Fig. 5 for the two alloys in both heat-treated and cold-worked conditions. The faceted shape of the craters in $1100 \mathrm{Al}$ is probably due to crystallographic effects of the particle impact being wholly contained in one grain. Figure 6 shows MPM hardness profiles made on the craters shown in Fig. 5 after they were cross sectioned. As with impacts at $30^{\circ}$ (Fig. 2), all materials undergo significant work hardening. Since there is no component of the velocity of the incident particle, which is tangential to the surface at $90^{\circ}$ incidence, the maximum fraction of the incident energy is transferred to the target, and plastic deformation effects may be expected to be most severe. This may be seen by comparing the extent of hardening in $1100 \mathrm{Al}$ as seen in Figs. 2 and 6. Although the velocities for the $90^{\circ}$ impacts are about twice as high as for $30^{\circ}$ impacts, the increase in hardness and the thickness of the hardened layer is at least 3 to 4 times as high for $90^{\circ}$ impacts compared to $30^{\circ}$ impacts.

MPM measurements under craters formed at $90^{\circ}$ showed distinct differences between the materials, as may be inferred from Fig. 6. As is intuitively obvious, the amount of material work hardened by an impact is greater in the softer material, althougil the differences are not as large as may be predicted based on alloy hardnesses. The interesting differences occur in the nature of hardening in the very-near-surface layers of the iron-aluminide alloy. In the heattreated state, the hardness increases monotonically toward the surface. However, in the coldworked FA-129 alloy, the hardness tends to drop off in a region about $80 \mu \mathrm{m}$ from the bottom of the crater. Because of the scatter in the data, there is no clear indication of a near-surface dropoff in hardness in $1100 \mathrm{Al}$. It appears that the near-surface layers in annealed $1100 \mathrm{Al}$ achieve a constant hardness under the impacts [Fig. 6(a)]. Figures 6(a) and $(b)$ show that relatively low hardnesses were measured at some locations in the near-surface layers of both annealed and cold-worked $1100 \mathrm{Al}$. However, the data for $1100 \mathrm{Al}$ show considerably more scatter than those from the iron-aluminide samples, and the trends cannot be as easily ascertained. The lower hardness in the surface layers of the impacted surface, as opposed to the hardness increasing continuously up to the surface, is hereafter referred to as near-surface softening.

There is somewhat greater certainty of near-surface softening in both $1100 \mathrm{Al}$ and FA-129 at higher velocities. Figure 7 shows cross-sectioned impacts made using the high-velocity gas gun at $90^{\circ}$ incidence at velocities of several hundred meters per second. At such high velocities, the particle penetrated a relatively long distance into the $1100 \mathrm{Al}$ and was embedded. Even in the harder iron-aluminide alloy, the particle seems to have penetrated to a depth greater 

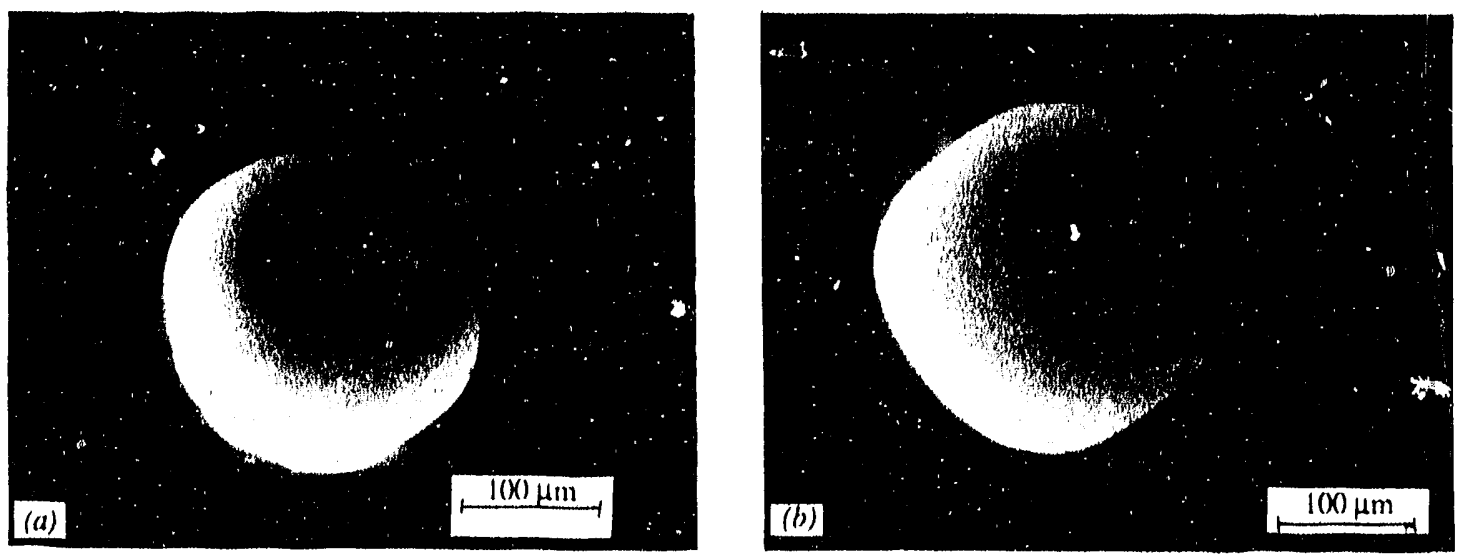

M31277

M31493
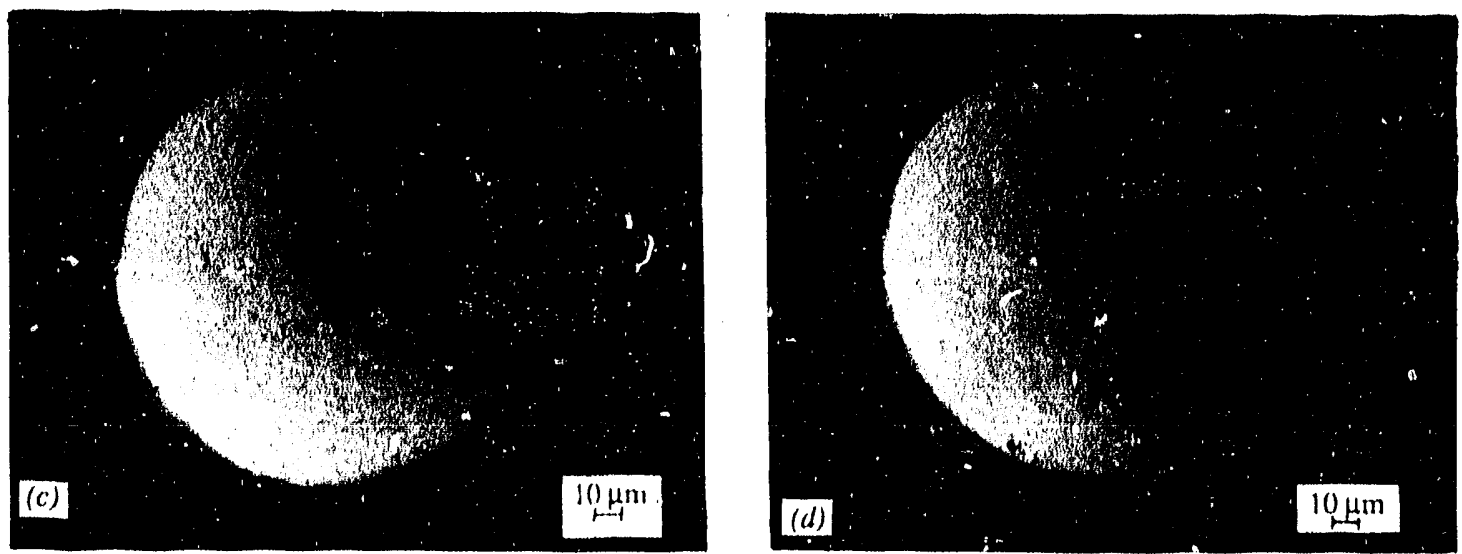

Fig. 5. Craters due to single-particle impacts at $90^{\circ}$ incidence on: (a) annealed $1100 \mathrm{Al}$ at $58 \mathrm{~m} / \mathrm{s},(b) 59 \%$ cold-worked $1100 \mathrm{Al}$ at $59 \mathrm{~m} / \mathrm{s},(c)$ ordered ironaluminide alloy at $59 \mathrm{~m} / \mathrm{s}$, and (d) $5 \%$ cold-worked ordered iron-aluminide alloy at $58 \mathrm{~m} / \mathrm{s}$. 
ORNL DWG 92-5051

ORNL DWG $92-5052$
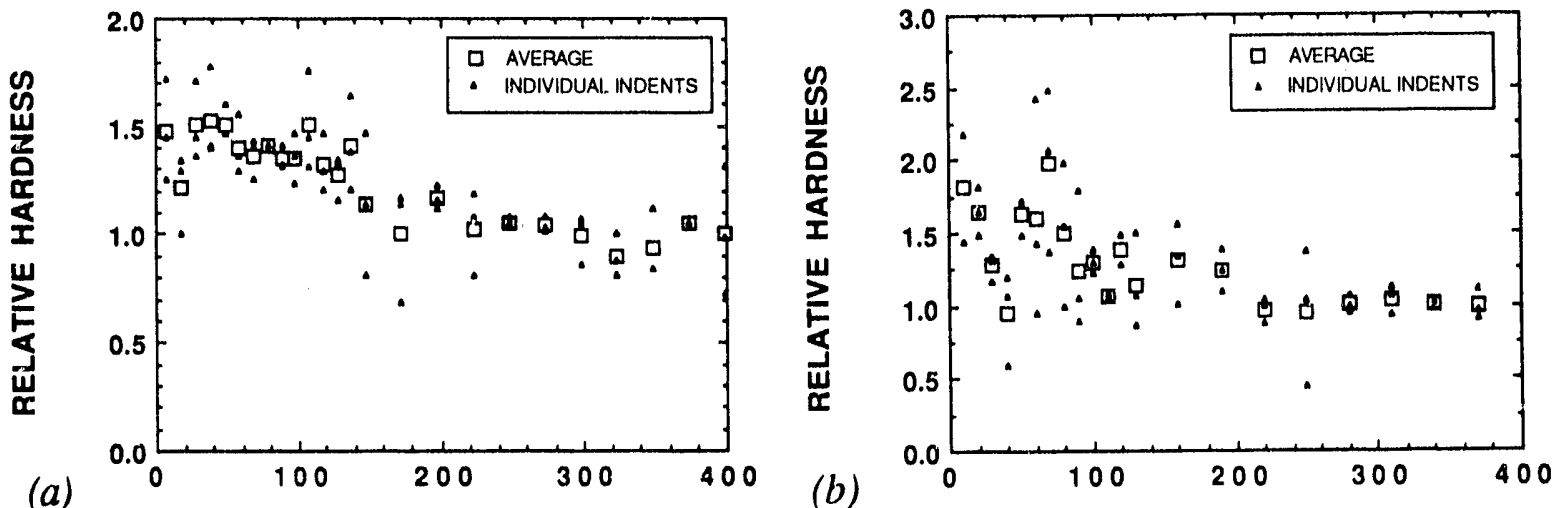

ORNL DWG 92-5053

ORNL DWG 92-5054
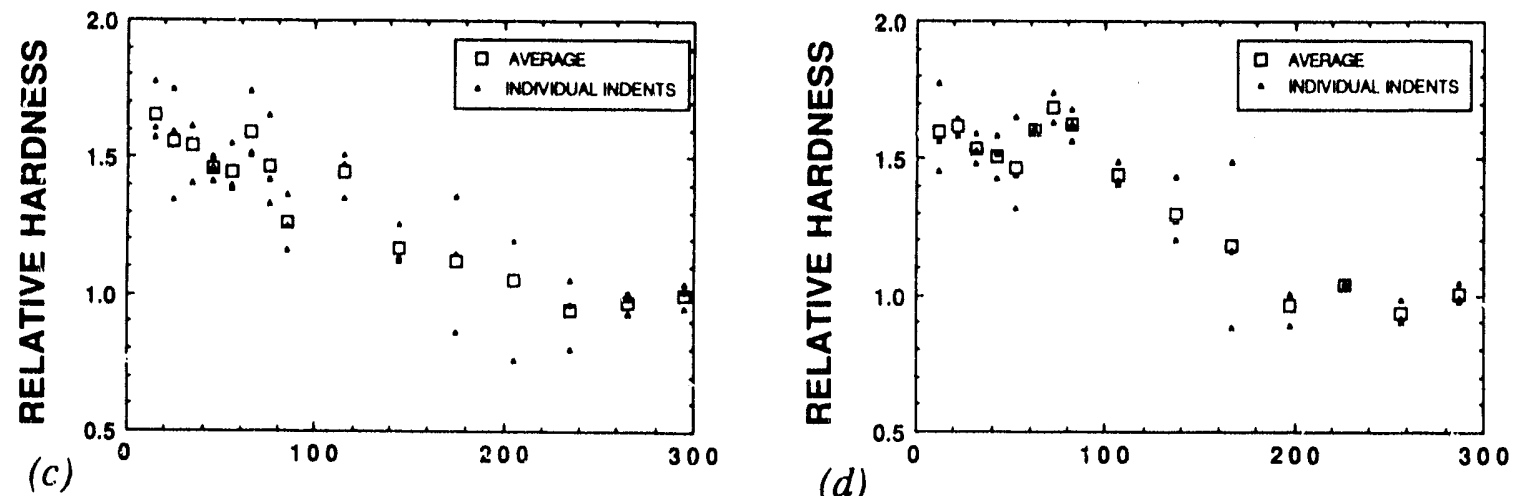

Fig. 6. MPM relative hardness profiles beneath craters formed due to single impacts at $90^{\circ}$ incidence on: $(a)$ annealed $1100 \mathrm{Al}$ at $58 \mathrm{~m} / \mathrm{s},(b) 50 \%$ cold-worked $1100 \mathrm{Al}$ at $59 \mathrm{~m} / \mathrm{s},(c)$ ordered iron-aluminide alloy at $59 \mathrm{~m} / \mathrm{s}$, and (d) $5 \%$ coldworked ordered iron-aluminide alloy at $58 \mathrm{~m} / \mathrm{s}$. Distance from the crater bottom is shown in $\mu \mathrm{m}$. 
YP11357

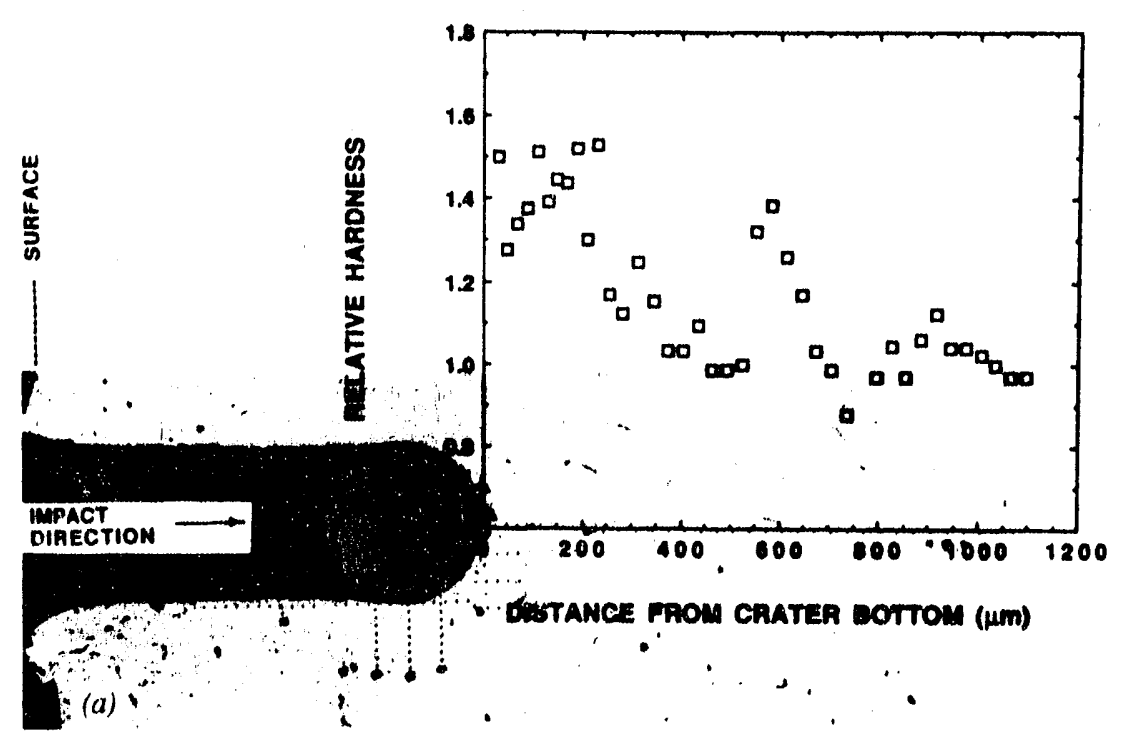

YP11356

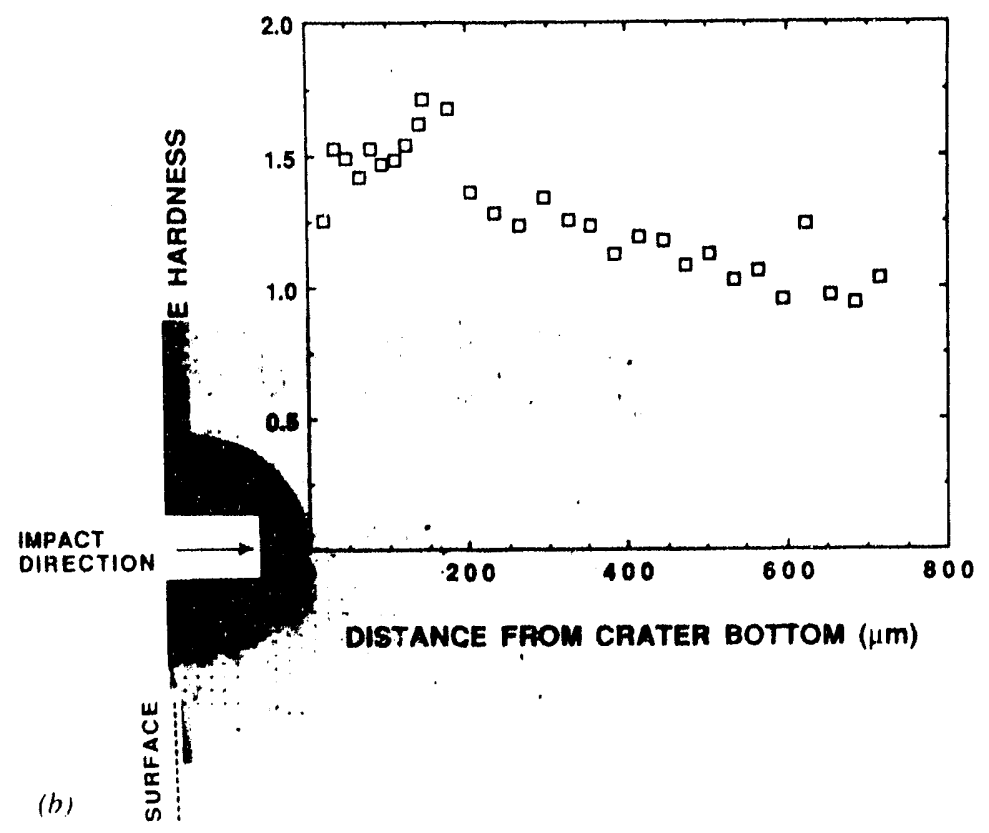

Fig. 7. Cross-sectioned, high-velocity impact craters with superimposed MPM relative hardness profiles for: (a) annealed $1100 \mathrm{Al}$ at $794 \mathrm{~m} / \mathrm{s}$ and $(b)$ ordered ironaluminide alloy at $894 \mathrm{~m} / \mathrm{s}$. 
than its radius. The superimposed MPM hardness profiles show that a near-surface hardness dropoff occurred in both cases. Closer inspection reveals that the extent of softening is greater in the iron-aluminide alloy.

The near-surface effects may be due to annealing of work-hardened material from heat generated during the impact. As described above, thermal effects associated with erosive particle impacts have typically been equated to the target material's thermal properties. One should, therefore, expect strong effects in low-melting $1100 \mathrm{Al}$, where even mocierate temperature rises will be significant compared to typical recrystallization temperatures of the alloy. However, equal (if not greater) apparent thermal effects are observed in the higher melting iron-aluminide alloy. This suggests that the mechanical properties of the alloy also have a strong influence on temperature excursions uider solid-particle impacts. These and other effects are considered in Sect. 5.

Some other data supporting an argument for thermal effects were provided by observations made during a study on the impact response of scales formed on $2.25 \mathrm{Cr} 1 \mathrm{Mo}$ steels during erosion-corrosion. 48 Samples were eroded-corroded at Lawrence Berke'ey Laboratory using fluidized bed-combustor, bed material impacting at velocities of 10 and $20 \mathrm{~m} / \mathrm{s}$ on samples at temperatures of 450 and $650^{\circ} \mathrm{C}$. The SEM gas gun was used to make single-particle impacts on the scales that formed (typically a few microns thick) at an angle of $90^{\circ}$ and velocities around $50 \mathrm{~m} / \mathrm{s}$. The MPM hardness profiles beneath impact craters on specimens previously eroded-corroded under three conditions are shown in Fig. 8. Also shown is the baseline profile beneath the scale on one of the samples, made in an area away from a single-particle impact location. This profile indicates a small amount of work hardening under the relatively mild mechanical impact conditions of erosion-corrosion (relatively soft particles impacting a surface protected by a scale at velocities between 10 to $20 \mathrm{~m} / \mathrm{s}$ ). Under higher velocity single impacts by harder WC particles, all three samples showed much greater work hardening along with a dropoff in hardness or a constant hardness in the near-surface layers. As described above, this near-surface effect may be accounted for by thermal effects associated with the single-particle impacts on the relatively deformationresistant, slightly work-hardened surfaces of the eroded-corroded steels. (This study was done in collaboration with A. V. Levy at Lawrence Berkeley Laboratory during the course of this pioject. It is not discussed further in this report since the specific subject deviates from the central theme of erosion mechanisms and, also, because the results and discussion have been published in their entirety. $)^{48}$ The observations on the eroded-corroded steels fall short of being conclusive evidence because detailed comparisons with other sample or test conditions 


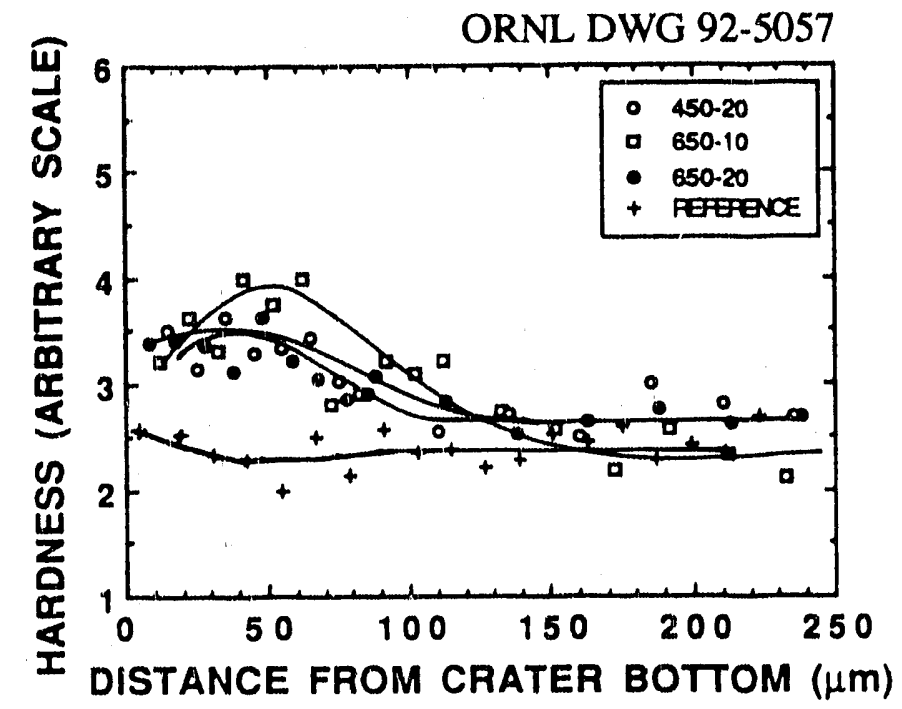

Fig. 8. Relative hardness profiles beneath craters formed due to single impacts at $90^{\circ}$ incidence and velocities around $50 \mathrm{~m} / \mathrm{s}$ on eroded-corroded 2.25Cr1 Mo stioels

were not made. The results on the impacted iron aluminide may also be attributed to disordering effects of mechanical deformation from the impacts. A detailed discussion of these effects is provided in Sect. 5 of this report.

In addition to the difference in hardening response between the two alloys, there were also considerable differences in the appearance of the impacted surfaces, which although not apparent at low velocities (Figs. 3 and 4), were very marked at high velocities. This can be seen by comparing the high-velocity impact craters formed at $30^{\circ}$ incidence in $1100 \mathrm{Al}$ (Fig. 9) and in the iron-aluminide alloy (Fig. 10). Figure 9 shows the progressively increased amount of damage on $1100 \mathrm{Al}$ as the velocity of the impacting ball increases. At the lowest velocity of $250 \mathrm{~m} / \mathrm{s}$ [Fig. $9(a)$ ], material is pushed forward in front of the ball, much like at lower velocities (Fig. 3) but to a much larger extent. Unlike the lower velocity impacts, there is also evidence of deformation along the side of the crater. This is clearly observable at higher velocities [Figs. $9(b)$ through $(d)$ ]. These indicate that the impacting particle "burrows" a significant distance into the material before being ejected, in which case it tears through the covering material forming large, stretched lips [Figs. $9(b)$ and $(c)$ ]. Sometimes, the ball rebounds straight back out without tearing the material, as in Fig. $9(d)$. (It was confirmed by EDXA that the particle had indeed ejected from the crater. However, the ball may also have fallen out during specimen handling.) The differences in velocity indicate that the burrowing 


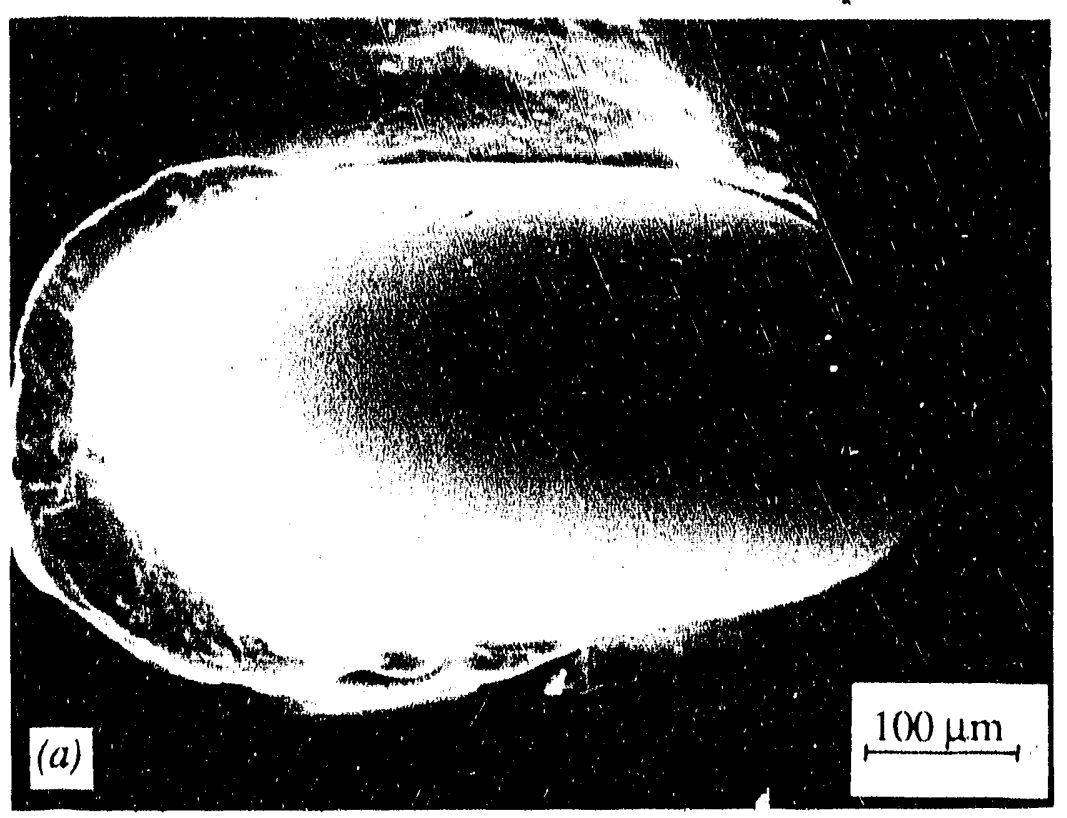

M31537

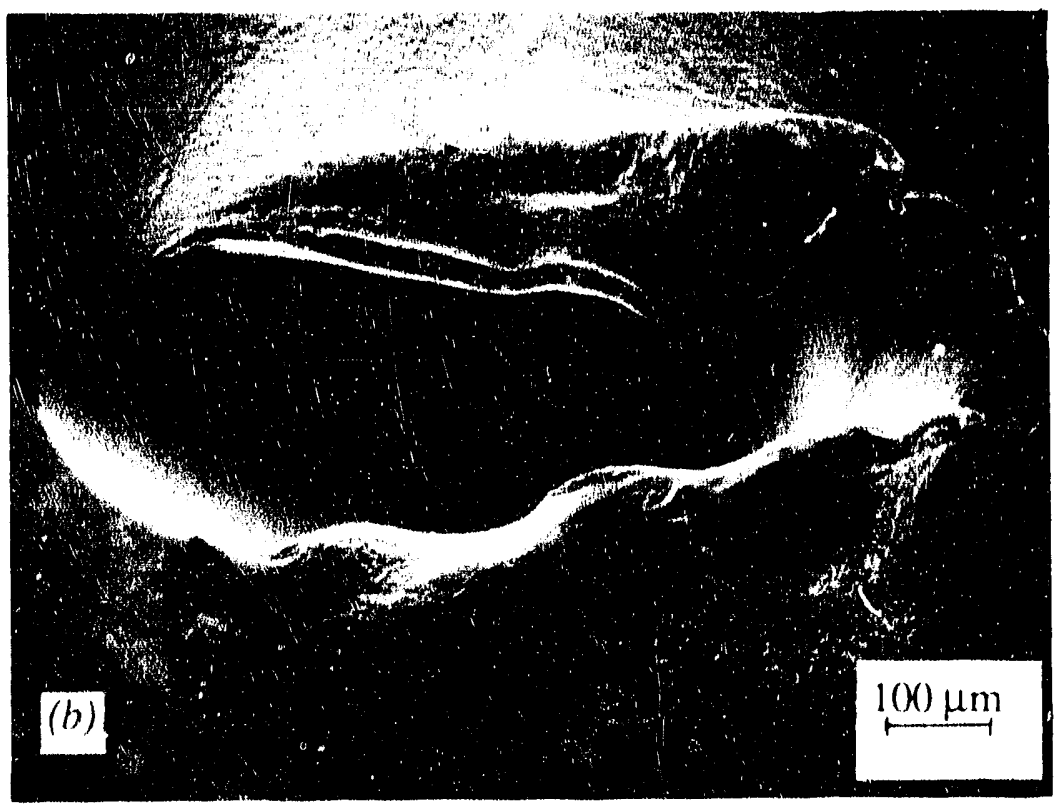

Fig. 9. Craters due to single-particle impacts at $30^{\circ}$ incidence on annealed $1100 \mathrm{Al}$ : (a) at $280 \mathrm{~m} / \mathrm{s}$, (b) $420 \mathrm{~m} / \mathrm{s},(c) 625 \mathrm{~m} / \mathrm{s}$, and $(d) 740 \mathrm{~m} / \mathrm{s}$. 
M31236

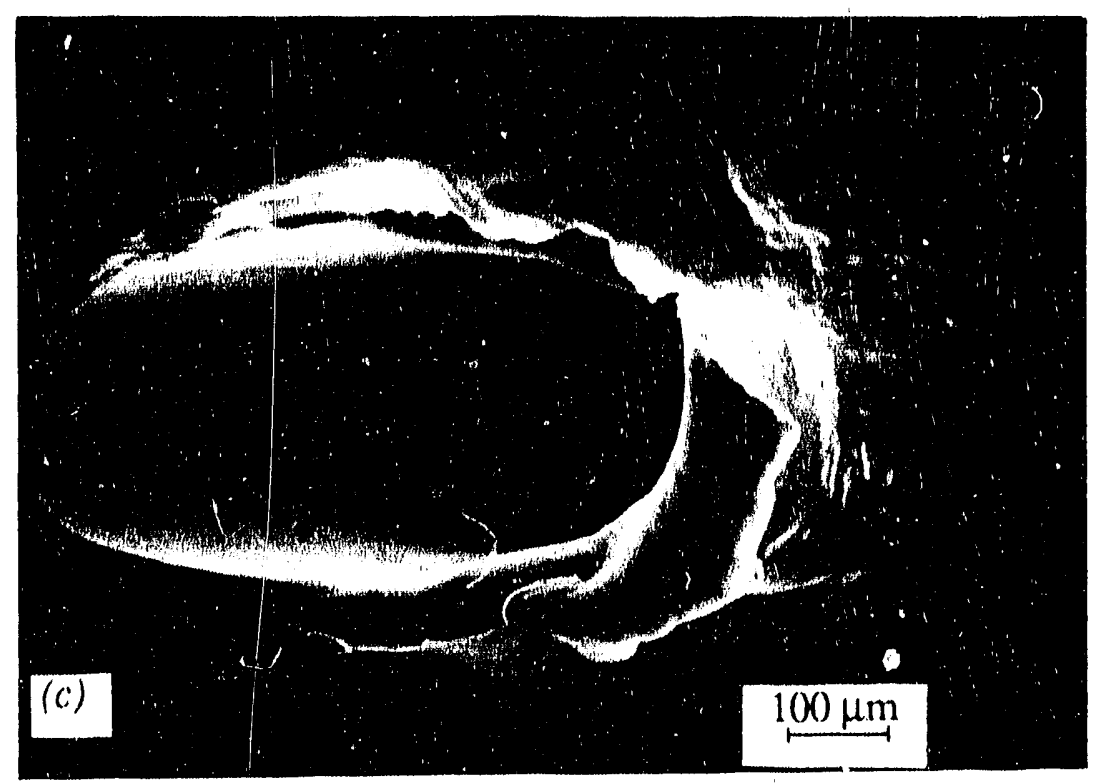

M31450

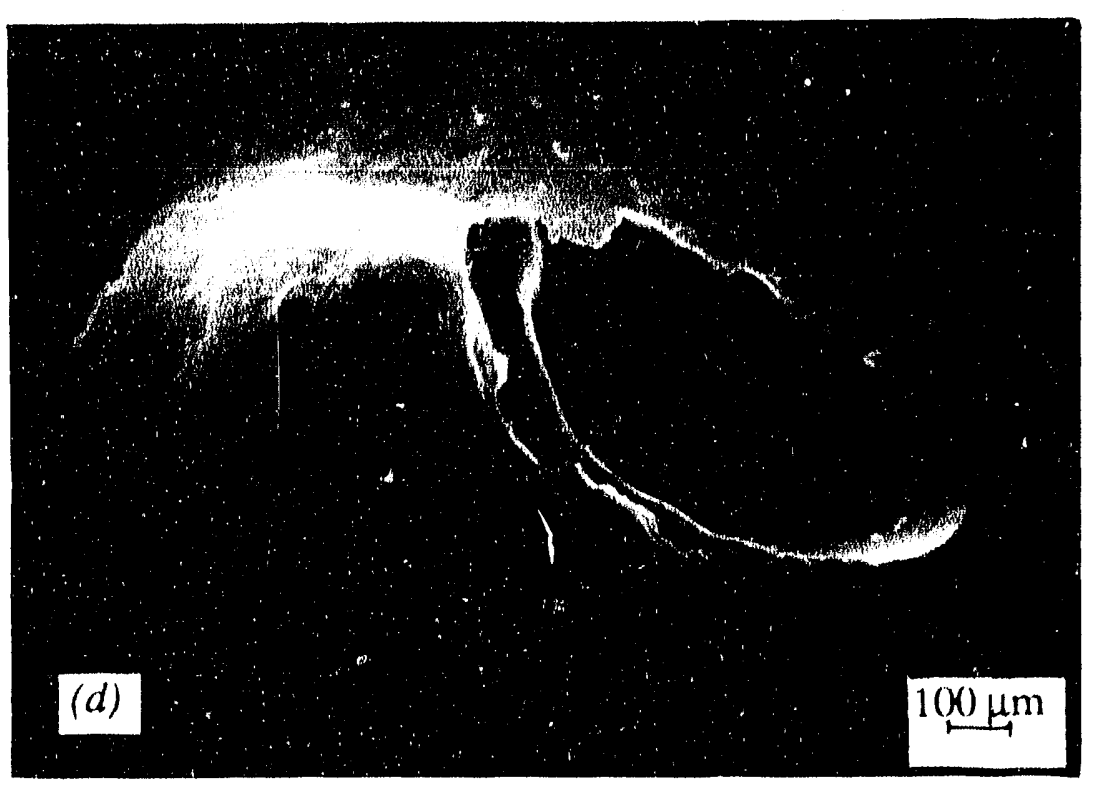

Fig. 9. (continued) 
M31241

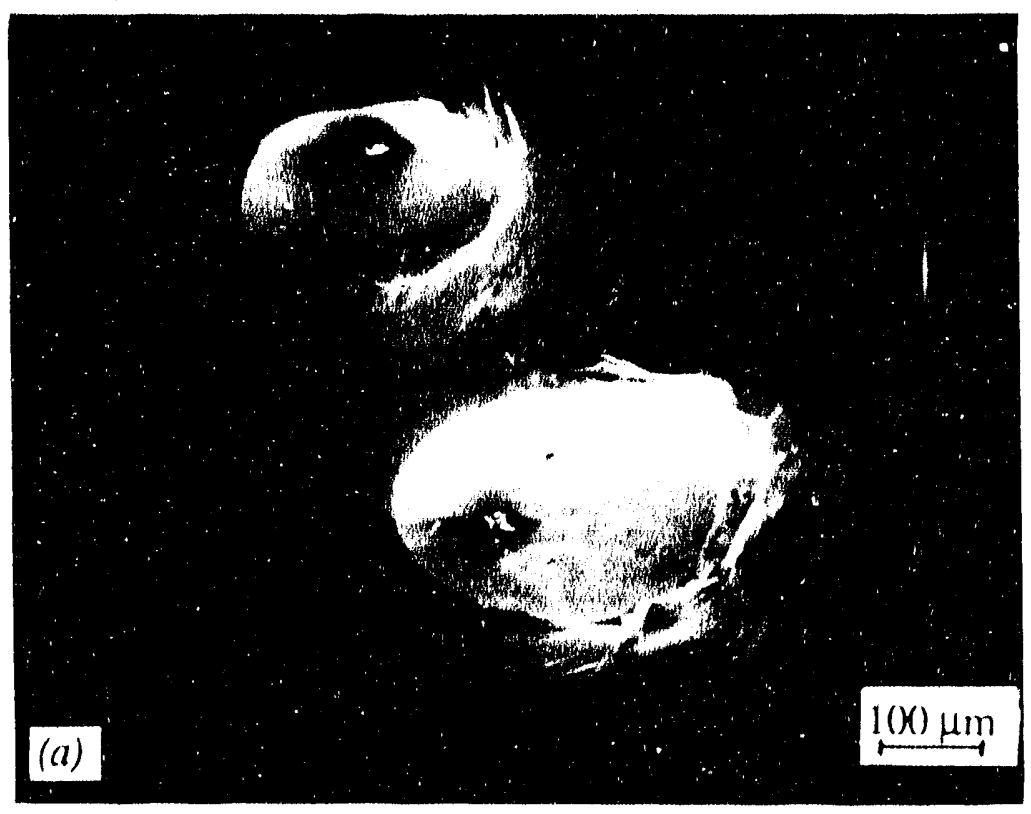

M31242

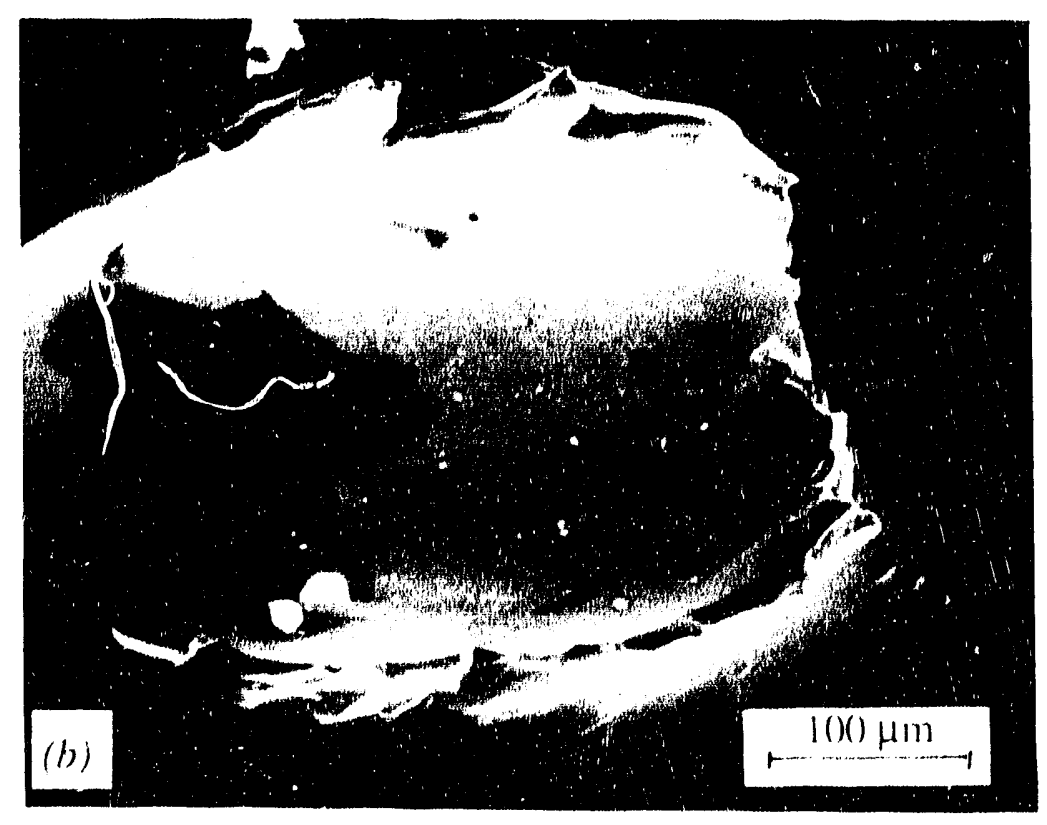

Fig. 10. Craters due to single-particle impacts at $30^{\circ}$ incidence on ordered iron-aluminide alloy: $(a)$ at 340 and $280 \mathrm{~m} / \mathrm{s},(b) 450 \mathrm{~m} / \mathrm{s}$, and $(c) 429 \mathrm{~m} / \mathrm{s}$. 


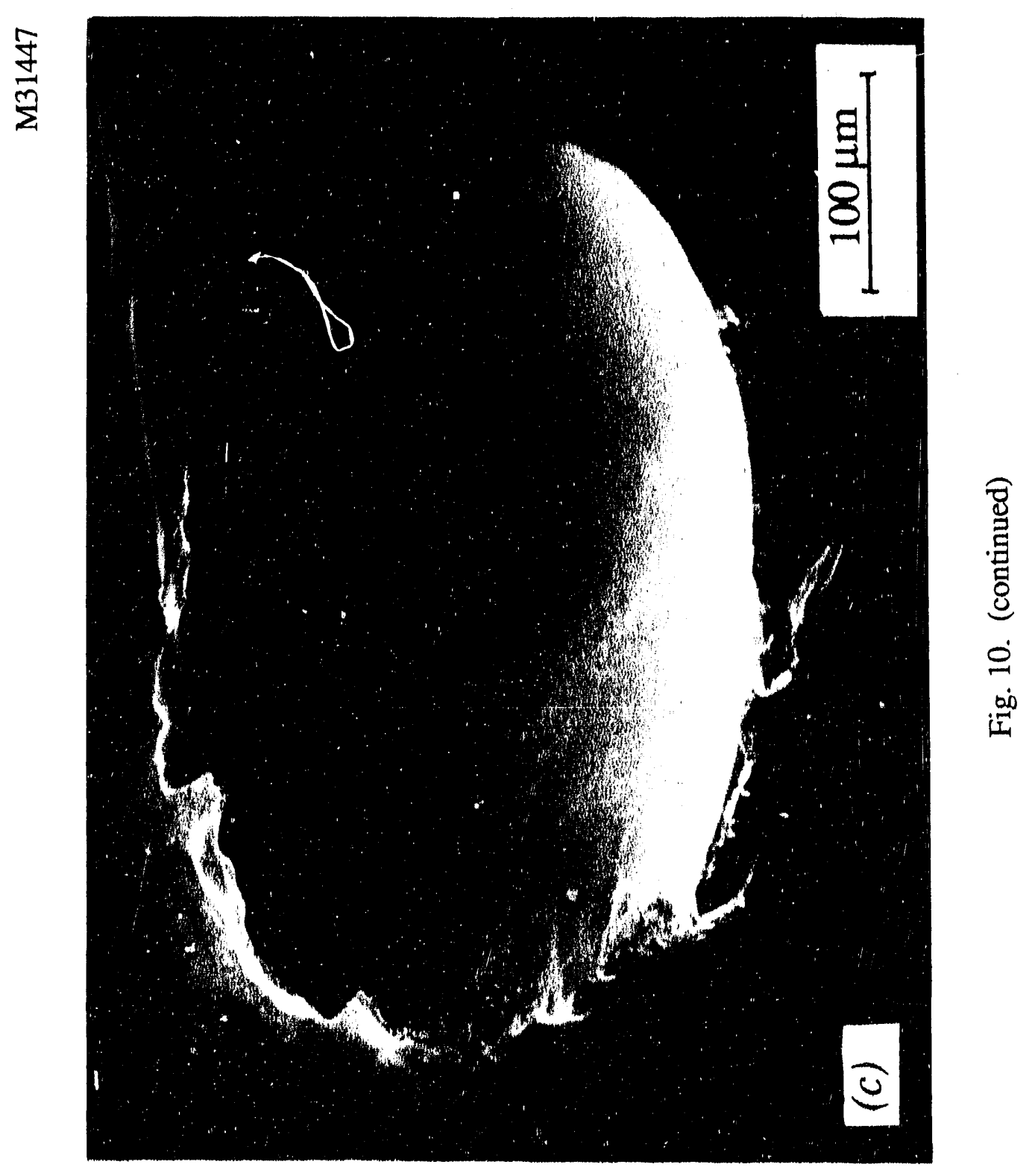


and tearing occur above some threshold velocity at which the particle can penetrate significantly into the material. However, a velocity or velocity range over which tearing may occur is not clearly defined.

Figure 10 shows that the iron aluminide responds quite differently to increasing the velocity of the impacts. As in $1100 \mathrm{Al}$, material is initially pushed forward to steadily greater extents [Fig. 10(a)]. However, a different phenomenon occurs at higher velocities. Instead of the deformation spreading, the extruded lip fractures at the exit edge of the particle. As in the case of $1100 \mathrm{Al}$, deformation can be seen to the sides of the craters. However, the deformation is much more contained, due to the higher strength of the aluminide alloy. The fractured lips are indicative of a loss of ductility in the material, the fracture strain evidently having been surpassed. Although FA-129 is part of a class of iron-aluminide alloys with enhanced roomtemperature ductility of 15 to $20 \%$ (ref, 34), the ductility is far less than that of annealed $1100 \mathrm{Al}(35 \%)$ [ref. 46]. The distinctive difference in the deformation and fracture response of the two alloys shows the importance of mechanical properties on material removal under impact conditions.

High-velocity impacts on previously work-hardened samples did not produce behavior significantly different than that described above. Two micrographs of impacts on cold-worked samples shown in Fig, 11 are very similar to those of impacts on heat-treated surfaces. A chiplike feature may be seen at the exit end of the crater on cold-worked $1100 \mathrm{Al}$ in Fig. 11(a). This feature is formed by the "flipping up" of a cap of material [as that seen in Fig. $9(d)$ ] as the ball burrows into the material and exits in the same direction. This is an unusual mechanism by which the impact of a spherical particle can actually remove features that look like machining chips. If the cap of material is weaker or thinner, it may split apart sideways as in Fig. $10(b)$ or a slightly different particle trajectory may create a partial "chip" as in Fig. $10(c)$.

An interesting point to note is that none of the micrographs of high-velocity impacts snow evidence of melting, as has been reported in the literature for significantly lower velocity impacts. 44 This is possibly because of the order-of-magnitude smaller particles used in our study. Since the kinetic energy contained in the ball varies as the cube of its size, a rough calculation shows that the energy transferred to the target on impact in our study is less than $1 \%$ of the literature studies (albeit distributed over a smaller impact area).

As a final characteristic of impact damage under high-velocity oblique impacts, Fig. 12(a) shows a cross-sectional view of the crater seen in Fig. $10(d)$ in annealed 11()) Al. (It is easy to imagine a "chip" forming if the ball had continued forward and exited in the same direction instead of apparently rebounding out of the entrance opening.) In this sectional view, fine precipitates contained in the $11(0) \mathrm{Al}$ were originally aligned in vertical rows. The deformation 


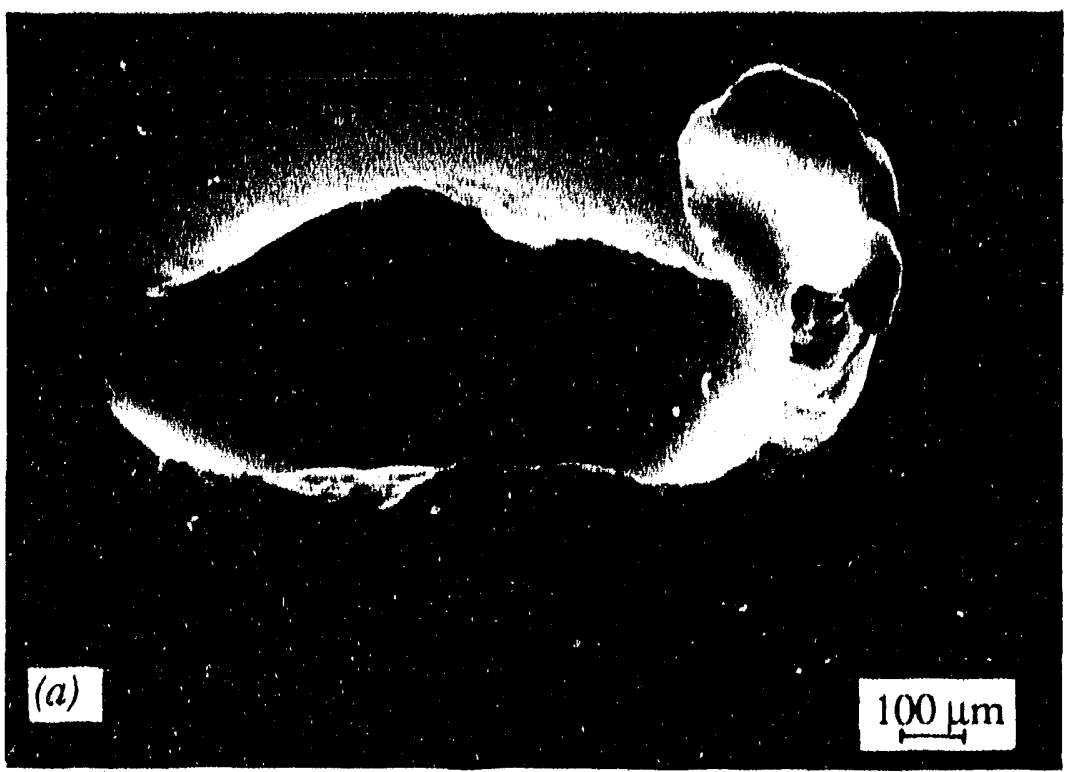

M31442

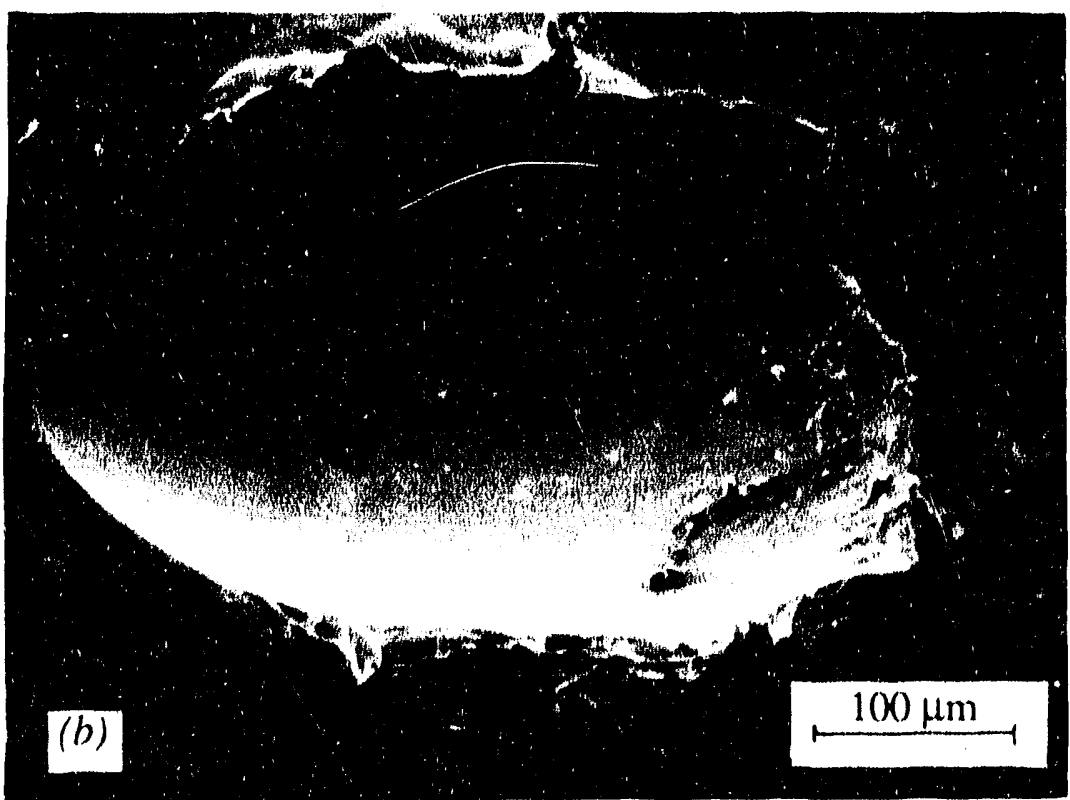

Fig. 11. Craters due to single-particle impacts at $30^{\circ}$ incidence on: (a) $50 \%$ cold-worked 1100 Al at $661 \mathrm{~m} / \mathrm{s}$ and (b) $5 \%$ cold-worked ordered iron-aluminide alloy at $464 \mathrm{~m} / \mathrm{s}$. 


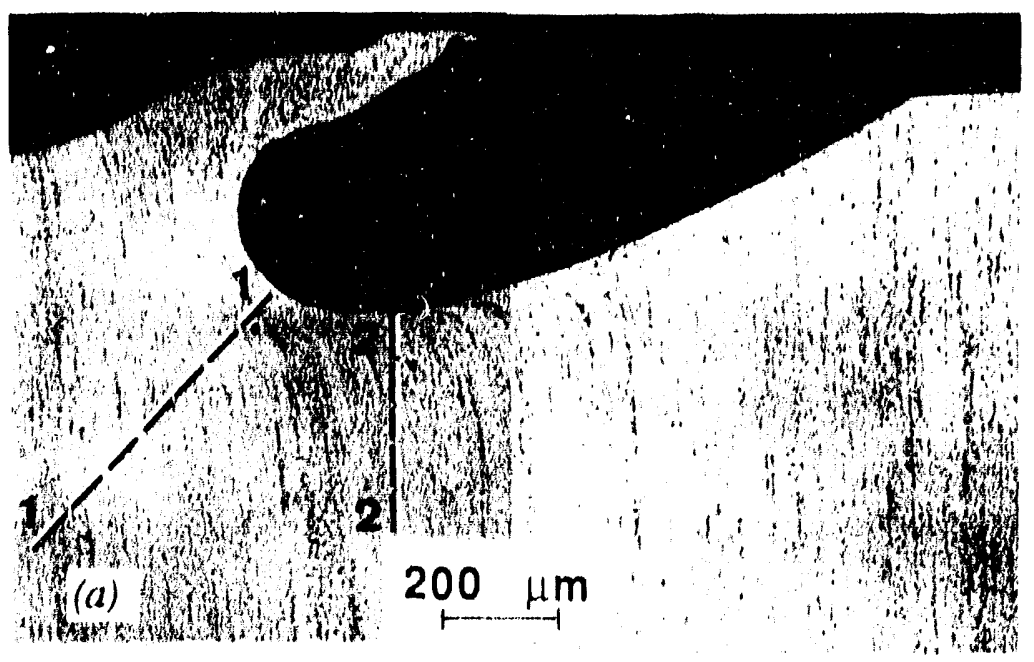

ORNL DWG 92-5058

ORNL DWG 92.5059
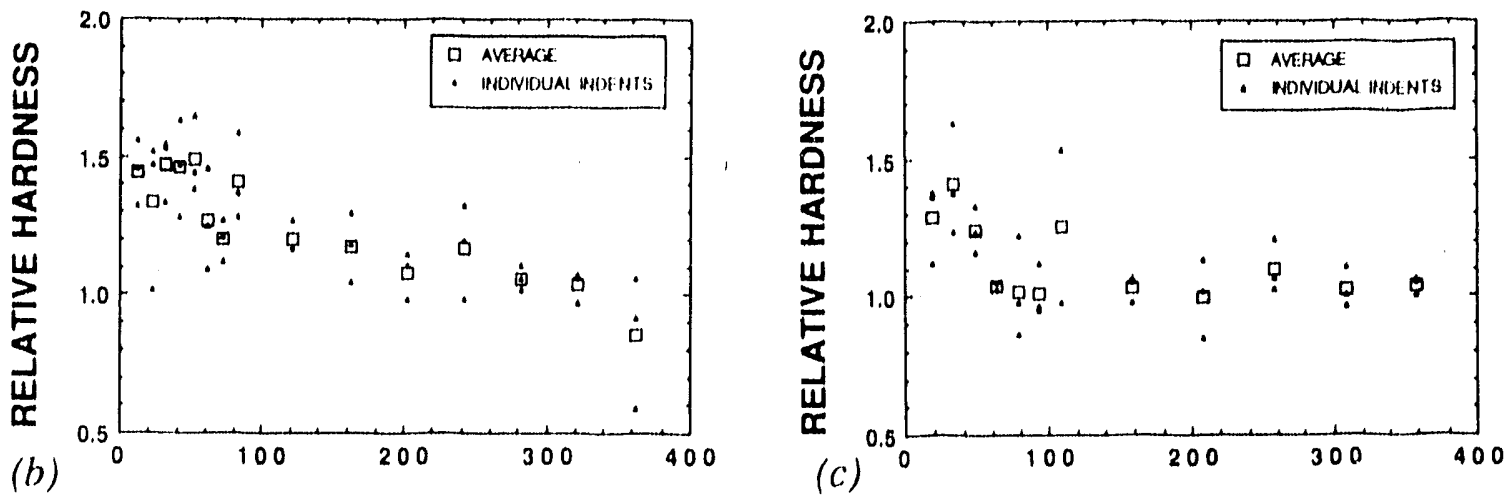

Fig. 12. (a) Cross-sectioned crater on annealed $1100 \mathrm{Al}$ due to single impact at $30^{\circ}$ incidence and $740 \mathrm{~m} / \mathrm{s}$. (b) and $(c)$ MPM relative hardness profiles along traces $1-1$ and 2-2 marked in $(a)$. Distance from surface is in $\mu \mathrm{m}$. 
associated with the impact distorts this regular arrangement, causing the rows to bend over in the impact direction. Using the extent of this distortion as a measure of the plastic strain imparted to the target, it can be seen that most of the deformation is restricted to the later stages of the impact, when the ball has penetrated well into the material; regions near the entrance to the crater show very little deformation. It is only as the impacting particle slows down that significant deformation can spread into surrounding material, and a major portion of the deformation occurs in the final stages of the impact. In other words, the deformation due to a single-particle impact is both spatially and temporally nonuniform. Figures $12(b)$ and $(c)$ show MPM hardness profiles along Sects. 1-1 and 2-2 indicated in Fig. 12(b). The hardness along Sect. 2-2 drops more sharply and over a shorter distance than the hardness along Sect. 1-1. The amount of deformation and work-hardened material is greater along Sect. 1-1, in keeping with the visual observations described above. Note also that there is little evidence of a nearsurface hardness dropoff due to the high-velocity impact along Sect. 2-2. A constant or lower value of hardness is more apparent near the crater bottom along Sect. 1-1, again due to the fact that more of the impact energy was released directly in front of the impacting ball during the final stages of impact. Close inspection also reveals that the work-hardened depths measured using the MPM agree well with visual estimates of deformation using the distorted precipitate arrays.

\section{RESPONSE OF METALLIC ALLOYS TO MULTIPLE- PARTICLE IMPACTS}

Studies of solid-particle erosion of metals and alloys have been carried out for a number of years, both on mechanistic interpretations of the process, as well as the influence of material properties on erosion resistance. It is now well established that ductile materials initially go through an "incubation" period where there is little or no mass loss (or even a mass gain due to particle embedment) followed by a steadily increasing rate of material loss. ${ }^{49}$ Ultimately, a steady-state erosion rate is established where the rate of mass loss achieves a constant value with respect to the amount of erodent impacting the surface.

Several other characteristics related to material-removal mechanisms are also well known. For ductile materials, erosion rates are maximum at grazing angles of incidence and decrease toward normal incidence. Models of erosion incorporate material loss due to micro-machining action of the erodent particles or removal of plate-like debris formed by straining the material beyond the fracture limit. These mechanisms are strongly influenced by erodent size and 
shape. Details of these aspects can be found in several review articles/volumes. $50,51 \mathrm{As}$ discussed earlier, material properties that have been correlated to erosion behavior with varying degrees of success include hardness, general mechanical properties, bond energies, melting points, and other thermal properties. Reported material responses range from melting or softening of the surface layers to material failure by brittle fracture in the surface layers.

Eroding surfaces develop characteristic topographies for both normal and glancing impacts. For normal impact, a rough surface consisting of hills and valleys tends to develop during incubation. 14,31,52 For oblique impact, characteristic ripples (which give an appearance similar to a wavy liquid surface) develop on the surface. ${ }^{53-57}$ The ripples are presumed to strongly influence material loss processes, with material loss from the breaking waves and material replenishment onto wave crests from the valley bottoms. 53,55,56 Final material removal can be related to the eventual loss of ductility in lips, ridges, platelets, etc., constituting the hills, waves, or valleys.

It is reasonable to expect that the material develops a steady-state substructure due to deformation associated with the regular impact and that during the initial periods of erosion, the eroding surface is developing a "mechanical" or "deformation" steady state. Thus, detailed information on topographical- and subsurface-deformation changes should provide valuable insights into material removal processes during erosion. Multiple-particle erosion studies were undertaken as part of this program with this specific goal. The general approach was to observe topographical changes as erosion progressed by means of the SEM while using the MPM to carefully monitor the changes in the subsurface regions concurrent with ripple or hill and valley formation. The information was then used to examine the nature of the deformation mechanisms during erosion.

\subsection{INITIAL STUDIES}

The initial multiple-particle impact study was motivated by earlier single-particle impact studies on heat-treated aluminum alloys, 46,47 which suggested that soft 1100 Al may have better erosion resistance than precipitation-hardened 7075-T6 Al because of its capacity to distribute the energy of impacting particles over large volumes. Consequently, samples of the two alloys were eroded to steady-state conditions at Lawrence Berkeley Laboratory using 6()$)$ - to $7(0)$ - $\mu \mathrm{m}$-diam steel shot impacting at $30^{\circ}$ incidence, as described above. A rippledsurface structure developed during erosion. After erosion, samples were sectioned parallel to the erosion direction, and MPM hardness measurements were made beneath wave crests and valleys of the rippled structure, providing hardness versus depth profiles from within $5 \mu \mathrm{m}$ of 
the surface. A work-hardened layer was found in both samples with the hardness decreasing monotonically from a maximum value at the surface. The MPM hardness profiles are shown in Fig. 13 and may be compared with the single-particle impact results in Fig. 2, bearing in mind

ORNL DWG 92-5060

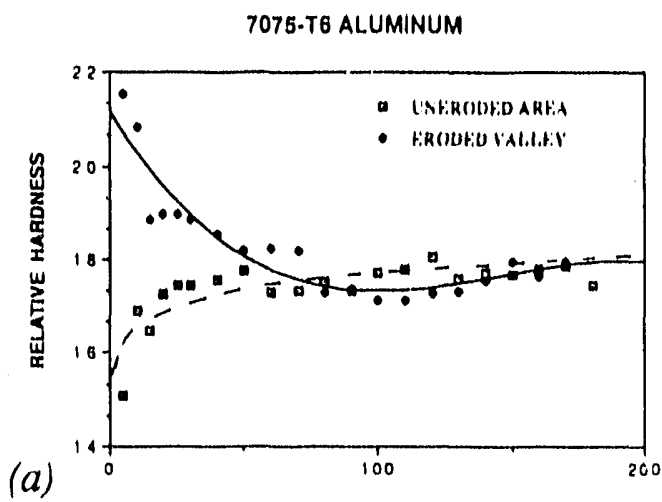

ORNL DWG 90-13925

ANNEALED 1100 AL.UMINUM

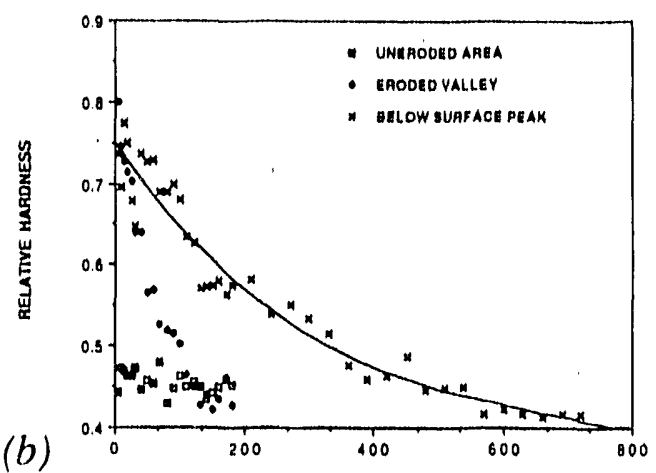

Fig. 13. MPM relative hardness profiles beneath: (a) 7075-T6 $\mathrm{Al}$ and

(b) annealed $1100 \mathrm{Al}$ eroded at $30^{\circ}$ incidence. Distance below surface is in $\mu \mathrm{m}$.

that the single-particle impacts were made using smaller (but denser) particles impacting at slightly lower velocities. The maximum hardness measured was significantly higher than that measured in the earlier studies under single-particle impact craters. However, the depth of hardening was similar under a wave valley and under a single-particle impact crater. It was also observed that hardening under wave crests extended to a depth equal to the height of the wave crest plus the depth of hardening below the valley. However, a similar value of maximum hardness was reached at wave crest and valley surfaces. The increase in hardness was greater in $1100 \mathrm{Al}$ compared to 7075-T6. The results, described in detail in refs. 58 and 59, suggested that the ripples were constituted of work-hardened material that had accumulated by impact-induced plastic deformation. The pattern of deformation made it clear that the subsurface strain accumulated gradually, even as material movement in the surface layers developed into the observed ripple structure during the incubation period of erosion. There is little information available concerning changes that occur during this period, and the next study was specifically undertaken to address this issue.

\subsection{EROSION OF 1100 AI AT $30^{\circ}$ INCIDENCE}

Samples of annealed $1100 \mathrm{Al}$ were eroded in the gas-jet tester at Lawrence Berkeley Laboratory, using 600- to 700)- $\mu \mathrm{m}$-diam spherical steel shot impacting at a velocity of $45 \mathrm{~m} / \mathrm{s}$ and an angle of $30^{\circ}$ to the specimen surface. The samples were subjected to either $5,10,20$, 
$40,80,120$, or $500 \mathrm{~g}$ of erodent, which covered the range of the incubation period. After erosion, each specimen was examined in an SEM, then taper sectioned, polished, and examined using an MPM as described earlier. Figure 14 shows a typical taper-sectioned sample made from one of the eroded specimens. Details of the hill-and-valley structure of the surface ripples are more clearly seen with the added magnification due to the taper.

YP7773

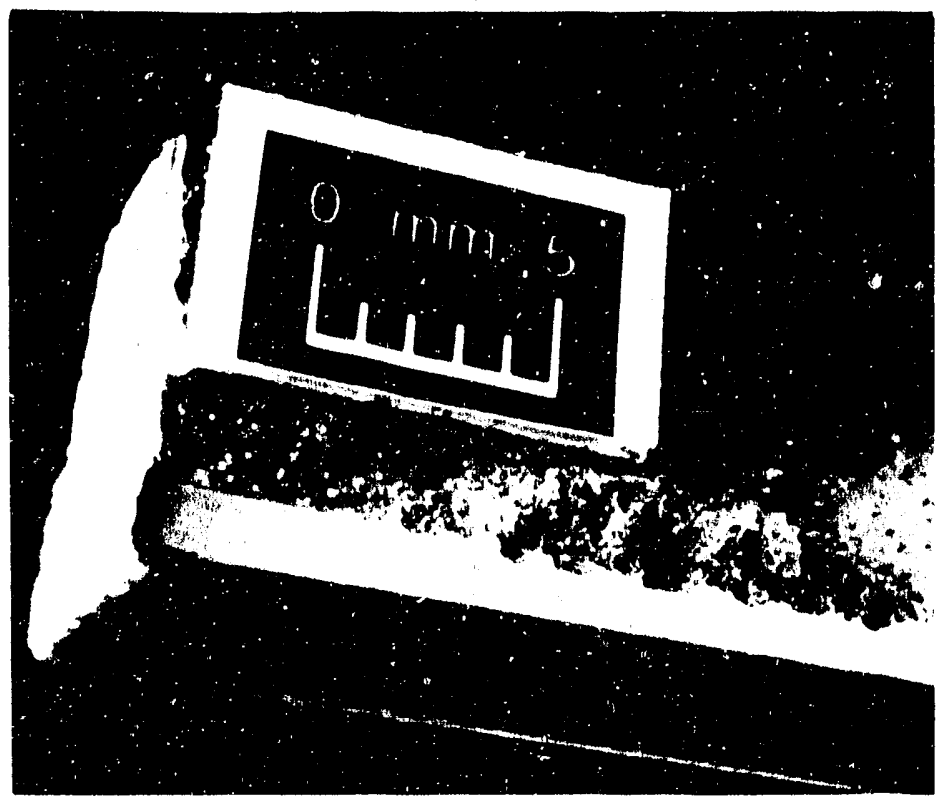

Fig. 14. Typical taper-sectioned specimen (eroded $1100 \mathrm{Al}$ ) used for making MPM measurements.

A typical erosion-mass loss curve for $1100 \mathrm{Al}$ exposed to conditions similar to those in this study is shown in Fig. 15. The incubation period typically extends to just beyond $100 \mathrm{~g}$ of erodent, after which the erosion rate achieves a constant value (steady state).

A comparison of the ripple structures was made by tracing surface contours from micrographs of the tapered sections. This is shown in Fig. 16. The 5-g sample shows small surface undulations associated with initial impacts indicating plastic flow from exit edges of craters. The start of a regular ripple structure can be seen by the $20-\mathrm{g}$ dose, at a stage where material loss is insignificant. The appearance of the wavy structure early in the incubation period and the shapes of the hills and valleys seen in the contours agree well with literature observations. ${ }^{53-57}$ Lips of material apparently on the verge of being removed can be seen on the sides of the peaks facing away from the impact direction. The ripple structure is well 

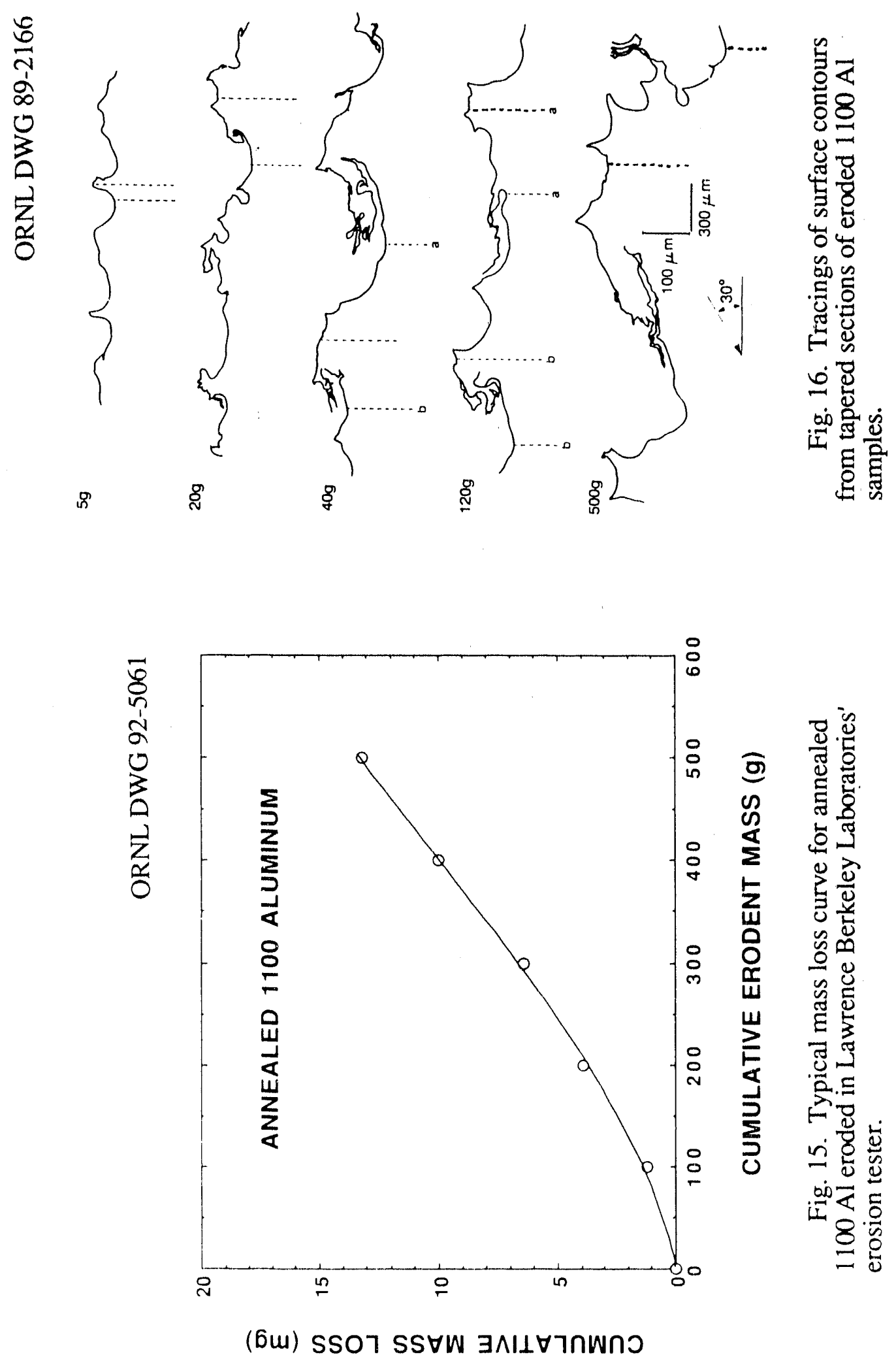
developed within the incubation period (less than 120-g erodent dose), although peak heights and spacings are larger during steady state. Exact crest heights are difficult to estimate because small differences in the taper angles magnify errors in the vertical direction.

The dotted vertical lines in Fig. 16 represent areas where indentation arrays were made using the MPM. Figures 17 through 21 are plots of average hardness (three to five indentations) versus distance below the surface for various crest-and-valley pairs indicated in Fig. 16. For ease of comparisull, the depths have been referenced to a common surface, arbitrarily taken as the tip of the highest crest, thus correcting for the different heights and depths of the features. For example, with reference to the 5-g sample in Fig. 16, the top of the crest containing the dotted line was taken as the reference surface. The surface of the adjoining valley lies about $50 \mu \mathrm{m}$ below this peak. Consequently, the hardness versus depth data from the valley is plotted starting from a distance of $50 \mu \mathrm{m}$ below the common reference, as seen in Fig. 17. Significant hardening can be seen even at this low dose: the surface layers are about twice as hard as the underlying annealed material. Material near the surface of the valley area appears to have hardened to a lesser extent than the crest. Although the thickness of the hardened layer is less under the valley, both the hardness profiles merge into a common profile at a depth of about $100 \mu \mathrm{m}$.

At higher doses, the extent of peak hardening increased over the 5-g sample, but the other trends were similar, as seen in Figs. 18 and 19 for the 20- and 4()-g samples, respectively. By a dose of $120 \mathrm{~g}$ (Fig. 20), there was little or no further increase in peak hardness. Figure 21 shows the hardness profiles for the $50($ )-g steady-state sample. The only difference is the greater overall depth of hardening because of higher crests. Hardness below the valleys drops off to bulk levels at approximately the same distance for both the 12()- and 5(0)-g samples.

There is some indication that the surface layers at the valleys may not achieve as high a hardness as the tops of the crests. Figures 17 through 21 show that the maximum hardnesses measured under valleys were 10 to $25 \%$ lower than the peak hardnesses under corresponding crests. Although some of this may be attributed to the lack of near-surface measurements for many valleys, as may be judged by the local surface indicators in the hardness profile, extrapolation of the hardness profiles to the surface still leaves the local surface at valleys consistently softer than at crests. However, the difference is not as great as that measured by Carter et al. 53 who reported surface microhardness values on valleys to be about half that on wave crests; the greater sensitivity of the MPM likely provides more accurate results. In some cases, however, surfaces of crests and valleys showed similar hardnesses. This is seen in Fig. 21 for the $5(x)$-g dose and was also observed in other measurements not reported here. This may indicate that the hardness distribution does continue to change during later incubation 
ORNL DWG 90-13927

ORNL DWG 90-13928
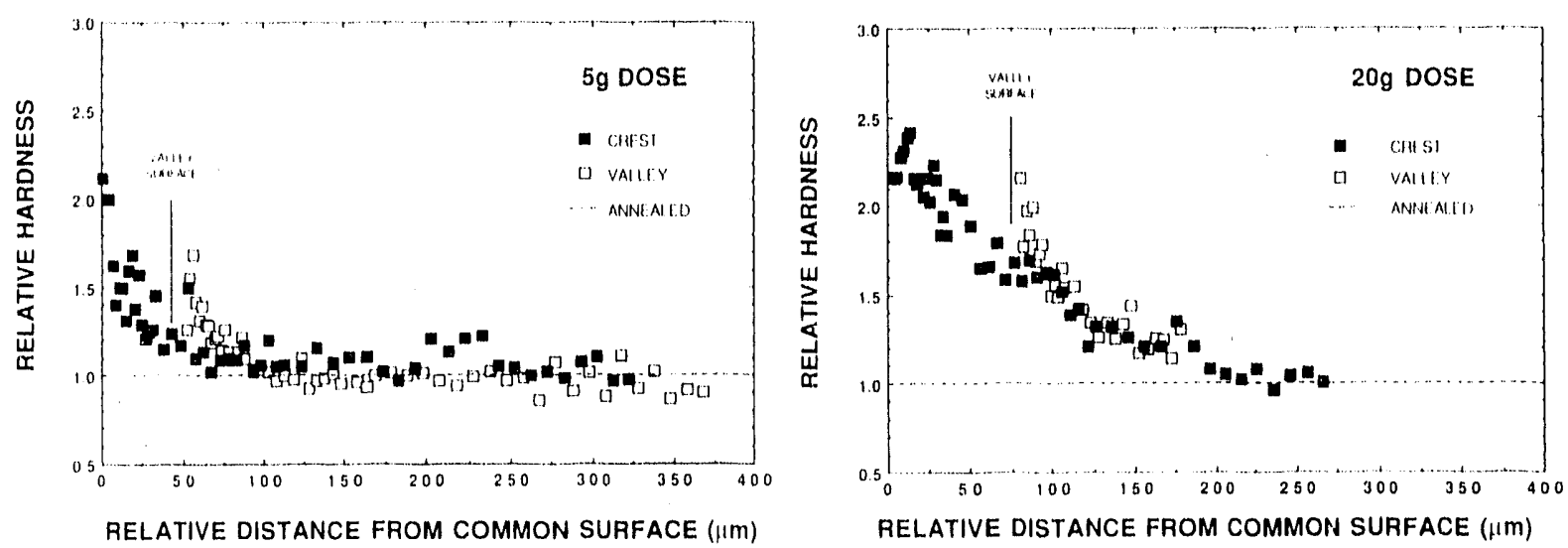

Fig. 17. Relative hardness versus depth below eroded surface for $1100 \mathrm{Al}$ eroded with $5 \mathrm{~g}$ of 600 - to 700 - $\mu \mathrm{m}$-diam steel shot at $45 \mathrm{~m} / \mathrm{s}, 30^{\circ}$ incidence. The depth has been corrected for the taper in this and subsequent graphs.

Fig. 18. Relative hardness versus depth below eroded surface for $1100 \mathrm{Al}$ eroded with $20 \mathrm{~g}$ of 600 - to 700 - $\mu \mathrm{m}$-diam steel shot at $45 \mathrm{~m} / \mathrm{s}, 30^{\circ}$ incidence.

ORNL DWG 90-13929

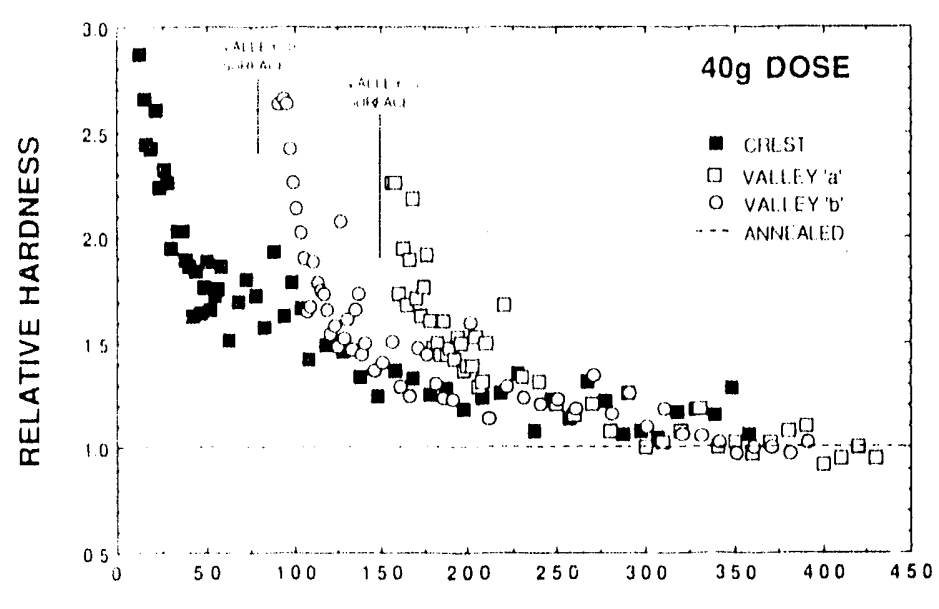

RELATIVE DISTANCE FROM COMMON SURFACE ( $\mu \mathrm{m})$

Fig. 19. Relative hardness versus depth below eroded surface for $1100 \mathrm{Al}$ eroded with $40 \mathrm{~g}$ of $6(0)$ - to 700 - $\mu \mathrm{m}$-diam steel shot at $45 \mathrm{~m} / \mathrm{s}, 30^{\circ}$ incidence. 
ORNL DWG 92-5062.

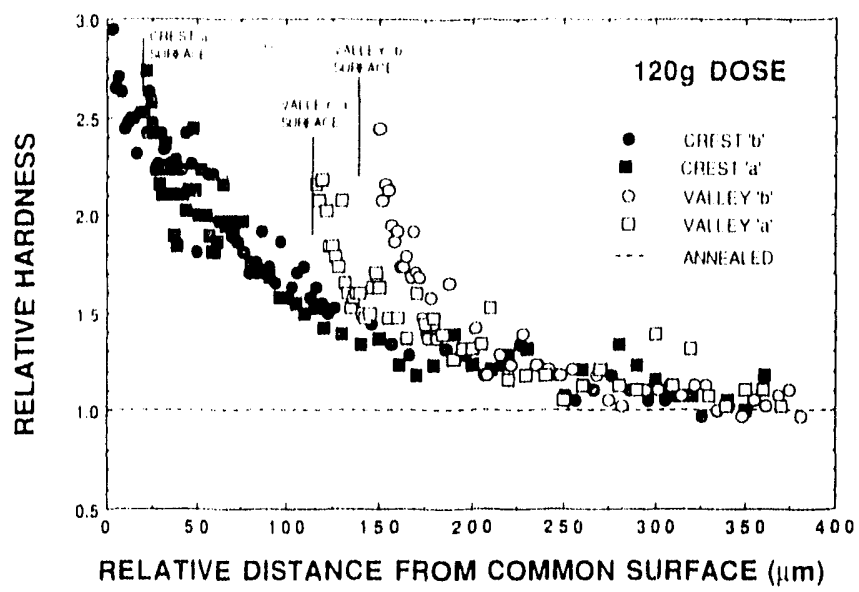

Fig. 20. Relative hardness versus depth below eroded surface data for $1100 \mathrm{Al}$ eroded with $120 \mathrm{~g}$ of 600 - to $700-\mu \mathrm{m}$-diam steel shot at $45 \mathrm{~m} / \mathrm{s}, 30^{\circ}$ incidence.

ORNL DWG 90-13930

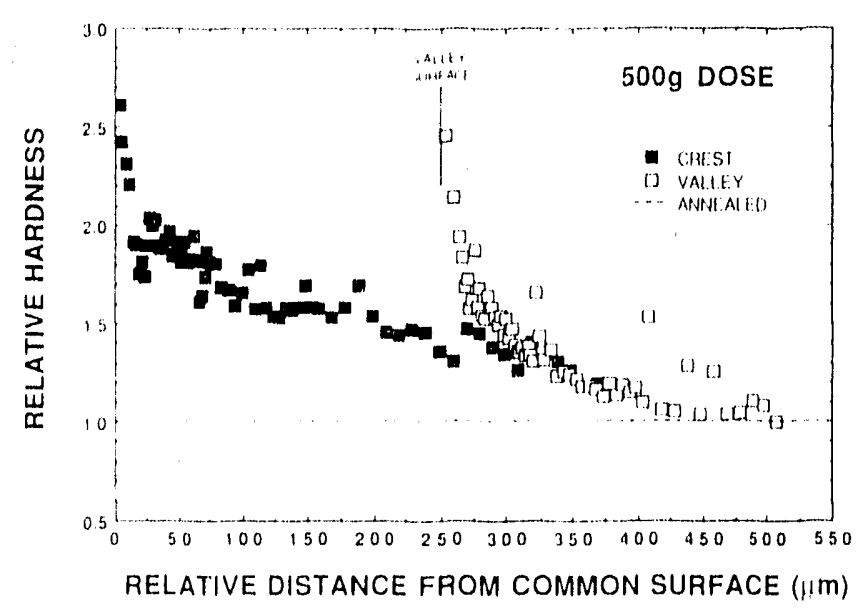

Fig. 21. Relative hardness versus depth below eroded surface data for $11(0) \mathrm{Al}$ eroded with 5() $0 \mathrm{~g}$ (steady state) of $6(0)$ - to $7(0)$ - $\mu \mathrm{m}$-diam steel shot at $45 \mathrm{~m} / \mathrm{s}, 30^{\circ}$ incidence. 
and early steady-state erosion, leading to an equihardness skin on crests and valleys, or that a certain amount of heterogeneity always exists in the hardness of the surface layers on valleys.

Data from the hardness profiles are summarized in Fig. 22, which includes data from the 80-g sample. The maximum hardnesses measured and the depth of hardening under the deepest valleys are shown as a function of erodent dose, indicating how deformation accumulates during erosion. Both parameters appear to saturate around a 40-g erodent dose

ORNL DWG 92-5063

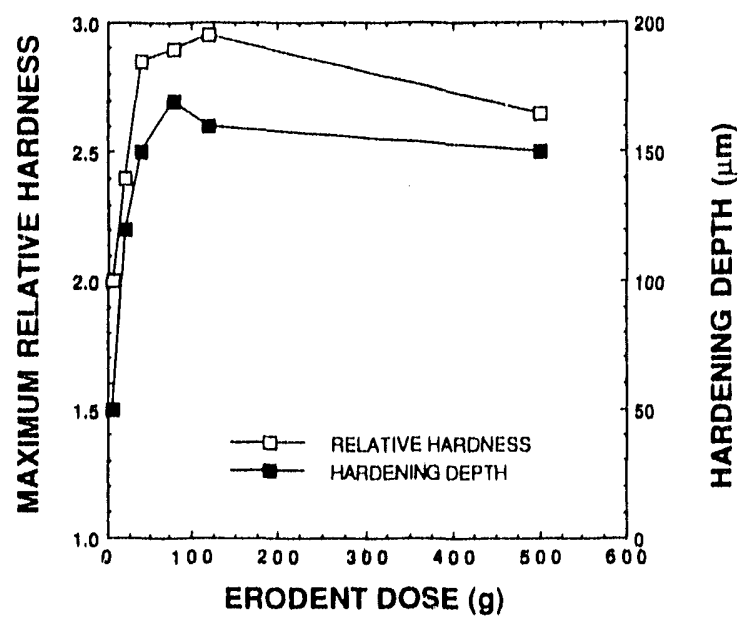

Fig. 22. Graph summarizing information from the hardness profiles in Figs. 16 through 21 as a function of erodent dose.

(partway through the incubation period). Maximum hardness is around 2.5 to 3 times the hardness of annealed material, and the maximum work-hardened layer under valleys extends to around $150 \mu \mathrm{m}$.

The saturation behavior observed in Fig. 22 is not surprising if one considers that the deepest plastic deformation would occur with initial impacts on annealed material. As the material work hardens, subsequent impacts plastically deform a smaller volume. In the earlier study of single impacts using 343- $\mu$ m-diam WC spheres, 46,47 the extent of hardening decreased from $100 \mu \mathrm{m}$ on annealed $1100 \mathrm{Al}$ to $30 \mu \mathrm{m}$ on $50 \% \mathrm{CW} 1100 \mathrm{Al}$. Thus, for multiple-particle impacts, the depth of hardening should quickly reach a steady-state value, while near-surface layers continue to harden to higher levels. The fact that peak hardnesses and maximum hardening depths occur at similar erodent doses may be purely coincidental. The earlier multiple-particle impact study on aluminum alloys ${ }^{58}$ showed that the peak hardness under single impacts was significantly less than under multiple impacts, indicating that several 
impacts are needed to reach peak hardnesses. This was seen in this detailed study, with a steady increase in peak hardnesses going from the 5- to the 40-g samples. Obviously, several overlapping impacts are necessary to achieve maximum strain hardening in $1100 \mathrm{Al}$.

The hardness profiles also showed that the hardness under a valley decreases much more rapidly than under a crest. The rapid decrease of hardness in the valleys is independent of their relative depths from the original surface, the hardened depth being essentially independent of dose (Fig. 22). On the other hand, the extent of hardening under a crest increases with the height of the crest. Figure 23 shows a relative hardness contour map for the sample eroded with $120 \mathrm{~g}$ of steel shot, drawn from hardness profiles and hardness traverses along the surface and other locations on crests and valleys. The crest-valley pair shown is the one marked "a" in Figs. 16 and 20. Multiple impacts cause a skin of high hardness to develop in the surface regions, and, underneath, the hardness decreases to that of the annealed material. Slightly higher hardness levels were measured in a narrow region directly facing the impinging particles. The entire crest is hardened to levels found only in the top 10 to $20 \mu \mathrm{m}$ of the valleys. Upon subsequent impacts, the material under wave crests tends to deform less because of higher flow stresses over larger volumes. This supports the view that wave crests are formed by ridges on impact craters or by material pushed up from the valleys ${ }^{53-56}$ since this

YP8016

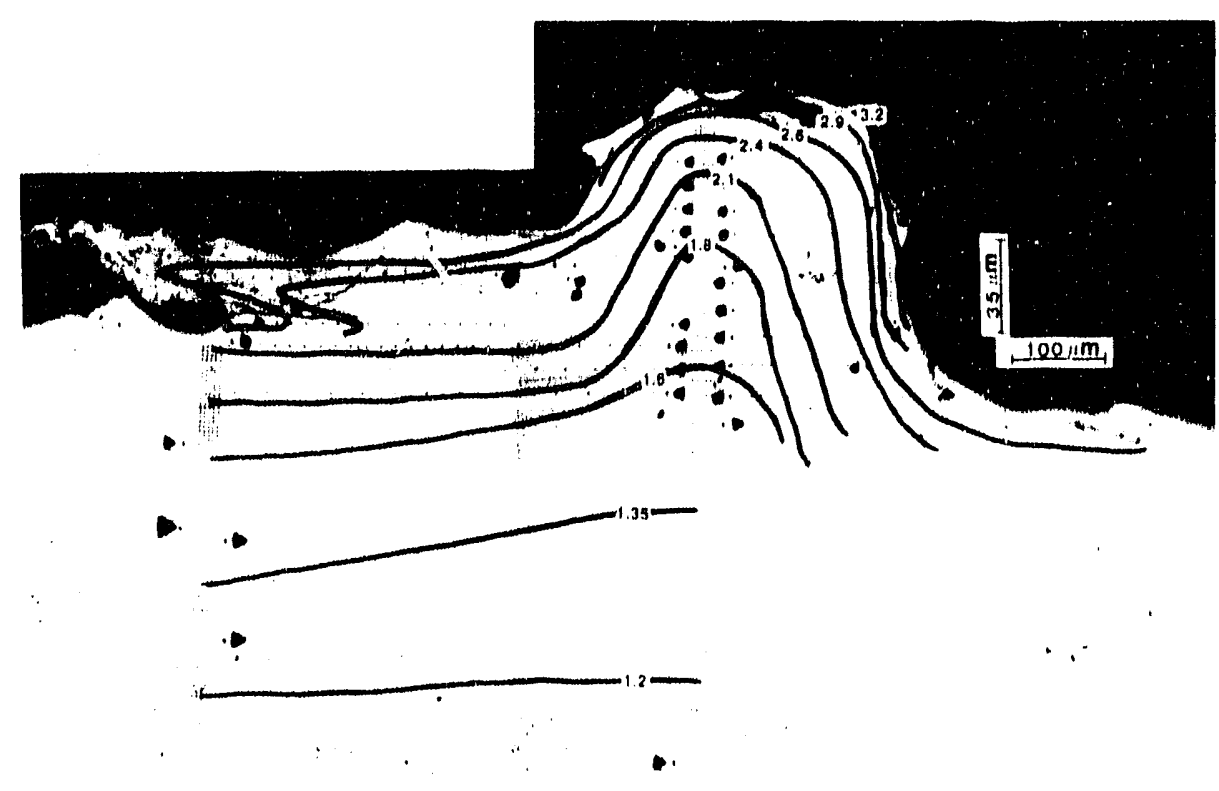

Fig. 23. Relative hardness contours drawn on a tapered-section micrograph from an area of the specimen exposed to $120 \mathrm{~g}$ of erodent. 
would leave the wave valleys as the most recently denuded area, and, thus, an area with the steepest hardness profiles. Material being pushed out would be highly strain hardened, as observed for wave crests. In addition, the hardness contours in Fig. 23 show that overall hardening seems to be greater on the side of the crest facing the erodent. These differences in local deformation would cause a ripple structure to persist, once formed.

The fact that maximum hardness levels are reached during incubation when erosion rates are still increasing indicates that the material continues to strain with no further hardening. Under high-strain-rate conditions, a saturation flow stress is achieved while the material continues to accommodate further deformation, due to dynamic recovery processes. ${ }^{60}$ Higher strains may therefore develop on the wave crests and on the fracturing lips seen on the leeward side of the wave crests. This material eventually fails as the fracture strain is exceeded. Material removal may also occur in the valleys as material is being pushed up, due to breaking up of ridges from overlapping craters or similar mechanisms.

Figure 24 shows an example of MPM indentations made across a lip of material apparently on the verge of removal, with a crack running almost all the way through it. The hardness values were similar to those measured at other locations at similar distances from the surface and showed no additional hardening or softening associated with the crack. This indicates that crack propagation and material fracture occur at the maximum flow stress, pertiaps on reaching a critical fracture strain. This is also supported by the fact that maximum hardness (and thus the flow stress) levels are reached early in the erosion process.

Details of the above study may be found in several publications. ${ }^{61-63}$ The absence of any indication of softening directly contradicts previously reported results for similar materials and erosion conditions. 16 The apparent lack of observable thermal effects may have been due to erosion conditions, which are not sufficiently severe. One way to increase severity is to increase particle velocities. Another is to increase the angle of impact so that particles impinge perpendicularly on the surface, transferring more of their energy to the target. As described earlier in this report, thermal effects were more severe for single-particle impacts at $90^{\circ}$ incidence compared to $30^{\circ}$ incidence.

\subsection{EROSION OF 1100 AI AT 90 ${ }^{\circ}$ INCIDENCE}

During multiple-particle erosion, both wave crests (formed at oblique incidence) and hills (formed at $90^{\circ}$ incidence) can be related to processes of subsurface material deformation. Following the study on ripple formation at $30^{\circ}$ incidence, the near-surface plastic flow in $1100 \mathrm{Al}$ eroded at $90^{\circ}$ incidence was also examined. Samples were eroded in the rotating-arm 


$$
\text { P }
$$


apparatus at the University of Notre Dame at a velocity of $45 \mathrm{~m} / \mathrm{s}$ using spherical-steel shot 297 to $420 \mu \mathrm{m}$ in diam. The particle size was somewhat smaller than that in the earlier erosion studies at $30^{\circ}$ incidence but was closer in size to the particles used in the single-impact studies. As in the earlier study, samples were eroded to various doses between 10 and $480 \mathrm{~g}$, examined in an SEM, and taper sectioned for MPM measurements. Since both particle size range and the test equipment used were different from the earlier study, some samples were also eroded at $30^{\circ}$ incidence and analyzed. The results were similar to those in the earlier study using larger particles.

Figure 25 shows the results from specimen-mass loss measurements made at various stages of erosion. Data are shown from samples eroded at both 30 and $90^{\circ}$ incidence. Whereas the specimens eroded at $30^{\circ}$ achieved a steady-mass loss rate as in the earlier study, erosion at $90^{\circ}$ incidence resulted in a continuously increasing mass. This mass gain was due to severe embedment of erodent-particle fragments, as described below.

ORNL DWG 92-5064

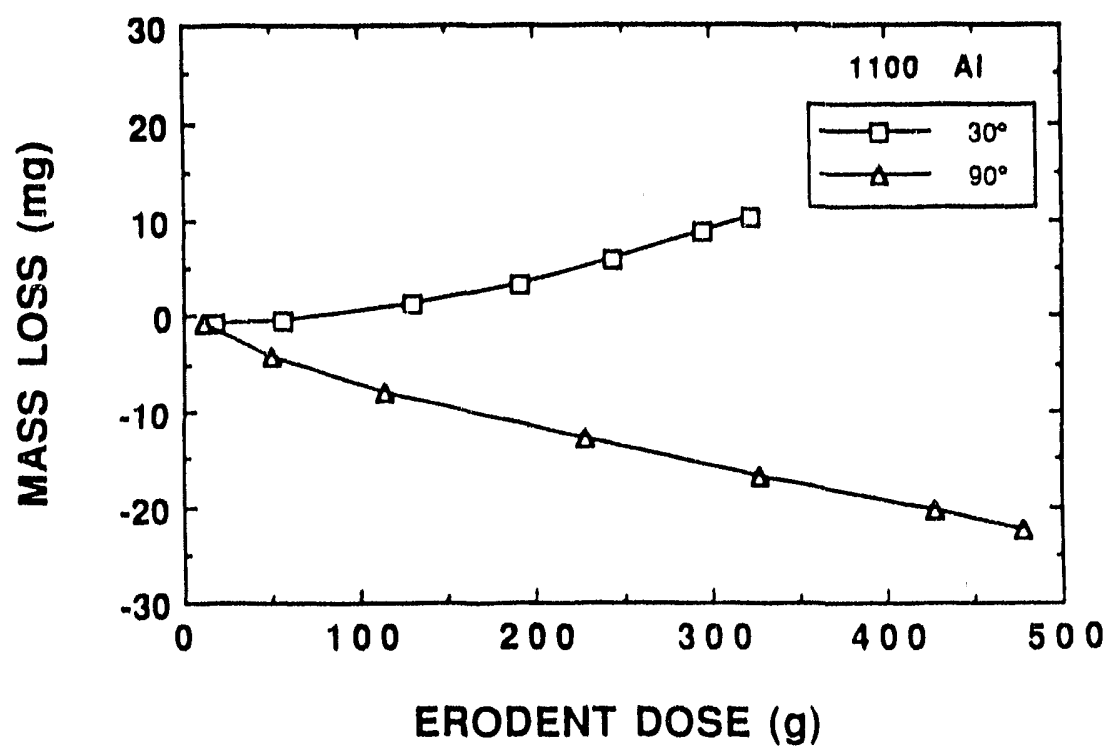

Fig. 25. Mass loss or gain of annealed $1100 \mathrm{Al}$ eroded at 30 and $90^{\circ}$ incidence in a University of Notre Dame rotating-arm erosion tester.

Figures $26(a)$ through $(c)$ show the surfaces of samples eroded at $90^{\circ}$ incidence through doses of 11,100 , and $480 \mathrm{~g}$. A hill-and-valley structure is clearly developed at the $480-\mathrm{g}$ dose but cannot be identified at the 11- or 100 -g doses. At the $480 \mathrm{-g}$ dose, surface height variations are much larger, and many of the craters have an elliptical shape from being smeared out due to locally oblique impacts. This may be more clearly seen in the higher magnification micrograph 


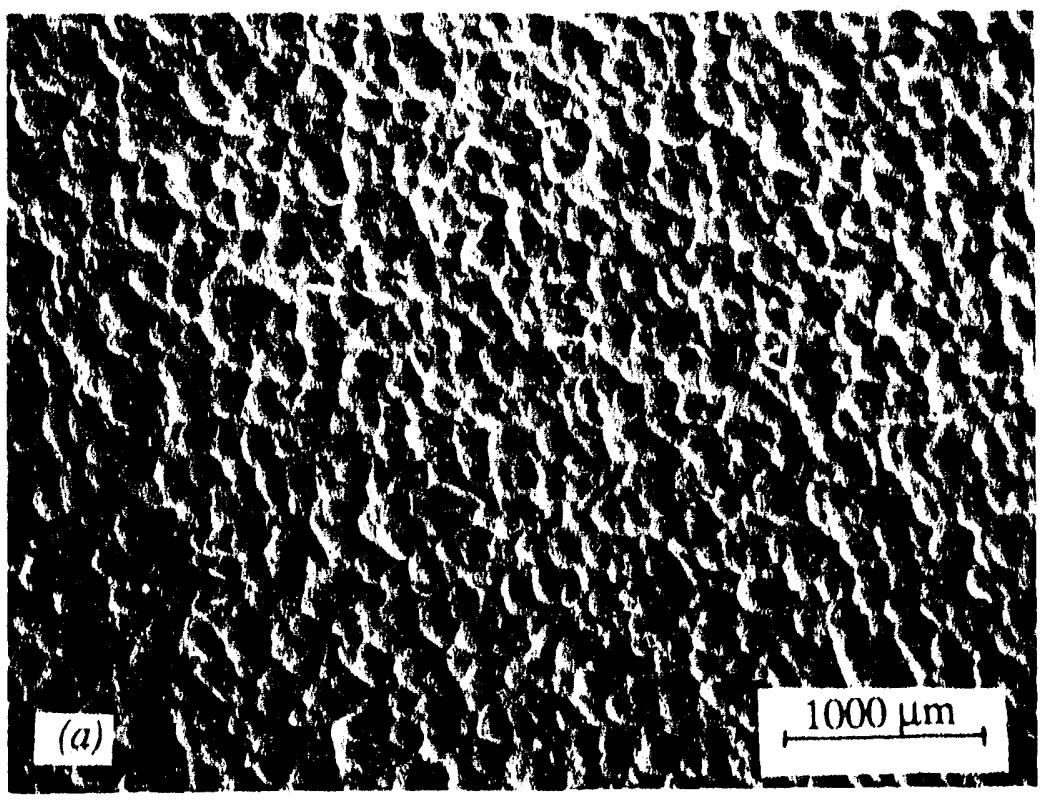

M31380

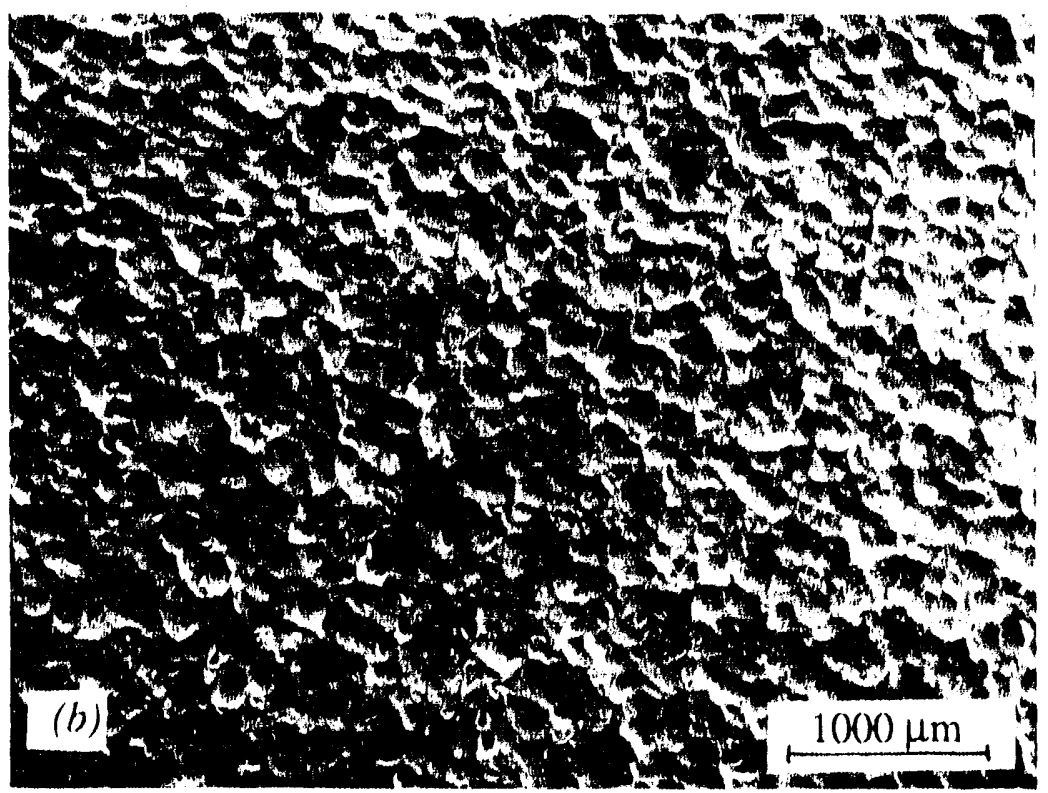

Fig. 26. Micrographs of $1100 \mathrm{Al}$ surfaces eroded at $900^{\circ}$ incidence by: (a) $11 \mathrm{~g},(b) 100 \mathrm{~g},(c)$ and (d) $480 \mathrm{~g}$ of 297 - to $420-\mu \mathrm{m}$-diam steel shot at $45 \mathrm{~m} / \mathrm{s}$. 


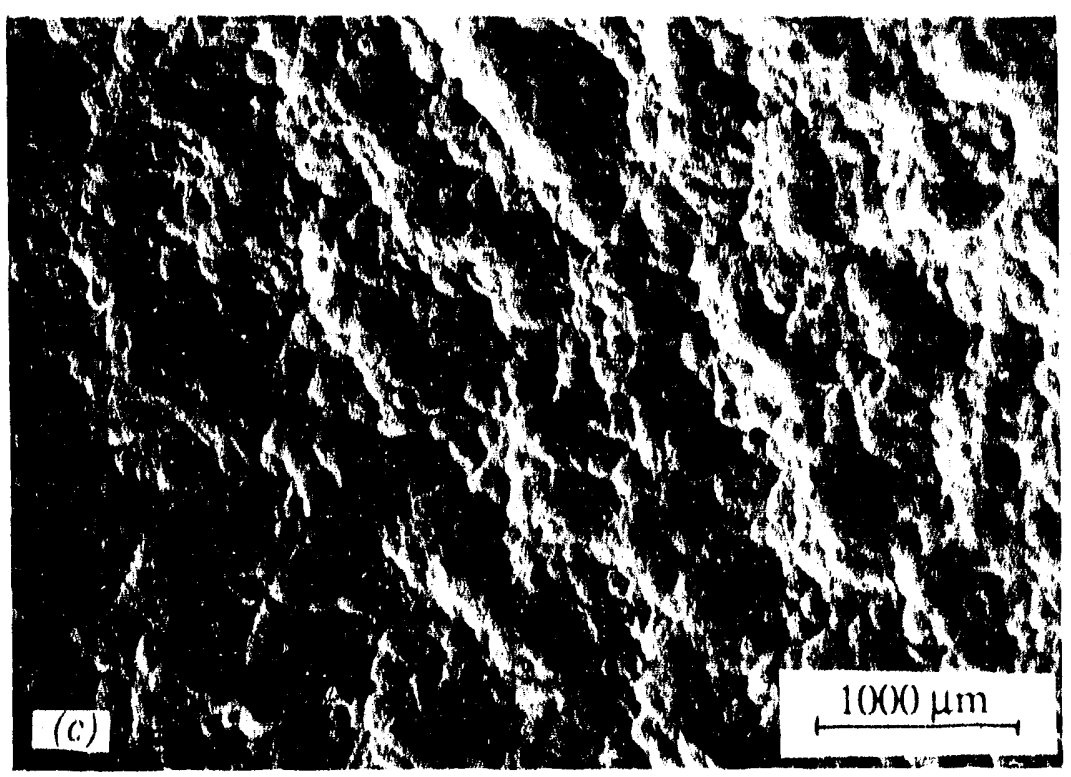

M30984

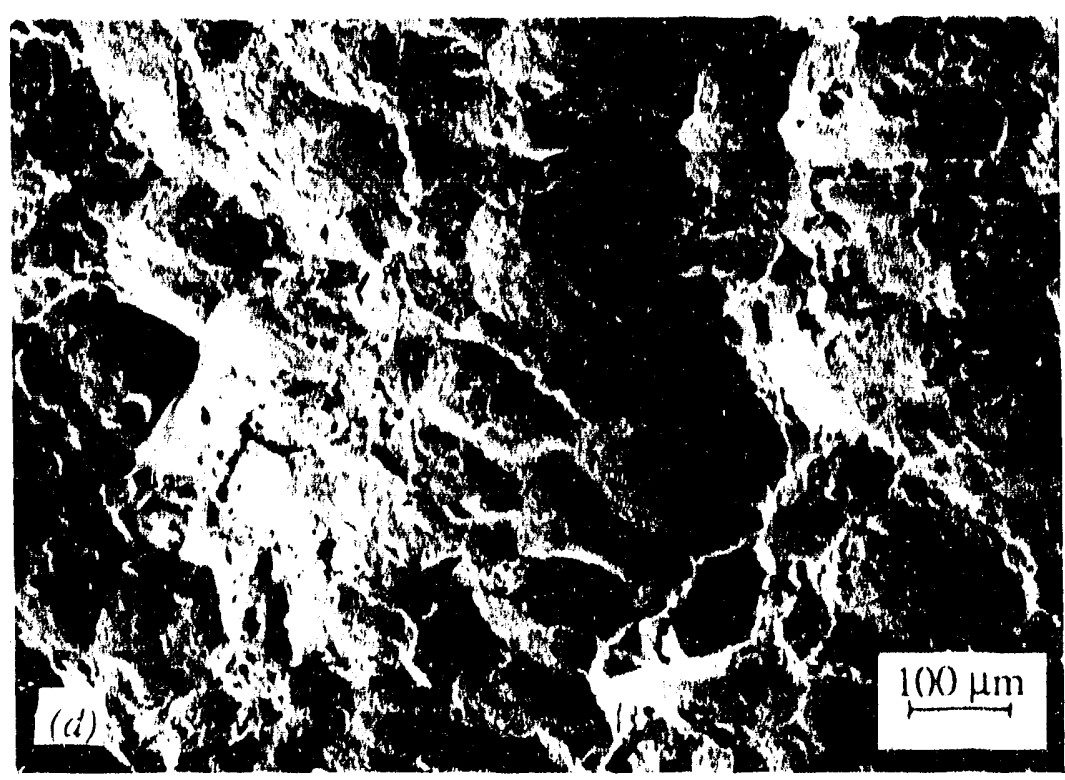

Fig. 26. (continued) 
in Fig. 26(d). Lips of material formed at the lower edges of such craters. A few examples of craters more circular in shape, indicating close to normal incidence locally, can also be seen.

There is evidence that material loss occurred from the specimens even though mass change measurements showed a steady mass gain in the sample. Figure 26 shows that for the low $11 \mathrm{~g}$ dose, such material removal may occur after a relatively short duration due to the overlap of successive impacts; lips of material that could be broken off by later impacts are observed to a larger extent in the higher dose specimens.

The impact geometry changes at higher doses. Initial impacts on the flat surface occur at $90^{\circ}$ incidence, pushing up material evenly around a crater of circular symmetry. However, as a hill-and-valley structure develops, the local impact geometry may differ significantly from $90^{\circ}$. Such impacts (for example on hillsides) will tend to push material forward and create more prominent lips, as indicated in Fig. 26(d). Due to the localization of deformation in one direction, such lips will be closer to fracture than lips of circular symmetry formed by $90^{\circ}$ impacts. The dominant mode of material removal would, therefore, move from crater overlap to lip formation and fracture as erosion progresses.

Figure $27(a)$ is a tapered section of the 11-g specimen showing little surface relief and non-overlapping impacts, as se $n$ in Fig. 26. Particle embedment is difficult to identify at this low dose. However, the Fe X-ray map in Fig. $27(b)$ indicates a slightly greater concentration of $\mathrm{Fe}$ in the near-surface layers, which must be associated with the impacting steel shot. This suggests that even with essentially single impacts, there is some fragmentation and deposition of the erodent particles on the surface.

Figure 28 shows a tapered section of the 100 -g specimen. There is significantly greater surface relief, and a partially developed hill-and-valley structure is identifiable. The Fe X-ray map shows that pockets of embedded erodent material are concentrated in some of the valleys, with smaller amounts distributed over the rest of the specimen surface.

Figure 29 shows a tapered section of the specimen subjected to a dose of $480 \mathrm{~g}$. Unlike observations at lower doses, pockets of erodent fragments can be seen under the hills at relatively large distances from the eroded surface. This implies that bulk material moved over hardened material and embedded fragments during erosion, pushing them far below the surface. However, similar observations were not made when the sample was sectioned at $90^{\circ}$ to the eroded surface, as shown in Fig. 30. Contrary to Fig. 29, there is no particle embedment directly below hilltops or at distances greater than about $100 \mu \mathrm{m}$ from the surface. Embedment is concentrated in the valley region, and the shape of the embedded fragment pockets suggests material is being pushed out from the valleys into the hills. Instances where bulk material has apparently flowed over particles embedded on hillsides can be seen on either 
YP12744
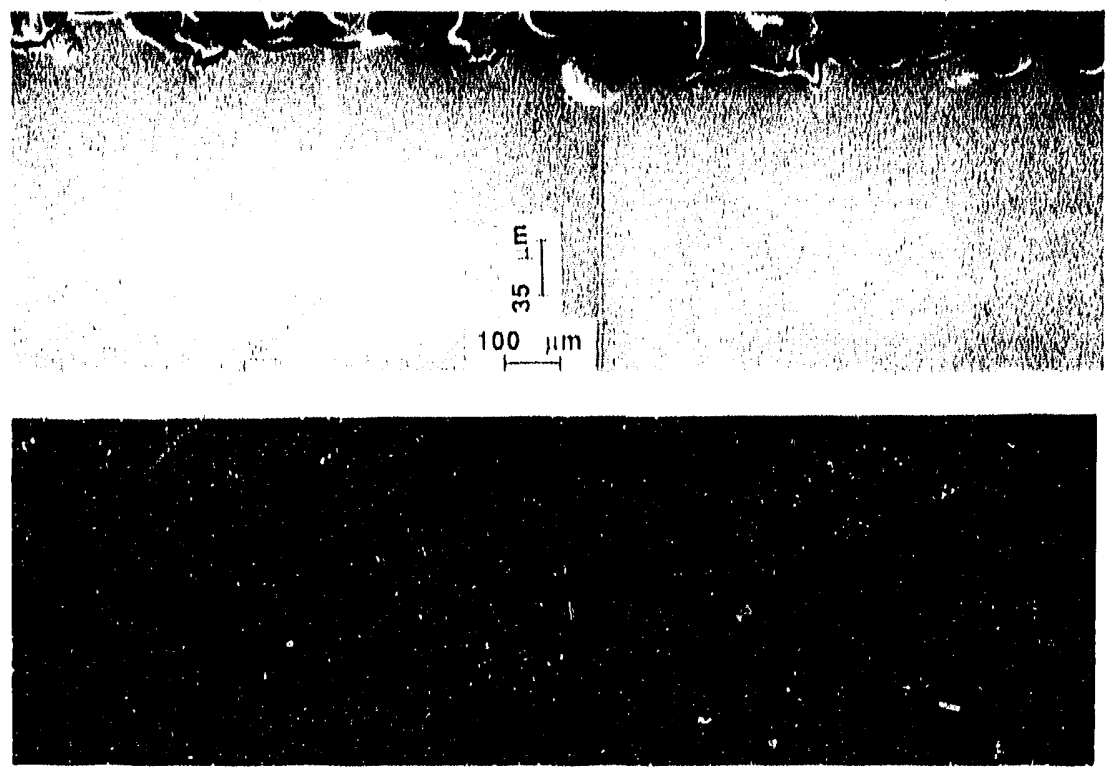

Fig. 27. 3:1 tapered section and corresponding Fe X-ray map of $1100 \mathrm{Al}$ specimen eroded with $11 \mathrm{~g}$ of 297 - to $420-\mu \mathrm{m}$-diam steel shot at $45 \mathrm{~m} / \mathrm{s}, 90^{\circ}$ incidence.

YP12745
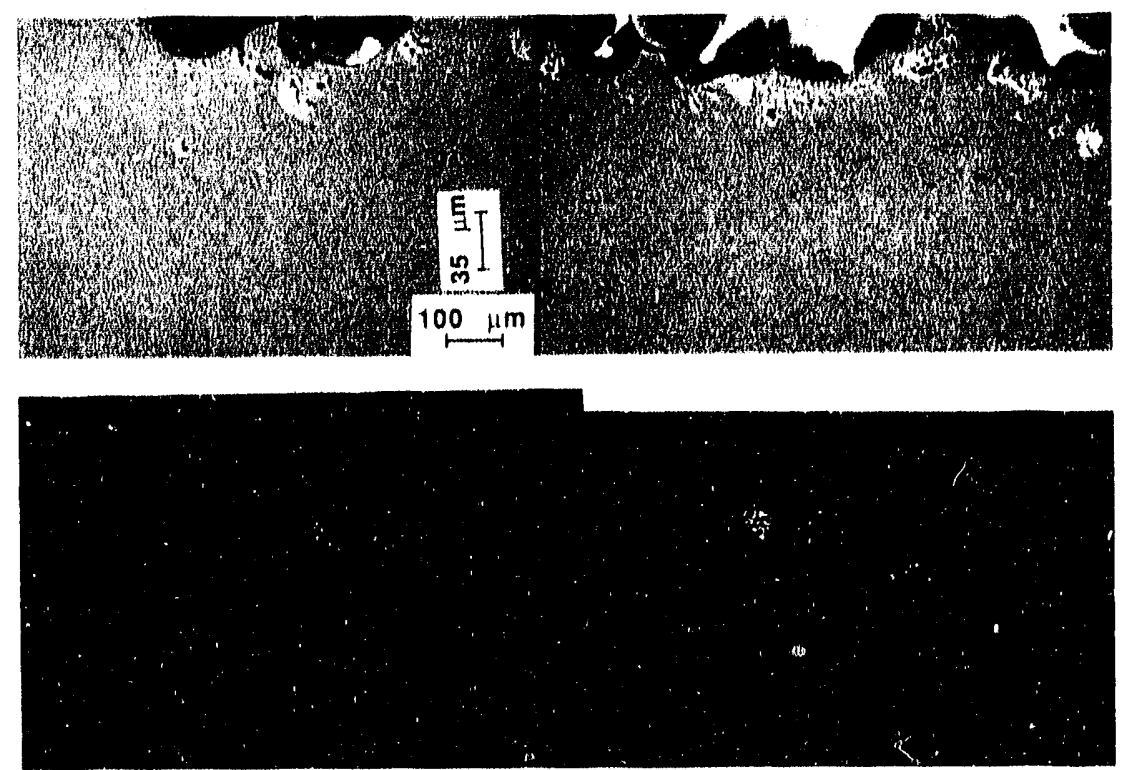

Fig. 28. 3:1 tapered section and corresponding Fe X-ray map of $1100 \mathrm{Al}$ specimen eroded with 10() $\mathrm{g}$ of $297-$ to $420-\mu \mathrm{m}$-diam steel shot at $45 \mathrm{~m} / \mathrm{s}$, 9()$^{\circ}$ incidence. 


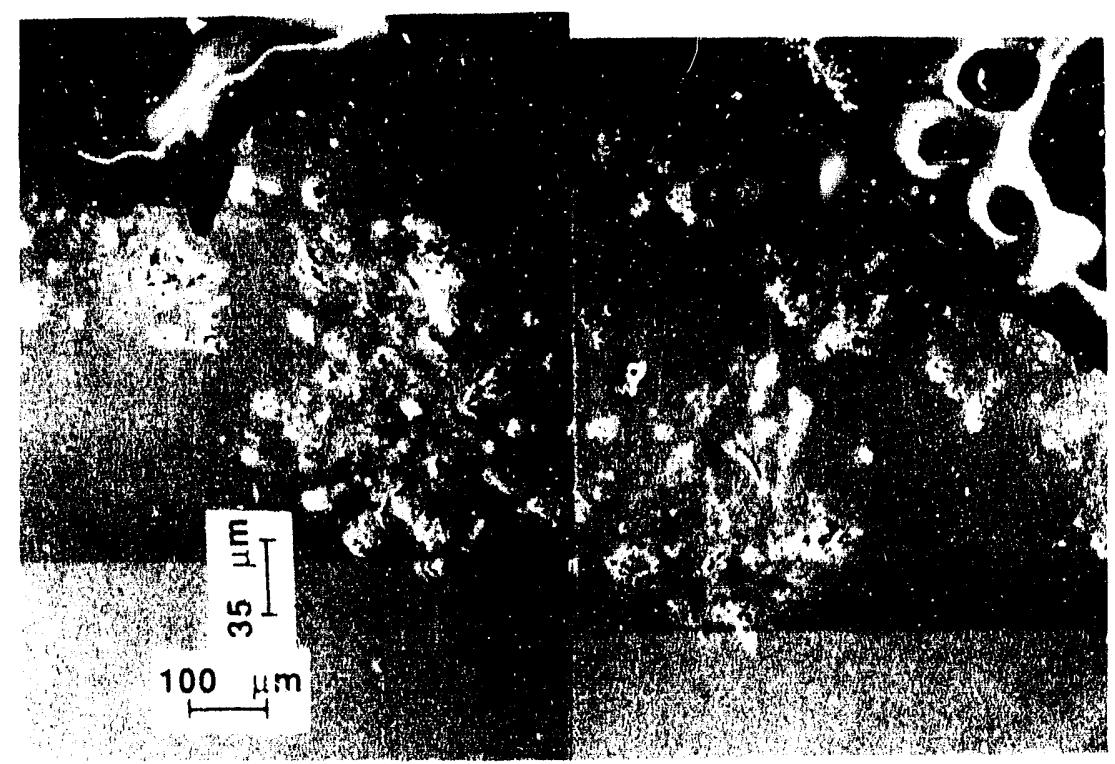

Fig. 29. 3:1 tapered section of $1100 \mathrm{Al}$ specimen eroded with $480 \mathrm{~g}$ of 297 - to 420 - $\mu \mathrm{m}$-diam steel shot at $45 \mathrm{~m} / \mathrm{s}, 90^{\circ}$ incidence.

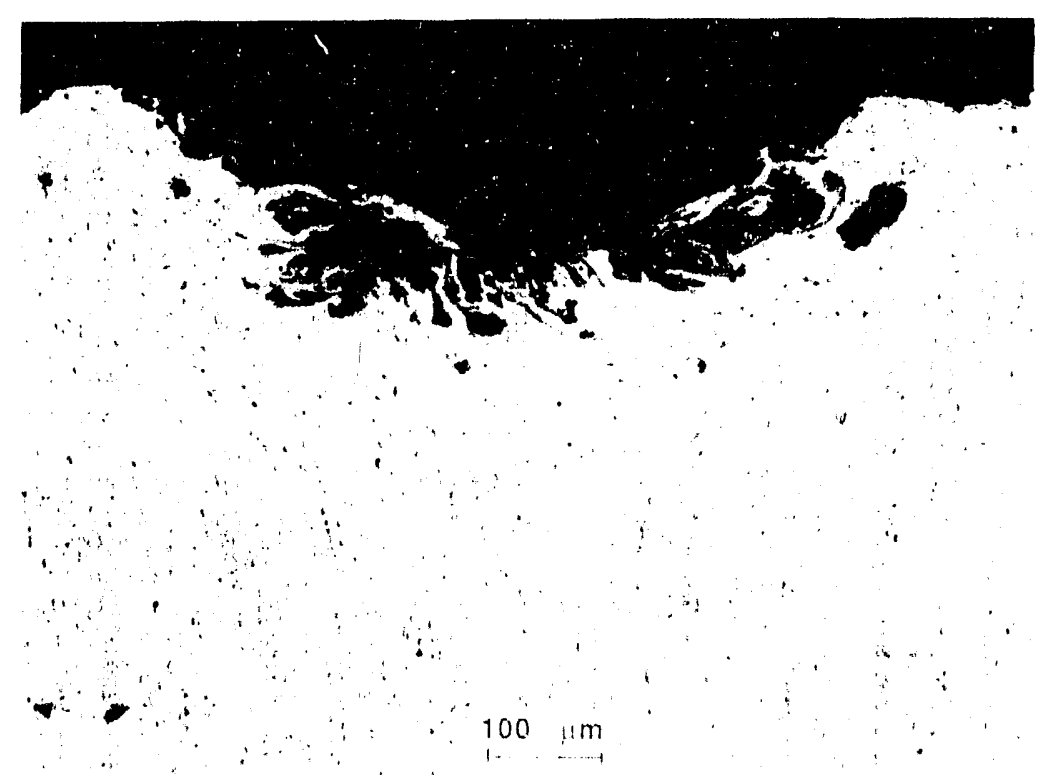

Fig. 30. Perpendicular cross section of sample subjected to an erodent dose of $480 \mathrm{~g}, 297$ - to 420$\mu \mathrm{m}$-diam steel shot, $45 \mathrm{~m} / \mathrm{s}, 90^{\circ}$ incidence. 
side of the central valley. The discrepancy between the observations on the tapered and perpendicular sections of the 480-g specimen is apparently due to the fact that the shallow taper plane is inclined at an angle of about $20^{\circ}$ to the plane of the eroded surface and hence cuts across neighboring hills and valleys (see later discussion with respect to Fig. 35). Each point on the taper plane, lying beneath some feature on the original surface, corresponds to some distance from that surface feature in a vertical direction. However, if one traces a straight line on the taper plane, then one point on the line may lie directly beneath a hill, whereas another point some distance away may lie underneath a valley. The area of embedded fragments directly beneath the hill in Fig. 29 could, therefore, be the surface of a neighboring valley exposed by the taper-sectioning process. The distance of the pocket of embedded fragments from the top of the hill is similar to the distance between a hilltop and valley on the surface of the specimen as estimated from Fig. 26(d). In light of this, MPM measurements are reported from the $90^{\circ}$ cross-sectioned specimen rather than from the taper-sectioned specimen. This also illustrates potential problems with taper-sectioning techniques while interpreting data, as discussed below.

In Fig. 30, arrays of fine precipitates can be seen in the $1100 \mathrm{Al}$. These arrays are distorted near the valley surface, spreading out toward the hills on either side, thus supporting the idea that material from the valley is pushed to the sides and up into the hills. The distorted lines of precipitates can be used to trace the flow of the material under impact. Figure 31 shows tracings from micrographs of two are $\mathrm{us}$ of the cross-sectioned $480 \mathrm{-g}$ sample. The flow lines show material movement from valleys into the hills. Impacts in the valleys appear to squeeze out material to either side. In the very-near-surface layers, and especially in the hills, the material flow is almust exclusively parallel to the surface.

One may expect less damage and thus less material loss from hilltops compared to areas near valleys where there is a higher fraction of oblique impacts, as pointed out in Fig. 26. The presence of voids among the embedded fragments could also lead to losses of larger amounts of material from the valleys where the voids are concentrated. More material loss could, therefore, be expected from the lower portion of hillsides and valley floors, causing the hilland-valley structure to develop further. At some point, however, material removal from the two regions will be balanced as valley regions become more inaccessible to impacting shot and as the material in near-surface regions is fully work hardened and stripped away more efficiently. This would correspond to steady-state erosion with a constant spacing and amplitude of hills and valleys.

Figure 32 shows the MPM results for the 11 -g taper-sectioned specimen obtained from under a small peak, similar to the several seen in Fig. 27, which may correspond to material 

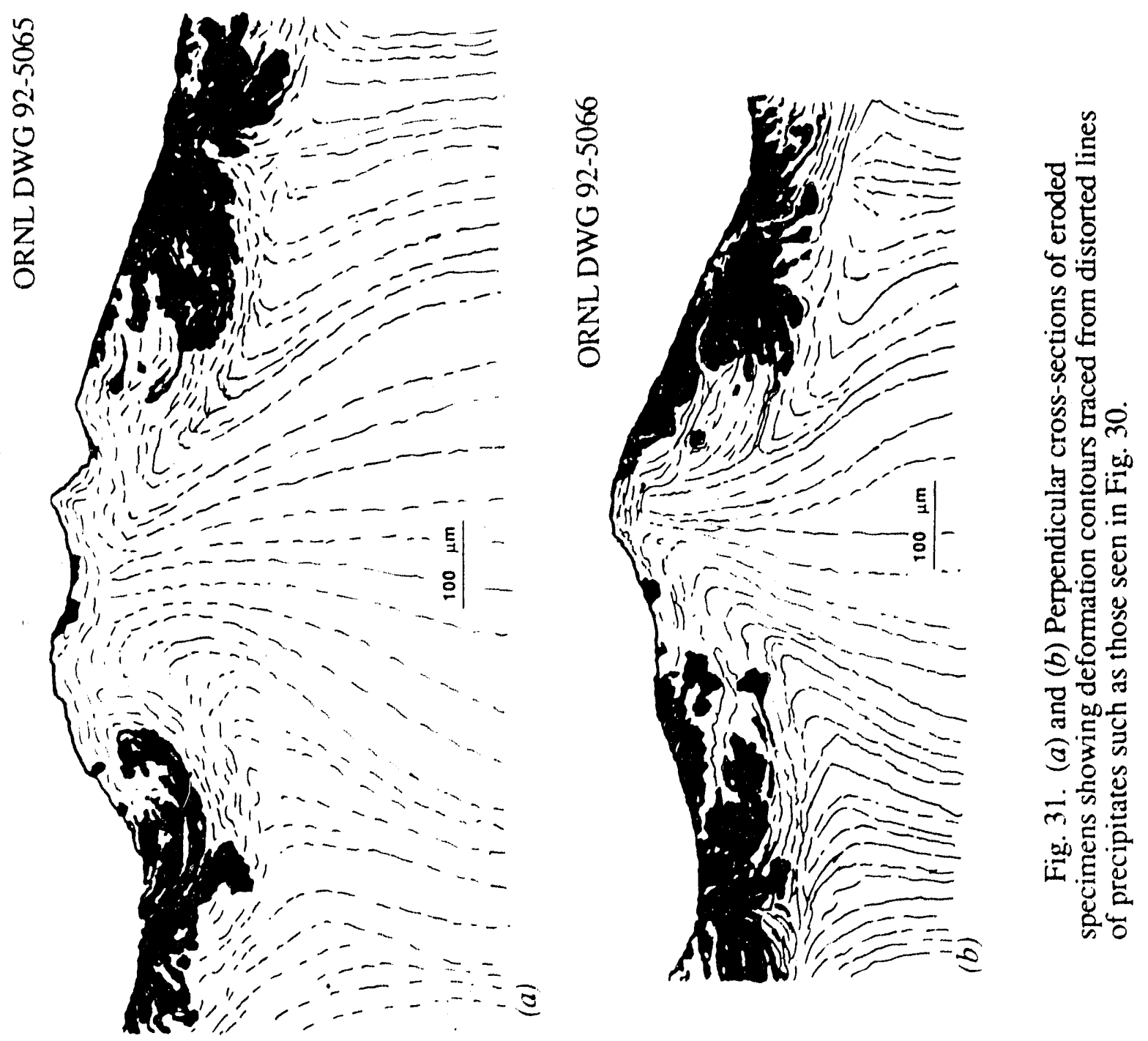
ORNL DWG 92-5067

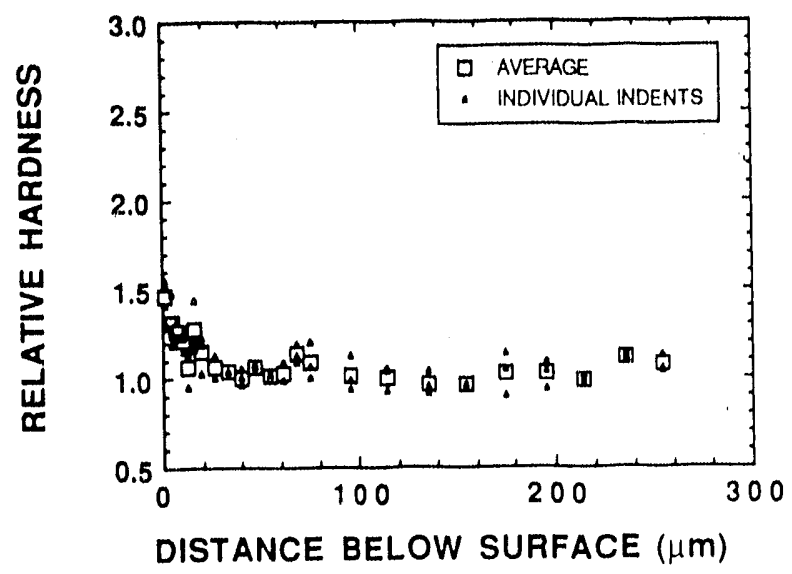

Fig. 32. MPM relative hardness profile on tapered section of sample subjected to an erodent dose of $11 \mathrm{~g}$.

pushed up by one or two impacts. As can be seen, the near-surface layers are work hardened by the impacts, but the hardening is restricted to the near-surface layers (about the top $50 \mu \mathrm{m}$ ). A maximum relative hardness of 1.5 is seen very close to the surface.

MPM data from the 100-g taper-sectioned specimen are shown in Figs. 33(a) and $(b)$, obtained from under neighboring hill and valley locations. In both cases, the hardness decreases continuously from a maximum at the surface. The extent of hardening at this dose is significantly greater than that for the $11 \mathrm{~g}$ specimen. The maximum hardness and the thickness of the hardened layer, which may be estimated by the distance over which the hardness decreases to the bulk value, is slightly greater under the hill than under the valley.

Figure 34 shows hardness profiles from the perpendicularly sectioned 480-g sample, made directly beneath the central valley and the hill on the left-hand side of Fig. 30 (the indentation arrays are faintly visible in the micrograph). The profiles show a monotonic decrease in hardness from the surface as seen for the other specimens. However, the maximum hardness appears to be less than that achieved on the $100 \mathrm{-g}$ specimen. Although there was a significant increase in the extent of hardening as the erodent dose increased from 11 to 10() $\mathrm{g}$, there is little, if any, further increase at the 480 -g dose. The extent of hardening under the hill appears to be somewhat less than under the valley. Note that hardness data are not available as close to the surface in the valley as they are under the hill, due to severe particle embedment in the near-surface regions of the valleys (Figs. 30) and 31). 
ORNL DWG 92-5068

ORNL DWG 92-5069
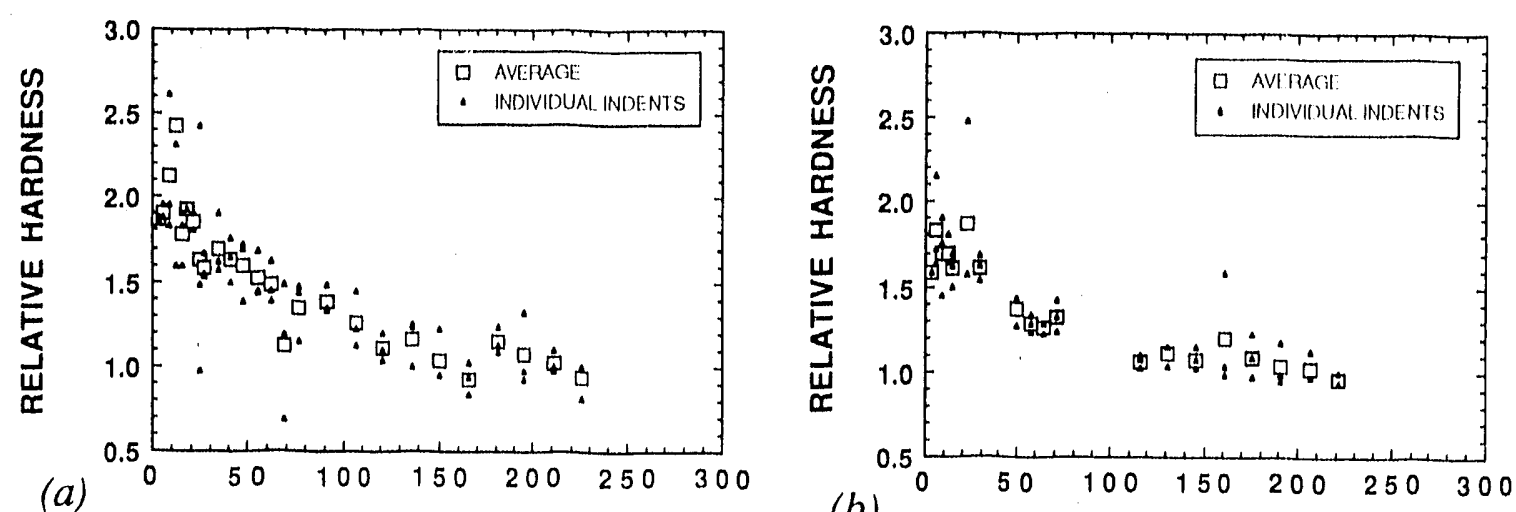

(b)

Fig. 33. MPM relative hardness profiles beneath: (a) hill and (b) valley locations on tapered section of sample subjected to an erodent dose of $100 \mathrm{~g}$. Distance below surface is in $\mu \mathrm{m}$.
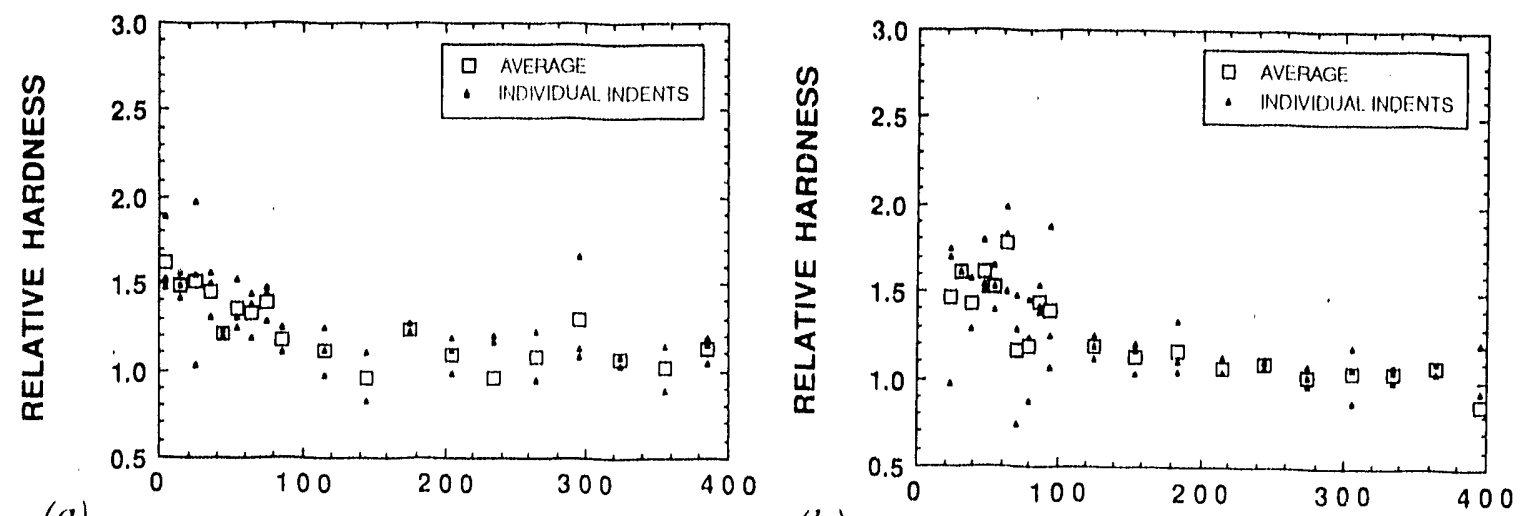

(a)

(b)

Fig. 34. (a) and (b) MPM hardness profile on perpendicular cross section seen in Fig. 30, along the vertical dotted lines marked "A " and "B," respectively. Distance from eroded surface is in $\mu \mathrm{m}$. 
As briefly described above, taper-sectioning techniques may reveal features different from conventional cross-sectioning techniques. The lesser hardening in the $480 \mathrm{-g}$ specimen compared to the $1(0)$-g specimen may, therefore, be more due to sample preparation than an actual physical effect. MPM data from the $480 \mathrm{~g}$ specimen are from a perpendicularly crosssectioned specimen, whereas data from the 11- and 100-g specimens are from taper-sectioned specimens. As shown schematically in Fig. 35, indentations made near the edge of tapersectioned specimens have more lateral support and are therefore likely to measure higher hardnesses. MPM arrays made on the taper-sectioned 480-g specimen gave higher hardness values than those measured on the perpendicularly sectioned specimen, although, as discussed above (Fig. 29), clear interpretation of the data was difficult due to interference between the taper-sectioning technique and the hill-and-valley topography. The maximum relative hardness values measured on the perpendicularly sectioned specimen were similar to those measured on perpendicularly sectioned $1100 \mathrm{Al}$ eroded at $30^{\circ}$ incidence in the initial multi-particle erosion study in this program (Fig. 13). The apparent differences in peak hardness between Figs. 33 and 34 are not considered to be a real effect.

The convolution of MPM data on the taper-sectioned 480-g specimen was due to the fact that the taper plane cut across several neighboring hills and valleys so that an indentation array several hundred microns beneath a hill or valley on the section may, in effect, traverse several hills and valleys. Although similar effects may be expected for the 11 - and 100 -g specimens,

ORNL DWG $92-5072$

ORNL DWG 92-5073

(a)
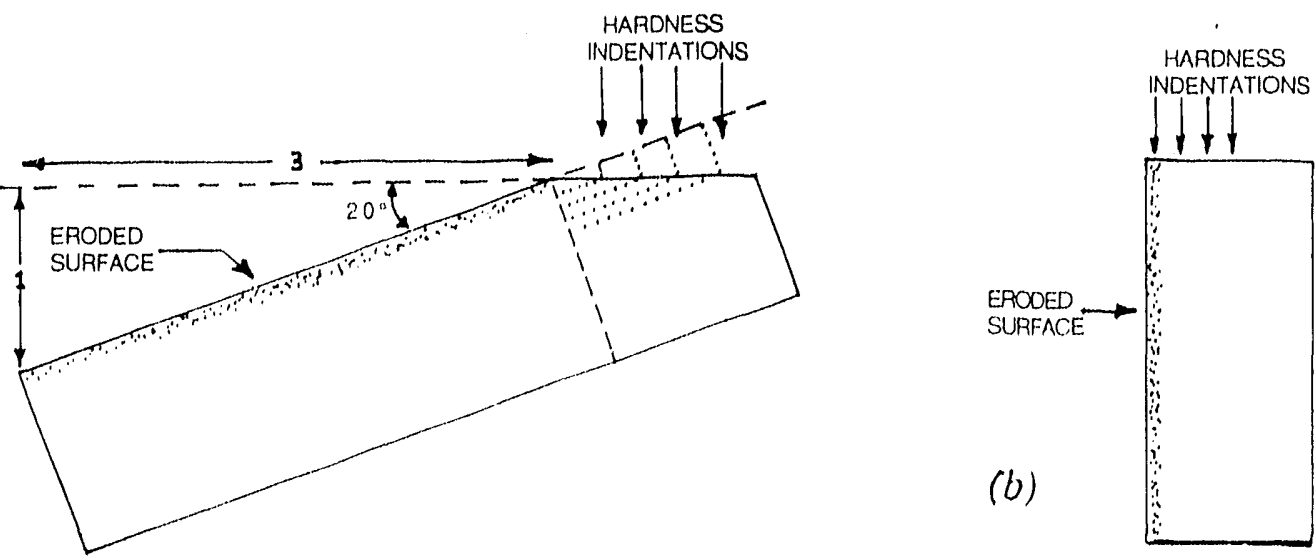

Fig. 35. Sketches showing that hardness indentations close to the eroded surface edge on a tapered-section specimen: (a) are supported by adjacent material to a greater extent than indentations on a perpendicularly cross-sectioned specimen $(b)$. 
they are not expected to be as significant since neither particle embedment nor the hill-andvalley topography is well developed at these doses (Figs. 27 and 28). In the earlier study examining the erosion of $1100 \mathrm{Al}$ at $30^{\circ}$ incidence, MPM profiles on tapered sections of specimens eroded at large doses where the ripple structure was well developed (Figs. 20 and 21) showed none of the effects described above for specimens eroded at $90^{\circ}$ incidence. This can be explained by considering the differences in the physical shape of the surface features, which develop at 30 and $90^{\circ}$ incidence. In the rippled structure, which develops at oblique angles of incidence, a particular wave crest or valley extends over the width of the specimen. Thus, a tapered section made with the taper edge parallel to the erosion direction would be inclined along the wave crest or wave valley in question. Hardness measurements on this section could, therefore, be correctly interpreted as being representative of regions directly below a single crest or valley. As discussed above, this does not hold for surface topographies developed at 9$)^{\circ}$ incidence since the features have a circular symmetry and extend to small distances in all directions. This demonstrates that taper sectioning may be a powerful tool but has to be used judiciously. Although the technique is ideally suited for flat, uniform surfaces, careful positioning of the taper plane or interpretation of data can extend its application to asymmetric surfaces.

The development of the hill-and-valley structure at $90^{\circ}$ incidence may occur by means of a back-extrusion process similar to that described by Brown et al, 55 and Cousens and Hutchings. 52 However, there are significant differences in our observations.

Brown et al. ${ }^{55}$ suggested that back extrusion of material occurred because of a higher density of impacts in valleys as particles bounced off hillsides onto the valley floor, forcing bulk material out into the hills. A higher impact density in the valleys is unlikely in the present work because of the relatively gentle slopes on the hillsides, as has also been pointed out in other work. ${ }^{52}$ In the study by Cousens and Hutchings, 52 embedded material created a composite surface layer covering both hills and valleys, and there was a sudden change in hardness between the disturbed layer and the bulk, which is contrary to the present results. They visualized a hard and brittle, disturbed layer hammering into the softer bulk causing it to be pushed back upward, creating the hill-and-valley structure. No discrete hard layer was seen in the present case. Therefore, it is easier to explain our results based purely on back extrusion and plastic deformation considerations of the cumulative effects of individual impacts. As seen in Fig. 27, some particle embedment had occurred by a dose of $11 \mathrm{~g}$, corresponding to only a few overlapping impacts. The initial hill-and-valley structure may develop as some local areas undergo more impacts than others, pushing out work-hardened material around the areas. Initial particle embedment in these areas would promote further 
embedment due to the formation of voids and fissures, each event tending to push material into neighboring nascent hills. Embedment would be less in these work-hardened areas because of their greater resistance to deformation and penetration by erodent fragments. The spacing of the hills and valleys would be directly related to the range of deformation due to the initial impacts and, hence, to particle size as has been experimentally observed. 64

\subsection{EROSION OF IRON-ALUMINIDE ALLOY FA-129 AT 30 AND $90^{\circ}$ INCIDENCE}

The final set of multiple-particle erosion experiments was conducted on the iron-aluminide alloy FA-129, the chemistry and heat treatment of which have been described earlier. Samples were eroded in the Notre Dame rotating-arm tester under the same conditions as used for the study of $1100 \mathrm{Al}$ eroded at $90^{\circ}$ incidence: steel shot 297 to $420 \mu \mathrm{in}$ in diameter impacting at a velocity of $4 \mathrm{~m} / \mathrm{s}$. Samples were eroded at angles of 30,60 , and $90^{\circ}$ to the surface. As in the previous studies, samples were examined after being subjected to various amounts of erodent.

An important difference between the studies on $1100 \mathrm{Al}$ and FA-129 is that the aluminide alloy is considerably harder, approaching the hardness of the impacting steel shot. Therefore, one may expect significantly different behavior under erosion conditions. Typical erodent particles are shown in Fig. 36. The particles are roughly spherical in shape, although some are fragmented or appear to have an oxide scale, which could break off easily. The thick scales can be seen more clearly in the sectional view in Fig. 36(b) and often do not cover the entire particle. Examination of over 100 ) sectioned particles showed that less than $15 \%$ of the particles were either completely or partially covered with a scale.

Microhardness measurements on the steel shot gave a wide range of results that could be roughly linked to the microstructure revealed by the etch. According to specifications provided by the manufacturer, the shot was expected to have a fine-tempered martensite structure, but the particles examined had structures ranging from untempered martensite to fine pearlite. Microhardness measurements near the center of 32 sectioned particles, which were whole, gave an average hardness of $296 \mathrm{HV}_{10}$ with a standard deviation of 56 . The microhardness of the scale surrounding some of the particles [Fig. 36(b)] was found to average $470 \mathrm{HV}_{10}$.

Microhardness measurements were also made directly on the 60)-grit, rough-polished surfaces of FA-129 subjected to erosion. These gave average hardnesses of $310 \mathrm{HV}_{10}$ with a standard deviation of 23. Considerable hardening of the iron aluminide occurred due to erosion, and hardnesses in the range of 400 to $450 \mathrm{HV}_{10}$ were measured at distances corresponding to $65 \mu \mathrm{m}$ below the eroded surface. 
M31134

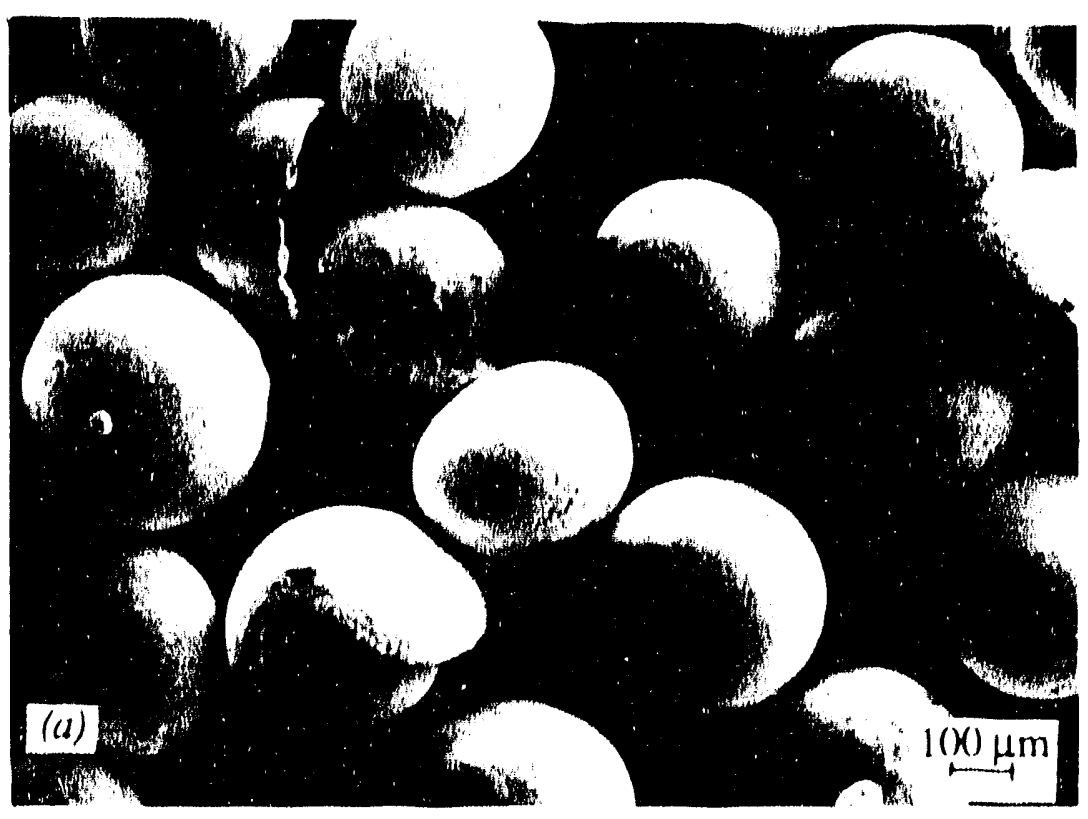

MR25

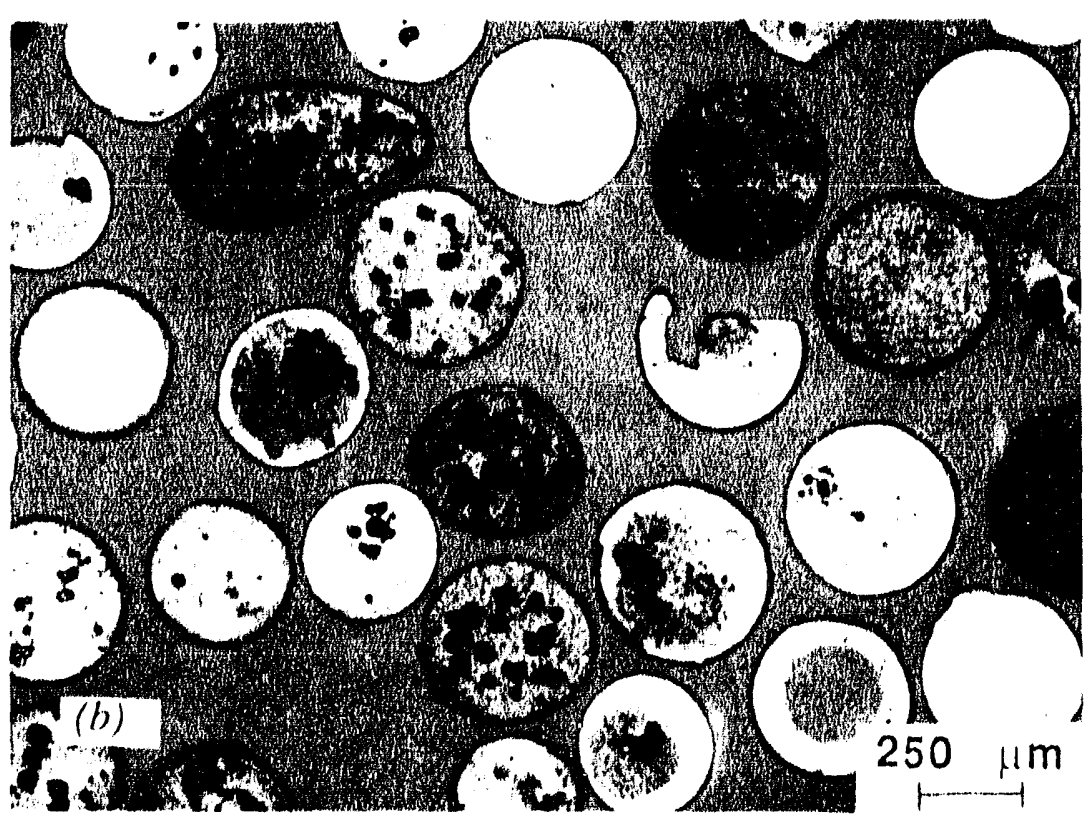

Fig. 36. Micrographs of the 297- to 420- $\mu$ m-diam steel shot used in the erosion experiments: $(a)$ whole and broken particles and $(b)$ cross-sectional view clearly showing the scale covering some particles. 
An approximate conversion to the Rockwell $\mathrm{C}$ scale 65 shows that only particles with hardnesses over $4(0) \mathrm{HV}_{10}$ meet the original specifications of a minimum hardness of $40 \mathrm{Rc}$. This was found in only 3 of the 32 particles whose hardnesses were measured near their centers. In contrast, 23 of the 32 particles had hardnesses below $310 \mathrm{HV}_{10}$, the average hardness of the target surfaces prior to erosion. Since only about $15 \%$ of the particles had a scale, it follows that less than $25 \%$ of the particles had a hardness greater than that of the surface on which they were impacting, and a significantly smaller fraction had a hardness greater than the work-hardened target ( 400 to 450$\left.) \mathrm{HV}_{10}\right)$. Under these conditions, deformation of the impacting particles can no longer be ignored, and erodent degradation and fracture becomes a distinct possibility. Unfortunately, it was not possible to collect spent erodent in order to estimate such processes since only a small fraction of particles accelerated by the rotating arm strike the sample. For example, approximately $43 \mathrm{~kg}$ of erodent had to be fed to achieve a specimen dose of $480 \mathrm{~g}$. It was impossible to separate the small amount of spent particles from the much larger quantity of unused particles with which they mixed after impact.

Figure 37 shows the results from specimen mass measurements made at various stages of erosion. A threshold/incubation period with mass gain is seen for all three angles of incidence and is most pronounced for $90^{\circ}$ erosion. Toward the end of the incubation period, the mass loss rate increased slowly and finally achieved a constant value (steady state) for the 30 and $60^{\circ}$ incidence tests. Approximate curves have been drawn through the data points to

ORNL DWG $92-5074$

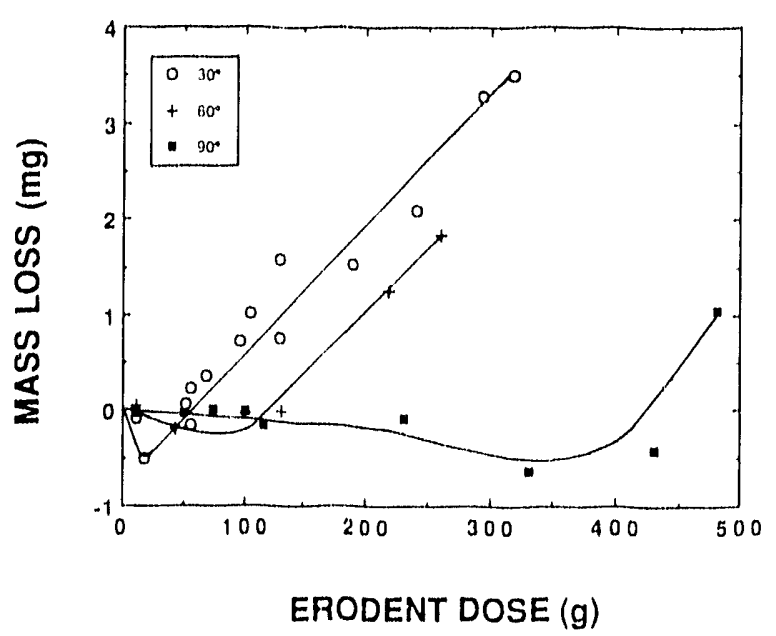

Fig. 37. Mass loss or gain of ironaluminide alloy FA-129 due to erosion as a function of the erodent dose at three angles of incidence. 
provide an indication of the steady-state erosion rate given by the slope of the linear regions. The scatter in the data at $30^{\circ}$ incidence is due to the fact that they were obtained from three sumples eroded to various extents. The steady-state erosion rate at $30^{\circ}$ incidence varies from 0.013 to $0.017 \mathrm{mg} / \mathrm{g}$ depending on which set of data is considered. The steady-state erosion rate is $0.013 \mathrm{mg} / \mathrm{g}$ for samples eroded at 6$)^{\circ}$ incidence. To a first approximation, similar steady-state erosion rates were observed for both 30 and 6()$^{\circ}$ incidence. For the $90^{\circ}$ tests, the total dose was insufficient to conclusively estimate a steady-state erosion rate.

Only the results from samples eroded at 30 and $90^{\circ}$ incidence are presented and discussed in detail. since little extra information was provided by samples eroded at $60^{\circ}$ incidence. In general, because of a larger component of incident particle velocity being perpendicular to the target surface, samples eroded at 6$)^{\circ}$ incidence were closer in appearance to those eroded at $90^{\circ}$ incidence.

Micrographs of eroded surfaces at $30^{\circ}$ incidence for erodent doses of 11 and $320 \mathrm{~g}$ are shown in Fig. 38. Figure 39 shows the appearance of the surfaces after erosion at $90^{\circ}$ incidence at erodent doses of 11 and $480 \mathrm{~g}$. Individual impact craters can be seen for the $11 \mathrm{~g}$ specimens at both angles of incidence. After $11 \mathrm{~g}$ at $30^{\circ}$ incidence, the craters are slightly elongated in the direction of impact, and small lips of material can be seen on the exit edges of the craters. Under 9()$^{\circ}$ impacts, the craters are more uniformly circular with few raised lips identifiable.

Especially at the larger doses in Figs. 38 and 39, a significant number of impact sites with sharp gouges and jagged edges can be seen at both impact angles. For $30^{\circ}$ incidence, a large number of roughly elliptical craters with small protruding lips can also be identified [Fig. 38(b)]. The irregular features were probably formed from the impact of the more angular, broken particles seen in Fig. 36. In addition, whole spherical particles covered with the thick scales, as seen in Fig. 36, may have disintegrated on impact creating irregular-shaped debris, some of which may have been re-impacted on the surface by succeeding particles.

Figure 4() shows high-magnification details of damage on the 11-g dose sample at 3()$^{\circ}$ incidence. Figure 4()$(a)$ shows an almost detached lip of material next to an impact crater on the 11-g dose specimen. The crater dimensions are unusually small in the impact direction, indicating that it may have been formed by an irregularly shaped or ricocheting particle or piece of debris. There appear to have been at least two overlapping impacts at this location. Impact craters clearly formed by rounded particles are shown in Fig. 4()(b). Both craters have thin lips of extruded material in the impact direction. There are also networks of smaller lips/extrusions within the craters themselves. Figure $40(c)$ also shows two overlapping craters. However, in 

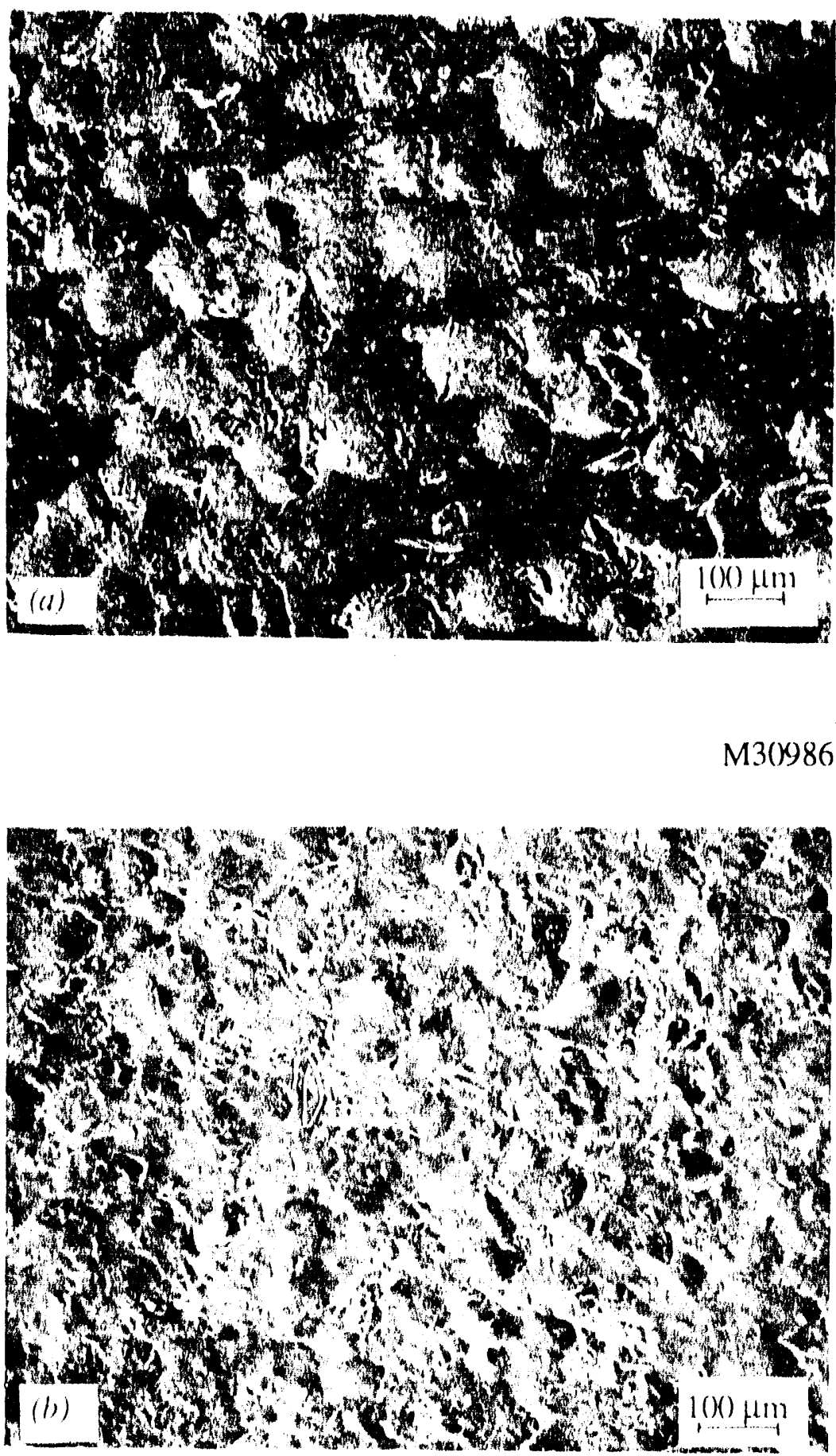

Fig. 38. Appearance of eroded surfaces of ironaluminide alloy FA- 129 at $30^{\circ}$ incidence after erodent doses of: (a) $11 \mathrm{~g}$ and (b) $320 \mathrm{~g}$. 

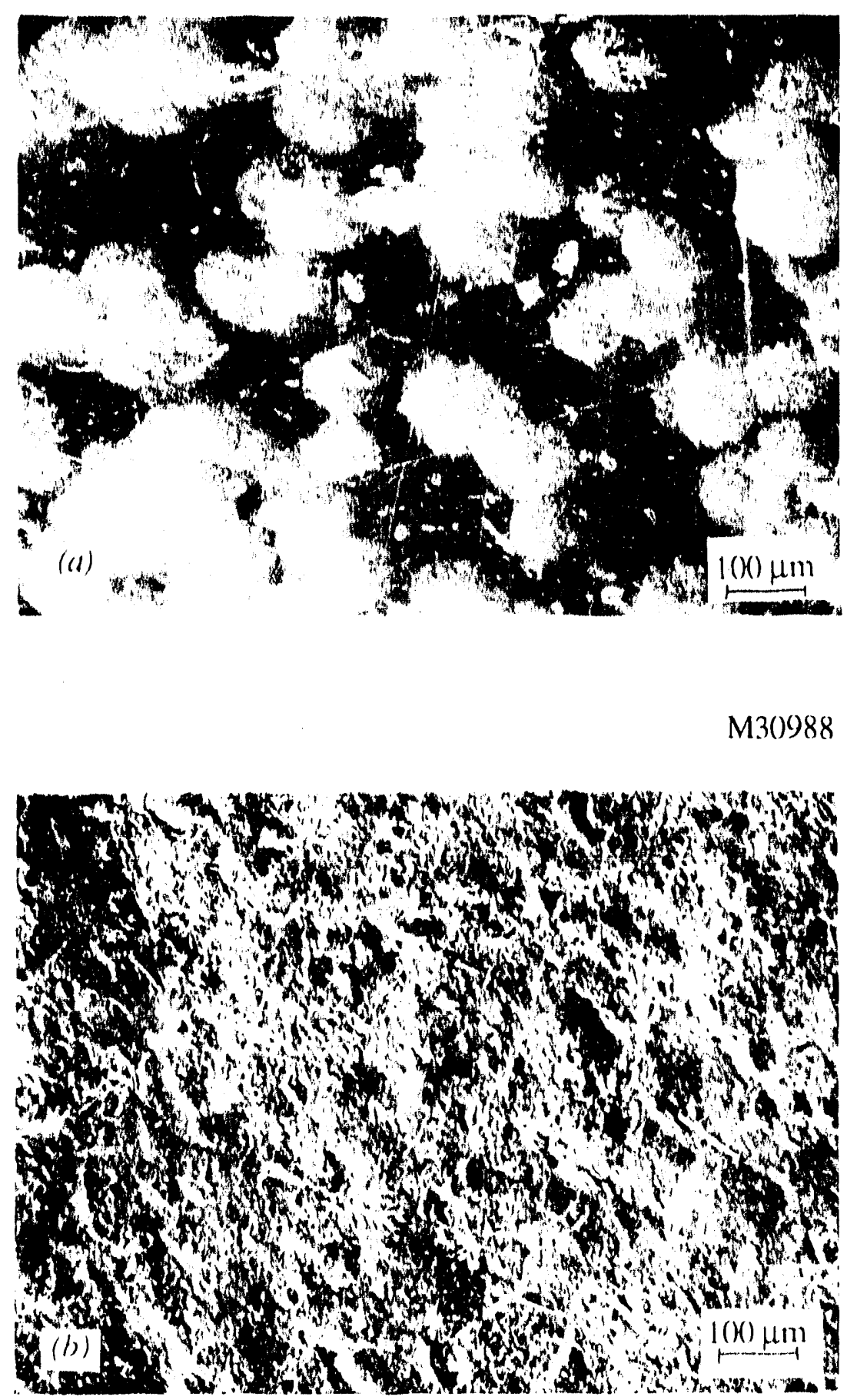

Fig. 39. Appearance of eroded surfaces of ironaluminide alloy FA-129 at 9$)^{\circ}$ incidence after erodent doses of: (a) $11 \mathrm{~g}$ and (b) $480 \mathrm{~g}$. 


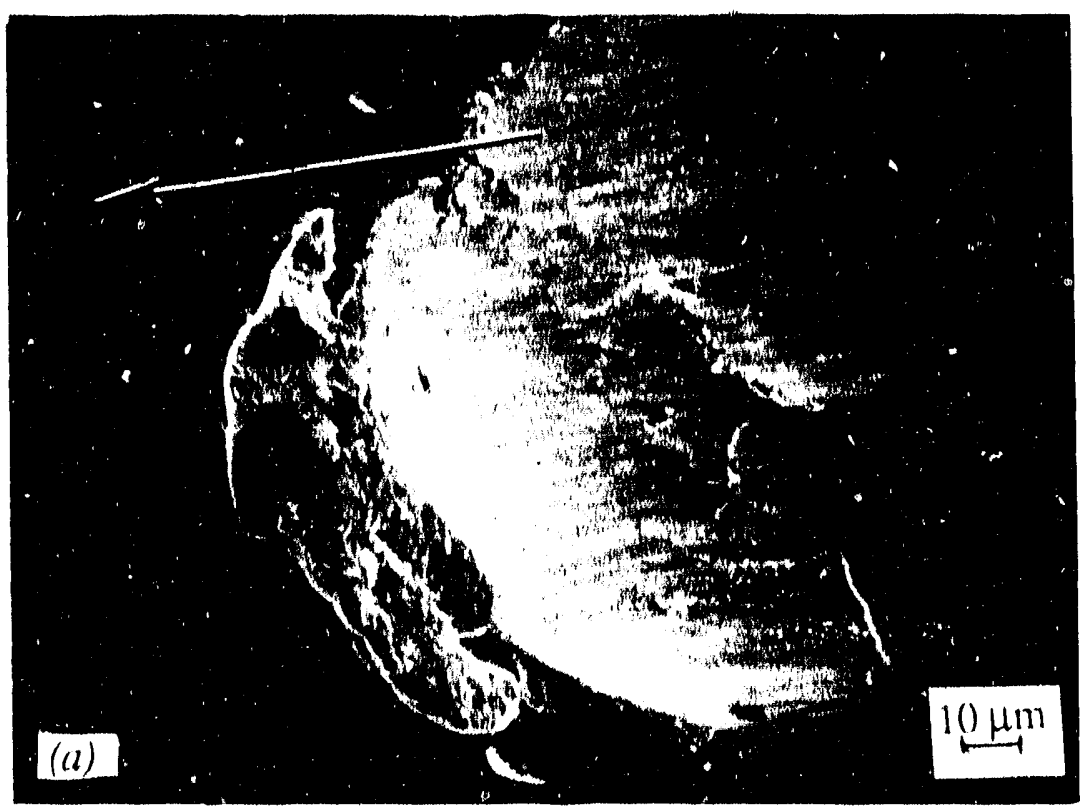

M31896

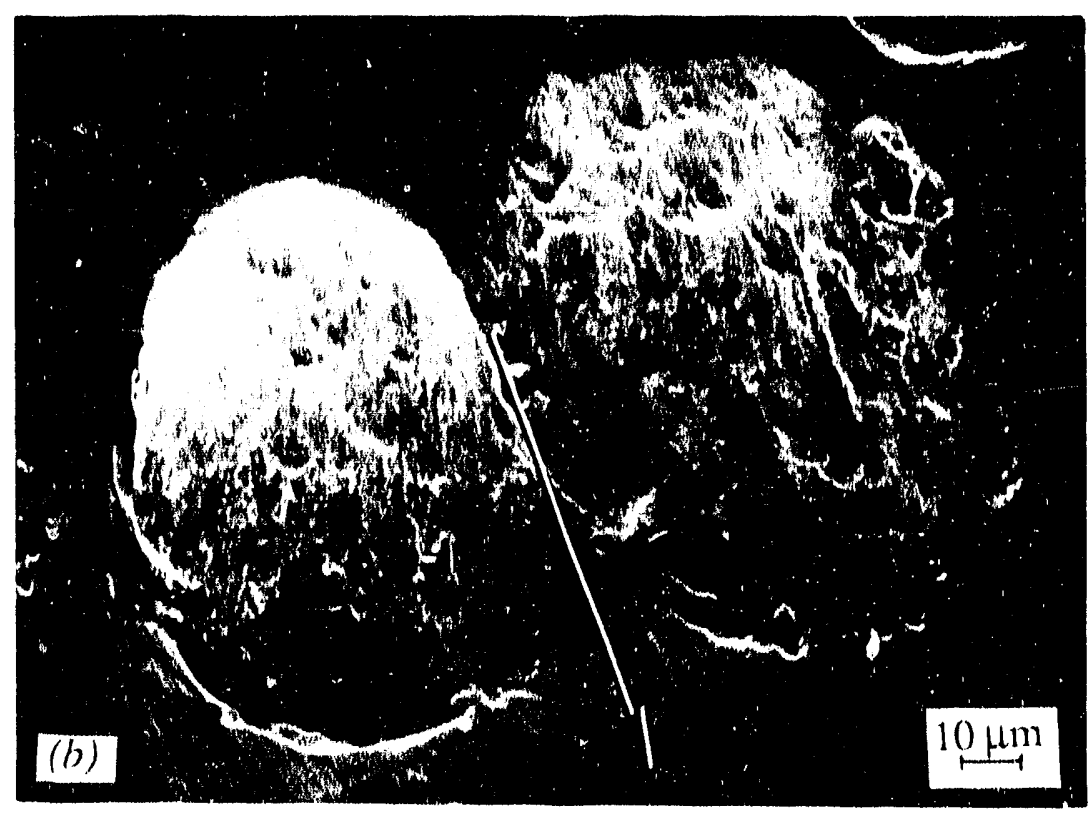

Fig. 40. Individual impact craters seen on iron-aluminide alloy FA-129 sample eroded by $11 \mathrm{~g}$ of erodent at $30^{\circ}$ incidence. 


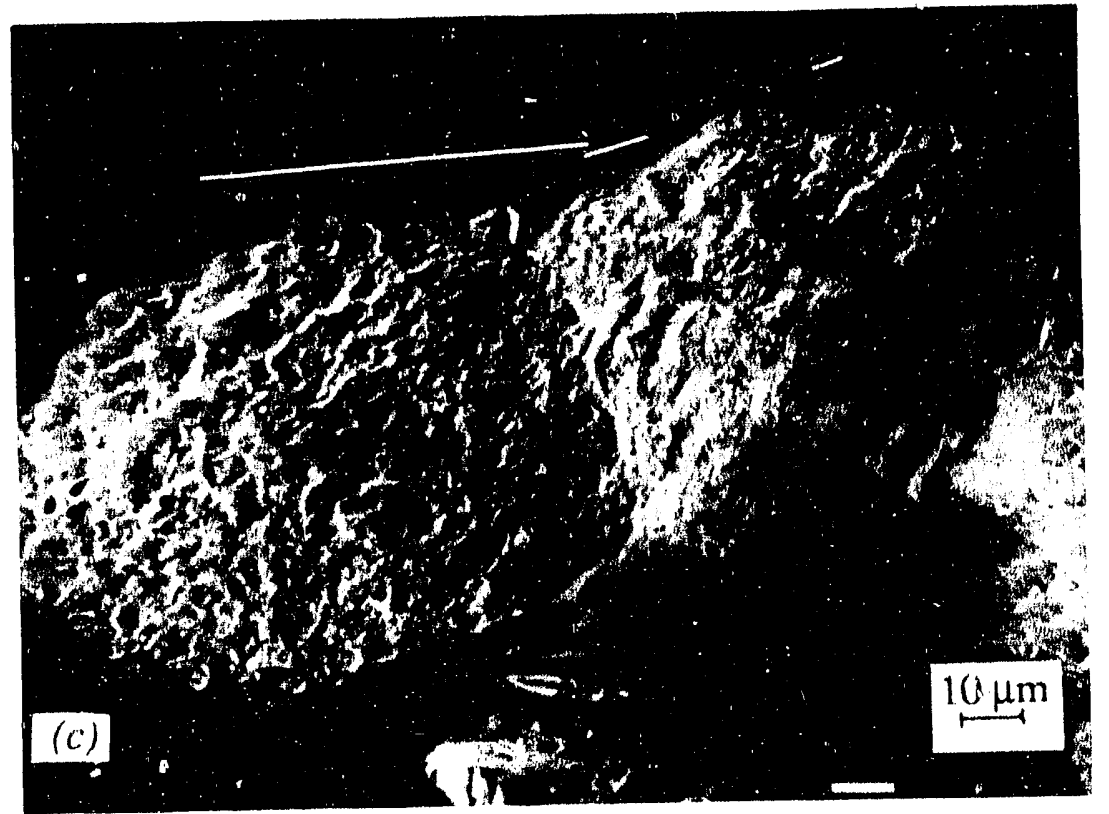

M31898

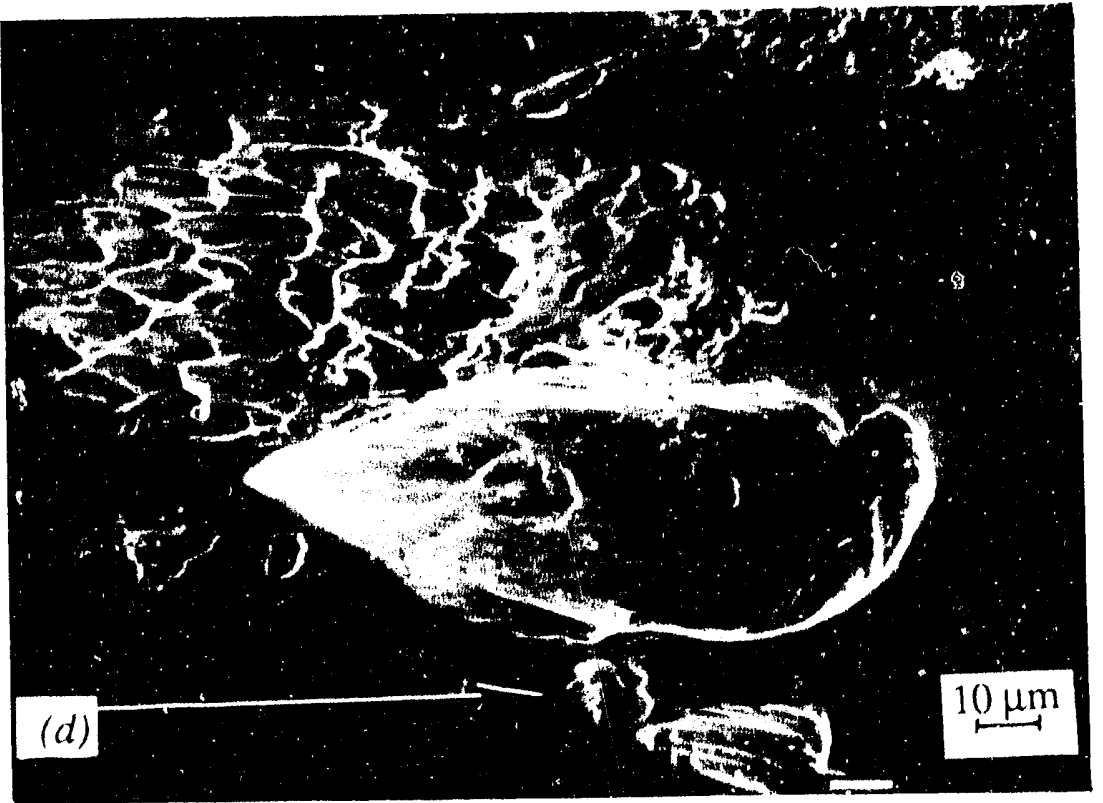

Fig. 40. (continued) 
this case, there is little evidence of lip formation or material extrusion. The pattern within the craters is also fundamentally different than that seen in Fig. $40(b)$ and appears to be basically an impression made by the impinging particles. Note that preexisting polishing grooves on the sample surface may be followed through the craters in Fig. $40(c)$. In Fig. 40(b), the grooves are obliterated by the greater deformation within the craters. Closer examination of lower magnification micrographs, such as in Fig. 38, shows that most of the craters covering the surface were of the types shown in Figs. $40(b)$ and $(c)$. Figure $40(d)$ is an example of a crater and chip apparently formed by the impact of an angular particle next to a site of a sphericalparticle impact. The latter shows the fine extrusions also seen in Fig. 40(b). It is clear that the potential material loss on subsequent impacts by breaking off the chip would be greater than material loss by local failures of the small extruded lips. The craters of both the impact sites producing chips [Figs. 40(a) and (d)] are relatively smooth, containing a set of parallel grooves aligned in the impact direction.

Figure 41 shows two areas from the 320 -g specimen eroded at $30^{\circ}$ incidence. Figure 41(a) shows several instances of elliptical impact craters with thin protruding lips/flakes on the exit sides. These features are indicative of the damage caused by the oblique impact of spherical particles. Note, however, that the individual impact craters are shallow and poorly defined. In-crater patterns, as seen in Fig. 40, are not as obvious but may still be located, for example, in the crater in the lower right quadrant of Fig. 41(a). Extruded lips can also be seen in Fig. 41(b), but there are also a large number of features formed by less well defined impact geometries. It was more common to find areas, as in Fig. 41(b), with a combination of impacts made by both rounded and irregular particles.

Figure 42(a) shows an impact crater in the $11 \mathrm{~g}$ sample eroded at $90^{\circ}$ incidence. The crater appears relatively shallow, judging by the small amount of distortion of preexisting polishing grooves on which the impact has occurred. The clarity of the polishing grooves and absence of lips on the crater edge show that there was little material movement in the crater on impact. As in the case for $30^{\circ}$ impacts, the crater itself contains a damage pattern. For $90^{\circ}$ impacts, this pattern may be most accurately described as consisting of small dents, gouges, and possible spalls. In areas near the center of the specimen, the impact sites were more closely clustered together, and individual impact locations could not be determined. In these areas, damage from angular particles was more evident, as seen in Fig. 42(b).

At higher doses, it was difficult to locate a damage site that could be attributed to the impact of a rounded particle. Figures $43(a)$ and $(b)$ show two areas from the $480-\mathrm{g}$ specimen eroded at $90^{\circ}$. In both cases, the gouges and tears make the surface look as if it had been croded using angular abrasives. A few extruded flakes, 10 to $20 \mu \mathrm{m}$ in size, can be seen in the 


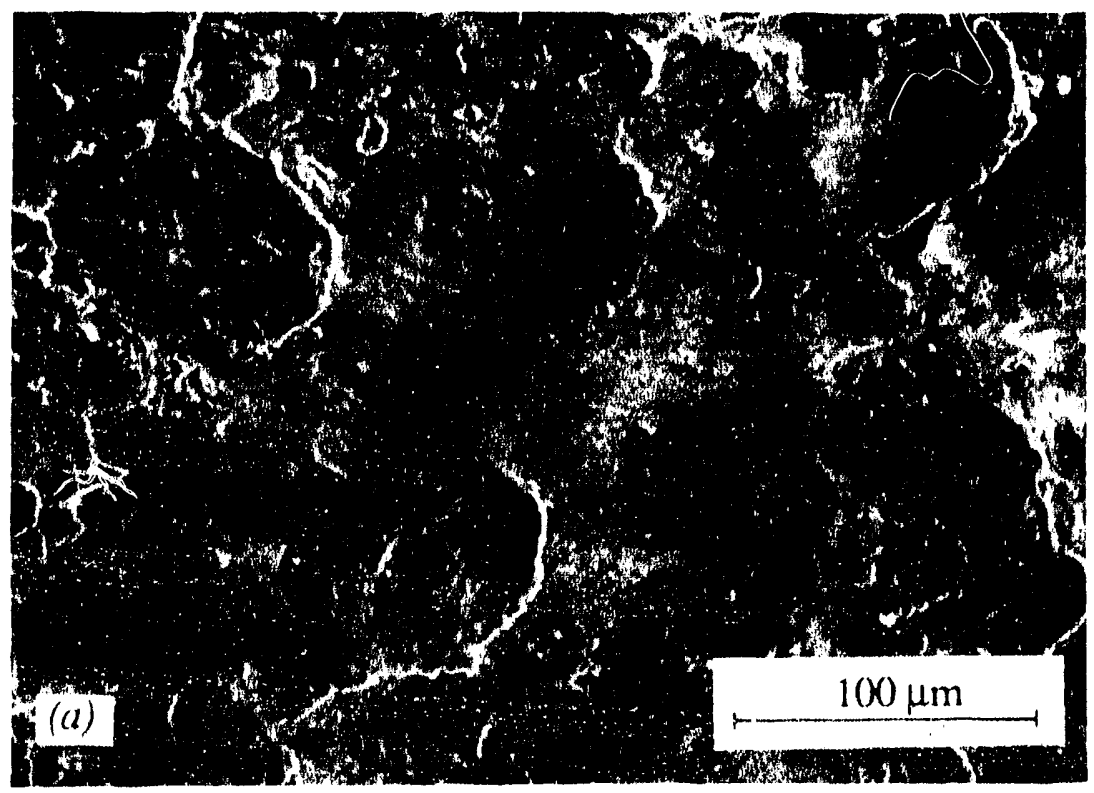

M31899

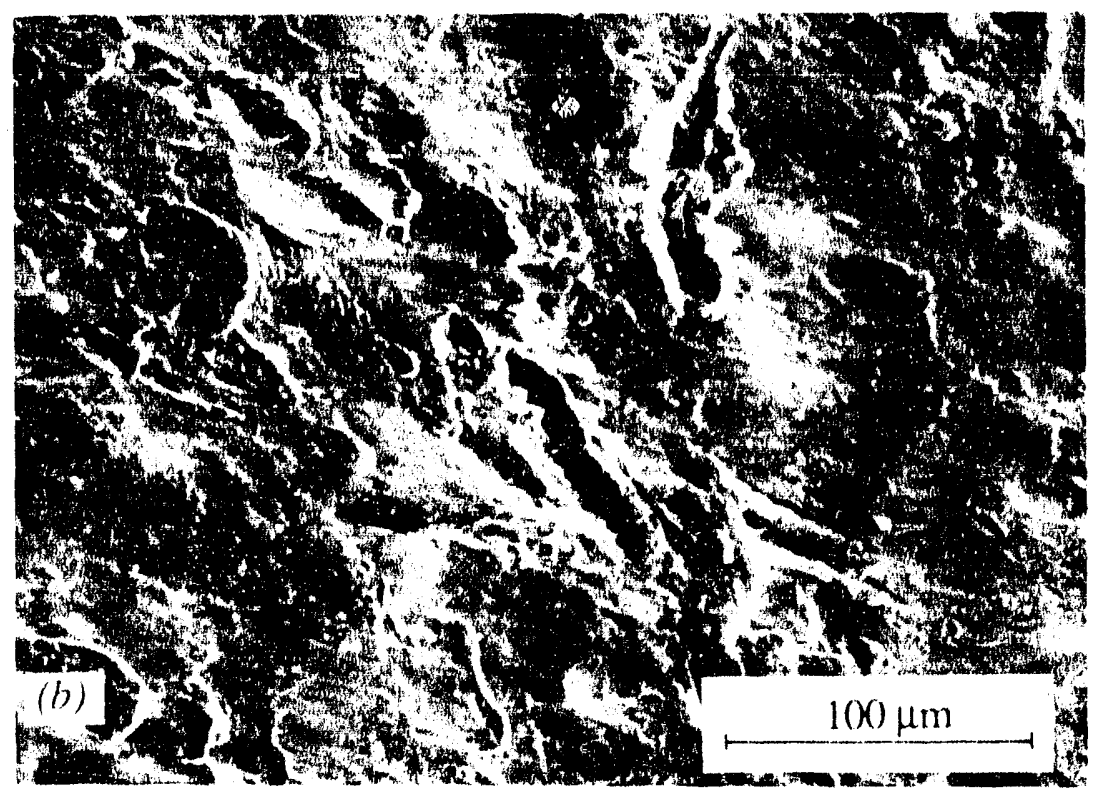

Fig. 41. Details of surfaces of iron-aluminide alloy FA- 129 eroded by $320 \mathrm{~g}$ of steel shot at $30^{\circ}$ incidence showing extruded platelets formed by the impact of rounded particles and ploughing and gouging due to impact of angular particles. 


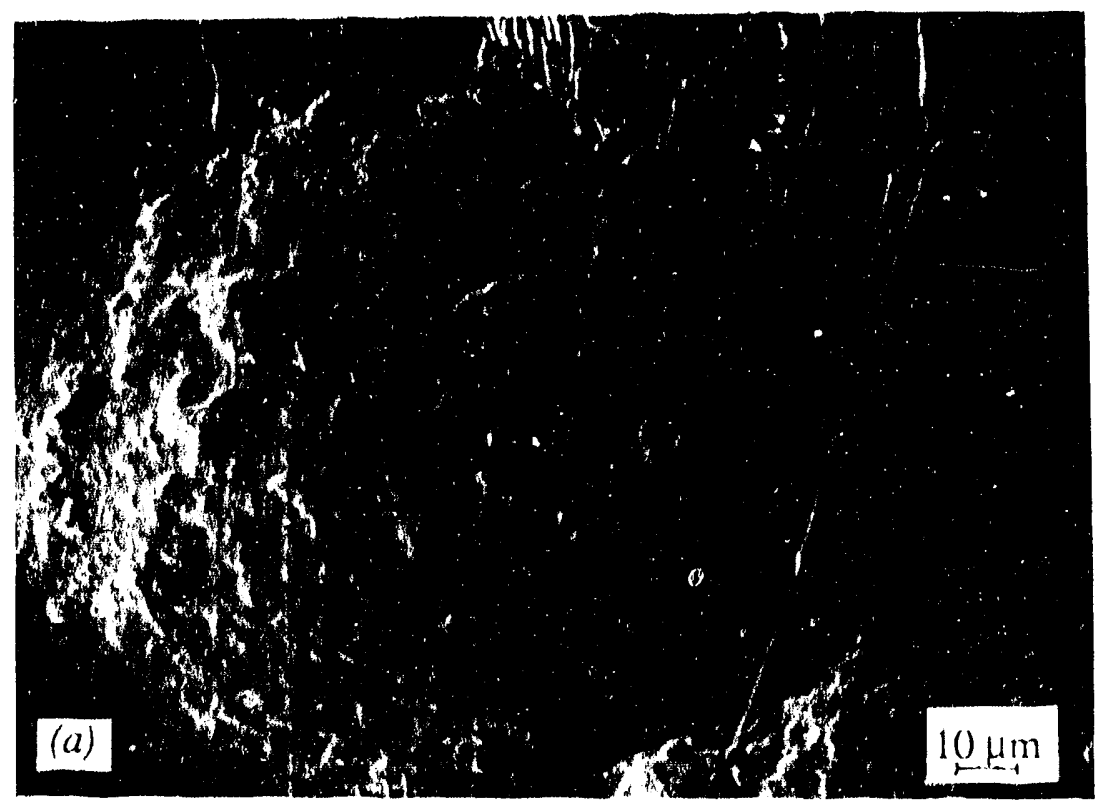

M31710

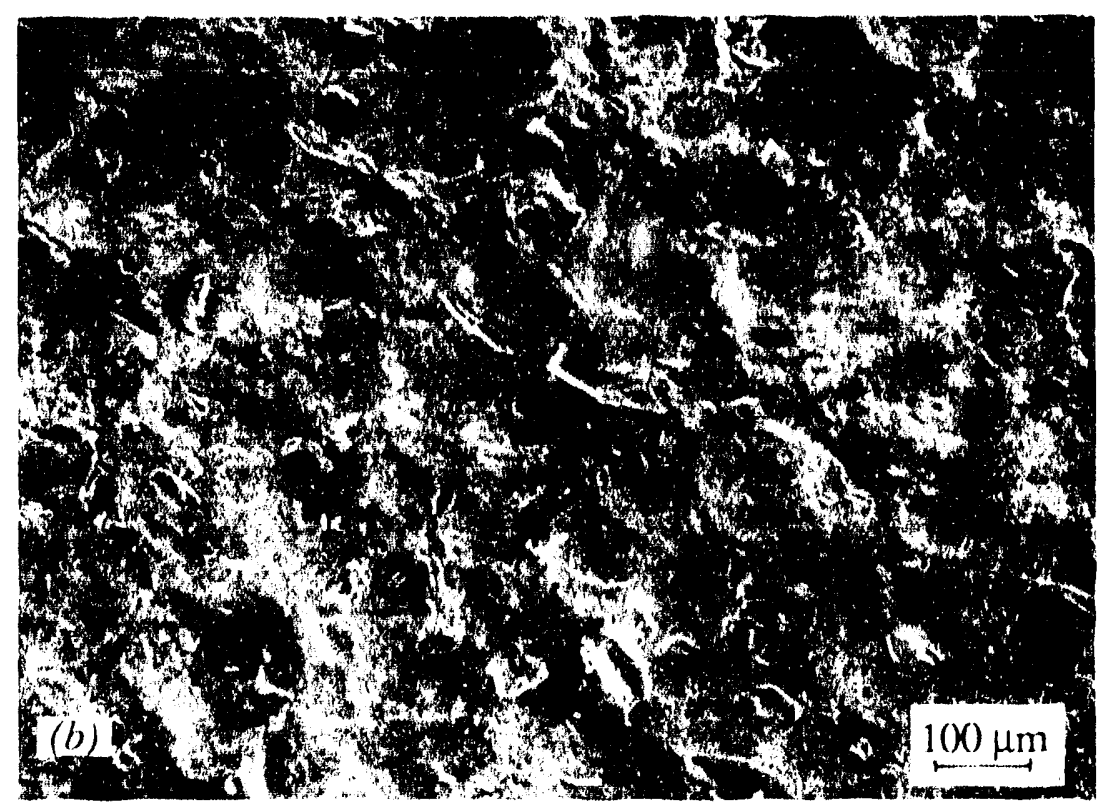

Fig. 42. Details of surfaces of iron-aluminide alloy FA-129 eroded by $11 \mathrm{~g}$ of steel shot at $90^{\circ}$ incidence: (a) single-impact crater showing little plastic deformation within or around the crater and (b) area near center of specimen where individual impacts cannot be identified. 


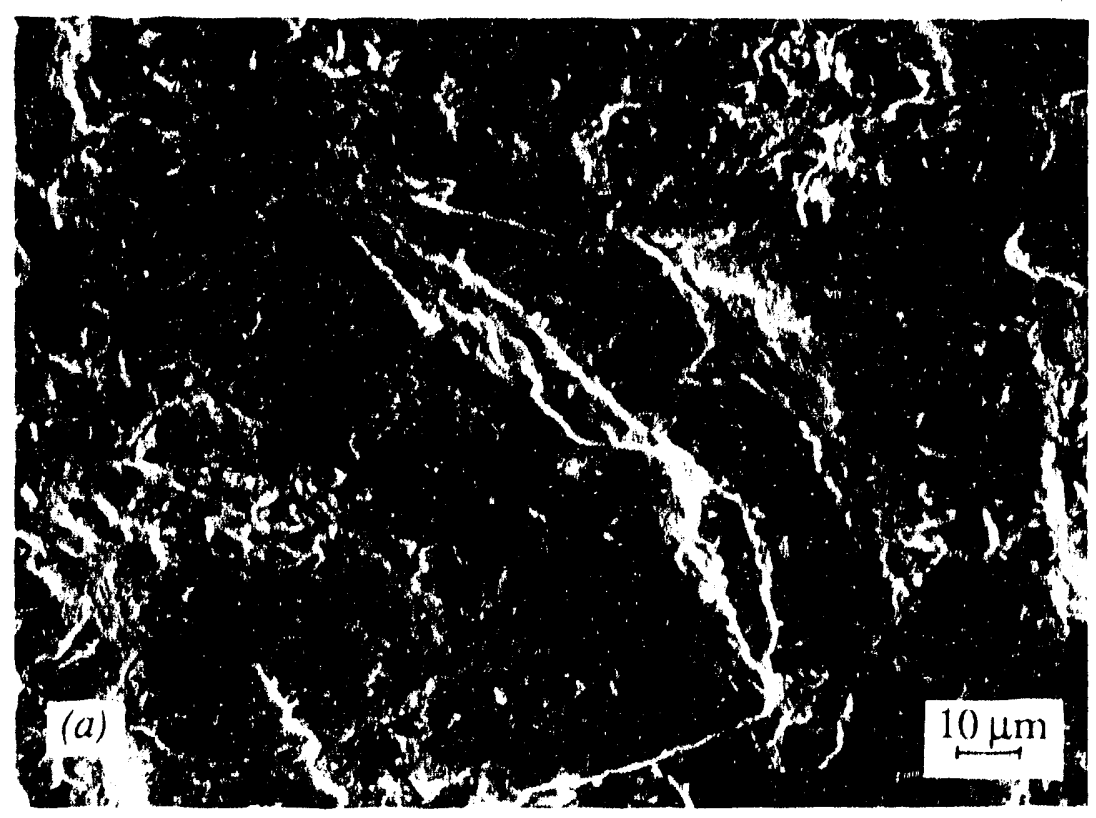

M31716

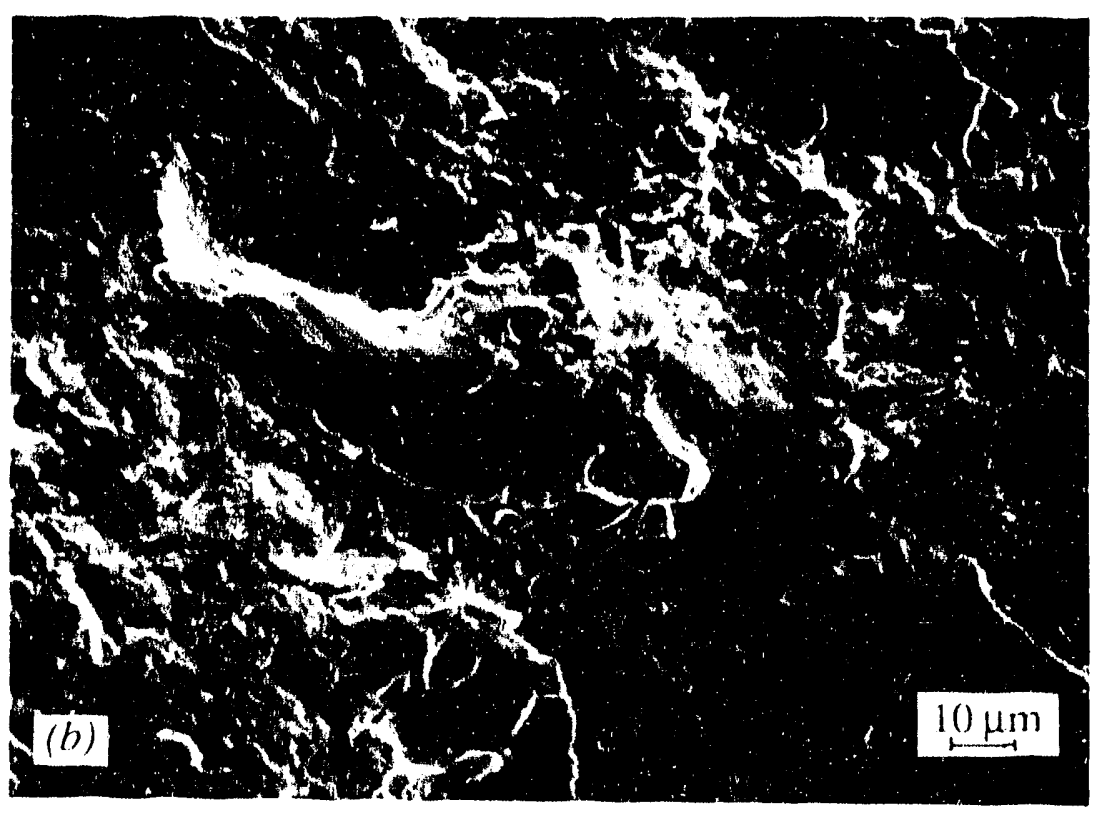

Fig. 43. Details of surfaces of iron-aluminide alloy FA- 129 eroded by $480 \mathrm{~g}$ of steel shot at $90^{\circ}$ incidence showing few extruded platelets and damage mainly by the impact of angular particles. 
upper portion of both micrographs and may have been created by the impacting spherical particles. However, a clear impact crater cannot be identified.

In most past studies of erosion by solid-particle impingement, the impacting particles have been considerably harder than the target material, and it is accepted that erosion efficiencies are relatively unaffected as long as the impacting particles are "much harder" than the target material. 66 Although it is known that erosion rates do not decrease suddenly to zero as the relative hardness of the erodent particles decreases, there is little detailed information on erosion by particles of hardness less than or comparable to that of the target material.

Head et al. 67 measured positive erosion rates on type 302 stainless steel by calcium fluorite particles, which were only $60 \%$ as hard as the steel. A surprising result of their study was that these erosion rates were twice as high as those obtained using similarly sized aluminum-oxide particles, which were $800 \%$ harder than the steel and significantly more angular than the calcium fluorite (which should increase their erosion efficiency). The authors offered no explanation for this anomalous effect. There were no reports on the appearance of the eroded surfaces, and it is possible that significant embedment of the aluminum-oxide abrasive may have occurred on impact, thereby skewing the mass-loss measurements.

Zhu and Mao studied the erosion of several engineering alloys by a wide variety of abrasives that were both harder and softer than the target materials. ${ }^{24}$ The target materials most comparable to that used in the present study were several steels in the hardness range of 206 to $923 \mathrm{HV}$, and they were eroded by particles having hardnesses between 90 to $2500 \mathrm{HV}$. A positive, though relatively low, erosion rate was measured for impacting particles that were significantly softer than the steel being eroded. Micromachining was the predominant material removal mechanism for the relatively hard particles, whereas a slower platelet extrusion and removal process dominated for relatively soft erodents. However, micromachining was also observed for relatively soft particles, which were unusually angular or friable. Heat treatment of the steels had little effect on their erosion resistance when impacted by harder particles. In the case of soft abrasives, erosion resistance of the steels increased as their hardness was increased by heat treatment. The authors postulated that efficient energy transfer to the target by relatively harder particles caused large temperature rises that eliminated heat-treatment effects. In contrast, relatively softer particles transferred much lower amounts of energy to the target causing a small temperature rise, which was not enough to cancel the thermal treatment effects.

The erosion mechanisms observed in the present study are similar to those described by Zhu and Mao for the action of soft abrasives. 24 Both micromachining and platelet extrusion processes were identified in Figs. 38 through 43. Studie: of relatively soft, single-metal 
spheres impacting harder metal substrates have shown that deformation occurs in both the impacting particle and target material, ${ }^{68,69}$ and the craters seen in Fig. 4()(c) for $30^{\circ}$ incident angle and Fig. 42(a) for $90^{\circ}$ incident angle may correspond to such impacts. The craters appear relatively shallow, and there is no evidence of material extrusion or other deformation markings around the crater. The damage pattern seen inside the craters may be impressions of features on the rough surface of the steel shot seen in Fig. 36.

Significant material removal directly due to impacts of spherical shot would be associated only with balls having a hardness higher than that of the work-hardened, near-surface layers. The craters with extruded platelets seen in Fig. 40(b) may be due to such impacts. Unlike the case just described, considerable deformation can be seen around these craters. This can be particularly clearly seen by following the polishing grooves on the surface adjacent to the crater on the left. All the features within the crater also show signs of being extruded along the impact direction. These may again be due to the individual action of macroscopic discontinuities and nodular features seen on the steel shot. The upper crater in the micrograph in Fig. $40(d)$ is a particularly striking example, showing fine extrusions associated with over a dozen such "asperities" acting as individual particles in concert. It may also be noted that most of the features seen on the steel shot are rounded in shape. Correspondingly, little or no micromachining can be seen within the impact craters made by the shot.

For erosion at a $90^{\circ}$ incidence angle, there was no evidence of lips or deformation around the individual impact craters [Fig. 42(a)], implying that the plastic zone associated with each impact does not reach the surface. Unlike oblique impacts, there is no component to the impact velocity tangential to the target surface, and all the impact energy must go into elastic and plastic deformation of the particle and/or the target. Because of the similar hardnesses of the two components, it is reasonable to assume that a significant portion of the impact energy goes into deforming the shot. A small amount of material removal may be associated with the gouges/spalls seen within the craters, as in Fig. 42(a). However, even at the $11-\mathrm{g}$ dose, portions of the specimen were covered with gouges and features more indicative of damage by irregularly shaped particles |Fig. 42(b)|. Platelet formation and removal plays a smaller role for erosion at $90^{\circ}$ incidence compared to $30^{\circ}$ incidence.

The relative lack of platelet formation at 9$)^{\circ}$ incidence may be contributed to the long threshold/incubation period seen in Fig. 37. At least initially, this mechanism would cause more material removal at oblique angles of incidence, and the shallower the angle the greater the amount of material removal. However, the contribution of particle embedment may also be significant at all three incidence angles. Even though no direct evidence of this is available, there can be no other explanation for the initial mass gains seen in all samples. A significant 
number of angular, broken particles were present in the initial erodent mix, and the possibility of scale fracture has also been discussed, as have examples of deep and narrow gouges on target surfaces, which are characteristic of impacts by angular particles. It is reasonable to assume that fragments of particles stayed embedded in several cases. Instances of this would increase as the normal component of the incident velocity increased, leading to the observed differences in the lengths of the threshold periods for the three angles of incidence. Attempts to locate fragments of embedded erodent particles by EDXA were unsuccessful, mainly due to the difficulty in identifying them as such, since both the erodent and alloy have iron as the major chemical constituent.

The above observations led to the issue of erosion mechanisms and the observed angular dependance of the steady-state erosion rates. Most metallic alloys are expected to show "ductile" erosion behavior with erosion rates at a maximum around a $30^{\circ}$ incidence angle as opposed to nominally "brittle" materials, which have highest erosion rates at 90 (') incidence. 1 However, erosion studies on steels (which are close in hardness and ductility to the present iron-aluminide alloy) show mixed results. Depending on the erodent, heat treatments, and test conditions, maximum erosion rates have been observed at values of the incident impact angle covering the range from $3\left(\right.$ ) to $90^{\circ}$ (refs. 22,23,7()-72). For example, Gulden 22 found that steels responded in a "ductile or brittle" manner depending on heat treatment and erodent particle size. Cousens and Hutchings ${ }^{72}$ found that changing the erodent particle shape from angular to rounded caused the erosion response of a mild steel to go from "ductile to brittle." Peterson et al. ${ }^{23}$ found that increasing impingement velocities could cause a shift in the erosion mode toward "brittle" behavior. Results can be further complicated by the use of relatively soft erodent particles. Head et al.67 reported a typical "ductile" response for the erosion of a steel by softer calcium-fluorite particles. However, Zhu and $\mathrm{MaO}^{24}$ observed a transition in the angular response as the hardness of the erodent was decreased below that of various steels that served as target materials. They observed "ductile" behavior as long as the erodent was harcier than the substrate. When softer erodents were used, the maximum in erosion shifted toward $9)^{\circ}$.

In the present study, the steady-state erosion rates were roughly similar at 30 and $60^{\circ}$, and steady-state erosion was not demonstratively reached at $90^{\circ}$ incidence. However, the steep upturn in the final portion of the mass-loss curve in Fig. 37 may indicate that a similar steadystate erosion rate may exist. In any case, the erosion rates at 60 and 9()$^{\circ}$ incidence belie their extended incubation periods. Material loss occurs from platelet extrusion and failure, as well as from the cutting action of angular particles or broken scale fragments. The more efficient cutting action is dominant at higher incidence angles. The amount of fragmentation and thus 
the amount of cutting damage by flying fragments of incident particles also increases at highincidence angles. This serves to keep material removal rates high, compensating for the lack of a platelet-forming mechanism. Finally, the effects of material removal by particle fragments are stronger at later stages of erosion, as the initially flat surface develops a relatively rougher topography, providing a better target for the flying fragments. However, most of the impacting particles are rounded, and the overall number of cutting events may be low. Fracture may be more frequent at higher incidence angles, but angular particles may cause proportionately more damage on hitting the surface obliquely. As seen in Fig. 40, impacts of angular particles at $30^{\circ}$ are more liable to produce debris in the form of a chip or ploughed-up material than an impact at $90^{\circ}$, which creates a deep gouge in the target (Fig. 43). The combination and frequency of these events may serve to provide an overall balance in the erosion rates at the three incident angles.

The aluminide alloy evaluated in the present study was from a family of like alloys that may possess room-temperature tensile ductilities of 15 to $20 \%$, achieved through compositional and thermal treatment control. ${ }^{34}$ However, some iron aluminides have been known to have as little as no measurable room-temperature ductility, ${ }^{34}$ and mechanical properties have been predominantly studied under tensile loading (though one would expect enhanced ductility in compressive or shear modes of loading). In this study, low ductility is indicated by the limited extent to which material was extruded into lips on impact, typically as a small fraction of the impact crater length, as seen in Figs, 40(b) and 41(a). Figure 40(a) shows that a loss of ductility leading to the lip breaking off may occur during the early stages of impact.

Reduced ductility, combined with the high strength of the alloy relative to the impacting shot, may also be responsible for the fact that the eroded surfaces of the iron-aluminide alloys were relatively flat compared to earlier observations on $1100 \mathrm{Al}$ eroded under similar conditions. Figures 38 through 43 show no evidence of the development of a ripple-structure hill or valley topography as erosion progressed. This was especially striking in 3:1 taperedsection samples, which showed very little surface relief, especially for $30^{\circ}$ incidence, indicating that little material movement had occurred over distances corresponding to impacting particle or damage site dimensions. Figure 44(a) shows a micrograph of a tapered section of the specimen eroded at $30^{\circ}$ incidence by an erodent dose of $320 \mathrm{~g}$. Figure $44(b)$ is a tapered section of an annealed $11(x) \mathrm{Al}$ sample eroded under identical conditions in the Notre Dame erosion tester. The characteristic wavy-surface structure is extremely well developed on the soft and ductile aluminum alloy but was not observed on the iron aluminide. A rougher topography developed on the iron-aluminide alloy for 9()$^{\circ}$ incidence, as may be expected from the direct hammering action of impinging particles. However, large-scale deformation or 


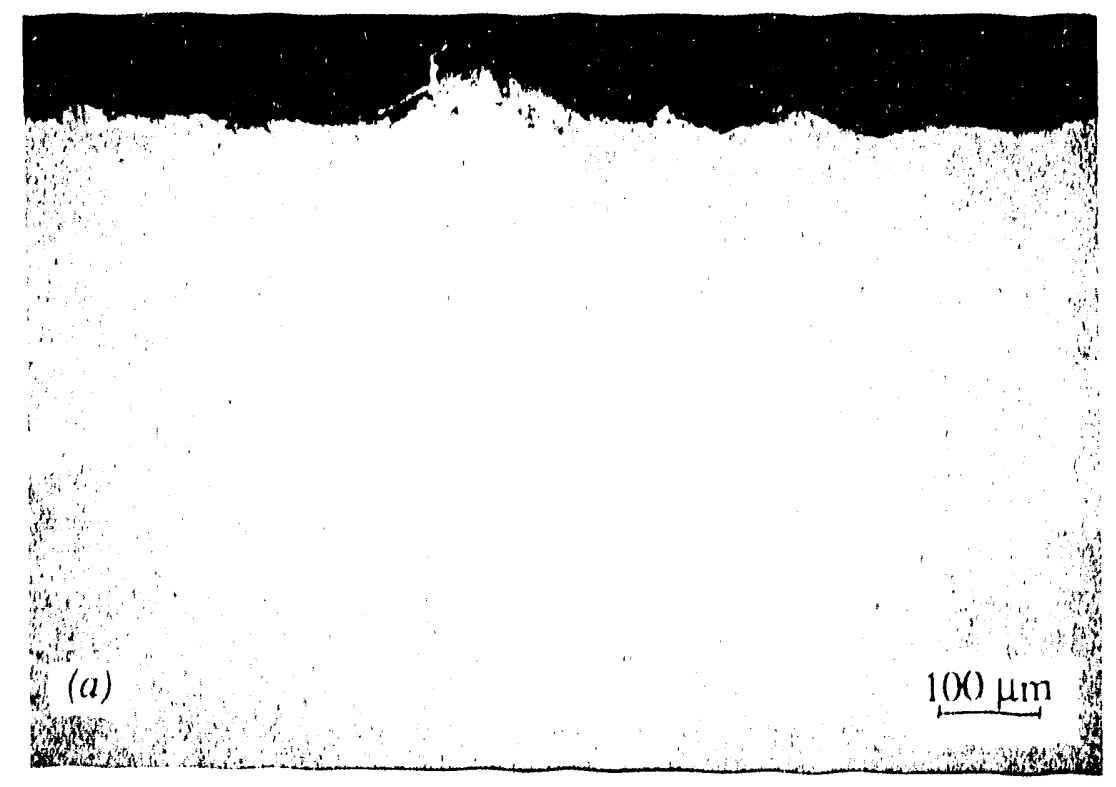

M31219

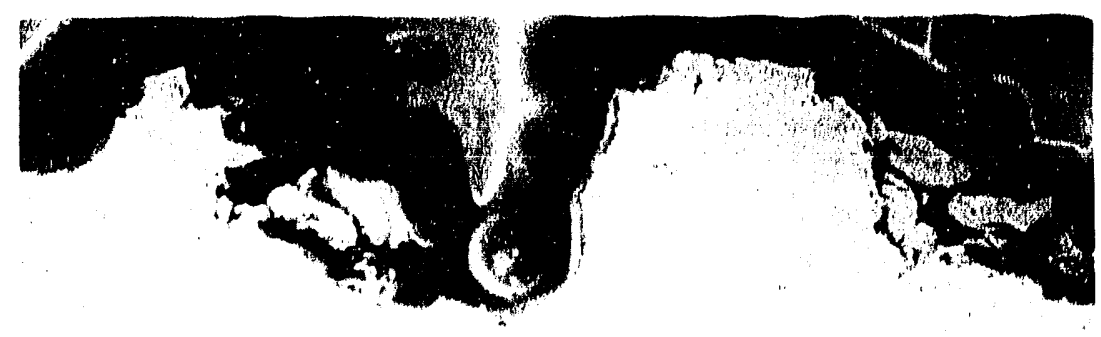

(b)

Fig. 44. Micrographs of 3:1 tapered sections of samples of: (a) iron-aluminide alloy FA-129 and (b) $1100 \mathrm{Al}$ eroded by $320 \mathrm{~g}$ of steel shot at $30^{\circ}$ incidence. 
plastic flow was still not evident. As discussed earlier, the formation of surface ripples apparently involves material movement from wave valleys into wave crests and typically involves distances of the order of particle dimensions. The high ductility of the $11(0) \mathrm{Al}$ makes this easily possible, but such ripples have also been observed on less ductile materials like steels, superalloys, and even ceramics, 57 implying added ductility was induced by the erosion conditions. Thus, it must be concluded that, under the conditions imposed by the erosion test, large amounts of ductility were neither inherent nor induced in the iron-aluminide alloy.

Vickers microhardness measurements on the target samples showed subsurface hardening to levels exceeding the hardness of the hardest balls. Thus, the damage contribution from relatively soft, rounded particles should decrease dramatically, as evidenced by the increase in the proportion of cutting and gouging action at higher doses. Nevertheless, as mentioned before and seen in Figs. 38 and 41, the impacts of rounded particles and associated material extrusion and platelet formation continue to be identifiable at high erodent doses at $30^{\circ}$ incidence, at least to the same extent as instances of damage by angular particles. This suggests that near-surface regions were not as resistant to deformation as the comparison of the Vickers microhardness values suggested. A clearer assessment of the work hardening due to the impacts was obtained by MPM hardness profiles on taper-sectioned eroded samples, similar to the previous studies on $1100 \mathrm{Al}$. Unlike eroded $1100 \mathrm{Al}$, however, profiles cannot be :eported under specific surface features (crests, hills, or valleys) because of the relatively flat surface on the iron aluminides. Figure 45 shows MPM relative hardness profiles from iron-aluminide samples eroded at $30^{\circ}$ incidence at doses of $11,1(0)$, and $320 \mathrm{~g}$. Figure 46 shows profiles from samples eroded at $90^{\circ}$ at doses of 11,100 ), and $480 \mathrm{~g}$. At both angles of incidence, significant work hardening occurred due to impact. The series of profiles from specimens exposed to steadily increasing doses of erodent show that the thickness of the hardened layer beneath the surface increased with erodent dose (as strain built up beneath the eroded surface) and was greater under $90^{\circ}$ impact conditions than for erosion at $30^{\circ}$ (since a greater fraction of the incident energy is transferred to the target at $90^{\circ}$ incidence). The peak value of relative hardness is similar (approximately 1.6) at both angles, indicating that the flow stress due to work hardening tends to increase and then saturate.

The most interesting feature of the MPM profiles is that the hardness drops off in nearsurface regions. This is more evident at higher doses and occurs more extensively at $90^{\circ}$ incidence. At low doses, the near-surface hardness dropoff is barely perceptible at $30^{\circ}$ incidence but is more apparent at $90^{\circ}$ incidence. However, as erodent dose increases, the thickness of the affected layer also increases, and the occurrence of near-surface softening is 

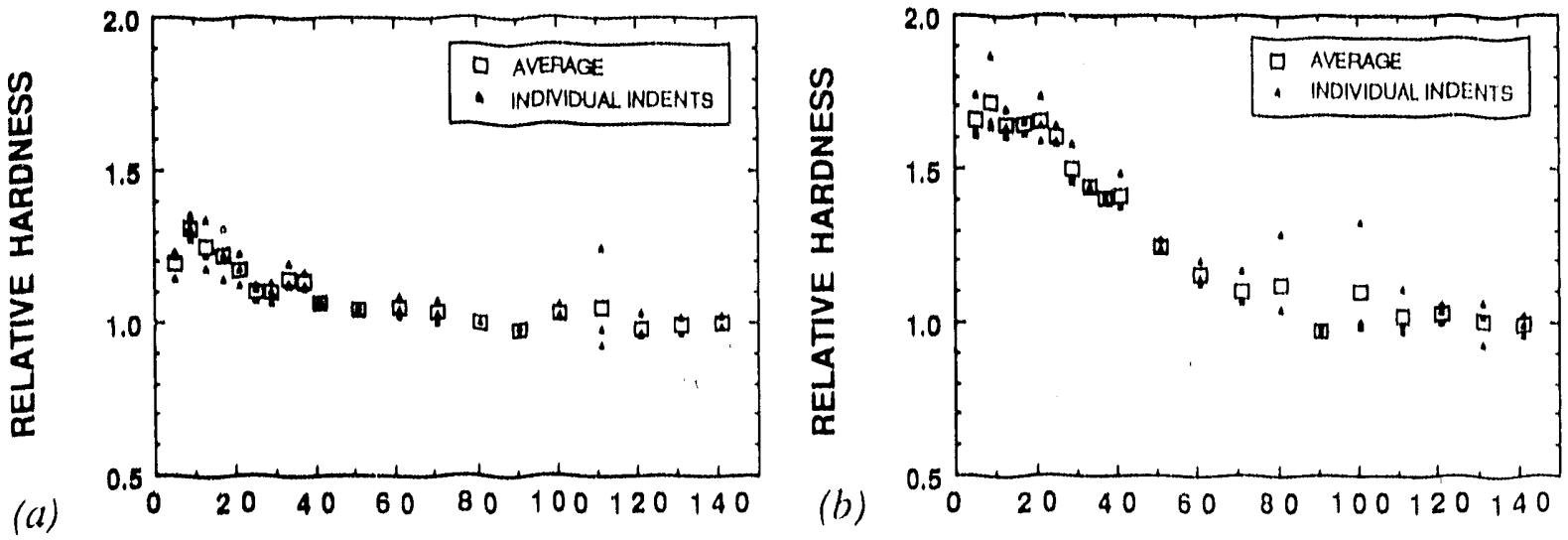

ORNL DWG 92.5077

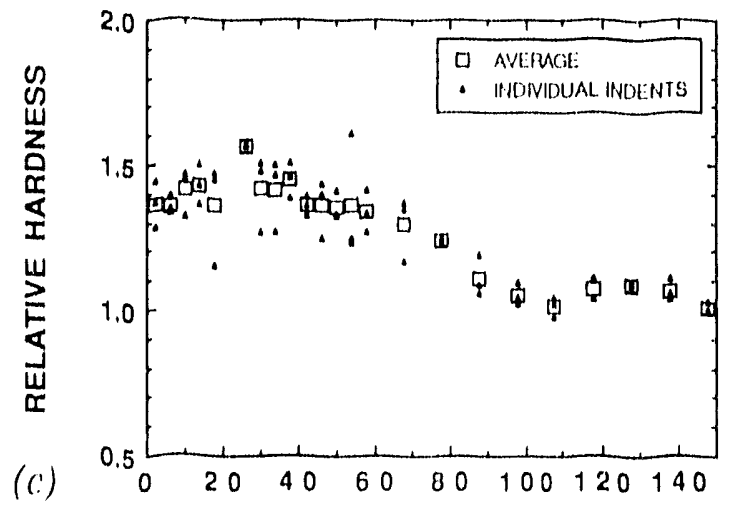

Fig. 45. Relative hardness versus depth below eroded surface for ironaluminide alloy FA-129 eroded with: (a) $11 \mathrm{~g},($ b) $1(0) \mathrm{g}$, and $(c) 320 \mathrm{~g}$ of 297- to 42()$-\mu \mathrm{m}$-diam steel shot at $45 \mathrm{~m} / \mathrm{s}, 30^{\circ}$ incidence. Distance from surface is in $\mu \mathrm{m}$. 
ORNL DWO 92-5078

ORNL DWG $92-5079$
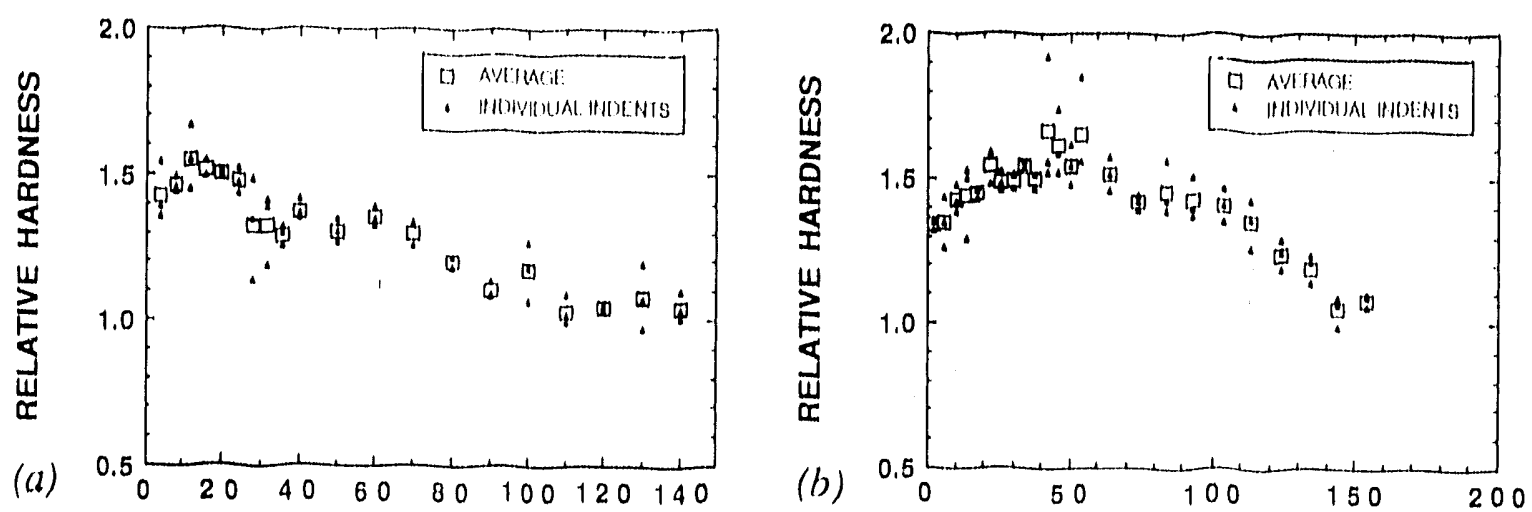

ORNL DWG 92-5080

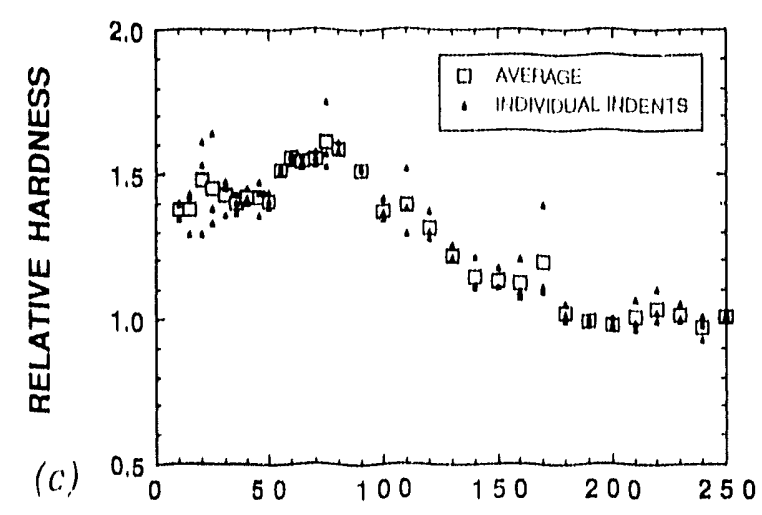

Fig. 46. Relative hardness versus depth below eroded surface for ironaluminide alloy FA-129 eroded with: (a) $11 \mathrm{~g}$, (b) $100 \mathrm{~g}$, and (c) $480 \mathrm{~g}$ of 297-to 42()- $\mu \mathrm{m}$-diam steel shot at $45 \mathrm{~m} / \mathrm{s}, 90^{\circ}$ incidence. Distance from surface is in $\mu \mathrm{m}$. 
more apparent at both angles of incidence. In Figs, 4.5(c) and 46(c), although the depth of softening is greater at $90^{\circ}$ incidence, the neur-surface hardness drops off ubout $20 \%$ at both incidence angles. However, the extent of the hardness dropoff was not the same at all locations. Figure 47 shows MPM profiles from different locations on the same specimens as in Figs, 45(c) and 46(c). The near-surface hardness drops off almost to the bulk value in both cases. There were no visible differences between the locations, and grain-to-grain hardness differences can be discounted since the hardness dropoff extends over several grains. Note, however, that the peak hardness values and the thickness of the affected layers in Fig. 47 are the same as in Figs. 45(c) and 46(c).

ORNL DWG $92-5081$

ORNL DWG 92.5082
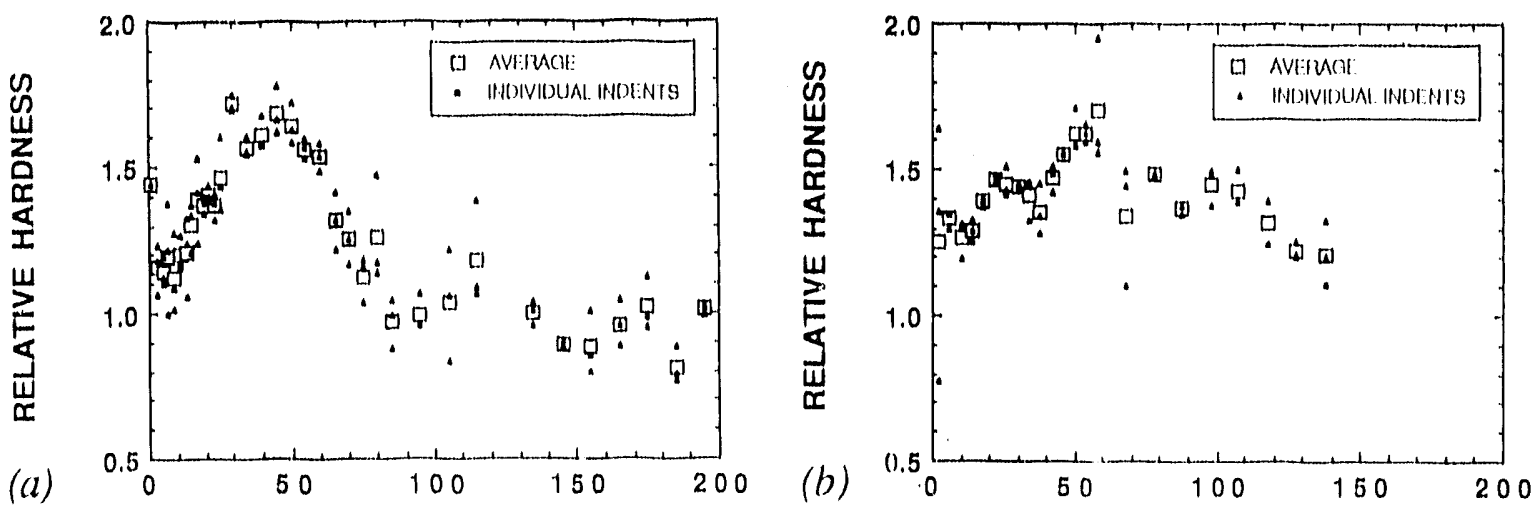

Fig. 47. Relative hardness versus depth below eroded surface for ironaluminide alloy FA-129 eroded with 297 - to 42()$-\mu \mathrm{m}$-diam steel shot at $45 \mathrm{~m} / \mathrm{s}$, showing greater near-surface softening than observed in Figs. 45 and 46:

(a) $30^{\circ}$ incidence, 32()$-\mathrm{g}$ dose, and $(b) 90^{\circ}$ incidence, 480-g dose. Distance from surface is in $\mu \mathrm{m}$.

The near-surface hardness dropoff observed in the iron-aluminide alloy is in clear contrast to the previously described observations on eroded $11(0) \mathrm{Al}$, in which case the hardness decreased monotonically from a maximum value at the surface. The tendency for greater softening in the iron-aluminide alloy compared to $110(0 \mathrm{Al}$ was also seen in the single-particle impact studies. The dropoff in near-surface hardness explains the significant deformation observable due to impacts by spherical particles at high erodent doses, since the Vickers microhardness measurements had indicated that the aluminide work hardened to levels greater than the hardest particles. As suggested in the single-particle impact studies, the softening behavior could be due to thermal effects, which are strongly influenced by the significantly different mechanical properties of the two alloys. 
If, indeed, the hariness dropoff in FA-129 is thermally activated, the effect of a temperature rise of several hundred degrees Celsius on erosion should be considered in light of the alloy's unique elevated-temperature properties. The erosion resistance of iron aluminides and similar ordered intermetallic alloys is largely unknown, since these alloys were not developed with erosion resistance as a goal. Wright and Mikkola 73 observed that ordered $\mathrm{Cu}_{3} \mathrm{Au}$ had superiog room-temperature cavitation erosion resistance compared to disordered $\mathrm{Cu}_{3} \mathrm{Au}$. Marquardt et al. ${ }^{74}$ studied ordered alloys based on the (Fe, $\left.\mathrm{Co}, \mathrm{Ni}\right)_{3} \mathrm{~V}$ system and found their room-temperature erosion behavior to be similar to type 316 stainless steel. More recently, Johnson et al. 75 studied the room-temperature cavitation erosion and abrasion resistance of nickel and iron aluminides and found them to be superior to many commercial erosion- and abrasion-resistant alloys. They attributed the good abrasion resistance of iron aluminides to a temperature increase during testing and their related, excellent elevatedtemperature strength, which dominated during the abrasion process. However, such an argument needs to be analyzed carefully. Iron-aluminide alloys show a peak in yield stress around $600^{\circ} \mathrm{C}$, which may be higher than the room-temperature value. ${ }^{34}$ However, examination of the flow curves shows that little work hardening occurs on further deformation at these temperature, ${ }^{34}$ so that even after moderate strains, the flow stress at elevated temperatures may actually be lower than at corresponding strains at lower temperatures. Near-surface regions are highly strained after abrasion or erosion (as was visually seen in Figs. 30 and 31 for eroded $1100 \mathrm{Al}$ ), and it may not be appropriate to characterize this state using the elevated-temperature yield behavior of the alloy without considering the rest of the flow curve. On the other hand, it may well be that even with lack of work hardening (or even work softening) at elevated temperatures, iron-aluminide alloys retain their strength advantage over other erosion- or abrasion-resistant alloys, thus providing greater wear resistance.

The near-surface softening effects observed in this study may not be thermally activated. MPM measurements were made after erosion at room temperature, and the lower hardness numbers indicate a lower resistance to indenter penetration, implying that the deformation in the nedr-surface layers was relieved prior to the measurements. This may well have been caused by thermal annealing of dislocation arrangements. However, possibilities of a disordered surface layer (giving a dislocation arrangement less resistar: io deformation) and near-surface residual stresses (which may act with or against indenter penetration) must also be considered. These issues are discussed in the next section in context of the overall results of the single-and multiple-impact studies.

The overall erosion resistance of alloy FA-129 is difficuit to gauge from this study. As mentioned earlier, several samples of anneal.d $11(k)$ A ${ }^{1}$ were also eroded along with the 
aluminides. Even though significant particle embedment occurred in the softer aluminum alloy (see Fig. 11), the erosion rate at $30^{\circ}$ incidence wris four times that measured on the iron aluminide. In Zhu and Mao's study, 24 the erosion rates for various steels eroded at $65 \mathrm{~m} / \mathrm{s}$ ranged from 0.04 to $0.5 \mathrm{mg} / \mathrm{g}$ for abrasive/steel hardness ratios varying from around 0.3 to 1.2. These erosion rates are significantly higher than those encountered in the present study. There may be several reasons for this, including the higher velocities in Zhu and Mao's work, the pronounced angularity of their particles, and the fact that the two test systems are quite different. Another study on a white, cast iron yielded erosion rates of around $0.02 \mathrm{mg} / \mathrm{g}$ using rounder quartz abrasive and around $0.065 \mathrm{mg} / \mathrm{g}$ using crushed (angular) quartz abrasive at both 30 and $90^{\circ}$ incidence. 76 The particle size range and velocity were comparable to the present study. The quartz was significantly softer than the $9.5 \%$ by volume of hard carbides present in the cast iron but harder than the remaining matrix of the white iron. These results indicate that the erosion resistance of iron aluminides may be comparable to, if not better than, that of materials they may replace. In the present study, none of the eroded aluminides displayed cracks or delaminations suggesting catastrophic failure of the material. Thus, the material had enough ductility to accommodate some amount of plastic strain. However, the limited extent of extrusion of lips and flakes suggests that erosion resistance would be improved if ductility could be further enhanced without sacrificing strength. Nevertheless, this study suggests that iron aluminides may find successful applications in situations requiring erosion resistance.

\section{SURFACE AND NEAR-SURFACE EFFECTS DUE TO PARTICLE IMPACTS}

The results presented in the previous sections summarized several studies, and each of these studies were analyzed independently. In the following sections, several aspects of material deformation and removal are discussed while an attempt is made to relate the results of the various experimental studies conducted during the course of the program. The discussion revolves around changes in the near-surface layers of the target, since this is the material most influenced by the impacts and closest to removal if erosion had continued.

\subsection{DEVELOFMENT OF SURFACE TOPOGRAPHY}

In the multi-particle erosion studies, surfaces of 110() $\mathrm{Al}$ developed distinctive ripples or hiiis and valieys, dependung on the angie of incidence of the credenti particles, whereas the 
surfaces of the iron-alurinide alloy remained relatively flat at all impingement angles. As discussed earlier, the development of the surface topography has been the subject of considerable research, but there is no satisfactory model of how the ripples or hill-and-valley topography develop in the first place.

Stringer and Wright 57 have recently suggested that the hill-and-valley morphology developed at $90^{\circ}$ incidence is a special case of the ripple patterns that develops at oblique incidence. They concluded that the observed surface topographies represented an intrinsic equilibrium state of the surface under conditions of erosion and that all surfaces would develop such features unless prevented by factors such as insufficient energy input or a high resistance to flow in the material. The instability inherent in maintaining a planar eroding surface was considered similar to that existing in the common boundary between two immiscible fluids when there is a net momentum acting parallel to the boundary.

The fact that ripples and hills and valleys developed on $1100 \mathrm{Al}$ samples tested in the Notre Dame rotating-arm machine makes it difficult to validate such an argument. Unlike typical gas-jet erosion systems, a rotating-arm-type tester does not use pressurized gas to accelerate the particles, and the entire arm assembly and samples are contained in an evacuated chamber. Thus, there is no continuous stream of high-pressure gas impinging on the surface along with the erodent. In addition, since the erodent is shot out tangentially from the opposite ends of a whirling arm, particles hit the sample intermittently. For the conditions used in the present study, it was estimated that approximately $10^{-2} \mathrm{~s}$ elapses before the arm rotates $180^{\circ}$ to deliver the next pulse of particles. Combining this with the time of test, the estimated erodent dose, the estimated size of the contact zone per impact, and the exposed specimen area, it was estimated that only $0.3 \%$ of the specimen area was covered by impacting particles per second. This translates to an average of several minutes before overlapping impacts may be expected in the same location. Hutchings 77 has estimated particle-sample contact times of around $10^{-6} \mathrm{~s}$ for 50()- $\mu \mathrm{m}$-diam particles. Therefore, for the experimental conditions used in our study, an area of the sample experiences large periods of rest between impacts relative to the contact time, and the dynamic conditions existing during one set of impacts do not persist until the next set of impacts. Therefore, a fluid mechanics approach, treating the stream of erodent particles impinging on a sample as a continuum, probably is not valid. The rotating-arm system cannot be treated as a special case either, since 110() $\mathrm{Al}$ samples, which were eroded in the tester at $30^{\circ}$ incidence, developed surface ripples very similar to those on samples eroded using a conventional gas-jet machine at Lawrence Berkeley Laboratory. This suggests that the observed topography develops purely from the interaction between individual particle impacts and deformation characteristics of the material. 
Stringer and Wright 57 also point out that since wave crests and valleys represent an equilibrium structure, there should be no correlation between erodent particle size and wavelengths of the ripple structure developed at oblique incidence. This argument should also be valid for the hill-and-valley topography seen for $90^{\circ}$ incidence. However, Brown et al.64 have tabulated literature observations until 1983 and shown that a good correlation exists between particle sizes and observed spacings of hills and valleys developed at $90^{\circ}$ incidence. Addition of data from later studies (including the present) shows some deviations, but a general increase in hill spacing with particle size is still observed. The correlation is fairly good considering that the data included several target materials, as well as erodents of different shapes impinging at various velocities. In addition, correlation between ripple wavelengths and particle sizes 53 or impact crater sizes 54 has been reported for erosion under oblique incidence.

Comparison of results from several studies of Brown et al.55,64,78 conducted under $90^{\circ}$ incidence conditions indicates that target material properties may have an effect on the topography developed. For $70-\mu \mathrm{m} \mathrm{SiO}_{2}$ spheres impinging at $122 \mathrm{~m} / \mathrm{s}$, hilltop spacings of $135 \mu \mathrm{m}$ were observed on $\mathrm{Al}$ (ref. 64) compared to 70 to $100 \mu \mathrm{m}$ for $\mathrm{Cu}$ and $\mathrm{Fe}$ (ref. 78). For $210-\mu \mathrm{m} \mathrm{SiO}_{2}$ spheres at $122 \mathrm{~m} / \mathrm{s}$, the spacings were $434 \mu \mathrm{m}$ for $\mathrm{Al}$ (ref. 64) and 200 to $300 \mu \mathrm{m}$ for Fe (ref. 55). The softer, more deformable material seemed to develop a more prominent topography. In our study on erosion of the iron-aluminide alloy, eroded surfaces were relatively featureless at all incidence angles, and a hill-and-valley topography or a ripple structure did not develop as on the $1100 \mathrm{Al}$ samples. Carter et al.53 reported ripples form ing on obliquely eroded lead, aluminum, copper, and mild steel but not on tungsten. These results suggest, as discussed earlier, that strength and ductility effects play an important role in developing the topography on eroded surfaces, and the characteristics of that structure may depend primarily on the mechanical properties and deformation characteristics of the target material.

Our observations on material movement and hardening observed under single- and multiple-particle impacts at 30 and $90^{\circ}$ incidence support views of the development of ripple or hills and valleys based on plastic deformation considerations, wherein the topography develops from interactions based on particle size and material deformation characteristics. These models describe the initial development of the structure either due to preferential material removal from initially depressed regions (crater bottons) 54 or preferential movement of material from depressed regions into extruded ridges, 53 the final ripple structure developing as the growing ridges interlock. However, there is no consideration of the development of hill-and-valley structures under $90^{\circ}$ incidence, and, in fact, the model of Carter et al.53 specifically predicts no 
development of a structure at $90^{\circ}$ incidence since it incorporates a component of forwarddirected material flow. The basic idea of differential plastic deformation may be used to predict both the formation of ripple and hill-and-valley structures. Incipient crests or hills may form in specific areas due to local instabilities such as higher-than-average number of local impacts. As discussed in the previous sections, incipient crests will form under oblique impacts as hardened material is pushed forward by the impacting particles, and incipient hills form for 9$)^{\circ}$ impacts due to back-extrusion processes associated with a locally high concentration of impacts, as well as preferential trosion from areas in which particle embedment initially occurs. These elevated areas will persist, once formed, due to relative hardness effects, namely that succeeding impacts will deform these hardened areas less than neighboring areas, leading to further relative growth. The rest of the topography will then develop as the elevated areas mechanically interlock. The size of these features would depend on the spatial range of plastic deformation associated with an individual impact - i.e., proportional to the impacting particle size, as described above. The spacing of the features should also increase with velocity, since the extent of deformation may be expected to increase. However, there are little data in the literature to confirm this.

The development of ripples or hills and valleys may be expected to influence material removal processes. From one point of view, a larger surface area and wider range of impact angles would be presented to the erodent particles, and, hence, these features should be associated with accelerated erosion rates. 57 However, a reverse argument may also be presented suggesting that development of the surface features increases erosion resistance. The MPM hardnes's profiles at various doses showed that material deformation and movement involved during the development of these features accommodated the energy from impinging particles, thus helping delay material loss. Therefore, within the same family of alloys, the alloy that develops a rippled surface would show the longest incubation periods. In addition, since a large part of the energy from each impact is used to push material into the substrate leading to the observed pattern of material movement from low-lying to elevated regions, steady-state erosion rates would also be lower. The increased amounts of surface exposure may not necessarily be associated with more material removal, since in many cases, and especially at glancing incidence, elevated regions may actually shield neighboring areas from impact. Therefore, the existence of ripples does not signify high erosion rates, per se. Rather, alloys that exhibit such features prominently would typically be those with low-flow stresses and, thus, low erosion resistance compared to high-strength alloys. 


\subsection{EFFECT OF INCIDENCE ANGLE ON NEAR-SURFACE HARDENING}

Table 2 summarizes the results of MPM measurements beneath single-particle impact oraters, including data not presented earlier in this report. Table 3 is a similar summary of results from multiple-particle erosion tests. MPM measurements beneath single-particle impact craters illustrate that the extent of hardening is greater under $90^{\circ}$ impacts than under $30^{\circ}$ impacts (Figs. 2 and 6 and Table 2), since a larger fraction of the incident energy is directed into the target material. However, since erosion rates were higher at $30^{\circ}$ incidence, especially for $1100 \mathrm{Al}$, larger volumes of deformed material do not directly equate to faster material removal under subsequent impacts. Rather, it is the state of stress in the deformed material that appears to control its final removal. The experimental results support the view that final material failure occurs as material in the near-surface layers is strained beyond its fracture limit by a combination of tensile and shear components of the impact forces. Material directly under a single $90^{\circ}$ impact is in compression, whereas material in front of a single $30^{\circ}$ impact is subjected to a large component of shear and, thus, would be closer to tensile failure. Examination of high-velocity $30^{\circ}$ impacts (Fig. 12) shows that more energy is dissipated by work-hardening material in front of the impacting ball along the particle's initial trajectory than in hardening material directly below the impact crater in a direction perpendicular to the original surface. For $90^{\circ}$ impacts, there are no direct shear forces pushing weakened material up to the surface where it can be removed. These effects would be magnified under cumulative impacts where there would be a potential for heavily deformed or softened material to be moved parallel to the surface or even up to the surface due to overlapping strain fields of neighboring impacts. However, for impacts at oblique incidence, there is a strong component of shear parallel to the target surface, which leads to lip and chip formation. Since most of the deformation occurs in front of the impacting particle, the material being pushed up ahead of the particle in the form of a lip would be most heavily strained.

The fundamentally different strain fields under single-particle impacts at 30 and 9()$^{\circ}$ incidence provide an indication of the different topographies that develop on the surfaces under multiple-particle impact conditions. The MPM profiles on multi-particle-eroded $11(0) \mathrm{Al}$ showed several similarities between samples eroded at 3() and 9()$^{\circ}$ incidence. In both cases, there was a monotonic decrease in hardness from a maximum value at the eroded surface. The data from specimens subjected to low erodent doses showed that the hardness increased slowly and that the maximum value developed over many impacts. Parts of the specimens achieved the maximum hardness, even though the characteristic surface structures had not completely developed. However, the MPM profiles also showed a major difference between $11(0) \mathrm{Al}$ 
Table 2. Summary of MPM drta from single-particle impact studies

\begin{tabular}{|c|c|c|c|c|c|c|}
\hline Target material & $\begin{array}{l}\text { Sample } \\
\text { number }\end{array}$ & $\begin{array}{c}\text { Impact } \\
\text { angle } \\
\left({ }^{\circ}\right)\end{array}$ & $\begin{array}{l}\text { Velocity } \\
(\mathrm{m} / \mathrm{s})\end{array}$ & $\begin{array}{c}\text { Hardening } \\
\text { depth } \\
(\mu \mathrm{m})\end{array}$ & $\begin{array}{c}\text { Near- } \\
\text { surface } \\
\text { softening } \\
\text { depth }(\mu \mathrm{m})\end{array}$ & $\begin{array}{l}\text { Maximum } \\
\text { relative } \\
\text { hardness } \\
\text { (bulk }=1 \text { ) }\end{array}$ \\
\hline $6061-\mathrm{T} 6 \mathrm{Al}$ & $\ldots a$ & 30 & 28.5 & 70 & -- & 1.2 \\
\hline $7075-\mathrm{T} 6 \mathrm{Al}$ & $\ldots a$ & 30 & 28.5 & 40 & -- & 1.15 \\
\hline Ann. $1100 \mathrm{Al}$ & $\ldots a$ & 30 & 28.5 & 100 & - & 1.1 \\
\hline$"$ & $11 A^{b}$ & 30 & 280 & 300 & 50 & 1.6 \\
\hline$"$ & $11 \mathrm{~A}^{a}$ & 30 & 280 & 200 & -- & 1.5 \\
\hline$"$ & $20 \mathrm{~A}^{b}$ & 30 & 740 & 360 & 50 & 1.5 \\
\hline$"$ & $20 \mathrm{~A}^{a}$ & 30 & 740 & 100 & $c$ & 1.4 \\
\hline$"$ & $18 \mathrm{~A}$ & 90 & 58 & 280 & $45^{d}$ & 1.5 \\
\hline$"$ & $5 \mathrm{~A}$ & 90 & 894 & 500 & 150 & 1.5 \\
\hline $\begin{array}{c}1100 \mathrm{Al}, 50 \% \text { cold } \\
\text { work }\end{array}$ & $--a$ & 30 & 28.5 & 115 & -- & 1.3 \\
\hline$"$ & $23 A^{b}$ & 30 & 625 & 100 & -- & 1.2 \\
\hline$"$ & $23 \mathrm{~A}^{a}$ & 30) & 625 & 50 & - & 1.15 \\
\hline$"$ & $28 \mathrm{~A}$ & 90 & 59 & 225 & $c$ & 1.7 \\
\hline Ordered FA-129 & $18 \mathrm{~F}^{a}$ & 30 & 45 & 120 & -- & 1.6 \\
\hline$"$ & $7 \mathrm{~F}^{b}$ & 30 & 470 & 425 & $20^{e}$ & 1.6 \\
\hline$"$ & $17 \mathrm{~F}$ & 90 & 59 & 240 & -- & 1.65 \\
\hline$"$ & $1 \mathrm{~F}$ & 90 & 357 & 400 & 125 & 1.6 \\
\hline$"$ & $4 \mathrm{~F}$ & 90 & 794 & 60() & 175 & 1.7 \\
\hline $\begin{array}{c}\text { FA-129, } 5 \% \text { cold } \\
\text { work }\end{array}$ & $30 \mathrm{~F}$ & 90 & 58 & 200 & 75 & 1.65 \\
\hline $\begin{array}{l}\text { Eroded-corroded } \\
2.25 \mathrm{Cr} 1 \mathrm{Mo} \text { steel }\end{array}$ & 65()$-10$ & 90 & 50 & 170 & 50 & 1.75 \\
\hline
\end{tabular}

${ }^{a}$ MPM profile along direction of impact. See Fig. 12.

${ }^{b}$ MPM profile vertically beneath impact crater. See Fig. 12.

cNear-surface trends difficult to estimate because of scatter in data.

$d$ No softening but constant near-surface hardness to depth of $45 \mu \mathrm{m}$.

eSoftening measured only in one row of indentations closest to surface. 


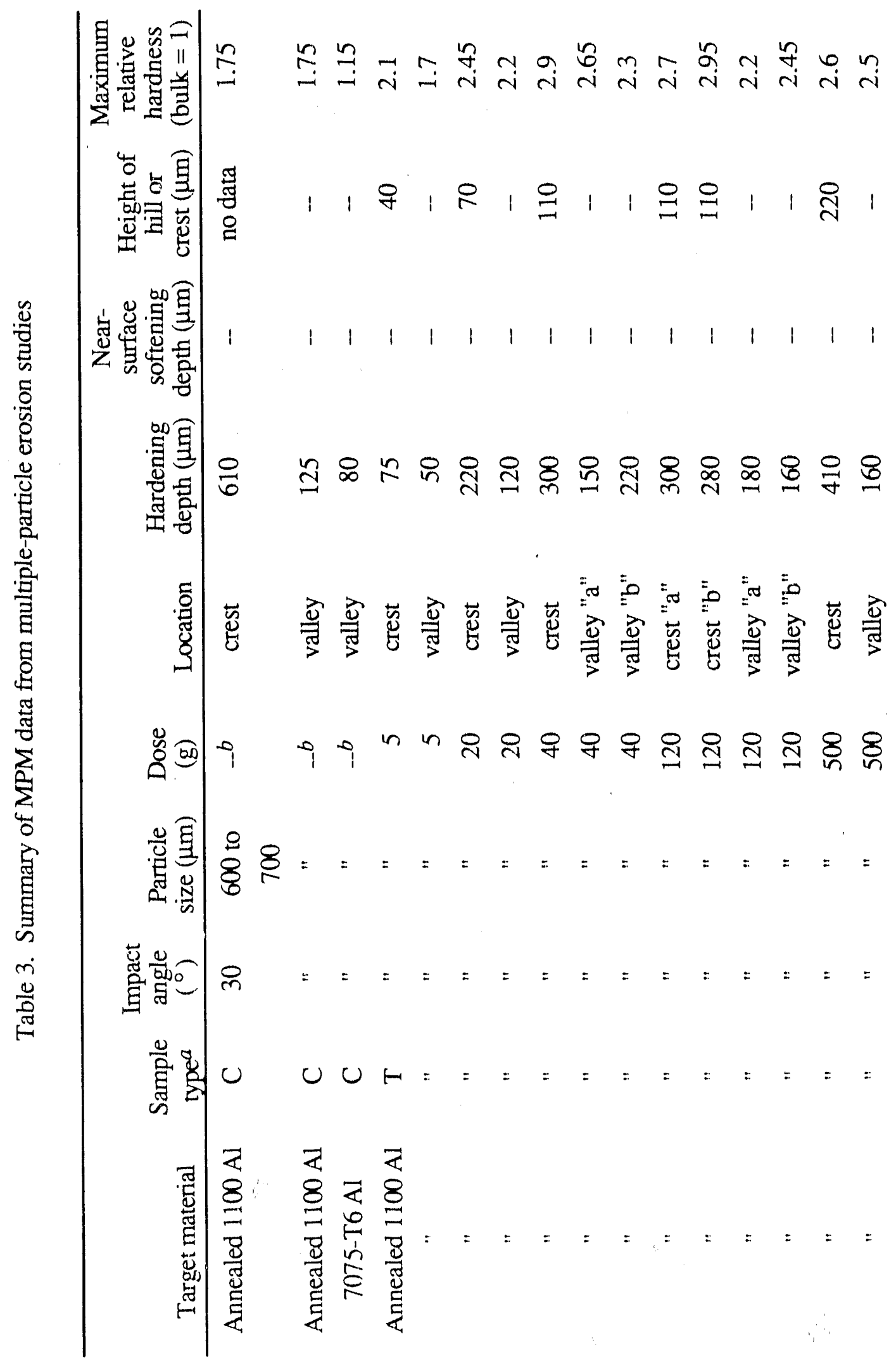




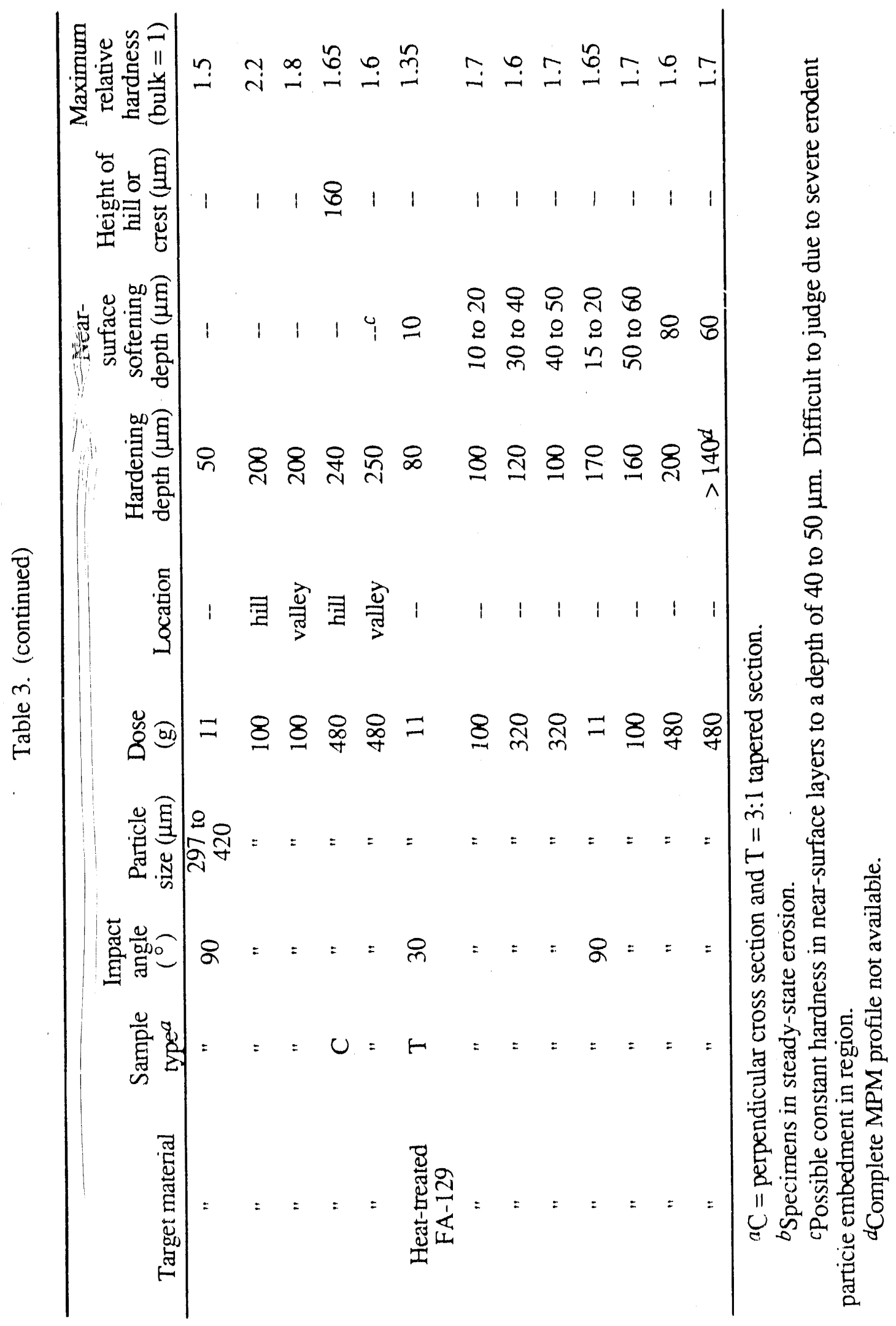


specimens eroded at 30 and $90^{\circ}$ incidence. Under conditions of oblique incidence, more material was hardenec' under a hill than under a valley, with excess hardening under wave crests over a distance roughly equal to the height of the crests (Figs. 17 through 21). It was visualized that this was due to material being pushed forward into the wave crests from the wave valleys. As seen in the single-impact studies, more deformation occurs in front of the obliquely impacting particle than beneath it. Therefore, a large component of the impacting force parallel to the surface pushes work-hardened material ahead, eventually forming wave crests. This mechanism necessitates that the crests be comprised fully of work-hardened material, as observed.

For samples eroded at $90^{\circ}$ incidence, the amount of hardening under hills and valleys was roughly equal (Figs. 33 and 34 and Table 3), and the distances over which the hardness falls off to the bulk value match well with the visually observed distortion (Fig. 31). Hardening under hills extends to depths greater than the height of the hills but not to the extent, as under oblique impacts, where wave crests were hardened over distances equal to the height of the crest plus the hardening depth beneath a valley. The latter was due to the material movement from valleys to crests. Transfer of material from valley regions to hills also occurs at $90^{\circ}$ incidence, as seen in Fig. 31. However, unlike at oblique incidence, the deformation contours indicate that this occurs over a skin of uniform thickness covering the hills and valleys. Under a $90^{\circ}$ impact, significant stress in a radial direction parallel to the target surface is confined to a relatively shallow depth beneath the impact crater. This is seen in Fig. 31, where the near-surface deformation contours are roughly parallel to the local surface. The component of the force leading to back extrusion of material from valleys into the hills is evidently too small to deform or move material directly under the hills. As observed for single $90^{\circ}$ impacts, work hardening will mainly occur directly under the impacting particle.

Therefore, the hardening depth will be similar at any impact location and will correspond to the distance over which a single impact may harden the material. As Tables 2 and 3 show, the hardening depth is about $250 \mu \mathrm{m}$ for 1100 Al eroded by $480 \mathrm{~g}$ of 297 - to $420-\mu \mathrm{m}$-diam steel shot at $90^{\circ}, 45 \mathrm{~m} / \mathrm{s}$, and $280 \mu \mathrm{m}$ for a single impact of a $343-\mu \mathrm{m}-$ diam WC ball at $90^{\circ}, 58 \mathrm{~m} / \mathrm{s}$. The single-impact depth has to be corrected downward to allow for the higher density of the WC ball and the slightly higher velocity.

It must be noted that all the $11(0) \mathrm{Al}$ samples eroded at 9()$^{\circ}$ were still in the threshold/incubation period of erosion. It may well be that the hill-and-valley structure would grow further as steady-state erosion was approached and that the hardness distributions may change as a result. However, it was observed during the study of $11(0) \mathrm{Al}$ eroded at $30^{\circ}$ incidence that the steady-state hardness distribution was reached well within the incubation 
period (Fig. 22), and it would be reasonable to expect similar saturation behavior for $9)^{\circ}$ incidence.

The distinctly different hardness distributions beneath wave crests formed at 3()$^{\circ}$ incidence and hills formed at $90^{\circ}$ incidence on 1100) Al led to the question of possible effects on erosion mechanisms. Although no erosion debris was directly examined, the micrographs of eroded surfaces presented in this report indicate that debris flakes are typically several microns (extruded flakes) to tens of microns (lips on wave crests) thick and, therefore, much thinner than the shallowest work-hardened layer measured in eroded specimens at either angle of incidence (Table 3). Hardened regions at relatively large depths would therefore not be expected to be directly involved in the material removal process. These regions will affect deformation by later impacts, but the range of influence will be restricted to the deformation depth associated with a single-particle impact. Therefore, it is doubtful if the excess hardened material beneath wave crests formed at $30^{\circ}$ incidence has a direct bearing on the erosion process, since it is essentially a sink for material pushed ahead from the valleys. The shape of the wave crests may, of course, influence the erosion process as discussed in the previous section.

As summarized in Table 3, there were indications that near-surface areas under valleys in $1100 \mathrm{Al}$ were somewhat softer than under elevated regions, at both 30 and $90^{\circ}$ incidence. This observation was not consistent at $30^{\circ}$ incidence, and the results at $90^{\circ}$ incidence may have been influenced by the presence of embedded erodent fr. igments and associated voids and fissures. The lower hardness in the observed cases may be due to preferential material movement/removal from valley regions during the incubation period as the ripple structure or hill-and-valley structure develops. A single impact may move a significant amount of workhardened material, as evidenced in the single-particle impact studies on $50 \%$ cold-worked $1100) \mathrm{Al}$ [Fig. 4(a)]. As seen in Figs. 17 through 22 and Table 3, the hardness differential exists until the steady state (although, as mentioned earlier, similar hardnesses were occasionally measureci in crest and valley near-surface regions in the lower dose specimens). The latter cases may be examples where the hardness built up over several impacts and may reflect a condition just prior to material movemen/removal. The maximum hardnesses measured in the steady-state sample are somewhat lower, which may reflect recent, uniform material removal from both the crest-and-valley surfaces. Note, also, that equal hardnesses were measured on steady-state crest-and-valley surfaces in the initial multiple-particle erosion study on $11(\%) \mathrm{Al}$ (Fig. 13 and Table 3). The results at 9$)^{\circ}$ incidence, if accurate, indicate a tendency to form a layer of constant hardness in near-surface valley regions (Table 3). This may reflect the greater energy transfer into the target at 9$)^{\circ}$ incidence. 
In the case of the iron-aluminide alloy FA-129, the eroded surface remained relatively flat, so that the depth of hardening was relatively uniform across a specimen. Since there is little material movement during erosion, the hardening depths are a direct function of the amount of deformation energy input into the material, consistent with observations from single-particle impacts. As seen in Figs, 45, 46, and Table 3, the thickness of the work-hardened layer and the near-surface softening depth are consistently higher for erosion at $90^{\circ}$ incidence. For the iron-aluminide alloy, the depth of hardening at a 10()$-\mathrm{g}$ dose is about 100$) \mu \mathrm{m}$ at $30^{\circ}$ incidence compared to $160 \mu \mathrm{m}$ at $90^{\circ}$ incidence. For $1100 \mathrm{Al}$, MPM data summarized in Table 3 show that the depth of hardening beneath valleys at $30^{\circ}$ incidence is about $150 \mu \mathrm{m}$ compared to $200 \mu \mathrm{m}$ observed for $90^{\circ}$ incidence. The increase in the depth of hardening at $90^{\circ}$ incidence is less in 1100) Al compared to the iron-aluminide alloy. Some of this may be due to the fact that larger particles were used for the tests on $11(0) \mathrm{Al}$ at $30^{\circ}$ incidence (Table 3), leading to correspondingly deeper hardening. Another reason may be that a larger fraction of the impact energy is directed toward development of the undulating surface topographies in the softer, more deformable $1100 \mathrm{Al}$ (as seen in the single-particle impact studies, Fig. 12). In other words, the angular dependence of impact associated with hardening is less pronounced in materials with a greater tendency to deform and flow under the impact conditions. This illustrates an indirect effect of a material's strength and ductility, discussed more completely in the next section.

In a recent paper, Sundarajan 79 presented data for hardness beneath cross-sectioned eroded surfaces measured using a Vickers indenter. In agreement with the above results, he observed greater hardening depths (which he termed plastic-zone size) at $90^{\circ}$ incidence compared to $30^{\circ}$ incidence. However, the data show an apparently random variation in the surface hardness of samples eroded at different angles. This may indicate erroneous data since, during steady-state erosion, the flow stress at the eroding surface should be independent of the incidence angle, as demonstrated in the results described in this report. In addition, Sundarajan 79 attempts to relate the plastic-zone size to erosion resistance. However, as again demonstrated in this report, the plastic-zone size is a strong function of the measurement location, especially for 3()$^{\circ}$ impacts where the hardening depth under crests can be more than double that under valleys. These discrepancies demonstrate the significant advantage gained with the greater resolution and sensitivity of the MPM when compared to conventional hardness measurement techniques. 


\subsection{EFFEC'T OF MECHANICAL PROPERTIES ON MA'TERIAL DEFORMATION AND REMOVAL}

The distinctive differences in the deformation and fracture response of the 110() $\mathrm{Al}$ and FA-129 show the importance of mechanical properties on material removal under impact conditions. These differences were especially clear in the visual observations made in the single-particle impact studies. Craters were significantly larger in the softer $1100 \mathrm{Al}$ with greater evidence of material deformation, especially at $30^{\circ}$ incidence. Low-velocity, singleparticle impact craters showed significantly less material pushed up ahead of the impacting ball in the harder iron-aluminide alloy (Fig. 3). However, the most dramatic differences were observed at high velocities, where extruded lips formed and fractured in the aluminide alloy under the action of a single impact (Fig, 10), whereas only severe extrusion and deformation were observed in the $1100 \mathrm{Al}$. It appears from Figs. 9 and 10 that although the stronger ironaluminide alloy is deformed to a lesser extent than the $1100 \mathrm{Al}$, more material loss occurs in the aluminide because of its lower ductility. Material loss in the aluminide may also be enhanced because of its ordered structure, which would tend to prevent dislocation cross-slip and localize deformation so that the fracture strain was reached in areas of the extruding lip, causing failure. Material removal may also be accelerated due to possible environmental embrittlement of the iron-aluminide alloy, though it is difficult to estimate the relative importance of such an effect.

Even though observations of material failure and removal were at unusually high velocities, it is reasonable to expect that a similar response would be observed under cumulative impacts at lower velocities. Relatively early failure of small extruded lips in FA-129 during multiple-particle erosion studies was described in earlier sections, illustrating the relationship between cumulative effects of lower velocity impacts and high-velocity, single-particle impacts. However, the effects are not additive, as a rough calculation readily shows. Figure $10(a)$ indicates that material removal in FA-129 due to a single-particle impact at $30^{\circ}$ incidence occurred at $340 \mathrm{~m} / \mathrm{s}$ but was not obvious at $280 \mathrm{~m} / \mathrm{s}$. A threshold velocity for material removal may be conservatively estimated as $200 \mathrm{~m} / \mathrm{s}$. From the multiple-particle impact studies at $45 \mathrm{~m} / \mathrm{s}$ and $30^{\circ}$ incidence, overlapping lips with some associated material removal were observed after a dose of $11 \mathrm{~g}$ (Fig. 38), Based on the number of particles corresponding to an $11-\mathrm{g}$ dose and impact-crater dimensions, it was estimated that hetween three and four overlapping impacts may be expected at any one location. Four steel spheres

impacting at $45 \mathrm{~m} / \mathrm{s}$ contain about $10 \%$ of the energy contained in one similarly sized WC ball (about twice the density) impacting at $200 \mathrm{~m} / \mathrm{s}$. Evidently, strain localization effects in 
extruded lips per impact event are significantly stronger than purely cumulative energy effects. In this sense, use of high-velocity, single-particle impacts and energy balances to estimate material removal at lower velocities would overestimate the erosion resistance, since removal will occur earlier than predicted.

In spite of the differences in response of $1100 \mathrm{Al}$ and FA-129 to high-velocity impacts, higher strength/lower ductility cannot, in general, be consistently related to less deformation and earlier' failure. Cold working increases strength and reduces ductility, but visual observations showed little difference in crater appearance between heat-treated and coldworked conditions of the two alloys (Figs. 3, 4, 5, 9, 10, and 11), apart from slightly smaller craters in cold-worked $1100 \mathrm{Al}$ compared to annealed $1100 \mathrm{Al}$. The lack of difference in the iron-aluminide alloy may be due to the relatively small amount of cold work. However, the similarity in the appearance of craters between the annealed $1100 \mathrm{Al}$ and $50 \%$ cold-worked $1100 \mathrm{Al}$ is striking since the tensile ductility decreased from 35 to $6 \%$ upon cold working. 46 Therefore, one may have expected fractured lips in the case of cold-worked Al, akin to the observations on the iron aluminide, which had tensile ductilities of 15 to $20 \%$ in the heattreated ordered state. ${ }^{34}$ The lack of this observation suggests an enhanced role played by the iron-aluminide alloy's characteristics in localizing the deformation, as well as possible thermal effects as discussed in Sect. 5.6.

During multiple-particle erosion of $1100 \mathrm{Al}$ and the iron-aluminide alloy at $90^{\circ}$ incidence, most of the edges of the impact craters at low doses appeared to be flush with the surface, with little protrusion of material over the edge [Figs. 26(c) and 39(a)]. This implies that an incubation period is associated with the process of material removal ty lip formation and fracture, due to a buildup of a critical amount of deformation as initial impacts work harden the surface layers. It has been experimentally shown that work-hardened surfaces have shorter incubation times than annealed surfaces. 80 Therefore, one may expect extruded lips to appear closer to fracture for single impacts on cold-worked alloys. Brown et al.55 reported thinner lips around impact craters on ground Fe compared to those on the annealed material, signifying that deformation was more localized in the work-hardened material. Such observations were not duplicated in our study.

The impact craters were significantly smaller in the iron aluminide compared to 110() $\mathrm{Al}$, reflecting the difference in hardnesses between the two alloys. Table 4 summarizes profilometer measurements on the 9$)^{\circ}$ impact craters shown in Fig. 5, for which MPM data were also obtained (Table 2). Crater volumes are typically five to six times higher for 11(X) Al compared to FA-129. Crater dimensions for $50 \%$ cold-worked $1100 \mathrm{Al}$ are little different from the dimensions for 
Table 4. Crater dimensions for single-particle impacts at $90^{\circ}$ incidence

\begin{tabular}{cccccc}
\hline Target material & $\begin{array}{c}\text { Sample } \\
\text { number }\end{array}$ & $\begin{array}{c}\text { Velocity } \\
(\mathrm{m} / \mathrm{s})\end{array}$ & $\begin{array}{c}\text { Crater } \\
\text { depth } \\
(\mu \mathrm{m})\end{array}$ & $\begin{array}{c}\text { Crater } \\
\text { diam } \\
(\mu \mathrm{m})\end{array}$ & $\begin{array}{c}\text { Crater } \\
\text { volume } \\
\left(10^{5} \mu \mathrm{m}^{3}\right)\end{array}$ \\
\hline Annealed 1100 Al & $18 \mathrm{~A}$ & 58 & 60 & 230 & 13.6 \\
$1100 \mathrm{Al}, 50 \%$ cold work & $28 \mathrm{~A}$ & 59 & 56 & 214 & 11.0 \\
Ordered FA-129 & $10 \mathrm{~F}^{a}$ & 58 & 17.5 & 146 & 1.5 \\
$"$ & $17 \mathrm{~F}$ & 59 & -- & $160^{b}$ & $1.8 c$ \\
FA-129, 5\% cold work & $30 \mathrm{~F}$ & 58 & 17.5 & 162 & 1.8 \\
Eroded-corroded 2.25Cr1Mo & $650-10$ & 50 & 22 & 160 & 2.1 \\
steel & & & & & \\
\hline
\end{tabular}

$a_{\text {No MPM measurements. }}$

$b$ From SEM micrograph, Fig. 5. No profilometer measurements.

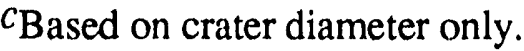

annealed $1100 \mathrm{Al}$, indicating that the resistance to dynamic impact is less than would be indicated by the hardness measurements (Table 1) and agreeing with the visual observations described above. Possibly, high dislocation mobility, due to the close-packed structure and high dynamic recovery of $1100 \mathrm{Al}$, distributes the deformation evenly throughout the substrate in spite of prior cold work.

MPM hardness profiles beneath low-velocity, singlé-particle impact craters at $90^{\circ}$ incidence (Fig. 6 and Table 2) also provide conflicting data on expected effects of mechanical properties on deformation. These profiles show that the depth of hardening under the impacts at velocities between 58 to $59 \mathrm{~m} / \mathrm{s}$ varies between 200 to $280 \mu \mathrm{m}$ for both the $1100 \mathrm{Al}$ and iron-aluminide alloys, in both heat-treated and cold-worked conditions. The work-hardened depths for the cold-worked conditions of the alloys appear to be on the lower end of the range, as may be expected. However, the depths can be accurately estimated only within 20 to $30 \mu \mathrm{m}$, and the differences between the heat-treated and cold-worked conditions of the alloys are not as great as may be expected, especially for $1100 \mathrm{Al}$ where a $50 \%$ increase in hardness was associated with the cold work (Table 1). Similar observations were made under high-velocity conditions. The asymmetry of deformation at $30^{\circ}$ incidence described in detail for a $740 \mathrm{~m} / \mathrm{s}$ impact on annealed $1100 \mathrm{Al}$ (Fig. 12) was also observed on a $625 \mathrm{~m} / \mathrm{s}$, $30^{\circ}$ incidence impact on $50 \%$ cold-worked $1100 \mathrm{Al}$. The reduced ductility of the cold-worked alloy did not change the pattern of deformation. As before, the major portion of the strain and 
associated softening effects were concentrated in regions directly in front of the ball toward the end of the impact. Table 3 shows that the hardening depth in the cold-worked alloy was less than in annealed $1100 \mathrm{Al}$ along the impact direction but was the same in the vertical direction perpendicular to the original surface. As was suggested by high-velocity impact crater features on cold-worked $1100 \mathrm{Al}$ (Fig. 11), there was no indication of further localization of strain due to the reduced ductility.

As described in Sect. 3.1, the initial study of single impacts on 1100$) \mathrm{Al}$ and precipitationhardened aluminum alloys had shown that not only did crater sizes decrease significantly with increasing alloy hardness but also that the depth of deformation decreased with increasing alloy hardness (Fig. 2), including hardening by cold work. As Table 2 shows, the depth of hardening for $28.5 \mathrm{~m} / \mathrm{s}, 30^{\circ}$ impacts decreased from 100 to $50 \mu \mathrm{m}$ between annealed $1100 \mathrm{Al}$ and $50 \%$ cold-worked $1100 \mathrm{Al}$. This is significantly different from the results described above and cannot be readily explained. There may be an effect due to the fact that MPM profiles were made vertically beneath the craters, whereas, as shown in Fig. 12, the bulk of the deformation occurs in front of the impacting ball for oblique impacts. The results also suggest that the extent of subsurface plastic deformation may more truly reflect an alloy's rosm-temperature strength and hardness at lower velocities where any thermal effects will be minimal, whereas at higher velocities, thermal effects may play an increasingly dominant role. This is discussed further below and in Sect. 5.6.

Another surprising result from Table 2 is that the difference in the deformation depths between $1100 \mathrm{Al}$ and FA-129 for $90^{\circ}$ impacts at 58 to $.59 \mathrm{~m} / \mathrm{s}$ does not reflect the great difference in hardnesses (Table 1). Unfortunately, time constraints did not allow detailed metallographic and MPM analyses of a cross-sectioned, high-velocity $30^{\circ}$ impact angle crater on the iron-aluminide alloy, but limited NIPM measurements produced profiles similar to those shown in Fig. 12 for annealed $1100 \mathrm{Al}$. In fact, as Table 2 shows, the hardening depth along the impact direction for a $470 \mathrm{~m} / \mathrm{s} 30^{\circ}$ impact on the iron-aluminide alloy was greater than the depths in the $740 \mathrm{~m} / \mathrm{s}$ impact on annealed $1100 \mathrm{Al}$ or the $625 \mathrm{~m} / \mathrm{s}$ impact on cold-worked $1100 \mathrm{Al}$. Similarly, for high-velocity $90^{\circ}$ single impacts, the deformation depth in the ironaluminide alloy appears to be greater than in annealed $1100 \mathrm{Al}$, although the velocity is more than 10\% lower (Fig. 7 and Table 2).

The similarity in hardening behavior can also be seen in the multiple-particle erosion tests, although hardening depths are more difficult to compare because of the distinctly different surface topographies developed in the two alloys. Samples $(110() \mathrm{Al})$ were generally hardened to greater depths than FA-129 samples, but the difference was much less than 1 ould be expected purely from hardness consideratiors. From Table 3, for example, for erosion at 
$90^{\circ}$ incidence at similar velocities and particle sizes, the hardening depth beneath hills or valleys in $110 \mathrm{CA}$ is only about $20 \%$ greater than the depth in FA-129 at the highest dose of $480 \mathrm{~g}$.

Sundarajan 79 measured the hardness beneath the eroded surfaces of several copper alloys and found that the hardening depth decreased with increasing alloy hardness for $30^{\circ}$ incidence but was independent of hardness at $90^{\circ}$ incidence. As discussed in the previous section, some accuracy may have been lost because of the lower resolution of a Vickers indenter compared to an MPM. Nevertheless, there are considerable similarities in the trends in his results and the observations described above.

It is also interesting to consider the results from single impacts on surfaces of erodedcorroded steels described earlier (Fig. 8). The steels had a Vickers hardness in the range of 130 to $140 \mathrm{HV}$, thus falling in between the hardnesses for $1100 \mathrm{Al}$ and the iron-aluminide alloy. The steels were impacted with $34-\mu \mathrm{m}$ WC balls at $90^{\circ}$ and velocities around $50 \mathrm{~m} / \mathrm{s}$. The surface scales formed during erosion-corrosion may be expected to influence the response to tive impacts. However, the scale had spalled prior to the single-particle impacts in one of the specimens (sample 650-10 in Fig. 8), and the results of impacts on this specimen may be compared with the results from $1100 \mathrm{Al}$ and the iron-aluminide alloy. For sample 650-10, the deformation depth estimated from the MPM profile in Fig. 12 is $170 \mu \mathrm{m}$, corresponding to a typical crater $160-\mu \mathrm{m}$ wide and $22-\mu \mathrm{m}$ deep with a volume of $2.1 \times 10^{5} \mu \mathrm{m}^{3}$. These numbers may be compared with those for $90^{\circ}$ impacts at velocities around $60 \mathrm{~m} / \mathrm{s}$ on $1100 \mathrm{Al}$ and iron aluminide (Tables 2 and 4 ). The numbers for the $2.25 \mathrm{Cr} 1 \mathrm{Mo}$ steel should increase somewhat if corrected for the $20 \%$ higher velocity, making the results very similar to those from the ironaluminide alloy. These comparisons show that the crater dimensions rank in the order of hardness of the three alloys, whereas the hardening depths tend to be higher than expected in the harder alloys.

The large hardening depths in FA-129 were especially clear at high velocities where, as described above, they sometimes exceeded hardening depths in $11(x) \mathrm{Al}$ at similar velocities. The possibility of erroneous MPM data has to be considered, especially for measurements on sectioned, singie-particle impact craters. Estimates of hardening distances may be artificially magnified or lessened if sections were not exactly perpendicular to the crater or if they did not accurately lie along the impact direction (for oblique impacts). Great care was taken in specimen preparation to ensure proper mounting and sectioning. However, some of the data are difficult to explain. As an example from Table $2,30^{\circ}$ impact samples $11 \mathrm{~A}$ and $20 \mathrm{~A}$ of annealed $110(0 \mathrm{Al}$ and $23 \mathrm{~A}$ of $50 \%$ cold-worked 110() $\mathrm{Al}$ may be compared. The data show greater hardening vertically beneath the crater in sample $11 \mathrm{~A}$, which was a significantly lower 
velocity impact $(280 \mathrm{~m} / \mathrm{s})$ than impacts $20 \mathrm{~A}(740 \mathrm{~m} / \mathrm{s})$ or $23 \mathrm{~A}(625 \mathrm{~m} / \mathrm{s})$. In addition, impact $23 \mathrm{~A}$ shows almost $70 \%$ less hardening than $20 \mathrm{~A}$ along the impact direction but equal hardening along the vertical direction. These differences are difficult to analyze since it is realistically not possible to obtain MPM profiles from several impacts at a similar velocity, and some of the discrepancies must be ascribed to measurement errors. The data for sample $23 \mathrm{~A}$, for example, may be questionable since the maximum relative hardness values measured in the profiles are significantly lower than for other impacts on $1100 \mathrm{Al}$ (except impacts at the lowest velocities of $28.5 \mathrm{~m} / \mathrm{s}$ ). However, in the case of FA-129, the extent of deformation is consistently higher than anticipated, outweighing any possible errors in actual values of the hardening depths.

It is generally assumed in the literature that for moderately shallow indentations, the volume of plastically deformed material is comparable to the volume of the indentation. 32 However, comparison of the impact-crater dimensions (Table 4) with the plastic-deformation depths as estimated by MPM measurements (Table 2), shows that the deformation depths are larger than crater depths, by at least an order of magnitude for FA-129 and about four to five times for $1100 \mathrm{Al}$. Plastic deformation associated with single-particle impacts is evidently more widespread than what is generally accepted. The results are also surprising because relative to the impact-crater size, more subsurface deformation occurs on the harder ironaluminide alloys. Intuitively, one would expect higher rebound velocity in a particle impacting a stronger surface, with less transfer cof energy into the target and, consequently, iess deformation. Impact processes such as in erosion are usually analytically modeled using Hertzian contact mechanics to estimate inelastic contact stresses under static conditions, which gives reasonable values for impacts at $90^{\circ}$ incidence. ${ }^{81}$ As described by Johnson, 81 the position of the elastic-plastic boundary under an indentation can be estimated from a model based on the observed symmetry in the deformation under a blunt indenter. The elastic-plastic boundary under a spherical indenter can be estimated from the equation:

$$
(I / Y)(a / R)=6(1-n)(c / a)^{3}-4(1-2 n)
$$

where

$\mathrm{E}=$ elastic modulus of substrate,

$\mathrm{Y}=$ yield strength of substrate,

$a=$ radius of circular impression left in substrate,

$\mathrm{R}=$ radius of indenter,

$\mathrm{n}=$ Poisson's ratio of substrate, and

$\mathrm{c}=$ radial distance from contact point to elastic-plastic boundary. 
The quantity $(\mathrm{a} / \mathrm{R})$ is a measure of the strain imposed by the spherical indenter. The elastic properties of the indenter are ignored, assuming that the indenter is considered to be a nondeformable body compared to the substrate, as is reasonably the case with the WC spheres in this study. Note that the quantity "a" itself depends on the elastic-plastic properties of the substrate and indenter. From this equation, the quantity "c" can be compared for various observed values of " $\mathrm{a}$ " in different materials generated by similar impacts. Using the measured hardnesses (Table 1) as estimates of the yield strength and observed values of "a" for $90^{\circ}$ impacts around $60 \mathrm{~m} / \mathrm{s}$ (Table 4), it was estimated that the quantity "c" for annealed $1100 \mathrm{Al}$ should be about 2.5 times that for ordered FA-129. In other words, the theory predicts that for observed crater dimensions, the plastic zone in $1100 \mathrm{Al}$ should extend 2.5 times deeper than in FA-129. This is not the case, implying that the deformation behavior is influenced by other effects. It must be noted, however, that Hertzian contact mechanics are valid only for indentations that are small relative to the size of the indenter. In $1100 \mathrm{Al}$, for example, the crater diameter is more than half the diameter of the indenting WC ball. On the other hand, Hertzian theory has been experimentally verified for indentations as large as $(\mathrm{a} / \mathrm{R})=0.3$, which was the maximum value of $(\mathrm{a} / \mathrm{R})$ used in the experiments. 81

Examination of the peak hardness values in the impact-hardened materials presents another aspect of the different impact responses of $1100 \mathrm{Al}$ and FA-129. The maximum hardness values after single and multiple impacts are tabulated in Tables 2 and 3. Hardnesses for $1100 \mathrm{Al}$ are compared only between perpendicularly sectioned specimens because of the possibility of higher hardnesses in tapered-section specimens due to more material support near the edge, as discussed with respect to Fig. 35 . This effect is not seen in the iron aluminide probably because indentations near the free edge of the stronger alloy are better supported than in the softer $1100 \mathrm{Al}$. For the iron-aluminide alloy, the maximum relative hardnesses under both single- and multiple-particle impacts are in the range of 1.6 to 1.7 . For $1100 \mathrm{Al}$, the maximum relative hardness under single impacts ranges from 1.4 to 1.6 , whereas that under multiple-particle impacts ranges from 1.6 to 1.75 in the perpendicularly sectioned specimens. Evidently, the maximum possible hardness is not reached in $1100 \mathrm{Al}$ under the action of a single impact. Note that this holds even for very-high-velocity impacts. For the impact of a single spherical ball on a flat surface, the average strain over the plastically deformed volume can be approximated by the quantity, $0.1 \mathrm{w} / \mathrm{R}$, where $\mathrm{w}$ is the diameter of the crater and $\mathrm{R}$ the radius of the impacting sphere. ${ }^{65}$ As the velocity increases, the crater size increases, leading to higher strains. This should lead to a higher work-hardened stress (as should contributions from strain-rate hardening as the velocity and, thus, the strain rate increase). However, the 
relationship breaks down as the crater size approaches that of the impacting ball, although it is reasonable to expect a steady increase in subsurface strain with increasing velocity.

The distinctly different observations provide an indirect clue to the hardening behavior of the two alloys. FA-129 evidently achieves a maximum flow stress under the action of a single, relatively low-velocity impact. Higher velocities or multiple impacts do not increase the hardness but result in an increasing amount of near-surface softening, as seen in Tables 2 and 3. The MPM measurements are quasi-static estimates of the flow stress of a deformed structure developed under conditions of strain and strain-rate existing under the impacting ball (and any subsequent relaxation). Therefore, the measured constant maximum hardness implies that a constant deformed structure is reached under the impact conditions. The near-surface softening implies that this structure is modified so that it is less resistant to quasistatic, roomtemperature deformation, i.e., dislocation mobility has increased. Since this increases with increasing velocity or with cumulative impacts, both of which build up strain on the surface, the aluminide presents a softer after-impact microstructure under increasing strain. This may be due to several factors, as discussed in the next sections. As the impact data show (Tables 2 and 3), the saturated peak hardness moves further into the material as the number or velocity of impacts increases. This indicates that the alloy cannot be hardened beyond a certain value, which is approximately $70 \%$ over its yield strength (based on the maximum relative hardness of 1.7). Once steady-state erosion is reached, the thickness of the "softened" layer should remain constant. Unfortunately, specimens subjected to high enough erodent doses were not available to confirm this. Assuming that this does indeed occur, it appears that the subsurface structure in FA-129 continues to develop until steady-state erosion is reached. This may be compared to the results in $1100 \mathrm{Al}$, where maximum hardnesses and the ripple structure were developed during the incubation period, suggesting that few changes occurred at later stages in the erosion process.

In $1100 \mathrm{Al}$, the flow stress builds up gradually over several impacts. Increasing the velocity of single impacts causes a dropoff in near-surface hardness before the maximum flow stress is achieved. As the tapered-section eroded specimens showed, several impacts were necessary before the maximum flow stress was achieved (Fig. 22). As shown earlier in this section, the energy contained in several low-velocity impacts is significantly less than the energy contained in a single, high-velocity particle. Therefore, the fact that the maximum flow stress is not achieved in a single, high-velocity impact is not due to a lack of sufficient plastic strain in the material, especially since the volume of plastically deformed material is not much different than that in the iron-aluminide alloy, which achieved maximum flow stress for similar impacts. The deformation substructure in $1100 \mathrm{Al}$ under a single-particle impact may be 
partially relieved by the end of the impact, so that further impacts on this deformed structure are needed to achieve maximum hardness. The MPM data in Table 2 for $50 \%$ cold-worked $1100 \mathrm{Al}$ show that if the questionable data from impact 23A are ignored, the maximum hardnesses achieved under single impacts are higher than under corresponding impacts in annealed $1100 \mathrm{Al}$, especially if one considers that the bulk relative hardness of 1 of the $50 \%$ cold-worked material is higher than the bulk hardness of annealed $1100 \mathrm{Al}$. (All relative hardnesses have been reported with respect to the bulk material after the appropriate thermoniechanical treatment. Although the Vickers hardness in Table 1 reflects 50 and 10\% increases in hardness in $1100 \mathrm{Al}$ and FA-129, respectively, after cold working, the MPM sensed only 30 and $5 \%$ increases, respectively.)

With respect to the possible effect of mechanical properties on erosion, results from $1100 \mathrm{Al}$ and the iron-aluminide alloy show that erosion resistance may be decreased in alloys where deformation tends to be localized, since this accelerates material removal. This supports the suggestion made in the early study on precipitation-hardened aluminum alloys, 46,47 that erosion resistance is related to an alloy's capacity to distribute the impact energy over a large volume. Cold working did not affect this in $1100 \mathrm{Al}$, since although the strength was increased, the deformation behavior was unchanged, as reflected in the appearance of the impact craters and the extent of subsurface deformation. In general, the extent of deformation associated with the impacts could not be explained on the basis of plasticity theory alone, implying that the effect of mechanical properties on erosion is modified by other effects. These effects, especially thermal effects as discussed in Sect. 5.6, may be responsible for the observed weak dependence of erosion resistance on strengthening treatments, as has been observed often in the literature. 17,31 It would be interesting to examine the high-velocity impact response of precipitation-hardened aluminum alloys, where observations may be fundamentally different than on $1100 \mathrm{Al}$ because of different deformation characteristics, allowing a comparison of mechanical properties effects as modified by other factors as velocity increased.

\subsection{IMPACT-INDUCED PHASE TRANSFORMATIONS}

As mentioned several times in the text, thermal effects associated with the impacts offer an obvious explanation for the various examples of near-surface softening seen in the experiments. However, other possible explanations need also to be considered. For the ironaluminide alloy, the possibility of a disordering reaction due to the energetic impacts cannot be discounted. It was not feasible to conduct a detailed study to examine this possibility. 
However, a limited X-ray diffraction study on three samples of the iron-aluminide alloy was conducted. Two samples were of uneroded, heat-treated material, one of which was polished through 600-grit $\mathrm{SiC}$ (the condition prior to multiple-particle erosion experiments) and the other polished through $0.1-\mu \mathrm{m}$ diamond (the condition prior to the single-particle impact experiments). The third specimen was the sample subjected to $480 \mathrm{~g}$ of steel shot in the Notre Dame erosion tester and subsequently showed the greatest extent of subsurface softening (Table 3). All samples showed a strong crystallographic texture attributable to the prior thermomechanical treatments. The polished specimens showed primarily disordered aFe with weak peaks of ordered $\mathrm{B} 2$. No ordered $\mathrm{DO}_{3}$ peaks were detected. The extent of ordering could not be quantified because of the strong texture. The eroded specimen showed only disordered aFe with significant peak broadening due to the deformation. No ordered phases were detected, implying that the impacts were sufficiently energetic to promote the phase transformation.

It may be argued that a disordering phase transformation may lead to the impact-induced near-surface effects since the disordered structure will be less resistant to plastic deformation. However, it is unclear how the large strains and strain rates associated with the impacts may affect the strength of the disordered or ordered structures, especially if temperature excursions occur during the impact process. Further, a steep strain gradient exists beneath the impacted surfaces. Therefore, the disordered material in the near-surface regions will be strained to a significantly greater extent than underlying ordered material. Greater work-hardening effects may more than compensate for any difference in strength between the two phases. Finally, disordering effects in the iron-aluminide alloy cannot explain impact-induced, near-surface softening in cases without any possibility of phase transformations, such as the observations in eroded-corroded steels for relatively low-velocity impacts or in $1100 \mathrm{Al}$ at higher velocities. On a related note, single-particle impact studies were conducted early in the program on several heat-treated steels to examine the possibility of impact-ind'ıced phase transformations, as monitored by MPM measurements. No evidence for phase transformations was found.

The implications of this limited X-ray sturly are unclear. The observation of the phase transformation in the iron-aluminide alloy may be important with respect to potential applications where the alloy may be exposed to particle impacts. In such cases, the ordering heat treatment may be of little significance. However, not enough data are available to make such judgments. The X-ray results on samples prior to erosion showed that the alloy was not completely ordered (or even mostly ordered). The extent of disordering due to erosion is unknown, and it may well be that some amount of order may have persisted after erosion if the starting alloy were more completely ordered. The depth dependence of the transformation is 
also unknown, and it would be useful to see if the thickness of the transformed layer matched the thickness of the softened layer beneath the eroded surface. Finally, an examination of impact response of iron-aluminide alloys prior to the ordering heat treatment would also provide critical information, establishing if near-surface softening was exclusively associated with the order-disorder transformation. Further detailed X-ray studies would clearly be useful.

\subsection{EFFECTS OF RESIDUAL STRESSES}

It is well known from the shot-peening literature 82,83 that peened surfaces develop significant compressive residual stresses. These effects are strongest for impact processes that tend to have large elastic components, such as with spherical particles (as opposed to angular grit, which will more easily deform the surface plastically). A combination of vertical Hertzian stresses (which are at a maximum some distance beneath the impact location) and plastic strains (which are maximum at the surface) set up characteristic depth distributions of residual stresses. The compressive residual stress tends to be maximum some distance below the surface for relatively hard materials (due to a larger contribution from elastic Hertzian stresses) and at the surface for relatively soft materials (due to larger plastic strains as well as possibly stronger adiabatic heating effects). Harcier materials also tend to show work softening in the near-surface layers, with a hardness depth distribution mirroring the compressive residual stress-depth distribution. The near-surface softening in these cases is not due to a more relaxed dislocation structure in the near-surface regions but rather due to the fact that higher compressive stresses some distance beneath the surface effectively raise the yield stress (and hence the hardness) in these areas. The maximum in hardness matches the maximum in compressive residual stress.

Residual stress effects offer an attractive explanation for most of the near-surface effects observed in the impact experiments, especially for the multiple-particle erosion results. The steel shot used was considerably harder than the 1100 Al but comparable in hardness to the iron-aluminide alloy. Therefore, compressive residual stress distributions as descri' ' above for relatively hard and soft materials may develop in the iron aluminide and 110() $\mathrm{Al}$, respectively, leading to a near-surface dropoff in hardness in the former and maximum hardness at the surface in the latter. Due to the buildup of residual stresses, near-surface softening would increase with dose, 82,83 as observed in the iron-aluminide alloy. Residual stress distributions would also explain the greater softening effects at $90^{\circ}$ impacts compared to $30^{\circ}$ impacts. 
Residual stresses also offer an alternative explanation for the peak hardness values observed after impact, since the measured hardnesses may reflect the flow stress of the alloys as raised by existing compressive residual stresses. Work hardening of the $1100 \mathrm{Al}$ substrate under impacts would lead to more resistance to plastic deformation. In time, the elastic Hertzian component of the impact force would increase, leading to an increase in compressive residual stresses and thus higher measured hardnesses. Thus, peak hardness in $1100 \mathrm{Al}$ would develop over several impacts, as observed. The effect may not be strong in the iron-aluminide alloy since the impacts have a strong elastic component, initially, and also because the alloy may not work harden to the extent of $1100 \mathrm{Al}$. Therefore, the peak hardness could develop as the result of a single impact.

Near-surface softening due to single-particle impacts is more difficult to explain. All target materials were relatively soft compared to the WC balls. It may be that for relatively lowvelocity impacts, the iron-aluminide alloy was hard enough to develop a compressive residual stress maximum beneath the surface, which may also have been the case for the erodedcorroded steels. However, this does not explain the increasing depth of near-surface softening with increasing velocity (Table 2). In shot peening of hard alloys, the maximum in compressive residual stress moves to greater depths with increasing velocity since more energetic impacts increase the Hertzian stress distribution. 83 However, for hard WC balls impacting on a relatively soft iron-aluminide alloy target, increasing velocities would be more logically associated with increasing plastic deformation. The observation of near-surface softening in $1100 \mathrm{Al}$ at higher velocities also cannot be explained on a residual stress basis. Finally, as extensively discussed above, the extent of plastic deformation beneath impacted surfaces in FA-129 was comparable to that in $1100 \mathrm{Al}$ and was actually greater in some cases. Therefore, the argument that material with a greater tendency toward plastic deformation develops a maximum compressive-residual stress (and, thus, maximum hardness) at the impacted surface fails to differentiate between the two alloys.

No attempts were made to measure residual stresses beneath the impacted samples. Although arguments based on residual stress cannot explain all the observed near-surface changes, possible residual stress effects cannot be ruled out. A stress-relief anneal after erosion could minimize residual stresses without significantly affecting the microstructure. MPM measurements before and after such treatments could evaluate the contribution of residual stresses. X-ray studies to examine residual stress issues could be rewarding. 


\subsection{THERMAL EFFECTS}

As described in the introduction to this report, much conflicting data have been generated over the years regarding the possible effects of impact-induced temperature rises on the erosion process. Evaluating the occurrence and relative importance of such effects was an underlying theme throughout $t_{x}^{\prime}$ is program.

The initial attempt to verify thermally induced near-surface softening was made early in the program through single-particle impact studies on Hastelloy C-276, as described earlier in this report. No softening was observed. However, since MPM indentations were only made in crater bottoms, no depth-dependent hardness variations could be observed. Therefore, it was unclear if higher hardness values would have been measured at larger depths below the surface, indicating possible thermal effects in the near-surface layers. In the following study, impact craters on aluminum alloys were cross sectioned, thus allowing hardness variations with depth to be obtained. Both this study and succeeding multiple-particle erosion studies on aluminum alloys showed maximum hardnesses at the impacted surface, leading to the initial conclusion that thermal effects were not dominant during erosion. However, as extensively described in this report, later studies showed numerous examples of a constant or lower nearsurface hardness associated with particle impacts. Softening was observed in FA-129 under many impact conditions, in $1100 \mathrm{Al}$ at high velocities, and in the one study conducted on 2.25Cr1Mo steels. As discussed above, these results cannot be completely explained by any one set of arguments, and the possibility of thermal effects cannot be dismissed.

Therma'. effects that occur must necessarily be associated with the individual impact event, even in multiple-particle impact studies. As shown earlier, the time between impacts in the Notre Dame rotating-arm tester is too large for the dynamic state of one impact to be retained until the next impact within its region of influence. The loading rates were larger in the Lawrence Berkeley Laboratory gas-jet tester, but estimated time between impacts is still quite large. Therefore, subsurface softening trends in the multiple-impact studies may be analyzed as being due to the action of individual particles. This wou! : explain, for example, the significant local variations in the extent of near-surface softening in the iron-aluminide alloy for erosion at both 30 and $90^{\circ}$ (Table 3). Areas that experienced the most recent impacts would show the greatest extent of softening. Note that the thickness of the softened layer appears to be independent of location, ruling out the possibility of a locally higher impact velncity leading to greater softening.

An interesting trend is revealed if the crater sizes and depths of hardening for $28.5 \mathrm{~m} / \mathrm{s}$ single impacts on aluminum alloys, 58 to $59 \mathrm{~m} / \mathrm{s}$ and high-velocity (several hundred meters per 
second) single impacts on $1100 \mathrm{Al}$ and FA-129, and $50 \mathrm{~m} / \mathrm{s}$ single impacts on the erodedcorroded 2.25Cr1Mo steel (Table 2) are compared. At the lowest velocity, the depth of hardening increases significantly with decreasing hardness. At the interinediate velocity, the depths of hardening are higher in the softer materials, but the differences are small, especially when compared to the hardness differential and the lower velocity data. As discussed in Sect. 5.3, the differences were much smaller than predicted by contact mechanics based on elasticity and plasticity theory alone, suggesting external influences. At velocities of several hundred meters per second, the hardening depths appear to be greater in the harder alloy, indicating a reversal in trend. However, at all three velocities, larger craters were consistently formed in the softer alloys. The conflicting trends are schematically shown in Figs. 48 and 49. (Note that in Fig. 48 , crater lengths at $30^{\circ}$ incidence cannot be directly compared with crater depths at $90^{\circ}$ incidence.)

In Figs. 48 and 49, there are no data on the precipitation-hardened aluminum alloys or the $2.25 \mathrm{Cr} 1 \mathrm{Mo}$ steel to estimate clearly the effect of velocity on hardening behavior as a function of alloy strength. Most of the data are from $1100 \mathrm{Al}$, and the iron-aluminide alloy and the trend reversal imply that as velocity increases, subsurface deformation either increases disproportionately slowly in $1100 \mathrm{Al}$ or disproportionately fast in the iron-aluminide alloy. For $1100 \mathrm{Al}$, between 58 and $894 \mathrm{~m} / \mathrm{s}$, crater depth increases by a factor of 15 while the hardening depth increases by a factor of 1.8. For the iron-aluminide alloy, between 58 and $794 \mathrm{~m} / \mathrm{s}$, crater depth increases by a factor of 9 while the hardening depth increases by a factor of 2.5 . Table 5 compares the ratio of single-particle, impact crater size in $1100 \mathrm{Al}$ to that in the ironaluminide alloy at various velocities, where the crater sizes were obtained from the various tables and micrographs in this report as weli as other unreported data. The crater size ratios are reasonably constant at both ang..s of incidence, except for the highest velocity impacts at $90^{\circ}$ for which the crater in $1100 \mathrm{Al}$ appears to be unusually deep.

Therefore, it appears that in $1100 \mathrm{Al}$ at high velocities, a larger fraction of the impact energy is used up in creating an unusually large crater, so that less energy is available for subsurface plastic deformation, leading to lower hardening depths than in the iron-aluminide alloy. Severe thermal effects at the head of the impacting particle can explain the excess penetration at high velocities.

A strong argument can be made for thermal effects occurring over most of the velocity range; the target material properties control response in terms of the extent of near-surface softening. Near-surface softening could occur either during the impact process or after the impact, due to residual heat in the plastically deformed area. Softening concurrent with deformation would be related to processes like the formation of adiabatic shear bands (a 
ORNL DWG 92-5083

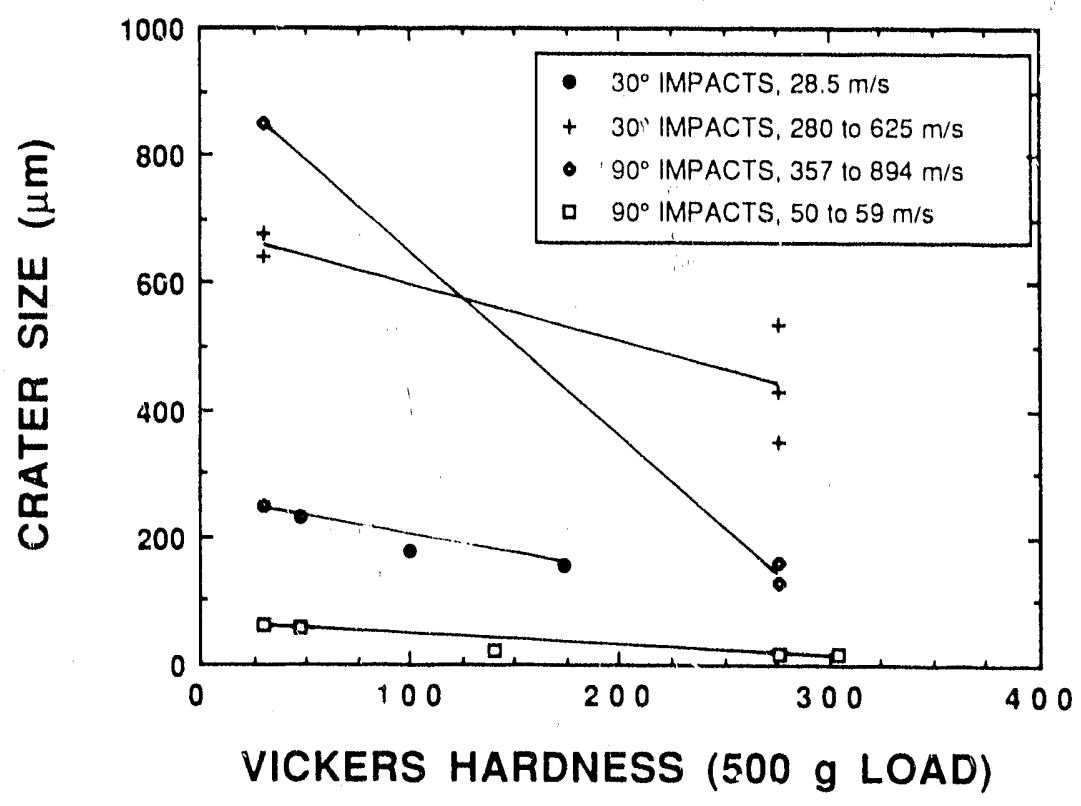

Fig. 48. Crater size versus alloy hardness for singleparticle impacts at various velocities.

ORNL DWG 92-5084

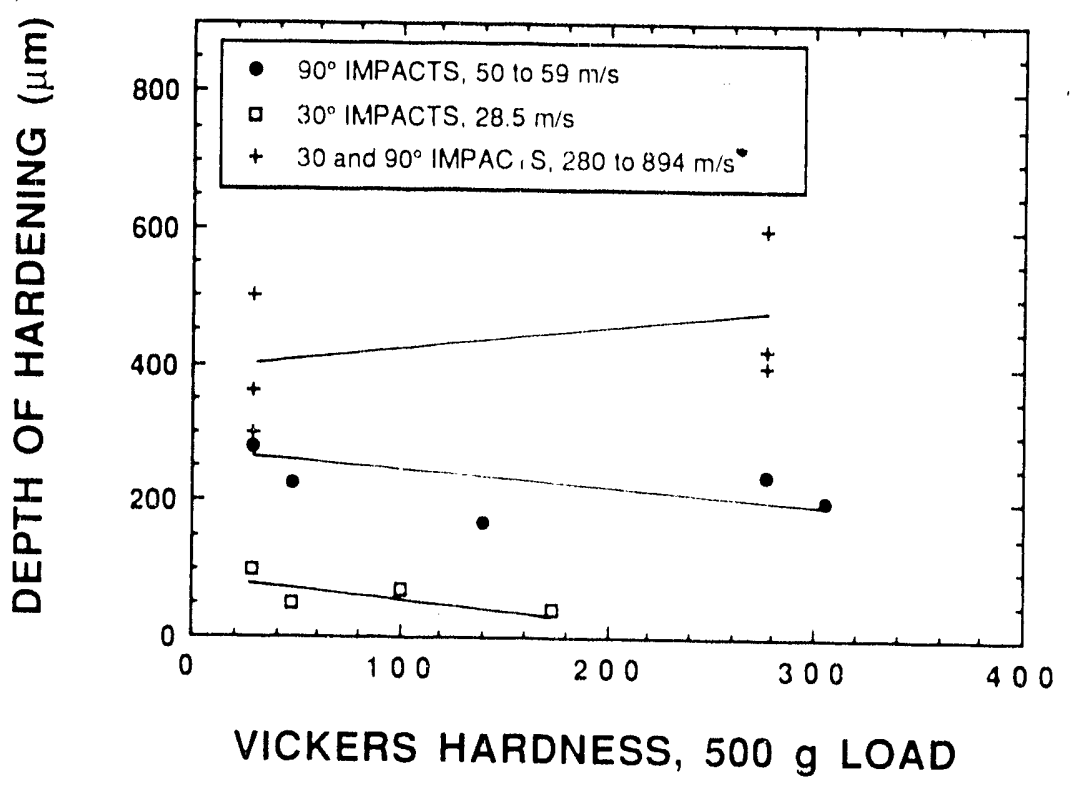

Fig. 49. Depth of hardening under single-particle impacts versus alloy hardness at various impact velocities. 
Table 5. Crater size ratios for single-particle impacts at 30 and $90^{\circ}$ incidence and various velocities

\begin{tabular}{cccccccc}
\hline & \multicolumn{6}{c}{ Impact velocity $(\mathrm{m} / \mathrm{s})$} \\
\cline { 2 - 7 } $\begin{array}{c}\text { Impact } \\
\text { angle }\left({ }^{\circ}\right)\end{array}$ & 17 to 19 & 50 to 60 & 280 & 357 to 381 & 420 to 429 & 794 to 894 \\
\hline & \multicolumn{1}{c}{ Crater } & size ratio & Annealed & 1100 & Al:Ordered & FA-129 \\
30 & 2 & 2 & 2.3 & -- & 2 & -- \\
90 & 3.5 & 3.3 & -- & 3 & -- & 5.5 \\
\hline
\end{tabular}

${ }^{a}$ Crater lengths for $30^{\circ}$ impacts and crater depths for $90^{\circ}$ impacts.

manifestation of localization of deformation) or dynamic recrystallization. In either case, strength levels will be higher than in the fully annealed state.

Aluminum is a material with excellent dynamic-recovery characteristics and tends to maintain a uniform substructure of very well defined dislocation cells during deformation, even at high strains, preventing localized deformation or dynamic recrystallization. 84 Whereas dynamic recrystallization will be associated with a drop in the flow stress, a dynamically recovered microstructure will tend to maintain a constant flow stress. For dynamic recrystallization to occur, a heterogeneous substructure needs to develop, with neighboring areas having significantly different dislocation concentrations. Therefore, it is promoted in materials that do not have a tendency to develop uniform dislocation cell structures during deformation, such as low-stacking-fault energy materials in which dislocation cross-slip is difficult. On this basis, dynamic recrystallization would be favored in the ordered ironaluminide alloy over $1100 \mathrm{Al}$.

For single impacts in $1100 \mathrm{Al}$, near-surface layers sometimes showed a constant hardness over several tens of microns for at least one relatively low-velocity impact, suggesting dynamic recovery effects. As Fig. 6 shows, this occurred in annealed $1100 \mathrm{Al}$ for a $90^{\circ}$ impact at $58 \mathrm{~m} / \mathrm{s}$ but was not as clear in the cold-worked alloy subjected to a similar impact. As velocity increases, near-surface softening occurs in $1100 \mathrm{Al}$, for impacts at both 30 and $90^{\circ}$. However, in all cases, the near-surface effects are not clear as in FA-129, as seen in Fig. 7 for a $90^{\circ}$ impact at $894 \mathrm{~m} / \mathrm{s}$ and Fig. 12 for a $30^{\circ}$ impact at $740 \mathrm{~m} / \mathrm{s}$. This suggests that dynamic recovery effects are strong in the $1100 \mathrm{Al}$ and that the softening may be due to annealing effects of residual heat. Recrystallization due to post-deformation annealing effects has been observed in abraded aluminum. 85 The unusually large crater in $1100 \mathrm{Al}$ due to impact at $90^{\circ}, 894 \mathrm{~m} / \mathrm{s}$, 
also supports such an occurrence. The material in front of the impacting ball may have been heated close to its melting temperature, offering little resistance to deformation. As the ball slowly lost energy and came to a rest, significantly less energy would be available for plastic deformation, leading to a relatively smaller deformation volume. The heat generated in the ball during penetration would be released into the deformed material, leading to the observed softening effects. Near-surface softening in $1100 \mathrm{Al}$ would, therefore, be observed only at relatively large velocities.

At moderate velocities, evidence of strong dynamic-recovery effects leading to a saturation in flow stress was not observed in the multiple-particle impact studies. The reason for this may be that the velocity was too low for significant thermal effects. In the single-impact studies, a constant or saturation near-surface hardness was observed for a $90^{\circ} \mathrm{impact}$ at $58 \mathrm{~m} / \mathrm{s}$, whereas the multiple-particle erosion tests were conducted at $45 \mathrm{~m} / \mathrm{s}$ with particles roughly half as dense as the single WC spheres. Especially at $30^{\circ}$ incidence, significantly less energy will be associated with each impact. Close inspection of the MPM results for $90^{\circ}$ multiple-particle erosion tests (Figs. 33 and 34) reveals some indication of a constant hardness in the nearsurface layers, especially in valley regions where deformation is more concentrated. In addition, dynamic recovery effects may be responsible for the fact that even for cases where obvious thermal effects are seen, single particle impacts do not fully harden $1100 \mathrm{Al}$, unlike FA-129. Dynamic recovery effects can also explain why old working the $1100 \mathrm{Al}$ did not cause a significaitly different response to single-particle impacts. The high dynamic recovery of $1100 \mathrm{Al}$ would enable the deformation to be spread evenly in the highly strained regions, negating cold-work effects. At very low velocities, these effects would be relatively small, and conventional strength effects would dominate. This was seen in the initial single-impact study on various aluminum alloys, which was conducted at a velocity of $28.5 \mathrm{~m} / \mathrm{s}$. At this velocity, both crater sizes and hardening depths clearly reflected the alloys' hardnesses.

The response of $1100 \mathrm{Al}$ to impacts can, therefore, be described as occurring in three regimes dominated by different processes: recrystallization due to residual heat at high velocities, dynamic recovery at moderate velocities, and no thermal effects at low velocities. For the $343-\mu \mathrm{m}$-diam WC balls used in this study, these velocities may be estimated to be several hundred $\mathrm{m} / \mathrm{s}$, around $60 \mathrm{~m} / \mathrm{s}$, and about $30 \mathrm{~m} / \mathrm{s}$ for the three processes, respectively.

The general absence of any evidence for thermal effects during the various multipleparticle impact studies on aluminum alloys during the program may simply be due to impact velocities being too low. In addition, thermal effects would more likely be observed in terms of a constant near-surface hardness, rather than near-surface softening, at the velocities in question $(45 \mathrm{~m} / \mathrm{s})$. The initial study on precipitation-hardened aluminum alloys may have 
generated more interesting results if conducted at higher velocities, especially considering their distinctly different deformation behavior compared to $1100 \mathrm{Al}$.

The more widespread near-surface softening in the iron-aluminide alloy may be attributed to stronger thermal effects because of its deformation characteristics. The ordered structure would promote local areas of high-stored energy under impact, which could lead to either dynamic recrystallization or "static" recrystallization due to post-impact annealing effects. Either process would cause a loss of order. The relatively large hardening depths compared to $1100 \mathrm{Al}$ suggest dynamic recrystallization, which would lead to greater deformed volumes. Small amounts of cold work would also localize deformation, leading to easier dynamic recrystallization, although the deformation itself would not be greatly reduced, as seen in the MPM profiles in Fig. 6. Similarly, the softening seen in the $2.25 \mathrm{Cr} 1 \mathrm{Mo}$ steel could also be due to dynamic recryst:llization, since the bec crysta' structure promotes planar slip, and localized deformation would also be enhenced by the prior work hardening during erosioncorrosion testing. Dynamic recrystallization, as the preferred thermal recovery process, is also indicated by the fact that if the iron-aluminide alloy retained its ordered structure during deformation and a significant tt.mperature increase occurred during the impact, then the alloy's elevated-temperature strength would restrict the deformation to smaller volumes.

Bellman and Levy 16 were the first to suggest the creation of a soft near-surface layer due to erosion. A work-hardened layer underneath this layer acted as an anvil, leading to heavy deformation in the soft surface zone followed by material removal. Our results are in partial agreement with this model. A soft layer does not form in all cases, even if thermal effects are significant and, at low velocities, thermal effects are insignificant. This is important since many erosion tests and applications are in the low-velocity regime (a few tens of meters per second).

Hutchings and Levy 86 have considered the significance of thermal effects in erosion in some detail. Based on considerations of an adiabatic temperature rise, they estimated velocity and particle size limits above which thermal effects may be expected to be important. These velocities were in the range of several tens of $\mathrm{m} / \mathrm{s}$ for particles several hundred microns in diameter, for typical engineering alloys and abrasives. The limits were found by equating the plastic-deformation depth associated with an impact with the expected diffusion distance of the heat generated over the duration of impact. Adiabatic conditions would be met if the diffusion distance were less than the plastic deformation depth, so that all heat was released in the deformed volume. Their calculation of the plastic deformation depth was based on the assumption that it could be equated to the depth of the indentation. As shown in our results and discussed in Sect. 5.3, deformation depths are many times impact crater depths even for 
moderately low-velocity impacts. In addition, Hutchings and Levy 86 assumed that the heat was released uniformly over the course of the impact. However, as shown in our results for high-velocity $30^{\circ}$ impacts, most of the plastic deformation occurs during the final stages of the impact. It is possible that heat generation may be restricted to the initial or final stages of the impact, further restricting its dissipation during the impact. Hutchings and Levy 86 concluded that thermal effects would be important only for large particle sizes or velocities. However, both the points made above would serve to lower the heat diffusion distance relative to the plastic deformation depth, favoring adiabatic conditions and making thermal effects important even at moderately low velocities. Thermal effects would, therefore, be a viable form of reasoning to explain the insensitivity of erosion resistance to strengthening treatments under commonly encountered erosion conditions. Note that thermal effects do not necessarily require the existence of a relatively soft surface layer. Increased dislocation mobility and dynamic recovery effects would serve the same purpose. Finally, in agreement with Hutchings and Levy, ${ }^{86}$ thermal effects are probably insignificant at lower velocities, which are also encountered in practice. Thermal effects would also be less significant with angular erodents at similar velocities, since material is removed more efficiently, leading to less energy transfer into the substrate and correspondingly less heat generation. This implies that in many erosion applications, the conditions have to be examined and weighed carefilly in order to anticipate possible thermal eifects.

As discussed in Sect. 5.5, a strong argument may be made for near-surface softening due to effects of residual stresses, especially for the iron-aluminide alloy. However, residual stress effects could not explain all the single-particle impact results. It may be argucd that residual stress effects give way to more dominant thermal effects at high velocities. However, MPM results of the iron-aluminide alloy eroded at relatively low velocity (Figs. 45 through 47) showed that the extent of dropoff in near-surface hardness varied from location to location, whereas the thickness of the softened layer stayed relatively constant. Residual stresses cannot explain this since the stress distributions are related directly to input energy, and local variations in this would lead to variations in the thickness of the softened layer. Residual stress effects cannot be ruled out either, since they explain several aspects of the results successfully. Therefore, a combination of residual stress and thermal effects may be occurring over the velocity range of impacts examined. The extent of each process is unknown for lack of more conclusive evidence (as, for example, from X-ray diffraction or TEM studies).

In either case, the results show that deformation characteristics of materials lead to subsurface flow stress distributions, which tend to average out large-strength differentials, especially toward higher impact velocities. This may explain results of various erosion studies, 
described earlier, which show that erosion resistance is typically insensitive to thermomechanical or alloying strengthening treatments. As an alloy's strength is increased, impacts create less defo.mation. However, this deformation tends to be more localized, promoting material removal, as well as intensifying other effects (such as thermal effects). This balances any advantages of the strengthening treatments. Erosion resistance would only increase if these phenomena were suppressed. One way, as suggested by this work, would be to develop microstructures that tend to distribute deformation evenly.

\section{SUMMARY AND CONCLUSIONS}

This report described the results of a seven-year experimental program to examine erosion mechanisms in metallic alloys. The program adopted a fundamental approach to examining erosion mechanisms by experimentally modeling the process using realistically sized single particles, as well as by examining material deformation and flow in multiple-particle erosion tests. Spherical particles were used in all the tests in order to facilitate analysis by maintaining a siruple-impact geometry. Studies were conducted from the perspective of how material properties, and especially mechanical properties, control their response to particulate impacts. Results of the two types of experiments were compared and correlated.

Two gas guns were built and used for the single-particle impact studies. The first gun, built at the program's initiation, is attached to an SEM and fires $343-\mu \mathrm{m}$ spheres at velocities between 10 to $60 \mathrm{~m} / \mathrm{s}$. The second gun, built in the sixth year of the program, fires sabots in air at velocities between 200 to $1000 \mathrm{~m} / \mathrm{s}$. The two guns were used to fire $343 \mu \mu \mathrm{m}$-diam WC spheres at various targets oriented at 30 or $90^{\circ}$ to the impacting particle.

Initial studies using the SEM gas gun showed that larger craters formed in softer alloys, but crater size could not be related to relative erosion rates. MPM measurements showed work hardening due to impacts, but no thermal effects were evident for impacts at velocities around $30 \mathrm{~m} / \mathrm{s}$ on a series of aluminum alloys. The depth of hardening was less in the stronger 7075-T6 alloy compared to $1100 \mathrm{Al}$. The significantly softer 1100 Al had shown superior erosion resistance in other studies, suggesting that the capacity to distribute the impact energy over large volumes improved a material's erosion resistance.

Detailed single-impact studies over a wide range of velocities were conducted on targets of $1100 \mathrm{Al}$ and an Fe3Al-based, ordered iron-aluminide alloy, FA-129, in both heat-treated and cold-worked conditions. For impacts at velocities around $60 \mathrm{~m} / \mathrm{s}$, craters were larger in the softer $1100 \mathrm{Al}$, and the amount of material hardened by the impacts was less in the ironaluminide alloy, but the difference was less than expected based on the hardness differential 
between the two alloys. In some cases, at velocities of several hundred $\mathrm{m} / \mathrm{s}$, the depth of hardening was greater in the iron-aluminide alloy. Near-surface softening was observed in the cold-worked iron-aluminide alloy, and possibly in annealed 110() $\mathrm{Al}$, at velocities around $60 \mathrm{~m} / \mathrm{s}$. Near-surface softening was observed in both alloys for impacts at velocities of several hundred $\mathrm{m} / \mathrm{s}$, although the softening effects could be identified more clearly in the ironaluminide alloy. This softening was also observed due to moderately low-velocity impacts on surfaces of previously eroded-corroded 2.25Cr1Mo steels, supporting the argument that greater softening occurred in more deformation-resistant materials.

MPM measurements showed that for $30^{\circ}$ incidence, more material was hardened in front of the impacting ball than vertically beneath the crater. Unlike at low velocities, significant differences were seen in the appearance of single-impact craters at $30^{\circ}$ incidence between $1100 \mathrm{Al}$ and the iron-aluminide alloy. Well developed, extruded lips were formed in $1100 \mathrm{Al}$, with considerable deformation around the impact site but no material removal. In contrast, the extruded lip in the iron-aluminide alloy fractured at the exit edge of the crater, perhaps due to low ductility in the material (around $15 \%$ ) compared to annealed $1100 \mathrm{Al}(35 \%)$. The velocity at which the extruded lips failed in the iron-aluminide alloy was not well defined. In contrast, no difference was seen in the appearance of craters or extruded lips in annealed and coldworked $1100 \mathrm{Al}$, even though the ductility was reduced from 35 to $6 \%$ upon cold working.

To allow comparison with the single-particle impact studies, multiple-particle erosion studies were conducted at a velocity of $45 \mathrm{~m} / \mathrm{s}$ using steel shot either $6(0)$ to 700$) \mu \mathrm{m}$ in diameter (earlier studies) or 297 to $420 \mu \mathrm{m}$ in diameter (later studies). The first study was conducted on $1100 \mathrm{Al}$ and 7075-T6 $\mathrm{Al}$ to examine the surface-ripple structure that developed during erosion at $30^{\circ}$ incidence. A work-hardened layer was observed in both materials, with a maximum hardness greater than observed in single-particle impact studies and no evidence of near-surface softening. Wave crests and valleys were identified, and it was found that the depth of hardening under a wave crest extended to a distance equal to the height of the wave crest plus the depth of hardening beneath a valley. The depth of hardening beneath a valley was similar to that under single-particle impacts.

The development of a ripple structure at $30^{\circ}$ incidence and a hill-and-valley structure at $900^{\circ}$ incidence was examined in detail for $11(0) \mathrm{Al}$. It was found that the surface structures developed early in the erosion process, and several overlapping impacts were necessary to achieve maximum strain hardening on the surface. The material continued to accumulate strain without fracture after the maximum flow stress was achieved. As in the earlier study, hardening extended to much greater depths under wave crests for erosion at $30^{\circ}$, supporting the view that strain-hardened material was pushed up from the wave valleys into the crests. In 
contrast, for erosion at $90^{\circ}$ incidence, the depth of hardening was approximately equal beneath hills and valleys. Significant embedment of erodent fragments, predominantly in the valleys, occurred for erosion at $90^{\circ}$. Deformation contours showed material being back-extruded from valleys into the hills, but most of this movement occurred near the surface rather than through the bulk of the material, leading to the observed hardness distribution. No near-surface softening was evident beneath the eroded surfaces of $1100 \mathrm{Al}$ at either 30 or $90^{\circ}$ incidence. However, there was some evidence for a constant hardness in the near-surface layers, especially at $90^{\circ}$ incidence. Material removal was controlled by the attainment of a critical fracture strain and occurs due to overlapping impacts or by the fracture of lips of material extruded from wave crests.

The surface structure apparently initiated due to locally high concentrations of impacts leading to incipient hills or wave crests, which persist because the impact energy is distributed over smaller volumes in the highly strain-hardened material. The hills/crests grow since for $30^{\circ}$ impacts, most of the hardened material is pushed in front of the impacting particle and for $90^{\circ}$ impacts, a higher concentration of voids and fissures associated with particle embedment led to greater deformation in valley regions. The peak hardness in valley regions was sometimes less than on hills/crests, perhaps due to recent material movement out of the valleys. The structures continue to grow until material removal rates from hills/crests and valleys are balanced.

Surface structure is expected to be strongly influenced by target material strength and ductilities, developing to a greater extent on softer, more deformable materials. The spacings of the features are expected to be related to the range of deformation associated with an impact and, therefore, to particle size (as has been observed), as well as to the impact velocity. Within the same family of alloys, the development of ripples or hills and valleys may contribute to increased erosion resistance due to longer incubation periods, greater absorption of the incident energy in material deformation and movement processes, and possible shielding from impact of low-lying areas by neighboring elevated regions.

Taper sectioning was shown to be a powerful technique to examine the near-surface deformation of eroded surfaces. However, the technique has to be used judiciously and the results analyzed carefully in order to avoid misinterpretation of the data.

The multiple-particle erosion of the iron-aluminide alloy FA-129 by steel shot was also examined in detail. It was found that erosion occurred even though most of the impacting particles were softer than the target material. Softer spherical particles appeared to merely form an impression on the target surface, whereas harder particles formed extruded lips, especially under oblique impact. Two distinct erosion mechanisms were observed: extrusion and 
fracture of platelets by the impact of spherical particles and a cutting or gouging out of material by the impact of angular particles, which were present in the shot as well as formed by fragmentation upon impact of an oxide scale covering many of the particles. The platelets and extrusions were relatively small, and angular particles had more damage associated with each impact event. Both mechanisms were observed at $30^{\circ}$ incidence, but damage by angular particles and debris dominated at higher angles. The steady-state erosion rates were roughly equal at 30 and $60^{\circ}$ incidence with some indication that the steady-state rate at $90^{\circ}$ may also be similar, due to a complex balance of the extent of platelet formation and cutting at the various angles.

The alloy work hardened significantly under impacts at both 30 and $90^{\circ}$ incidence. Unlike $1100 \mathrm{Al}$, the hardness dropped off in near-surface layers, and the thickness of this softened layer increased with erodent dose. Also unlike $1100 \mathrm{Al}$, the value of the peak subsurface hardness was similar to that under single-particle impacts. The depth of overall work hardening, as well as the thickness of the softened near-surface layer, was greater for erosion at $90^{\circ}$ because a greater iraction of the energy of impacting particles was transferred to the target. The angular dependence of the depth of hardening was less pronounced in $1100 \mathrm{Al}$, implying that in softer, more deformable materials, a larger fraction of the impact energy is expended in moving material and developing the surface topography.

The surface of the iron aluminide did not develop features observed on eroded $1100 \mathrm{Al}$, suggesting limited ductility under the erosion test conditions. The platelets and extrusions created by the impinging shot were also small, implying an inability of the material to sustain large plastic strains. However, there were no signs of cracks or delaminations that would indicate macroscopic brittle failure in the material. The near-surface layers of the ironaluminide alloy were found to be in a disordered state after erosion. However, the effect of this phase transformation on the erosion process was not clear. Data from available literature showed that the aluminides may have an erosion resistance comparable to other engineering alloys, and the overall results indicate relatively good resistance of iron aluminides to solid particle erosion, which may be improved by increasing the alloy's ductility.

In the case of the iron-aluminide alloy, the maximum hardness reached was similar in single- and multiple-particle impact studies. However, in $1100 \mathrm{Al}$, the flow stress built up over several impacts. Increasing the velocity of the single impact caused near-surface softening before the maximum flow stress was achieved. This indicated possible thermal effects.

Single-particle impact studies at high velocities were found to correlate well with results from low-velocity, multiple-particle erosion experiments. It was found that although a single impact can remove material at high velocities, the several overlapping impacts needed to 
remove material at relatively low velocities expend less overall energy due to strain localization effects in the extruded lips formed on impact. Single-particle impacts will therefore tend to underestimate the erosion rate.

Relatively early material loss in the iron-aluminide alloy in both single- and multipleparticle impact tests could be related to its lower ductility, as well as its propensity to localize deformation due to its ordered nature. In contrast, the high dynamic recovery and stacking fault energy of $1100 \mathrm{Al}$ allowed impact energy and deformation to be spread more uniformly, explaining the lack of brittle failure observations in cold-worked $1100 \mathrm{Al}$ even though ductility was greatly reduced.

The mechanical properties of a material alone could not consistently explain the observed deformation behavior and material removal under the various impact conditions. Contrary to what is generally assumed, the volume of deformed material due to an impact was significantly larger than the crater volume. It was shown that elastic-plastic contact mechanics did not accurately predict the similarity in hardening depths between the heat-teated and cold-worked $11(00 \mathrm{Al}$ and iron-aluminide alloys for impact around $60 \mathrm{~m} / \mathrm{s}$ and that influences other than pure mechanical properties effects were important at these velocities.

Residual stress effects explained the occurrence of near-surface softening in the ironaluminide alloy but could not satisfactorily explain the hardening behavior observed for singleparticle impacts at various velocities. Thermal effects could more completely explain the results based on the argument that at moderate velocities, strong dynamic recovery effects in $1100 \mathrm{Al}$ promote the development of a constant flow stress, whereas localization of deformation in the iron-aluminide alloy promotes dynamic recrystallization effects, leading to near-surface softening. At very high velocities, stronger thermal effects dominated over dynamic recovery effects in $11(0) \mathrm{Al}$, leading to near-surface softening, probably due to recrystallization from residual heat. At low velocities, thermal effects no longer dominate, and the impact response is controlled mainly by the mechanical properties of the alloy. Thermal effects may be expected to be significant over a significant portion of the velocity range for erosion applications. However, at any velocity, thermal effects will be less important for impacts with angular particles compared to spherical. Since thermal effects need not necessarily create a soft surface layer, erosion conditions have to be analyzed carefully to anticipate possible effects.

Thermal effects could explain lack of difference in hardening depths between the two alloys for moderately low-velocity single impacts and the higher hardening depth in the ironaluminide alloy for high-velocity single impacts. It was estimated that clear evidence of thermal effects in $1100 \mathrm{Al}$ during multiple-particle impact experiments would be seen under experimental conditions somewhat more severe than in the present study. 
Potential areas for future work include erosion studies in iron-aluminide alloys using angular particles; erosion-induced, order-disorder transformations in iron-aluminide alloys; residual stress effecis during erosion; and high-velocity, single-impact studies on various aluminum alloys or steels to study relative influence of mechanical properties and thermal effects on erosion.

\section{ACKNOWLEDGMENTS}

The authors acknowledge the contribution of several people toward this project. The velocity-measuring device for the SEM gas gun was designed and built by A. V. Blalock of the Instrument and Controls Division. The high-velocity gas gun was designed and built by M. J. Gouge and C. R. Foust of the Fusion Energy Division. All tests at Lawrence Berkeley Laboratory were conducted by A. V. Levy. Laboratory facilities at the University of Notre Dame were provided by T. H. Kosel. The iron-aluminide alloy was provided by V. K. Sikka. The X-ray diffraction studies were conducted by C. R. Hubbard. The authors also thank P. F. Tortorelli, N. C. Cole, and J. R. DiStefano for reviewing the manuscript; C. J. Overton for composition and makeup; and K. Spence for editing. 


\section{REFERENCES}

1. I. Finnie, J. Wolak, and Y, Kabil, J. Mater, 2, 682 (1967).

2. G. P. Tilly, Wear 14, 63 (1969).

3. G. L. Sheldon, J. Eng. Mater. Technol, 133 (April 1977).

4. A. K. Vijh, Wear 39, 173 (1976).

5. C. E. Smeltzer, M. E. Gulden, and W. A. Compton, J. Basic Eng. 92, 639 (1970).

6. H. Brauer and E. Kriegel, Chem. Ing. Technol. 37, 265 (1965).

7. P. Ascarelli, "Relation Between the Erosion by Solid Particles and the Physical Properties of Metals," U. S. Army Mater. Mech. Res. Cent. Tech. Rep. 71 -47 (1971).

8. I. M. Hutchings, Wear 35, 371 (1975).

9. S. Malkin, Wear 69, 391 (1981).

10. W. H. Jennings, W. J. Head, and C. P. Manning, Jr., Wear 40, 93 (1976).

11. I. M. Hutchings, "Mechani:ms of the Erosion of Metals by Solid Particles," p. 59 in Erosion: Prevention and Useful Applications, ed. W. F. Adler, American Society for Testing and Materials, Philadelphia, 1979; also in ASTM Spec. Tec'n. Publ. 664.

12. T. L. Urso, "Model for Single-Particle Erosion of Ductile Materials," Morgantown Energy Technology Center, DOE/METC-86/4()66, January 1985.

13. T. Christman and P. G. Shewmon, Wear 54, 145 (1979).

14. R. Brown and J. W. Edington, Wear 77, 347 (1982).

15. C. S. Yust and R. S. Crouse, Wear 51, 193 (1978).

16. R. Bellman, Jr. and A. V. Levy, Wear 70, 1 (1981).

17. A. J. Ninham, Wear 121, 307 (1988).

18. R. E. Winter and I. M. Hutchings, Wear 34, 141 (1975).

19. L. K. Ives and A. W. Ruff, Wear 46, 149 (1978).

20. J. W. Edington and I. G. Wright, Wear 48, 145 (1978).

21. T. H. Kosel, R. O. Scattergood, and A. P. L. Turner, "An Electron Microscopic Study of Erosive Wear," p. 192 in Proceedings of the International Conference on Wear of Materials, Dearborn, Michigan, April 16-18, 1979, ed. K. C. Ludema, W. A. Glaeser, and S. K. Rhee, American Society of Mechanical Engineers, New York, 1979.

22. M. E. Gulden, "Influence of Brittle to Ductile Transition on Solid-Particle Erosion Behavior," in Proceedings of the International Conference on Erosion by Liquid and Solid Impact, 5th, Cambridge, U. K., September 3-6 1979, ed. J. E. Field, Cavendish Laboratory, University of Cambridge, Paper No. 31, 1979. 
23. L. G. Peterson, G. A. Sargent, and H. Conrad, "Effect of Microstructure on the Erosion of Steels by Solid Particles," p. 661 in Proceedings of the International Conference on Wear of Materials, Vancouver, Canada, April 14-18, 1985, ed. K. C. Ludema, American Society of A teichanical Engineers, New York, 1985.

24. W. Zhu and Z. Y. Mao, "Study of Erosion by Relatively Soft Particles," p. 787 in Proceedings of the International Conference on Wear of Materials, Houston, Texas, April 5-9, 1987, ed. K. C. Ludema, American Society of Mechanical Engineers, New York, 1987.

25. 1. Finnie, Wear 3, 87 (1960).

26. D. G. Rickerby and N. H. Macmillan, Wear 60, 369 (1980).

27. I. M. Hutchings and R. E. Winters, Wear 27, 121 (1974).

28. T. Christman and P. G. Shewmon, Wear 52, 57 (1979).

29. I. Finnie, A. Levy, and D. H. McFadden, "Fundamental Mechanisms of the Erosive Wear of Ductile Metals by Solid Particles," p. 36 in Erosion: Prevention and Useful Applications, ed. W. F. Adler, American Society for Testing and Materials, Philadelphia, 1979; also in ASTM Spec. Tech. Publ. 664.

30. R. A. Mayville, "Mechanisms of Material Removal in the Solid-Particle Erosion of Ductile Materials," M. S. Thesis, LBL-7333, University of California, 1978.

31. A. V. Levy, Wear 108 (1986).

32. I. M. Hutchings, Wear 70, 269 (1981).

33. G. Sundarajan and P. G. Shewmon, Wear 84, 237 (1983).

34. V. K. Sikka, C. G. McKamey, C. R. Howell, and R. H. Baldwin, "Fabrication and Mechanical Properties of Fe3Al-Based Iron Aluminides," ORNL/TM-11465, Martin Marietta Energy Systems, Inc., Oak Ridge Natl. Lab., March 1990.

35. J. R. Keiser, "Design, Construction and Initial Results for an Erosion-Corrosion Te:t System," ORNL/TM-10()49, Martin Marietta Energy Systems, Inc., Oak Ridge Natl. Lab., May 1986.

36. S. L. Milora, S. K. Combs, and C. R. Foust, Rev. S'ci. Instrum. 59, 2356 (1989).

37. Nano Instruments, Inc., P. O. Box 14211, Knoxville, Tenn.

38. M. F. Doerner and W. D. Nix, J. Mater. Res, 4, 601 (1989).

39. L. Lapides and A. Levy, Wear 58, 301 (1980).

40. G. L. Sheldon and A. Kanhere, Wear 21, 195 (1972).

41. I. M. Hutchings and R. E. Winters, J. Phys. D: Appl. Phys. 8, 8 (1975).

42. I. M. Hutchings, R. E. Winters, and J. E. Field, Proc. R. Soc. London A 348, 379 (1976). 
43. D. G. Rickerby and N. H. Macmillan, "Mechanisms of Solid-Particle Erosion in Crystalline Materials," in Proceedings of the International Conference on Erosion by Liquid and Solid Impact, 5th, Cambridge, U. K., September 3-6 1979, ed. J. E. Field, University of Cambridge, Paper No. 29, 1979.

44. T. Christmian and P. G. Shewmon, Wear 54, 145 (1979).

45. J. R. Keiser, "The Relationship of an Alloy's Mechanical Properties to Its Response to Individual Erosive-Particle Impact," p. 345 in Proceedings of the Conference on Corrosion-Erosion-Wear of Materials at Elevated Temperatures, Berkeley, California, January 27-29, 1986, ed. A. V. Levy, National Association of Corrosion Engineers, Houston, 1987.

46. J. R. Keiser, R. C. Heidersbach, D. L. Dobbs, Jr., and W. C. Oliver, Wear 124, 105 (1988).

47. J. R. Keiser, R. C. Heidersbach, D. L. Dobbs, Jr., and W. C. Oliver, J. Mater. Eng. 10, 273 (1988).

48. M. Rao, J. R. Keiser, A. V. Levy, and B. Q. Wang, "Mechanical Behavior of Erosion-Corrosion Scales on Steels as Characterized by Using Single-Particle Impacts," submitted for publication in Wear.

49. G. P. Tilly, Wear 14, 63 (1969).

50. C. M. Preece, ed., Erosion, Treatise Material Science Technology, Vol: 16, Acädemic Press, New York, 1979.

51. W. F. Adler, ed., Erosion: Prevention and Useful Applications, American Society for Testing and Materials, Philadelphia, 1979; also ASTM Spec. Tech. Publ.664.

52. A. K. Cousens and I. M. Hutchings, Wear 88, 335 (1983).

53. G. Carter, M. J. Nobes, and K. I. Arshak, Wear 65, 151 (1980).

54. I. Finnie and Y. H. Kabil, Wear 8, 60) (1965).

55. R. Brown, E. J. Jun, and J. W. Edington, Wear 70, 347 (1981).

56. R. Brown and J. W. Edington, Wear 79, 335 (1982).

57. J. Stringer and I. G. Wright, "Some Views on the Formation of Ripples on Eroded Surfaces," in Proceedings of the International Conference on Erosion by Liquid and Solid Impact, 7th, ed. J. E. Field, University of Cambridge, Paper No. 47, 1987.

58. J. R. Keiser, D. F. Wilson, J. N. Hines, and A. V. Levy, J. Mater. Eng. 12, 245 (1990).

59. J. R. Keiser and M. Rao, "Comparison of the Response of Aluminum Alloys to Single- and Multiple-Particle Impacts," in Corrosion 90, National Association of Corrosion Engineers, Houston, Paper No. 289, April 1990. 
60. U. S. Lindholm and G. R. Johnson, Material Behavior Under High Stress and Ultrahigh Loading Rates, ed. J. Mescall and V. Weiss, Plenum Press, New York, p. 61, 1982.

61. M. Rao. J. Keiser, and D. Wilson, Scr. Metall. 23, 1475 (1989).

62. M. Rao, J. R. Keiser, and D. F. Wilson, "Subsurface Hardening and Flow of Aluminum During the Incubation Period of Solid-Particle Erosion," in Proceedings of the Berkeley Conference on the Corrosion-Erosion-Wear of Materials at Elevated Temperatures, 4th, Berkeley, California, January 31-February 2, 1990, National Association of Corrosion Engineers, Houston, Paper No. 6, 1991.

63. J. R. Keiser, M. Rao, and D. F. Wilson, "Material Behavior During Solid-Particle Erosion of Annealed 1100 Aluminum," p. 391 in Proceedings of the Annual Conference on Fossil Energy Materials, 4th, Oak Ridge, Tennessee, Conf. 900546, comp. R. R. Judkins and D. N. Braski, ORNL/FMP-90/1, Martin Marietta Energy Systems, Inc., Oak Ridge Natl. Lab., August 1990.

64. R. Brown, S. Kosco, and E. J. Jun, Wear 88, 181 (1983).

65. D. Tabor, The Hardness of Metals, Clarendon Press, Oxford, 1951.

66. A. W. Ruff and S. M. Weiderhorn, "Erosion by Solid Particle Impact," p. 69 in Erosion, Treatise on Materials Science and Technology, Vol. 16, ed. C. M. Preece, Academic Press, New York, 1979.

67. W. J. Head, L. D. Lineback, and C. R. Manning, Wear 23, 291 (1973).

68. S. P. Timothy and I. M. Hutchings, Philos. Mag. A 54, 93 (1986).

69. S. P. Timothy and I. M. Hutchings, Philos. Mag. A 54, 103 (1986).

70. T. Foley and A. Levy, Wear 91, 45 (1983).

71. G. L. Sheldon and I. Finnie, Trans. ASME B 88, 387 (1966).

72. A. K. Cousens and I. M. Hutchings, "Influence of Erodent Particle Shape in the Frosion of Mild Steel," in Proceedings of the International Conference on Erosion by Liquid and'Solid Impact, 6th, Cambridge, U. K., September 5-8 1983, ed. J. E. Field, Cavendish Laboratory, University of Cambridge, Paper No. 41, 1983.

73. R. N. Wright and D. E. Mikkola, Mater. Sci. Eng. 26, 263 (1976).

74. B. J. Marquardt, D. M. Baker, and J. J. Wert, "Erosive Wear of Ductile Ordered Alloys," p. 693 in Proceedings of the International Conference on Wear of Materials, Vancouver, Canada, April 14-18, 1985, ed. K. C. Ludema, American Society of Mechanical Engineers, New York, 1985.

75. M. Johnson, D. E. Mikkola, P. A. March, and R. N. Wright, Wear 140, 279 (1990). 
76. S. S. Aptekar and T. H. Kosel, "Erosion of White Cast Irons and Stellite," p. 677 in Proceedings of the International Conference on Wear of Materials, Vancouver, Canada, April 14-18, 1585, ed. K. C. Ludema, American Society of Mechanical Engineers, New York, 1985.

77. I. M. Hutchings, J. Phys. D: Appl. Phys. 10, L179 (1977).

78. R. Brown, E. J. Jun, and J. W. Edington,Wear 74, 143 (1981-82).

79. G. Sundarajan, "The Depth of Plastic Deformation Beneath Eroded Surfaces-The Influence of Impact Angle and Velocity, Particle Shape, and Material Properties," p. 111 in Proceedings of the International Conference on Wear of Materials, Orlando, Florida, April 7-11, 1991, ed. K. C. Ludema and R. G. Bayer, American Society of Mechanical Engineers, New York, 1991.

80. M. Naim and S. Bahadur, Wear 98, 15 (1984).

81. K. L. Johnson, "Contact Mechanics," Cambridge University Press, Cambridge, England, 1985.

82. O. Vohringer, "Changes in the State of the Material by Shot Peening," p. 185 in Shot Peening, Proceedings of the International Conference on Shot Peening, 3rd, 1987, ed. H. Wohlfahrt, R. Kopp, and O. Vohringer, DGM, Germany, 1987.

83. H. Wohlfahrt, "Shot Peening and Residual Stresses," p. 71 in Residual Stress and Stress Relaxation, Sagamore Army Materials Research Conference, Vol. 28, ed. E. Kula and V. Weiss, Plenum Press, New York, 1982.

84. H. J. McQueen and J. J. Jonas, "Microstructural Changes at High Temperatures," p. 393 in Plastic Deformation of Materials, Treatise on Materials Science and Technology, Vol. 6, ed. R. J. Arsenault, Academic Press, New York, 1975.

85. M. Rao, A Study of Subsurface Microstructural Changes Due to Abrasion of Aluminum, Copper, and Nickel, Ph. D. dissertation [microfilm], Univ. Microfilms, Ann Arbor, Mich., 1986; Publication No. DA8523612.

86. I. M. Hutchings and A. V. Levy, Wear 131, 105 (1989). 
ORNL/TM-11946

\section{INTERNAL DISTRIBUTION}

1-2. Central Research Library

3. Document Reference Section

4-5. Laboratory Records Department

6. Laboratory Records, ORNL-RC

7. ORNL Patent Section

8-10. M\&C Records Office

11. P. J. Blau

12. P. T. Carlson

13. N. C. Cole

14. D. F. Craig

15. J. H. DeVan

16. M. L. Grossbeck

17. F. M. Haggag

18. L. L. Horton

19. C. Hsueh

20. C. R. Hubbard

21. R. R. Judkins
22-31. J. R. Keiser

32. P. J. Maziasz

33. H. E. McCoy, Jr.

34. W. C. Oliver

35-39. M. C. Rao

40. V. K. Sikka

41. G. M. Slaughter

42. P. F. Tortorelli

43 L. J. Turner

44. A. A. Wereszczak

45. D. F. Wilson

46. Y. A. Chang (Consultant)

47. H. W. Foglesong (Consultant)

48. J. J. Hren (Consultant)

49. M. L. Savitz (Consultant)

50. J. G. Simon (Consultant)

51. K. E. Spear (Consultant)

\section{EXTERNAL DISIRIBUTION}

46-47. DOE, OAK RIDGE FIELD OFFICE, P. O. Box 2001, Oak Ridge, TN 37831

Assistant Manager for Energy Research and Developmen:

E. E. Hoffman

48. DOE, OFFICE OF BASIC ENERGY SCIENCES, Materials Sciences

Division, ER-131 GTN, Washington, D.C. 20545

J. B. Darby

49. DOE, OFFICE OF CONSERVATION AND RENEWABLE ENERGY, CE-12 Forrestal Builaiing, Washington, D.C. 20545

J. J. Eberhardt

50. DOE, OFFICE OF FOSSIL ENERGY, FE-14 GTN, Washington, D.C. 20545

J. P. Carr 
51-54. DOE, PITTSBURGH ENERGY TECHNOLOGY CENTER, P. O. Box 10940, Pittsburgh, PA 15236
A. H. Baldwin
G. V. McGurl
R. Santore
T. M. Torkos

55. IDAHO NATIONAL ENGINEERING LABORATORY, P. O, BOX 1625 , Idaho Falls, ID 83415

R. Wright, Senior Scientist

56. UNION CARBIDE COATINGS SERVICE CORPORATION, 150() Polco Street, Indianapolis, IN 46222

T. Taylor, Developmet it Associate

57. UNIVERSITY OF NOTRE DAME, Department Of Electrical Engineering, Notre Dame, IN 46556

T. Kosel

58. UNIVERSITY OF PITTSBURGH, Departrisnt Of Materials Science and Engineering, 848 Benedum Hall, Pittsburgh, PA 15261

\section{Simko}

59-68. DOE, OFFICE OF SCIENTIFIC AND TECHNICAL INFORMATION, Office of Information Servies, P. O. Box 62, Oak Ridge, TN 37831 For distribution of microfiche as shown in DOE/OSTI-45()), Distribution Categories UC-103 (Fluidized Bed Combustion), UC-105 (Flue Gas Cleanup), UC-106 (Gas Stream Cleanup), UC-108 (Coal Liquefaction), UC-109 [Coal Gasification (Surface and Underground)], UC-110) (Fuel Cells), UC-111 (Heat Engines), and UC-114 (Coal Based Materials and Components) 

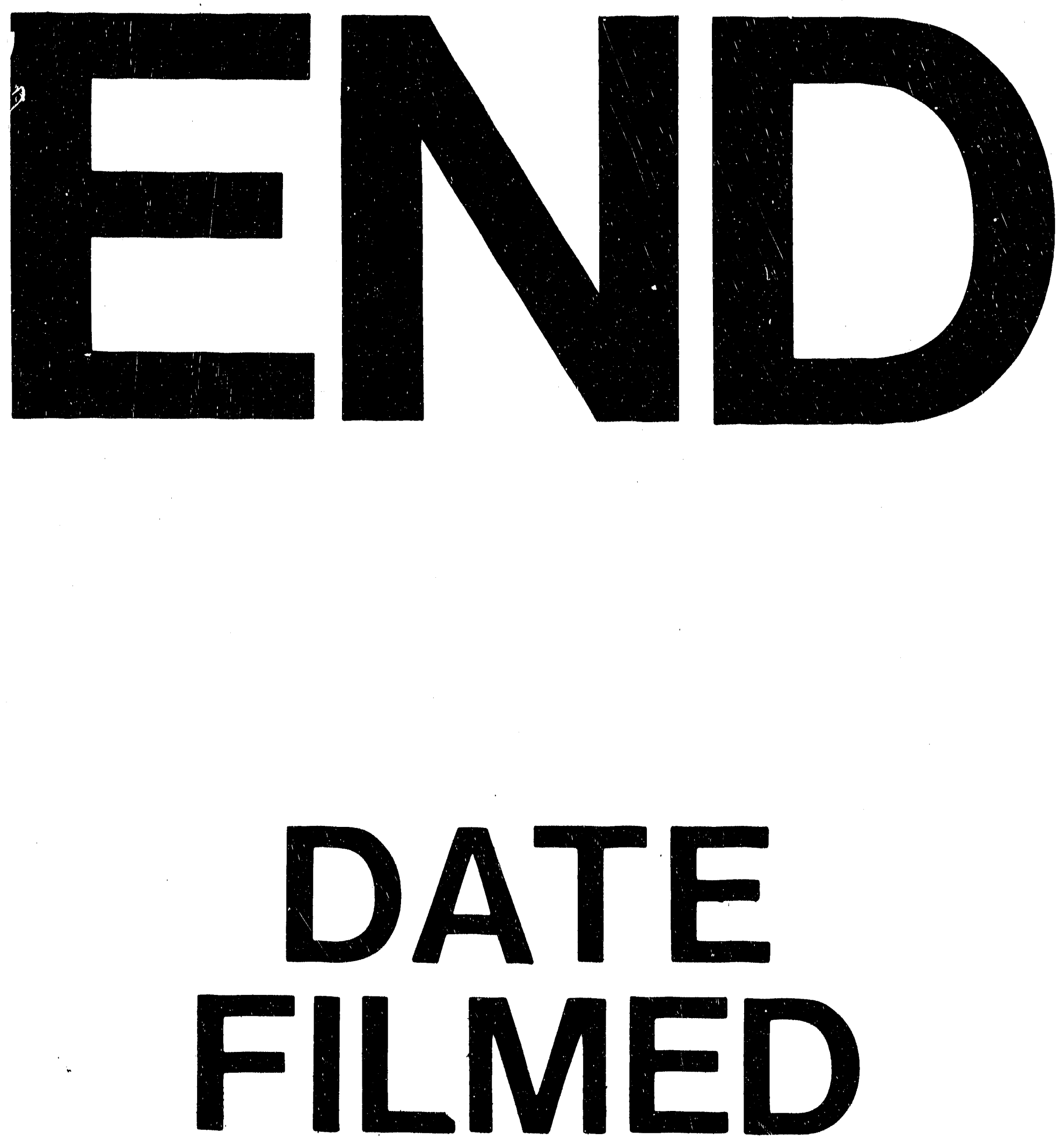

$\uparrow$

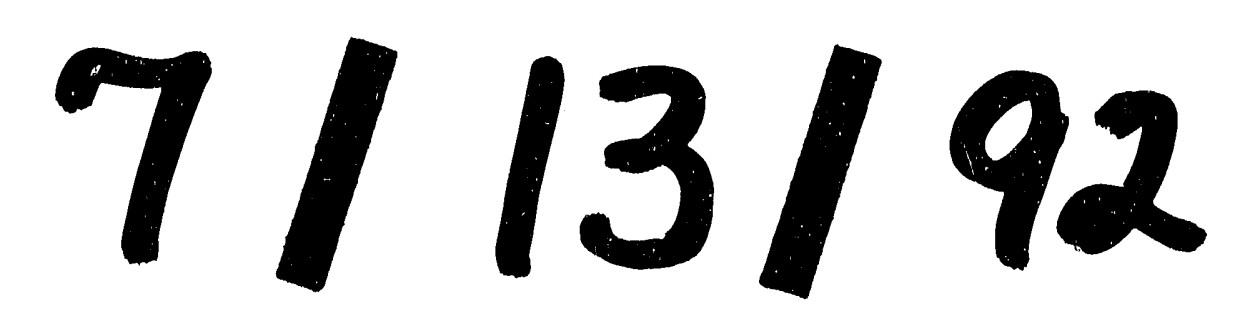


